\title{
Sedimentology and Stratigraphy of the Palisades, Lower Comanche, and Arroyo Grande Areas of the Colorado River Corridor, Grand Canyon, Arizona
}

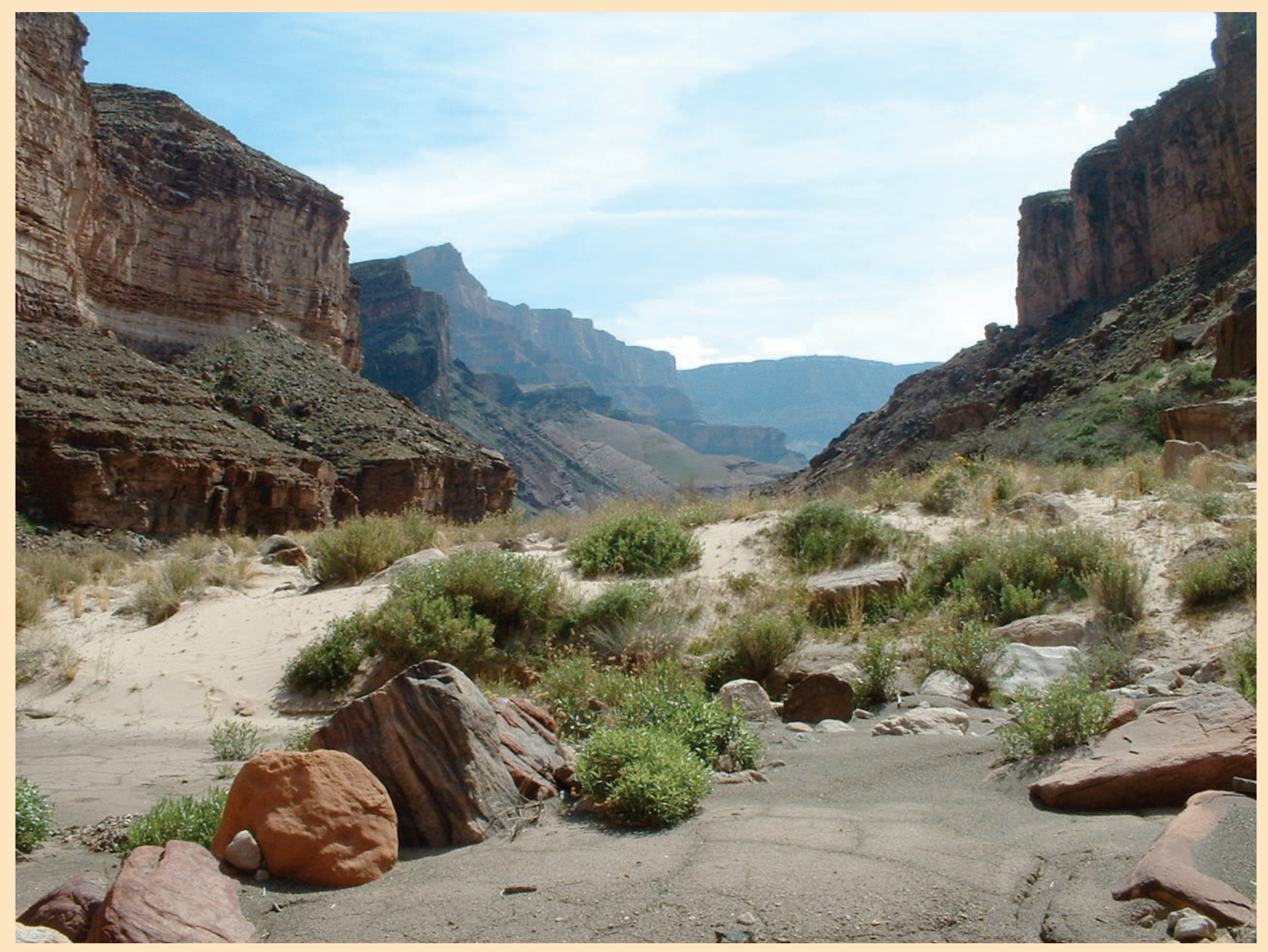

Scientific Investigations Report 2005-5072 


\section{Sedimentology and Stratigraphy of the Palisades, Lower Comanche, and Arroyo Grande Areas of the Colorado River Corridor, Grand Canyon, Arizona}

By Amy E. Draut, David M. Rubin, Jennifer L. Dierker, Helen C. Fairley, Ronald E. Griffiths, Joseph E. Hazel, Jr, Ralph E. Hunter, Keith Kohl, Lisa M. Leap, Fred L. Nials, David J. Topping, and Michael Yeatts

This report analyzes various depositional environments in three archaeologically significant areas of the Colorado River corridor in Grand Canyon.

Archaeological features are built on and buried by fluvial, aeolian, and locally derived sediment, representing a complex interaction between geologic and cultural history. These analyses provide a basis for determining the potential influence of Glen Canyon Dam operations on selected archaeological sites and thus for guiding dam operations in order to facilitate preservation of cultural resources.

Scientific Investigations Report 2005-5072

U.S. Department of the Interior

U.S. Geological Survey 


\section{U.S. Department of the Interior \\ Gale A. Norton, Secretary}

U.S. Geological Survey

Charles G. Groat, Director

Any use of trade, product, or firm names in this publication is for descriptive purposes only and does not imply endorsement by the U.S. Government.

United States Government Printing Office: 2004

For additional copies please contact:

USGS Information Services

Box 25286

Denver, CO 80225

This report and any updates to it are available at: http://pubs.usgs.gov/sir/2005/5072

Additional USGS publications can be found at http://geology.usgs.gov/products.html

For more information about the USGS and its products:

Telephone: 1-888-ASK-USGS (1-888-275-8747)

World Wide Web: http://www.usgs.gov/

Manuscript approved for publication, April 5, 2005

Text edited by Peter H. Stauffer

Layout and design by Stephen L. Scott

Cataloging-in-Publication data are on file with the Library of Congress 


\section{Contents}

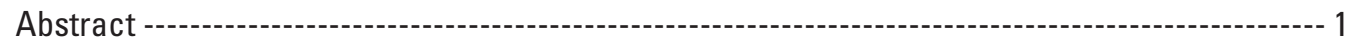

Introduction --- 1

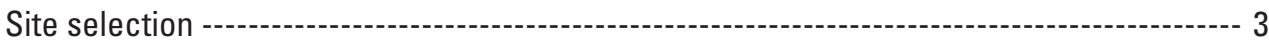

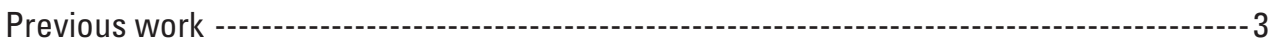

Methods--------------------------------------------------------------------------------- 4

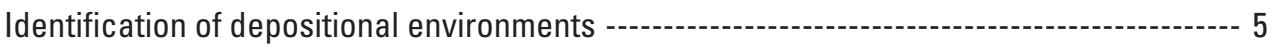

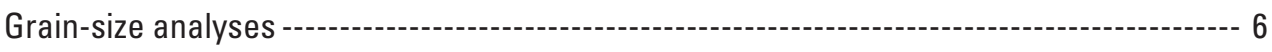

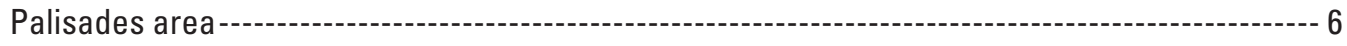

Geomorphic setting ------------------------------------------------------------ 6

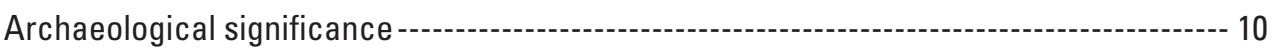

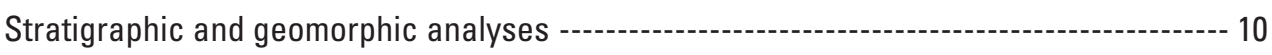

Grain-size analyses ----------------------------------------------------------- 10

Driftwood elevation survey: Palisades stage-discharge relationship -------------------- 10

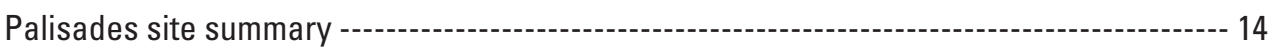

Lower Comanche area --- 14

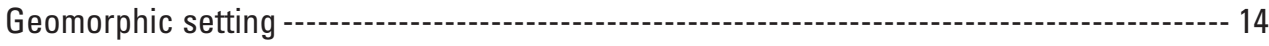

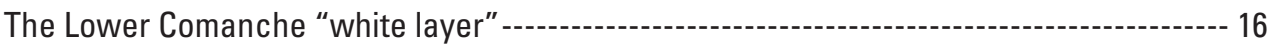

Archaeological significance ------- 18

Stratigraphic and geomorphic analyses ------------------------------------------------------- 18

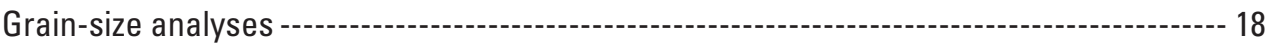

Driftwood elevation survey: Lower Comanche stage-discharge relationship---------------- 18

Lower Comanche site summary---- 20

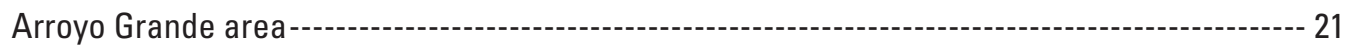

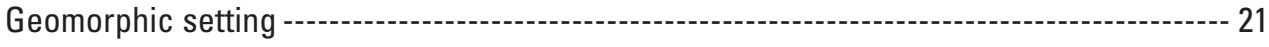

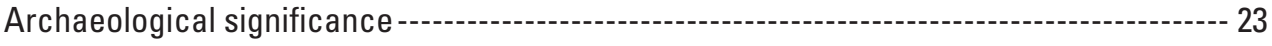

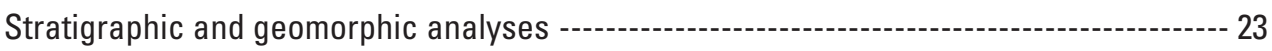

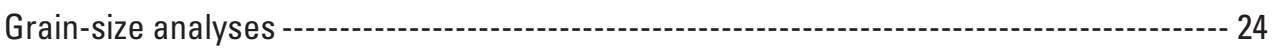

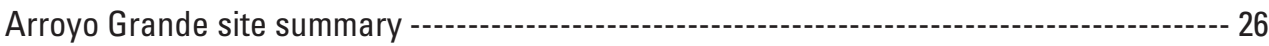

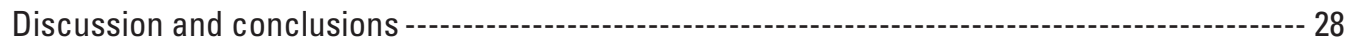

Observations related to aeolian sediment --- 28

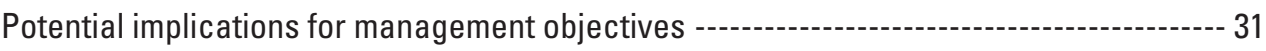

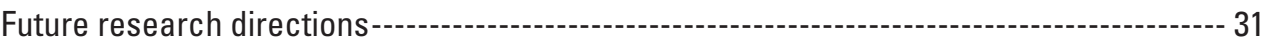

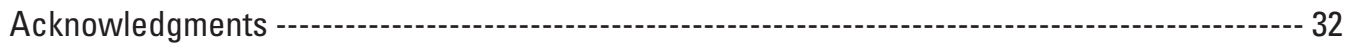

References---------------------------------------------------------------------------------- 32

Appendix 1: Descriptions of stratigraphic sections and geomorphology at archaeological site locations, Palisades area ------------------------------------- 37

Appendix 2: Descriptions of stratigraphic sections and geomorphology at

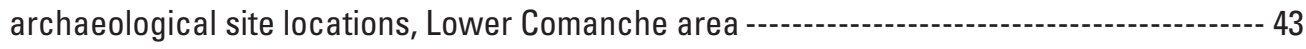

Appendix 3: Descriptions of stratigraphic sections and geomorphology

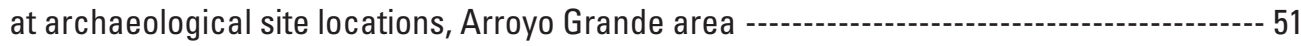




\section{Figures}

1. Location map of Grand Canyon, with study areas indicated--------------------------- 3

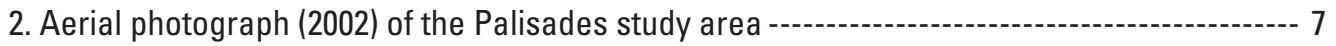

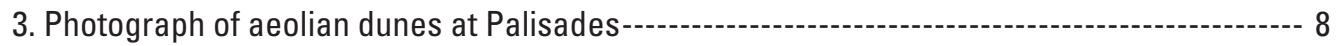

4. Photographs of playa deposits at the eastern edge of the Palisades study area -------------- 9

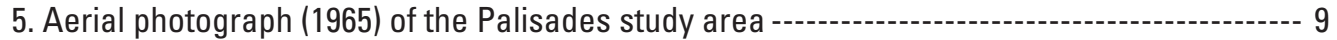

6. Grain-size plots for units $F$ and $G$ of section 1, Palisades -------------------------------- 11

7. Grain-size plot for unit $\mathrm{H}$ of section 3, Palisades --- 11

8. Grain-size data from section 4, Palisades--- 11

9. Grain-size data for samples of a flood deposit, unit B of section 4, Palisades --------------- 11

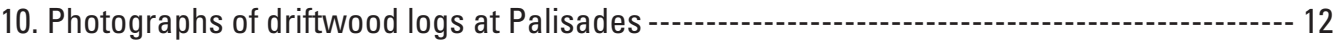

11. Graph of stage-discharge relationship for the Palisades area, based on elevations of driftwood logs --- 13

12. Graph showing proportions of sediments of different depositional environments in sections at Palisades --------------- 13

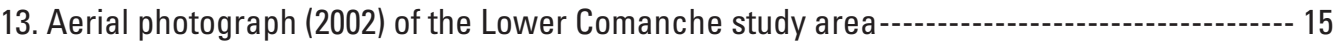

14. Aerial photograph of the arroyo system at Lower Comanche ------- 15

15. Aerial photograph (1965) of the Lower Comanche area----- 16

16. Photograph of the white-layer horizon at Lower Comanche --------------------------- 16

17. Grain-size plots for units $C$ and $F$ of section 2, Lower Comanche ---------------- 19

18. Grain-size plots for units B, E, and F of section 6, Lower Comanche ------- 19

19. Graph of stage-discharge relationship for the Lower Comanche area, based on elevations of driftwood logs----- 20

20. Graph showing proportions of sediments of different depositional environments in sections at Lower Comanche --- 20

21. Aerial photographs (2002) of the Arroyo Grande study area----.-- 22

22. Photographs of the main arroyo network at Arroyo Grande -------------------- 22

23. Aerial photograph (1965) of the Arroyo Grande area --------------------------- 23

24. Photograph showing a wide drainage at the downstream end of the

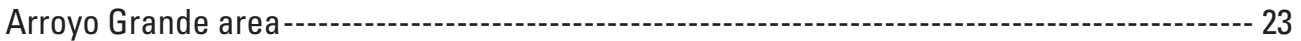

25. Grain-size plots for sections 1a and 1b, Arroyo Grande---------------------------- 24

26. Grain-size plots for two flood units (units $C$ and $H$ ) in section 5, Arroyo Grande -------------- 25

27. Grain-size plots for subunit G3 of section 6, Arroyo Grande ------------ 25

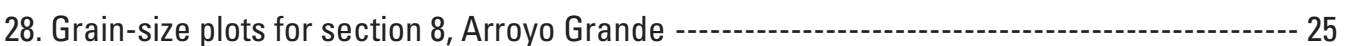

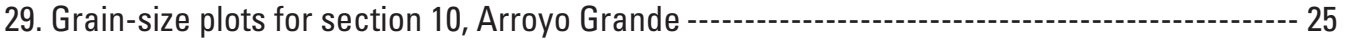

30. Graphs showing grain-size trends within four flood units at Arroyo Grande ------------------ 26

31. Graph showing proportions of sediments of different depositional environments in sections at Arroyo Grande --- 27

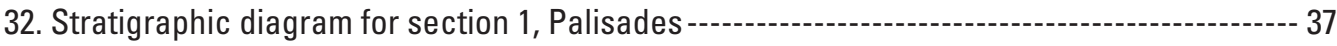

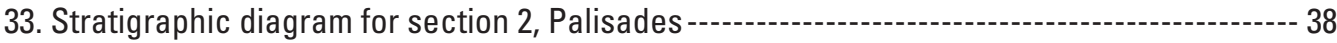

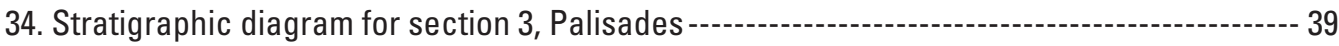

35. Photograph showing units $A, B$, and $C$ of section 4 , Palisades ---.--- 40

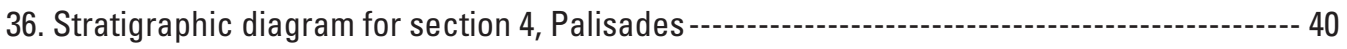


37. Photograph showing aeolian and fluvial sediment at archaeological site C:13:99, Palisades ------- 41

38. Photograph showing migrating sand dune at archaeological site C:13:100, Palisades ------------------------------------------------ 42

39. Photograph showing thin sedimentary cover at archaeological

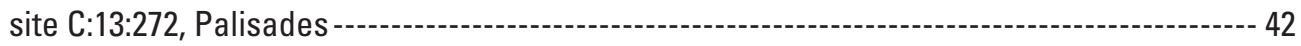

40. Photograph of section 2, Lower Comanche--- 44

41. Stratigraphic diagram for section 2, Lower Comanche ---------------- 44

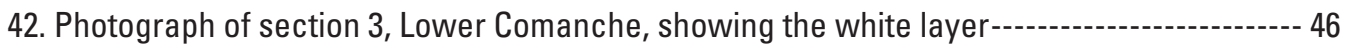

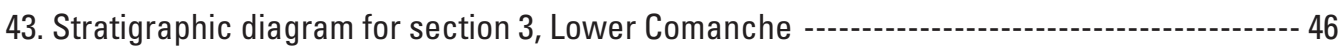

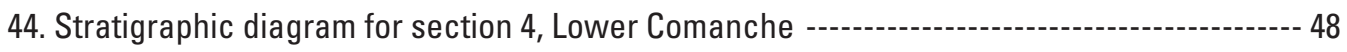

45. Stratigraphic diagram for section 5, Lower Comanche --- 48

46. Stratigraphic diagram for section 6, Lower Comanche ------------ 49

47. Photograph of one of the roasting features, feature 3 , at archaeological site C:13:273, Lower Comanche ---- 50

48. Photograph of a roasting feature at archaeological site C:13:333, Lower Comanche ----- 50

49. Photograph of archaeological site C:13:337, Lower Comanche -------------------------- 51

50. Stratigraphic diagram for sections 1a and 1b, Arroyo Grande ---

51. Stratigraphic diagram for sections 2a and 2b, Arroyo Grande ------------------------- 53

52. Field sketch of section 3, Arroyo Grande--- 55

53. Photograph of section 4, Arroyo Grande --- 55

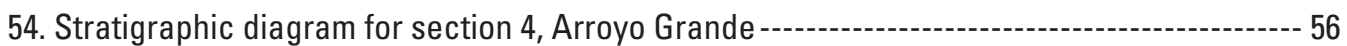

55. Photograph of fluvial climbing ripples in unit $\mathrm{C}$ of section 5, Arroyo Grande -------------- 57

56. Close-up photograph of one ripple crest in unit $C$ of section 5, Arroyo Grande ------------ 58

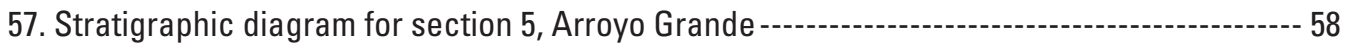

58. Uninterpreted and interpreted photographs of sedimentary couplets in unit $\mathrm{G}$ of section 6, Arroyo Grande--- 59

59. Uninterpreted and interpreted photographs of sedimentary couplets in upper part of unit I of section 6, Arroyo Grande -- 60

60. Stratigraphic diagram for section 6, Arroyo Grande -- 60

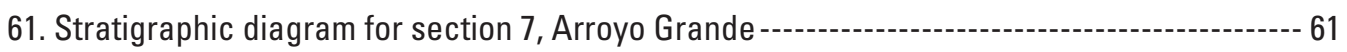

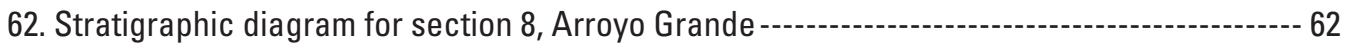

63. Stratigraphic diagram for section 9, Arroyo Grande ------- 64

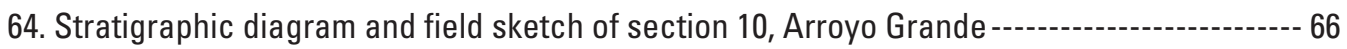

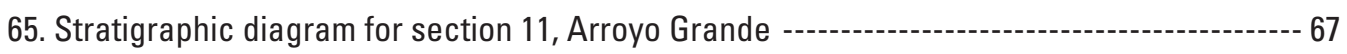

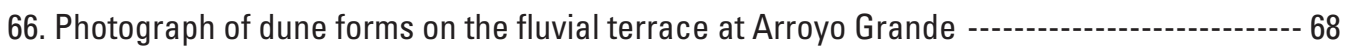

67. Photograph of feature 1 at archaeological site G:03:064, Arroyo Grande ------------------ 68

68. Photograph of feature 12 at archaeological site G:03:064, Arroyo Grande---------------- 68 


\title{
Sedimentology and Stratigraphy of the Palisades, Lower Comanche, and Arroyo Grande Areas of the Colorado River Corridor, Grand Canyon, Arizona
}

\author{
By Amy E. Draut ${ }^{1}$, David M. Rubin ${ }^{1}$, Jennifer L. Dierker ${ }^{2}$, Helen C. Fairley ${ }^{3}$, Ronald E. Griffiths ${ }^{3}$, \\ Joseph E. Hazel, Jr' ${ }^{4}$, Ralph E. Hunter ${ }^{1}$, Keith Kohl ${ }^{3}$, Lisa M. Leap ${ }^{2}$, Fred L. Nials ${ }^{5}$, David J. Topping ${ }^{3}$, \\ and Michael Yeatts ${ }^{6}$
}

\section{Abstract}

This report presents initial results of a joint effort between geologists and archaeologists to evaluate the significance of various depositional processes and environments in the prehistoric formation and modern preservation of archaeological sites along the Colorado River corridor in Grand Canyon National Park. Stratigraphic investigations of the Palisades, Lower Comanche, and Arroyo Grande areas of Grand Canyon yield detailed information regarding the sedimentary history at these locations. Reconstruction of past depositional settings is critical to a thorough understanding of the geomorphic and stratigraphic evolution of these three archaeologically significant areas. This examination of past sedimentary environments allows the relative significance of fluvial, aeolian, debris-fan, and slope-wash sedimentary deposits to be identified at each site. In general the proportion of fluvial sediment (number and thickness of flood deposits) is shown to decrease away from the river, and locally derived sediment becomes more significant. Flood sequences often occur as 'couplets' that contain a fluvial deposit overlain by an interflood unit that reflects reworking of fluvial sediment at the land surface by wind and local runoff. Archaeological features are built on and buried by sediment of various depositional environments, implying a complex interaction between geologic and cultural history. Such field analysis, which combines geological and

\footnotetext{
${ }^{1}$ U.S. Geological Survey, 400 Natural Bridges Drive, Santa Cruz, CA 95060

${ }^{2}$ National Park Service, 823 San Francisco St., Suite B., Flagstaff, AZ 86001

${ }^{3}$ U.S. Geological Survey, Grand Canyon Monitoring and Research Center, 2255 N. Gemini Drive, Flagstaff, AZ 86001

${ }^{4}$ Department of Geology, Northern Arizona University, Flagstaff, AZ 86011

${ }^{5}$ GeoArch, 10450 W. 8th Place, Lakewood, CO 80215

${ }^{6}$ Hopi Cultural Preservation Office, Northern Arizona University Department of Anthropology, Flagstaff, AZ 86011
}

archaeological information and techniques, can provide a basis for future determination of the effects of Glen Canyon Dam operations on selected areas of the river corridor. This knowledge is essential to the development of preservation strategies for cultural resources in Grand Canyon.

\section{Introduction}

Since the closure of Glen Canyon Dam in 1963, drastic changes in the natural hydrologic and sedimentologic regime have resulted along the Colorado River environment in Grand Canyon (see, for example, Andrews, 1986; Webb and others, 1999). The dam has reduced the supply of sediment at the upstream boundary of Grand Canyon National Park by about 95 percent, with the Paria River remaining the only major supplier of sediment at the upstream park boundary. The predam mean annual sediment load at the upstream park boundary was $\sim 60$ million metric tons; the postdam mean annual sediment load is $\sim 3$ million metric tons (Topping and others, 2000a). The other substantial postdam supplier of sediment is the Little Colorado River, which enters the Colorado $98 \mathrm{~km}$ downstream from the Paria River and supplies an additional 5-10 percent of the predam sediment load (Topping and others, 2000a).

Operation of the dam smoothes natural variations in the river's hydrograph that occurred in response to snow melt and other seasonal climatic fluctuations. Predam discharge records from the Colorado River gage at Lees Ferry, Arizona (US Geological Survey station number 09380000), $24.5 \mathrm{~km}$ below Glen Canyon Dam, indicate that discharge was typically below $226 \mathrm{~m}^{3} / \mathrm{s}\left(7,980 \mathrm{ft}^{3} / \mathrm{s}\right)$ for approximately half of the year, while the mean annual spring snow-melt flood was $2,410 \mathrm{~m}^{3} / \mathrm{s}\left(85,000 \mathrm{ft}^{3} / \mathrm{s}\right.$; Topping and others, 2003). The discharge range released from the dam is substantially less than this natural variability; maximum power-plant capacity calls for flows no greater than $940 \mathrm{~m}^{3} / \mathrm{s}\left(33,200 \mathrm{ft}^{3} / \mathrm{s}\right)$, and 
flows above $708 \mathrm{~m}^{3} / \mathrm{s}\left(25,000 \mathrm{ft}^{3} / \mathrm{s}\right)$ occur under the current operating regime only for isolated experimental purposes. Although seasonal variations in the hydrograph have been flattened, daily discharge fluctuations generally occur over a much greater range than in the predam state (Topping and others, 2003). Control of river discharge by dam operations has important implications for the storage and redistribution potential of sediment in the river corridor. In the absence of flood events, the relatively little sediment that the river now carries cannot be deposited at the higher elevations that received sediment regularly prior to dam closure. In the absence of lower flows $\left(<142 \mathrm{~m}^{3} / \mathrm{s}\left[5000 \mathrm{ft}^{3} / \mathrm{s}\right]\right)$, which are no longer allowed to be released from the dam under the 1996 Record of Decision signed by the Secretary of the Interior, the sediment-storage capability in the main channel is greatly reduced (Topping and others, 2000a, 2003). Sediment supplied by tributaries below the dam is exported from the canyon on time scales of weeks to months under the present flow-operation regime (Topping and others, 2000a, b; Rubin and others, 2002).

Numerous studies have identified consequences of the altered hydrograph and sediment content in the Colorado River. The size and number of subaerial sand deposits, many of which are used as camping beaches by river runners, have shown a systemwide decrease over the past four decades, punctuated by episodic aggradation during the 1983 flood of $2,700 \mathrm{~m}^{3} / \mathrm{s}\left(97,000 \mathrm{ft}^{3} / \mathrm{s}\right)$, the 1996 and 2004 beach/habitat building flow (BHBF) experiments $\left(1,270 \mathrm{~m}^{3} / \mathrm{s}\right.$ $\left[45,000 \mathrm{ft}^{3} / \mathrm{s}\right]$ and $1,160 \mathrm{~m}^{3} / \mathrm{s}\left[41,000 \mathrm{ft}^{3} / \mathrm{s}\right]$, respectively), and sediment input from occasional tributary floods (Beus and others, 1985; Schmidt and Graf, 1987; Budhu and Gobin, 1994; Kearsley and others, 1994; Kaplinski and others, 1995; Schmidt and Leschin, 1995; Wiele and others, 1996; Hazel and others, 1999; Schmidt and others, 2004). Riparian vegetation has colonized areas at lower elevations than would have been possible in predam time when annual floods removed young vegetation; vegetation encroachment has contributed significantly to the loss of open sand area along the river (for example, Turner and Karpiscak, 1980). The reduction in open sand-bar area has affected recreational use of the river corridor; sand-bar erosion and vegetation growth have altered the biomass composition and riparian habitat in complex ways (for example, Dolan and others, 1977; Carothers and Brown, 1991; Webb and others, 1999). The biological community within the postdam river has undergone major changes as a result of colder water temperatures (as subsurface reservoir water is released from the dam), increased light penetration, and alterations in food sources associated with the low sediment input. Such conditions are believed to have contributed to the decline in native fish populations in Grand Canyon, among other effects (Carothers and Brown, 1991; Valdez and Ryel, 1995; Douglas and Marsh, 1996).

The effect of Glen Canyon Dam operations on archaeological resources in Grand Canyon has received little research attention to date. At the time that the Bureau of Reclamation sponsored the creation of the Glen Canyon
Environmental Studies (GCES) research initiative in 1982, primary research objectives included physical and biological resources, while effects on cultural resources were not addressed (Fairley and others, 1994; Fairley, 2003). The relative inattention paid to potential dam effects on archaeological sites largely stemmed from the perception that, because few archaeological remains were preserved within the river's annual flood limit, cultural features would not be greatly affected by dam operations. It has more recently been suggested (Hereford and others, 1993, Yeatts, 1996, 1997; Thompson and Potochnik, 2000) that postdam alterations in the sediment load and flow regime of the Colorado River may significantly affect the preservation potential of archaeological sites within the river corridor, even above the annual flood zone.

Of the nearly 500 archaeological sites that have been recorded in the river corridor between Glen Canyon Dam and Separation Canyon (255 river miles), more than 250 are considered to be within the Area of Potential Effect (APE) of dam operations designated by the National Park Service (NPS; Fairley and others, 1994; Neal and others, 2000). Repeated monitoring visits have shown that many of the sites located in or on poorly consolidated sediment deposits are actively eroding due to incision by gullies, aeolian deflation processes, and visitor impact (for example, Leap and others, 2000; Pederson and others, 2003, Fairley, 2003). The process of gully incision, and the base level to which small, ephemeral drainage systems respond, were first proposed to be linked to dam operations by Hereford and others (1993). In a study of surficial geology and archaeological site erosion, Hereford and others (1993) documented increased erosion of predam fluvial terrace deposits, and associated archaeological sites, by gully incision that accompanied unusually high precipitation in the mid-1970s. From these observations followed the hypothesis that rapid rates of incision were caused by the lowering of base level at the mouths of ephemeral drainages to meet the new, postdam elevation of high-flow sediment deposition. Hereford and others (1993) proposed that incision rates would remain high until gully morphology has equilibrated to the postdam base level, as much as 3-4 m below the lowest predam alluvial terraces.

Thompson and Potochnik (2000) revisited this hypothesis in a comparative study of alluvial terrace evolution in Grand and Cataract Canyons. These authors modified the base-level concept to include the restorative effects of fluvial deposition in the mouths of gullies and arroyos (thus raising base level), and the potential for aggradation of predam fluvial terrace deposits by aeolian deposition of reworked flood sand. Thompson and Potochnik (2000) concluded that sediment deprivation and lack of floods, caused by dam operations, have removed the potential for sediment deposition that could ameliorate precipitation-induced gully development. They developed a predictive geomorphic model designed to identify areas prone to gully incision, a concept later modified by Pederson and others (2003). The emphasis of Thompson and Potochnik (2000) on the poten- 
tial for aeolian deposition to protect fluvial terraces, and, by extension, archaeological sites, led to the conception of the present study; it has been further suggested elsewhere that aeolian deposition in incipient gullies is "one of the strongest restorative forces operating at archaeological sites" (Neal and others, 2000, p. 77). Repeated high-resolution mapping conducted after the 1996 BHBF experiment confirmed that such floods can deposit sediment in arroyo mouths and that such deposits can serve as a source for wind-blown sand that accumulates at higher elevation, leading to net deposition above the flood stage elevation (Yeatts, 1997; Hazel and others, 2000).

In order to evaluate the degree to which the presence and operation regime of Glen Canyon Dam may influence the stability of archaeological features, site-specific stratigraphic and geomorphic knowledge is essential. Establishing the local importance of fluvial, aeolian, and other processes in predam time is an important precursor to any future assessments of dam-operation effects on these and other areas of the river corridor. Detailed field investigations of the stratigraphic record at three locations along the Colorado River corridor in Grand Canyon were initiated for the purpose of determining the relative importance of various depositional environments in areas known to have been occupied by prehistoric cultures. This study focuses on the Palisades, Lower Comanche, and Arroyo Grande areas of Grand Canyon (fig. 1). Locations of study sites are not specified explicitly because of the need to keep archaeological-site locations confidential.

This work is intended to provide examples of applicable methods and relevant data that can facilitate similar studies in other areas; stratigraphic interpretations from these three sites are not intended to be extrapolated to other regions of the river corridor. Although the depositional processes that control the sedimentary history at these locations are certainly important in other areas, the relative importance of each in these three particular locations as determined by this study should not be assumed for any other area without sitespecific investigation.

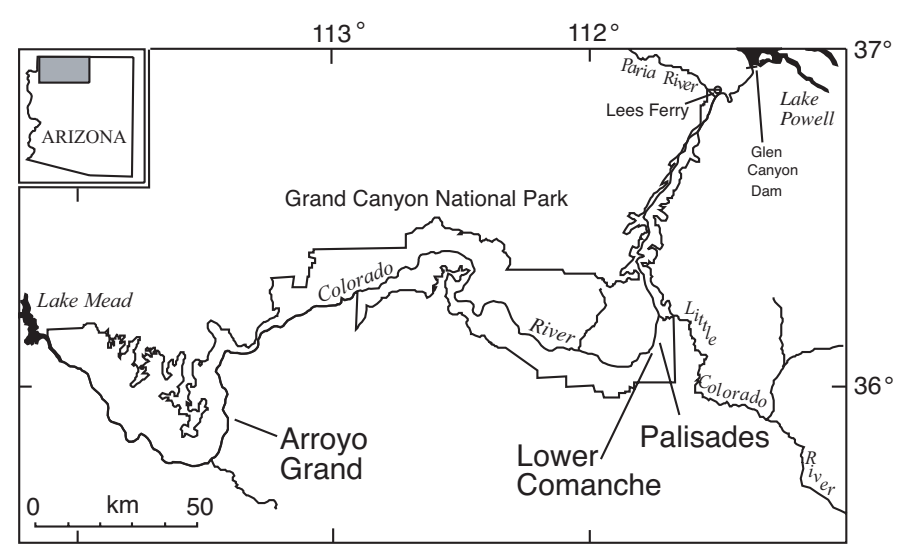

Figure 1. Location map of Grand Canyon with the three study areas indicated.

\section{Site Selection}

In May 2003, reconnaissance work was done to assess the sedimentary and geomorphic setting of approximately 40 archaeologically significant areas along the Colorado River corridor. The purpose of this initial survey was to observe interaction between aeolian sediment and archaeological sites, as a basis for ongoing investigations studying the connection between aeolian deposition and archaeological site preservation. The three sites discussed in this report were identified for further study as a result of observations made during the 2003 reconnaissance field work. In selecting the Palisades, Lower Comanche, and Arroyo Grande areas for detailed stratigraphic analysis, the research group chose to focus on areas where aeolian deposition was suspected to form an important component of the sedimentary history. Operating on the hypothesis that aeolian deposition might form a substantial component of the stratigraphy studied at these three sites, members of this research group spent 3-5 days at each site in May 2004 studying stratigraphy in sufficient detail that the relative importance of aeolian sediment deposition could be more thoroughly assessed.

Each of the three sites targeted for this study has experienced reduction in a source of aeolian sand since the closure of Glen Canyon Dam in 1963. Multiple sets of aerial photographs that span the time period from 1965 to 2002 (available from the Grand Canyon Monitoring and Research Center) indicate that the area of open sand exposed near river level has, at each of the three locations, decreased because of both loss of sand (erosion of sand bars) and increased vegetation cover. Low-elevation areas of nearby sand bars spend more time submerged as a result of flow fluctuations, reducing the potential source area for wind-blown sand because sand must be dry to be entrained by the wind. Two of the three sites (Palisades and Lower Comanche) experienced some sediment deposition during the 1996 controlled flood experiment, indicating that future flood experiments could potentially be used to alleviate erosion that has occurred in those areas (Grand Canyon Monitoring and Research Center, aerial photographs; Yeatts and others, 1996, 1997). Instrument stations have been established at Palisades and Lower Comanche in November 2003 and April 2004, respectively, to quantify aeolian sand transport; results of stratigraphic analysis at those sites presented here are intended to supplement the concurrent aeolian sediment-transport data that will be discussed in a separate publication.

\section{Previous Work}

A number of previous studies have presented sedimentary and geomorphic data from Grand Canyon that are relevant and complementary to this investigation. Geomorphic mapping by Hereford (1993) and by Hereford and others $(1993,1996)$ in the Palisades area generated detailed interpretations of the surficial geology that are discussed and 
expanded upon in this present study. Radiocarbon dating work (Hereford, 1993; Hereford and others, 1996) has also provided much of the available information on the timing of various alluvial terraces and debris-fan deposits at Palisades. It is noteworthy that the Palisades area was one location used by Hereford and others (1993) to outline the baselevel hypothesis discussed above. Thompson and Potochnik (2000) studied the Palisades area during the formulation of their restorative base-level hypothesis, and they concluded that drainage catchment areas at Palisades did support the idea that incision of alluvial terraces could be attributed to dam-induced lowering of base level. Thompson and Potochnik (2000) list Palisades and Arroyo Grande as two areas where, during their geomorphic survey and modeling study, they identified stratigraphic evidence for paleogullies that had filled with aeolian sand.

Grams and Schmidt (1999) used ground (oblique) and aerial photography of the Palisades area, among other study sites, to evaluate changes in the extent of surficial sand deposits since 1890. Repeated high-resolution mapping by Yeatts $(1996,1997)$ and Hazel and others (2000) demonstrated erosion and aggradation of sand deposits at Palisades as a result of the 1996 BHBF experiment. Notably, Yeatts (1997) and Hazel and others (2000) documented the migration of sediment deposited in the main arroyo mouth at Palisades to higher elevation over the year following the flood, attributed this migration to aeolian processes, and identified such consequences of the BHBF as potentially beneficial for preservation of cultural resources above the $1,270-\mathrm{m}^{3} / \mathrm{s}$ $\left(45,000-\mathrm{ft}^{3} / \mathrm{s}\right)$ level. Gellis (1994) reported field observations of erosion at archaeological sites during work with the Zuni Tribe, including parts of the Palisades and Lower Comanche areas discussed here. Pederson and others (2003) monitored arroyo incision at both Palisades and Arroyo Grande, among other sites, in a geomorphic study of gullying processes and an assessment of the effectiveness of erosion-control structures such as checkdams.

Mapping of surficial deposits at Granite Park (approximately $2 \mathrm{~km}$ downstream of the Arroyo Grande site discussed here) by Hereford and others (2000) provides information applicable to geomorphic interpretations at Arroyo Grande. Several radiocarbon dates listed in Hereford and others (2000) were for samples from stratigraphic units at Arroyo Grande, aiding age determination of deposits in that area.

Fairley and others (1994) completed the first comprehensive survey of archaeological sites along the river corridor in Grand Canyon. This survey provided baseline data for defining the depositional context of many archaeological sites, and it generated the first data set against which later monitoring surveys could be compared. Subsequent monitoring summaries by NPS have provided repeated geomorphic observations related to archaeological site location, condition, and preservation (Coder and others, 1994a, b, 1995; Leap and others, 1996, 1997, 1998, 2000, 2003; Leap and Kunde, 2000; Dierker and others, 2001, 2002). Pederson and others (2003) used repeated aerial surveys to evaluate rates of gully incision in areas known to be archaeologically significant, including Arroyo Grande.

Sedimentology and stratigraphy of flood deposits in Grand Canyon have been addressed by several previous studies. McKee (1938) first presented facies descriptions of Colorado River flood strata at a number of exposures at tributary mouths in the canyon. Rubin and others (1990) and Schmidt (1990) used stratigraphic exposures in active river-level sand bars to describe the formation and evolution of separation and reattachment bars in zones of flow recirculation in eddies. Rubin and others (1994) analyzed stratigraphy within deposits from the $19832,700 \mathrm{~m}^{3} / \mathrm{s}\left(97,000 \mathrm{ft}^{3} / \mathrm{s}\right)$ flood and weaker flood events in 1984-1986, using the data to estimate deposition rates and to evaluate the potential impact of various dam-controlled flow regimes on the erosion and accumulation of sediment on camping beaches. O'Connor and others (1994) used paleoflood deposits, dated by radiocarbon techniques, to estimate discharge levels for floods as old as 4,500 years BP. The peak discharges of the paleofloods studied by O'Connor and others (1994) were subsequently revised by Topping and others (2003) using archived US Geological Survey gaging data that were not readily available for previous analysis.

Grain-size analyses of sediment sampled from flood deposits in Glen Canyon (below the dam) and Grand Canyon have demonstrated sediment-supply limitation in both predam and postdam flood events (Rubin and others, 1998; Topping and others, 2000a, b; see also Rubin and Topping, 2001). Supply limitation in flood deposits was shown by those studies to be manifested by a coarsening upward of grain size within individual flood deposits, in contrast to the fining-coarsening-fining or fining-upward fluvial sequences that result from supply-unlimited flows. Upward coarsening of deposits from supply-limited floods occurs as suspended sediment becomes progressively depleted of fine-grained material in a supply-limited system (the finer sizes having been transported downstream first and farthest). Fine sediment can then be winnowed from the stream bed during the later stages of the flood, increasing the median grain size of the sediment that remains exposed at the bed (Rubin and others, 1998). The relationships between sedimentsupply limitation in the Colorado River and the resulting sedimentology of flood deposits discussed by Rubin and others (1998) and Topping and others (2000a, b) are further developed in this study of predam fluvial sequences.

\section{Methods}

Data collected from the three sites discussed in this report were obtained primarily through detailed examination of vertical stratigraphic sections. At all three locations, the presence of arroyo networks facilitated the exposure of vertical faces for this purpose; at Palisades and Lower Comanche, several additional sections were exposed by digging small 
pits. Sedimentary characteristics were described, and unit thicknesses were measured in detail, for most of the sections discussed. At selected locations, sediment samples were collected for subsequent grain size analysis using a Coulter laser particle-size analyzer at the Grand Canyon Monitoring and Research Center laboratory in Flagstaff, Arizona. Geomorphic observations, supplemented by shallow test-pits, were made in the general area of archaeological sites in order to evaluate sedimentary and geomorphic processes directly relevant to each of the sites of interest. To standardize stratigraphic sections, all sections in this report are described beginning with the uppermost unit and progressing downsection. Unless otherwise specified, measurements of stratigraphic depth refer to depth below the land surface.

Surveying equipment was used to document the locations of stratigraphic sections, as well as the thalweg location and headward extent of major arroyo branches at Palisades and Arroyo Grande. At Palisades and Lower Comanche, the locations and elevations of logs and milled timber interpreted as driftwood were also surveyed; these data are used to place flood events that occur in the stratigraphic record within the context of historic flood discharge levels.

Stratigraphic work, including sediment sampling, has been permitted at these locations under National Park Service Research and Collecting Permit \#GRCA-2003-SCI0101 issued by Grand Canyon National Park. Research that took place at Arroyo Grande, located in the Area of Cooperation (AOC) between the Hualapai Nation and the National Park Service, was also authorized by the Hualapai Office of Cultural Resources. All stratigraphic investigations have been conducted in close collaboration between geologists and archaeologists to ensure that culturally significant areas are treated with extreme care. Sediment pits and arroyo wall exposures that were logged and studied during this work were located away from the immediate vicinity of archaeological features. No cultural artifacts were exposed or collected during this work. All artificial pits were filled in at the completion of the field work to conceal the work areas.

\section{Identification of Depositional Environments}

Within a vertical stratigraphic exposure, small-scale sedimentary structures are used as the best diagnostic indicator of depositional environment. Structures that are characteristic of fluvial and aeolian environments, respectively, can often be identified by the dimensions, scale, grain-size sorting, and spatial orientation of bedding apparent in outcrop exposure. Diagnostic features of fluvial and aeolian stratification have been described thoroughly elsewhere (for example, Walker, 1963; Stokes, 1968; Harms and others, 1975; Hunter, 1977a, b; McKee, 1979; Rubin and Hunter, 1982, 1987; Rubin, 1987) and will not be discussed in detail here. Some manifestations of fluvial and aeolian sedimentary structures appear similar and can be difficult to distinguish (for example, aeolian ripples with low climb angles and flu- vial structures that represent upper plane-bed conditions). In such cases, depositional environment may sometimes be inferred by observation of lateral gradation into other, more diagnostic structures.

Numerous stratigraphic horizons studied in these and other areas of Grand Canyon do not contain well preserved sedimentary structures. In most cases, absence of sedimentary structures in fine-grained surficial sediment is attributable to biologic effects. The presence of vegetation on the land surface interferes with the development of sedimentary structures as aeolian sediment is deposited; wind ripples forming on a sparsely vegetated surface have shorter crests and less regular trough elevation than on unvegetated surfaces, while denser vegetation cover reduces or prevents aeolian entrainment and transport of sand (for example, Olson, 1958; Bressolier and Thomas, 1977; Ash and Wasson, 1983; Buckley, 1987). Organic debris on the land surface can also interfere with the development of wind ripples, as can a variable wind direction during deposition. Bioturbation by trampling, animal burrowing, and the growth of plant roots can disturb or destroy sedimentary structures after they have formed. Particularly in cases where the rate of sediment deposition is slow, bioturbation in both subaerial and subaqueous environments can quickly obscure sedimentary structures (for example, Dott and Bourgeois, 1982; Wheatcroft, 1990; Boudreau, 1994).

Textural differences (grain size analysis) may in some cases distinguish fluvial and aeolian material if sedimentary structures are indistinct. However, the range of grain sizes observed to occur within Colorado River fluvial deposits (a function of sediment availability, discharge, and proximity to flooding tributaries) is great enough that there is some overlap between textural characteristics of fluvial and aeolian deposits in Grand Canyon. Textural analysis as a diagnostic tool should therefore be used with caution. If sedimentary structures are not distinct, reworking of a primary sedimentary deposit by wind may be inferred on the basis of the morphology of the deposit (for example, presence of sand shadows or coppice dune accumulation).

Identification of slope-wash sedimentation is commonly based on the presence of locally derived lithic clasts in a deposit; slope-wash materials are commonly more poorly sorted and immature (with respect to mineralogy and weathering of sediment grains) than primary fluvial or aeolian deposits (for example, Benito and others, 2003). Surficial runoff events may result in the development of channel features; channels filled with locally derived sand and gravel were observed in a number of the stratigraphic sections described during this work. In some locations studied, notably Arroyo Grande, subaerial reworking of surficial sediment may be identified by the presence of charcoal and ash concentrations in the soil. Horizons that contain such burned material are readily distinguishable from isolated cultural hearth features; the more widespread, diffuse charcoal occurrences that are common in Arroyo Grande imply a regional burning event at the land surface, such as a grass fire. 


\section{Grain-Size Analyses}

Grain-size analyses of sediment samples provide information about sedimentary dynamics that cannot necessarily be determined in the field. Grain-size data can, in some cases, also facilitate identification of the depositional environment of certain stratigraphic units. Although variation may occur between the grain-size distributions of sedimentary units deposited by the same type of event, and these data are therefore not necessarily representative of every deposit with a similar event history, 36 samples with known depositional environments that were analyzed during this study yielded distributions with little enough overlap between, for example, fluvial and aeolian fields that this technique may be considered useful in identifying a likely depositional environment for samples without diagnostic sedimentary structures.

The grain-size distribution of flood deposits is determined by the concentration and grain size of sediment available in the flow at various stages of the flood event; concentration and grain size are in turn determined by the nature and intensity of the event that initiated the flood (main-stem river snow-melt flood vs. tributary flood, for example) and the source area from which the sediment is derived. The latter is influenced in part by channel morphology; in areas where a river flows over an alluvial floodplain at high discharge, the flow may entrain finegrained floodplain sediment that is not available as a sediment source when the river is confined to its main channel at lower discharge.

Within aeolian deposits, grain-size distribution depends upon such factors as the intensity and duration of the wind, which determine the degree of winnowing and sorting that occur, as well as the composition and grain size of sand in the source region that provides sediment to the aeolian deposits. Slope-wash deposits contain probably the greatest range of possible sedimentary characteristics; their local derivation leads to substantially less 'maturity' of the resulting deposit compared to fluvial or aeolian strata, in which grains have typically undergone extensive transport before deposition. The grain-size distribution and sediment composition of slopewash deposits depend on the intensity, location, and duration of the precipitation event that generated them, as well as the lithology of source rocks that produce the sediment. Local precipitation often transforms the landscape in ways that alter characteristics of the stratigraphic record where such deposits are found; rill and gully formation and subsequent filling can result in channel-fill structures and lens-shaped slope-wash deposits.

Sediment samples were analyzed for grain-size distribution using a Beckman Coulter LS 100Q laser particle-size analyzer linked to a LS variable-speed fluid module. The Beckman Coulter LS 100Q computes particle-size distributions based on the Fraunhofer laser diffraction theory, which states that small particles in the path of a laser will diffract the light in a known, symmetrical pattern. The angle of diffraction inversely corresponds to the size of the particle. This instrument uses 126 detector rings to measure the pattern of dif- fracted light intensities as a function of the angle from the axis of the original laser beam in order to compute the particle-size distribution. Particles from $0.375 \mu \mathrm{m}$ to $948.2 \mu \mathrm{m}$ in diameter can be measured in this way (http://www.coulter.com/products/instrument/partChar/pc_1s230.asp).

Sample preparation was minimal because of the overall lack of organic material and relative coarseness of the samples, negating the need for hydrogen peroxide $\left(\mathrm{H}_{2} \mathrm{O}_{2}\right)$ and sodium hexametaphosphate $\left(\left(\mathrm{NaPO}_{3}\right)_{6}\right)$ treatments. Deionized water was added to the samples in a small beaker, and the beaker placed on a stir plate for agitation. A representative subsample was then extracted from suspension in the beaker using a pipette. The sediment and water mixture was added into the Coulter until the optimum obscuration range (8-12 percent) was reached. This process was repeated up to four times for each sample; the average of the 4 runs was used in subsequent data analysis to minimize potential subsampling errors. Grain-size distribution is reported as percent by volume and assumes spherical particles.

\section{Palisades Area}

\section{Geomorphic Setting}

The Palisades (Palisades of the Desert) area (fig. 2) lies within the fluvial geomorphic reach described by Schmidt and Graf (1987) as the Furnace Flats reach. Bedrock at river level in this area is the Dox Formation, a series of interbedded fine-grained sandstones and shales of Precambrian age that commonly display a characteristic red to nearly purple color (originally named the Dox Sandstone ${ }^{7}$ by Noble, 1914, this unit was redescribed by Stevenson and Beus, 1982, as the Dox Formation on the basis of its varied lithology). Sandstone beds of the Dox Formation are locally offset by major fault displacement along the Palisades segment of the Butte Fault, a northwest-trending structure related to the east Kaibab Monocline that crosses the river in this area (Huntoon and others, 1996).

Various surficial deposits are present on the wide, relatively flat expanse downstream of Palisades Creek. At least three episodes of Holocene debris-fan activity have been inferred for the Palisades Creek debris fan on the basis of stratigraphic relationships and repeat photography (Hereford, 1993; Hereford and others, 1996), the youngest having occurred between 1965 and 1984. Additional, undated recent debris-flow activity is apparent in leveed, unvarnished debrisfan deposits on the tributary north of Palisades Creek. Terrace morphology in the central Palisades area is attributed to fluvial deposition. Hereford (1993) mapped four alluvial terrace

\footnotetext{
${ }^{7}$ Dox Sandstone remains the official USGS name of this unit. This report follows the use of 'Dox Formation' introduced by Stevenson and Beus (1982), based on the shale-rich lithology of this unit in the study area.
} 


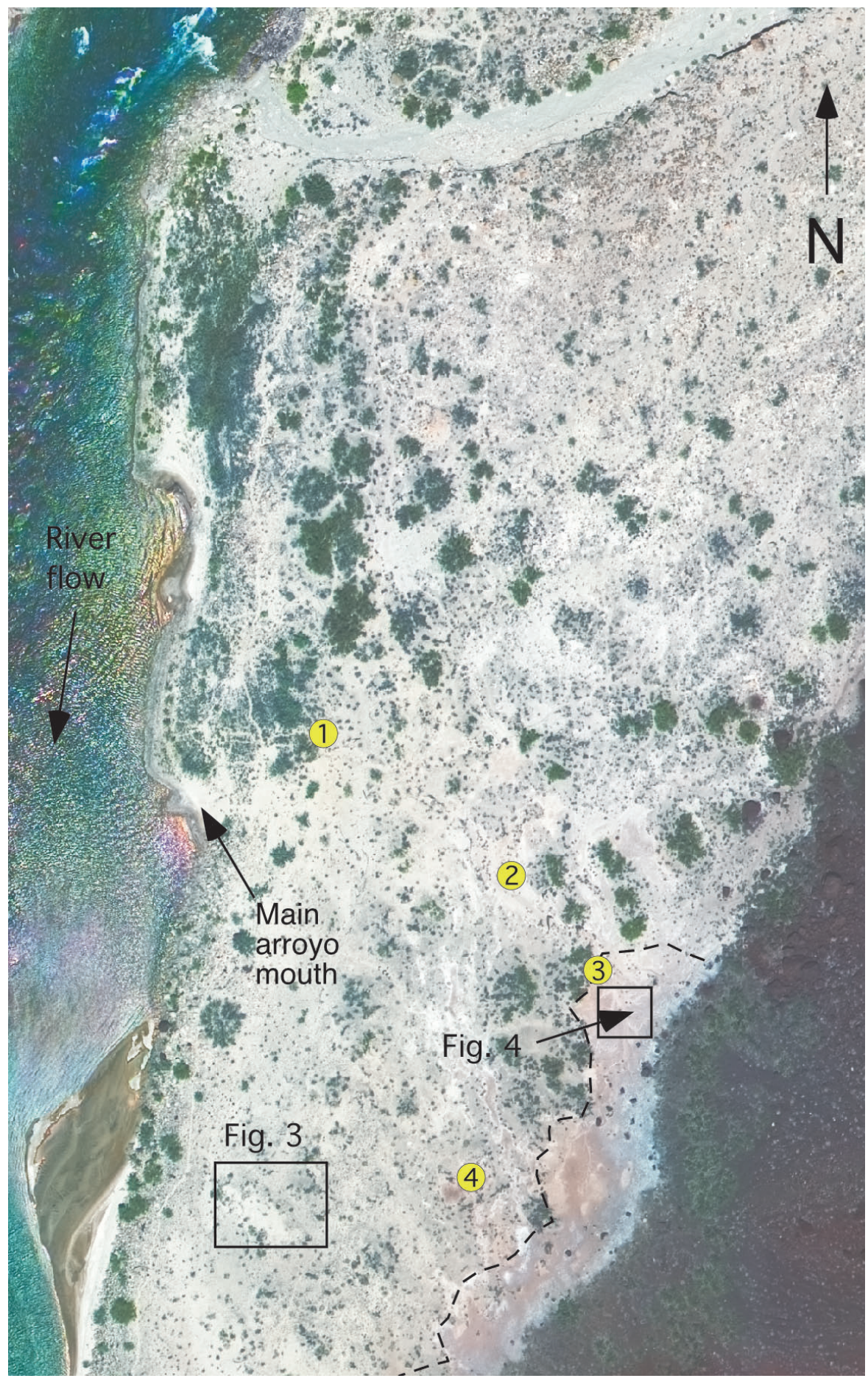

Figure 2. Aerial view (May 2002) of the Palisades study area. Locations of stratigraphic sections 1 through 4 are indicated by numbered dots. The dashed line marks the approximate boundary of playa deposits, which show a pink-red color because of derivation of sediment from the Dox Formation (Stevenson and Beus, 1982) in the adjacent canyon wall. Boxes indicate locations of photographs in figures 3 and 4 . The location of the arroyo mouth is indicated, though the arroyo network is not readily visible in this image. River discharge in this photograph is $226 \mathrm{~m}^{3} / \mathrm{s}$. 
units that could be dated to predam fluvial activity, in addition to postdam flood deposits present at lower elevation. The predam terrace deposits described on river left at Palisades by Hereford and others $(1993 ; 1996)$ include (from oldest to youngest): (1) Alluvium of Pueblo-II age (map unit 'ap'), a unit 1-3 $\mathrm{m}$ thick that was inferred, on the basis of archaeological artifacts, to have a probable age range of before A.D. 950 to A.D. 1075-1200. (2) Upper mesquite terrace (map unit 'umt'), a terrace-forming very fine to fine sand unit as much as $2 \mathrm{~m}$ thick that contains multiple fluvial deposits within it; radiocarbon ages and archaeological remains suggested deposition of this unit between A.D. 1270-1470 and A.D. 1882-83, though analysis of driftwood location and elevation made during this study implies that the 1884 flood $\left(5,940 \mathrm{~m}^{3} /\right.$ $\mathrm{s}, 210,000 \mathrm{ft}^{3} / \mathrm{s}$; Topping and others, 2003) apparently covered most of the 'umt' area. (3) Lower mesquite terrace (map unit 'Imt'), fluvial sediments within the elevation limit of the 1921 flood $\left(4,800 \mathrm{~m}^{3} / \mathrm{s}, 170,000 \mathrm{ft}^{3} / \mathrm{s}\right.$; Topping and others, 2003) based on the location of driftwood lines; Hereford (1993) attributed an age of A.D. 1884 to the 1930s to this unit. (4) Predam alluvium (map unit 'pda'), an exposure of sediment 1-2 $\mathrm{m}$ thick at lower elevation than 'Imt' but above the 1983 flood sand; topographic position suggested a date of early 1930s to 1957. An additional alluvial package, which Hereford (1993) named the "striped alluvium" (map unit 'sa') on the basis of interbedding of alluvium with locally derived Dox Formation sediment, is present on river right in this area but not on river left where this study focused; the striped alluvium is the oldest and highest-elevation alluvial deposit recognized in this part of the river corridor. Dates obtained from exposures believed to be correlative with this 'sa' unit range from 2500 B.C. to A.D. 300 (2568 to 2289 B.C. in upper Marble Canyon, O'Connor and others, 1994; older than 1300 B.C. at Granite Park, river mile 209, Hereford and others, 2000; 800 B.C. to A.D. 300 in eastern Grand Canyon, Hereford, 1993).

A large, river-based arroyo network (one whose outlet, or base level, is at the elevation of the main river channel) has incised these alluvial terraces; the age of the arroyo incision is uncertain, but it appears to have begun after 1890, on the basis of historical photograph analysis by Hereford (1993). Incision has deepened since 1965, judging from aerial photograph comparison (Hereford, 1993; Hereford and others, 1993). Photographic evidence discussed by Thompson and Potochnik (2000) suggests that in 1973, a partial arroyo network was present that was blocked by the 'pda' alluvium and associated aeolian dunes. By 1980, the arroyo channel had breached the dunes and drained into the Colorado River (Thompson and Potochnik, 2000). Repeated survey work by Pederson and others (2003) documented incision of this arroyo related to precipitation events during the 2002 monsoon season.

Aeolian dune forms are present over a widespread area atop the fluvial terraces described by Hereford (1993); that study mapped an area of coppice dune accumulations. Recent active dune migration is apparent in this area, with milled timber and an historic-era horse skull having been partially buried by aeolian dunes; much of the land surface today is cryptogamic and colonized by grasses, and it appears deflated over much of its extent (fig. 3).

The dune field is bordered at its eastern (landward) margin by playa deposits that show evidence of local sediment derivation (receiving slope-wash from the red Dox Formation immediately above) and recent ponding and desiccation (fig. 4). Two drainage divides are evident within the playa zone. Most of its area drains to the north, feeding the main arroyo network. A second drainage basin collects water that evaporates in a ponding area west of the main playa expanse, immediately east of the Beamer hiking trail, with no outlet to the river. A third, southern drainage network brings runoff from the eastern playa area to the small arroyo developed at the extreme southern end of the Palisades area.

The river in the Palisades area is in a zone of flow expansion below two debris fans, where the river corridor widens to more than $400 \mathrm{~m}$, in part because of drainage control by the Palisades segment of the Butte Fault. A separation bar and reattachment bar form in the long, narrow eddy downstream of this rapid (Grams and Schmidt, 1999), with a second lowelevation sand bar sometimes present that is episodically exposed subaerially (fig. 2). Examination of ground and aerial photographs by Grams and Schmidt (1999) has shown that the extent of open (unvegetated) sand area on these sand bars has greatly decreased relative to the predam exposure. Reduction of open sand area at Palisades has been due both to a loss of high-elevation sand (Grams and Schmidt, 1999) and to a substantial increase in colonization by riparian vegetation (figure 47 of Turner and Karpiscak, 1980). Recent survey of a large

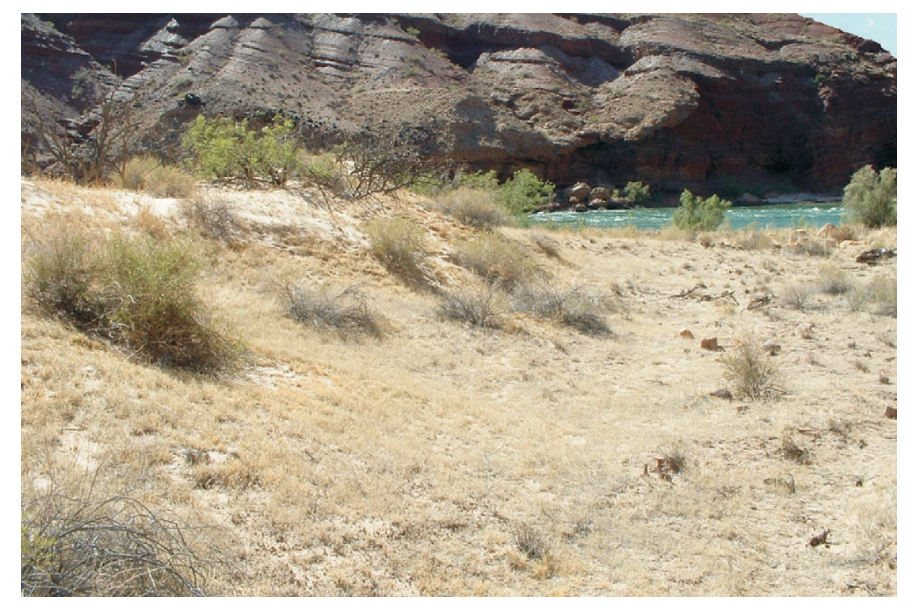

Figure 3. Aeolian dunes at Palisades (location shown on figure 2). The dune at the left side of the photograph is one of the more active dunes in this area, with exposed, unvegetated loose sand at its crest. Although dune forms are present on the terrace surface and reach heights of $2 \mathrm{~m}$ (relative to the surrounding terrace elevation), much of the landscape shows evidence of deflation and recent inactivity. Vegetation cover is abundant though typically thin (for example, cheat grass, shrubs, and occasional mesquite); cryptogamic soil and pedestal development are common. 
boulder that appears partly buried in sand in a 1941 groundbased photograph indicates that a large part of the eddy sand bar at Palisades deflated by at least $2 \mathrm{~m}$ between 1941 and 2000 (D. J. Topping, unpub. data, 2000); aerial-photograph analysis suggests that most of this deflation was due to erosion that occurred after the closure of Glen Canyon Dam (Grams and Schmidt, 1999). An aerial view of the Palisades area as it looked in 1965 is shown in figure 5. Modeling work by Wiele and Franseen $(1999,2001)$ indicated that flood stages exceeding $1,270 \mathrm{~m}^{3} / \mathrm{s}\left(45,000 \mathrm{ft}^{3} / \mathrm{s}\right)$ could result in substantial deposition on the sand bars immediately below Palisades Creek (with greater deposition predicted at flows in excess of 2,800 $\mathrm{m}^{3} / \mathrm{s}\left[\sim 100,000 \mathrm{ft}^{3} / \mathrm{s}\right]$, even assuming a relatively low sediment concentration in the flow). On the basis of these hydrographic models, such flows have been suggested as a means by which to improve preservation of archaeological sites in the Palisades area (Wiele and Franseen, 1999).

The $1,270 \mathrm{~m}^{3} / \mathrm{s}\left(45,000 \mathrm{ft}^{3} / \mathrm{s}\right)$ controlled flood experiment in 1996 caused scour and erosion of sand deposits in

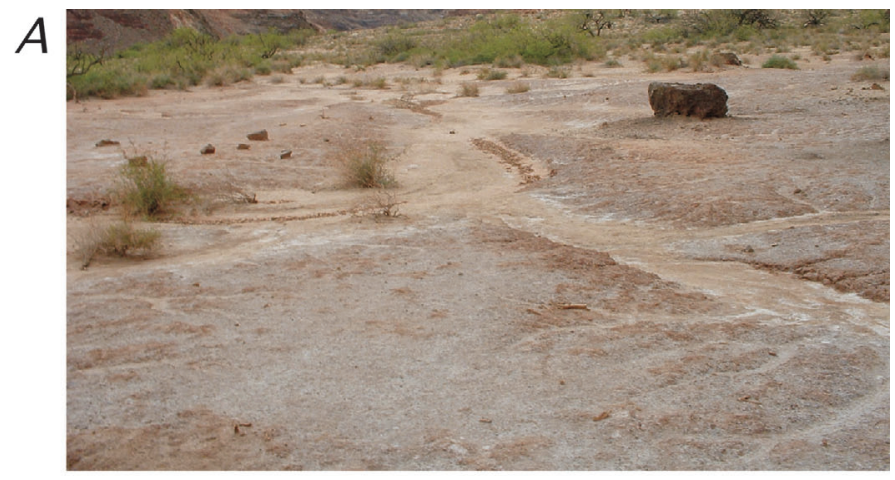

\section{$B$}

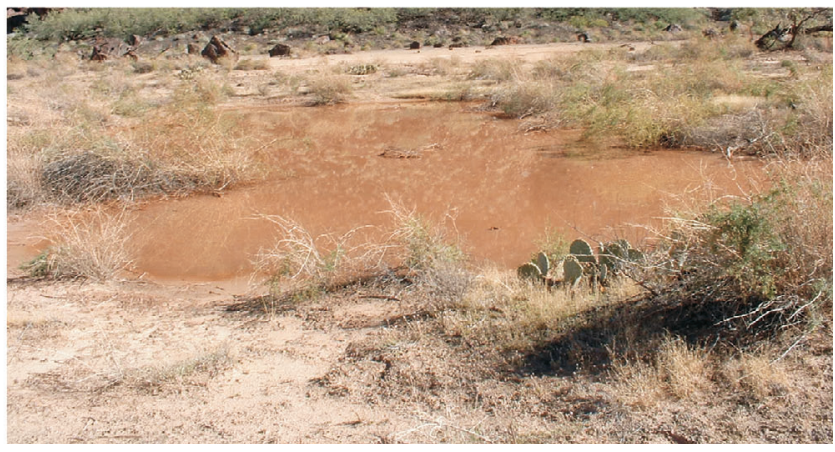

Figure 4. Playa deposits at the eastern edge of the Palisades study area. $A$, The drainage channel in the northern (upstream) playa deposits is the source for the main arroyo network, which affects several archaeological sites (photograph taken in April 2004). B, Standing water in the central part of the playa (photograph taken in November 2003). The reddish color of the playa sediment reflects local derivation from the Dox Formation (Stevenson and Beus, 1982), in contrast to the typically buff-colored Colorado River flood deposits. Analysis of photographs by Thompson and Potochnik (2000) indicates that, prior to 1980 , drainage of the playa area was blocked by aeolian dunes, and had not yet reached the river as the northern part of it does today. the Palisades eddy on river left. Although a net loss of sediment occurred in this area during the experiment, the flood deposited sand in the mouth of the main arroyo (Yeatts, 1996). Repeated high-resolution surveys in the year following the 1996 flood demonstrated a slight net gain of sediment $\left(17 \mathrm{~m}^{3}\right.$ in the survey area) above the $1,270 \mathrm{~m}^{3} / \mathrm{s}$ line $(45,000$ $\mathrm{ft}^{3} / \mathrm{s}$; surveys at Palisades were conducted two months and 13 months after the flood). This accretion indicated that sediment deposited in and around the arroyo mouth had apparently been transported to higher elevation by wind action (Yeatts, 1997), consistent with the 'restorative' processes proposed by Thompson and Potochnik (2000). Survey mapping conducted

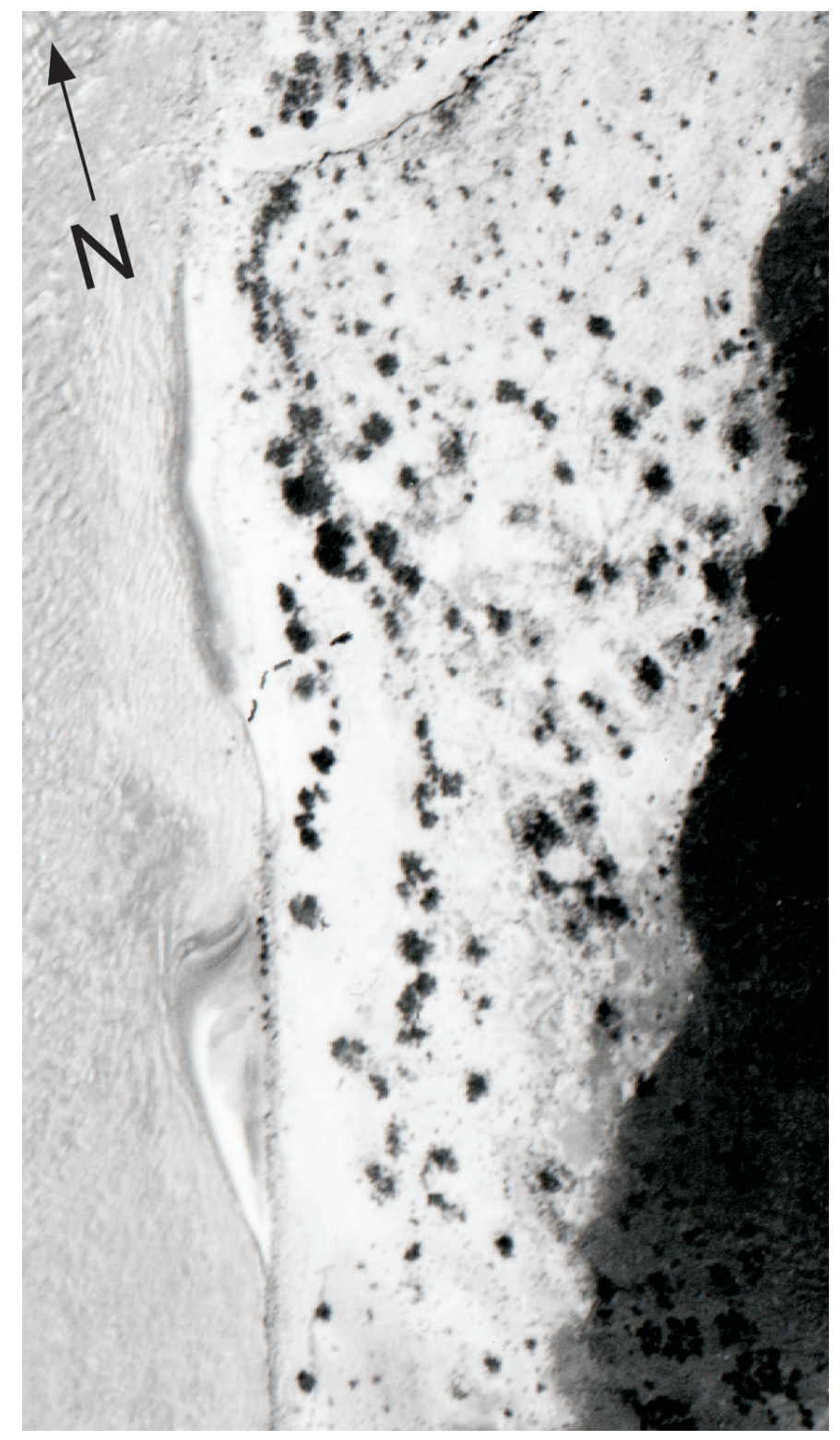

Figure 5. Aerial photograph (1965) of the Palisades study area (photograph from the Grand Canyon Monitoring and Research Center). River discharge is between 680 and $792 \mathrm{~m} / \mathrm{s}$. 
in 1998 and 1999 showed that aeolian sediment deposited after the 1996 BHBF flow had been retained at Palisades, and that arroyo incision in the 3.5 years following the flood had not yet reduced the arroyo flood elevation to its preflood level (Hazel and others, 2000). Medium-format photographic stations were established before the $1996 \mathrm{BHBF}$ flood at locations where the arroyo showed filling and erosion after the flow. NPS archaeologists continue to take photographs at those locations, as part of the site-monitoring program, at selected areas to monitor these processes near the mouths of significant arroyos such as the one at Palisades (for example, Balsom and Larralde, 1996).

\section{Archaeological Significance}

The wide, relatively flat land in the Palisades area contains abundant evidence of prehistoric human occupation. Nine separate prehistoric archaeological sites have been identified, several of which contain multiple habitation and artifact features (National Park Service, 2004). Sites have been dated by radiocarbon methods and artifact identification to Pueblo I and Pueblo II (PI and PII) periods (A.D. 800-1000 and A.D. 1000-1150 respectively; Fairley and others, 1994). Several of the sites are affected by the development of an arroyo system in the central Palisades area, which has contributed to the loss of artifacts in some areas. Checkdams have been placed in several branches of the arroyo by the National Park Service (NPS) and representatives from the Zuni Tribe to reduce the erosion of artifacts by arroyo incision (Leap and Coder, 1995). To limit damage to archaeological sites by visitor impact, NPS relocated a section of the Beamer Trail through the Palisades area in 1992.

In addition to prehistoric cultural features, historical artifacts are present at Palisades dating back to mining operations in this area during the late 1800s and early 1900s. Two mine shafts, with tailing piles, are left as evidence of copper ore extraction at the Tanner-McCormick mine, which ceased to be actively mined in 1920 . Historical features include the remains of a cabin (used between 1890 and 1910) with associated metal and glass artifacts; many items have been removed by visitors in the last few decades (Coder, 1994).

\section{Stratigraphic and Geomorphic Analyses}

Locations of stratigraphic sections described below are shown on figure 2. Detailed stratigraphic logs are described in appendix 1 (see figs. 32 through 36). Section 1 is a vertical face that forms the north wall of the main arroyo trunk at low elevation. Section 2 is located $78 \mathrm{~m}$ landward (east; up-arroyo) from section 1, and was compiled from sediment exposures in an arroyo wall as well as a shallow pit excavated in the arroyo floor at the base of the naturally exposed wall. Section 3 is located farther up the arroyo, $40 \mathrm{~m}$ from section 2 , and is a pit dug into the surface at the northern (upstream, with respect to the Colorado River) margin of the extensive playa deposits behind the dune field. Section $4,85 \mathrm{~m}$ southwest of section 3 , is a pit dug into the surface of a small playa exposure west of the main playa area.

Geomorphic characteristics of the area surrounding each archaeological site studied at Palisades are discussed in appendix 1 (figs. 37 through 39). Stratigraphic data and geomorphic observations are summarized in the section below titled "Palisades Site Summary".

\section{Grain-Size Analyses}

Figure 6 shows the results of grain-size analyses on two horizons from section 1. Unit F, an aeolian unit, is shown to be coarser than unit $\mathrm{G}$, a fluvial deposit within this stratigraphic section. Figure 7 shows the grain-size distribution for unit $\mathrm{H}$ of section 3 at Palisades; this horizon contained no diagnostic sedimentary structures, and its depositional environment could not be definitively ascertained in the field. The grain-size plot is ambiguous also; this sample plots between the fields defined by known fluvial and aeolian deposits (fig. 7). The most likely explanation for this horizon is that it is a fluvial deposit that has undergone some degree of winnowing by wind, but not enough to remove all of the fine grains that would leave a mature aeolian lag deposit.

Grain-size analyses for three horizons within section 4 are shown in figure 8 . Three of these samples were collected from unit B, a flood deposit with well-defined fluvial climbing ripples. This flood deposit coarsens upward slightly (fig. 9). Upward coarsening of deposits has been attributed by Rubin and others (1998) and Topping and others (2000a) to sediment-supply limitation during the flood that deposited a particular stratum. This inverse grading occurs as fine-grained suspended sediment becomes progressively depleted throughout the duration of the flood (the finer sizes having been transported downstream earliest and farthest); given unlimited sediment supply, constant bed conditions, and sufficient accommodation space, a flood deposit should first coarsen and then fine upward, mimicking suspended-sediment response to the hydrograph. Unit E of section 4, the poorly sorted distal debris flow sediment, exhibits a coarser overall grain-size profile than the fluvial units (fig. 8). The one sample analyzed from the fluvial deposit unit $\mathrm{F}$ in section 4 is finer than any of the three samples from unit B (fig. 8).

\section{Driftwood Elevation Survey: Palisades Stage- Discharge Relationship}

In order to establish an approximate stage-discharge relationship for flood elevations in the Palisades area, the location and elevation of driftwood logs were surveyed during field work in May 2004 by D. J. Topping and J. E. Hazel. Horizontal coordinates of survey data are referenced to the NAD83(1999) epoch and were projected into NAD83 Ari- 


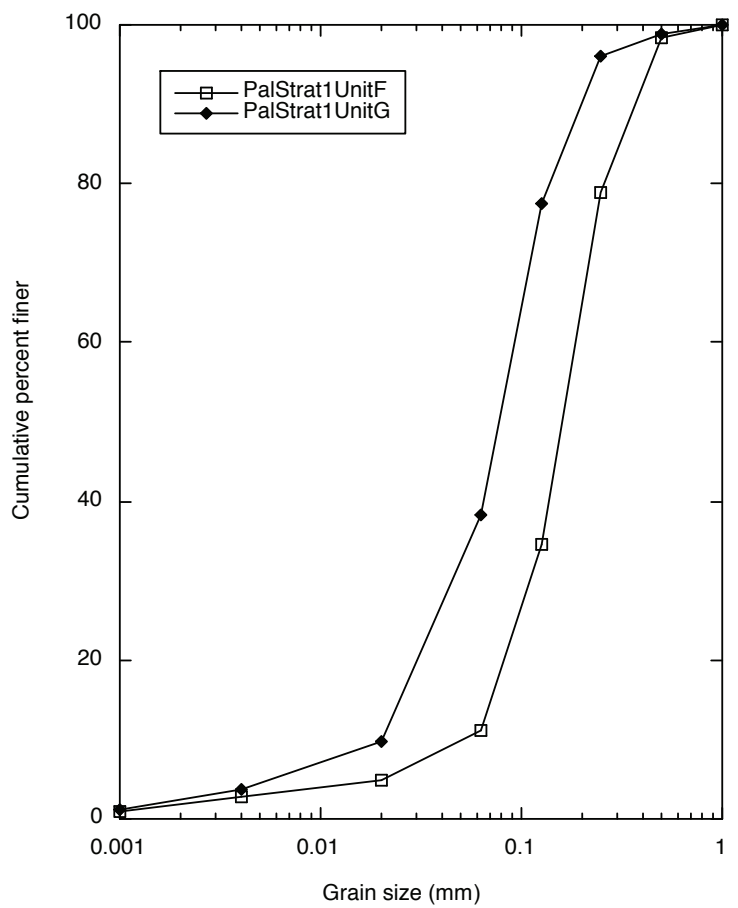

Figure 6. Grain-size plots for units $F$ (an aeolian deposit) and $\mathrm{G}$ (a fluvial deposit) of section 1, Palisades. See appendix 1 for sample descriptions.

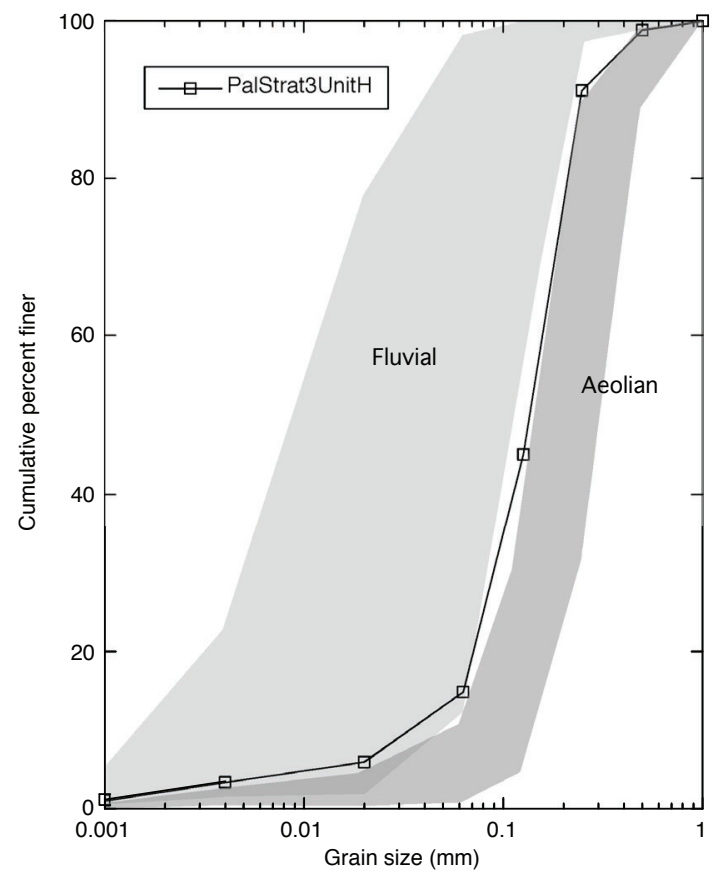

Figure 7. Grain-size plot for unit $\mathrm{H}$ of section 3 at Palisades, a horizon with no depositional environment clearly identifiable in the field. The gray fields show the range of grain-size distributions obtained from known fluvial $(n=27)$ and aeolian $(n=9)$ deposits (inferred from sedimentary structures and/or geomorphic features). The grain-size distribution of unit $\mathrm{H}$ suggests some degree of aeolian reworking that has partially winnowed a fluvial deposit. See appendix 1 for sample descriptions.

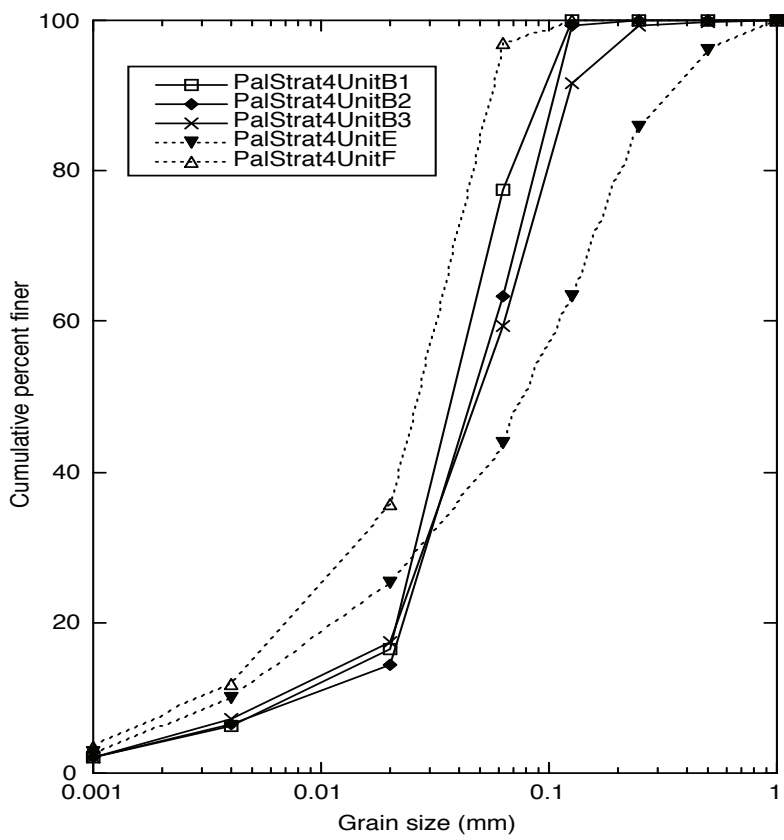

Figure 8. Grain-size data from section 4 at Palisades. Unit $B$ is a Colorado River flood deposit; within unit B, sample \#1 was collected $1 \mathrm{~cm}$ above the base of the flood unit, sample \#2 from $9 \mathrm{~cm}$ above the base of the flood unit, and sample \#3 from $28 \mathrm{~cm}$ above the base of the flood. Unit $E$ is a distal debris-flow deposit. Unit $F$ is a fluvial deposit. See appendix 1 for sample descriptions.
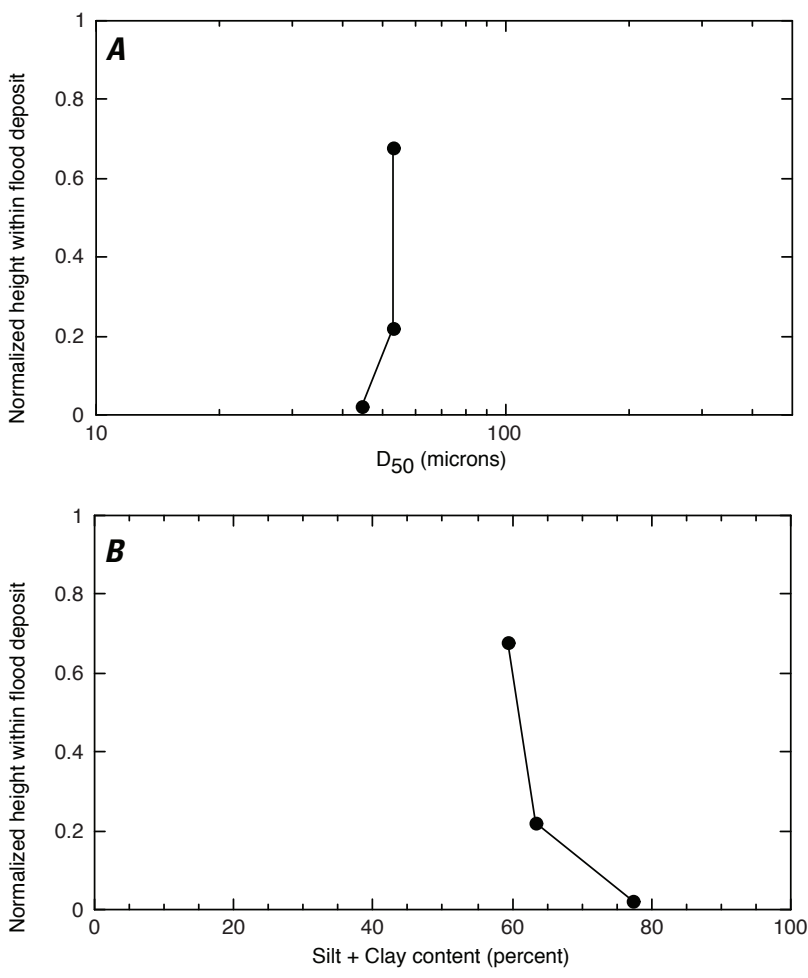

Figure 9. Grain-size data for three samples taken within a 41-cm-thick flood deposit, unit B of section 4 at Palisades. The deposit coarsens upsection with respect to median grain size $(A)$, a minor change, and with respect to the proportion of silt and clay $(B)$. See appendix 1 for sample descriptions. 


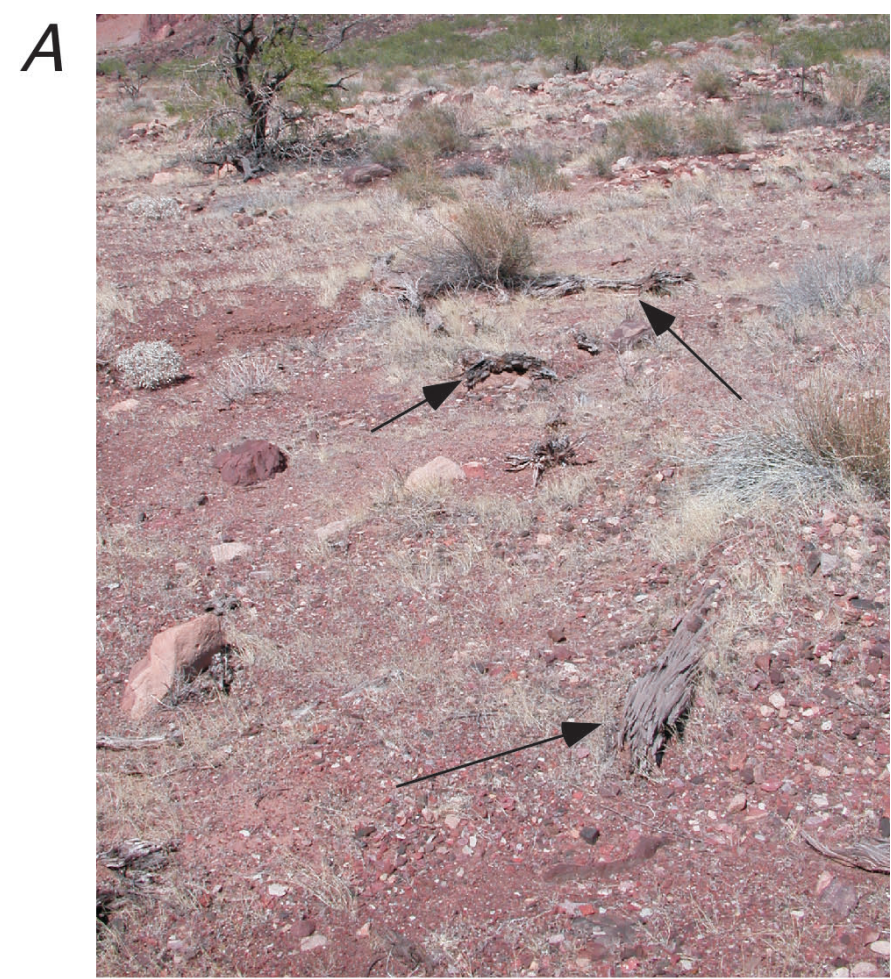

$B$

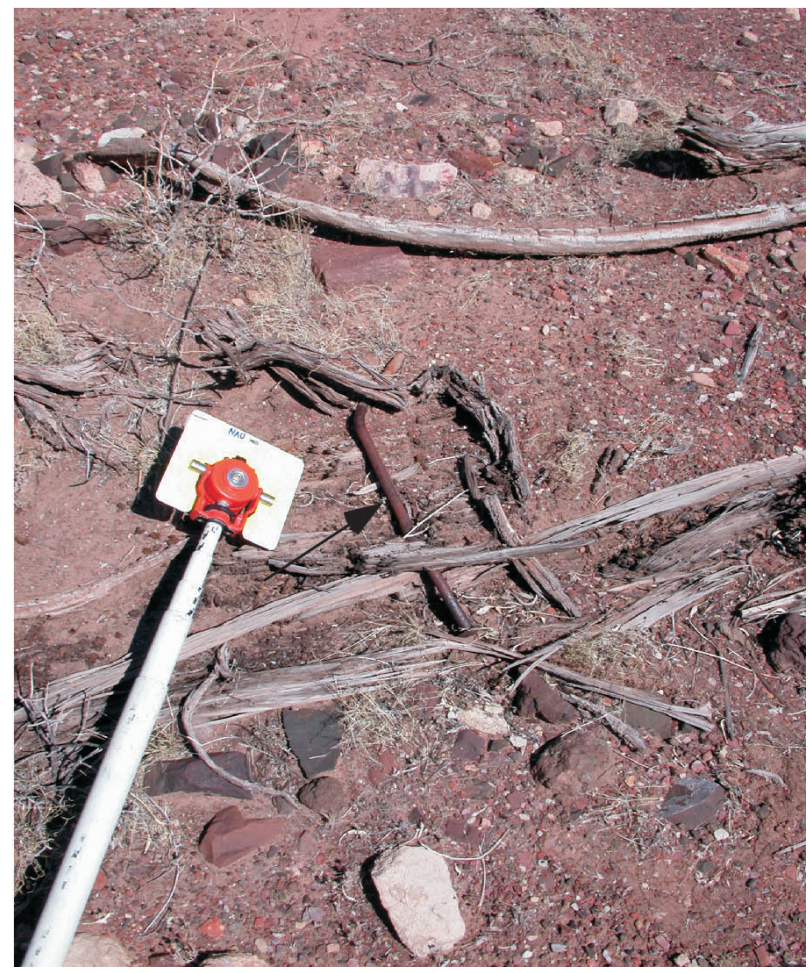

Figure 10. Examples of driftwood logs surveyed at Palisades. $A$, Logs (indicated by arrows) from the 1884 flood are underlain and overlain by locally derived fan sediment. $B, 1921$ driftwood (with metal bolt indicated by arrow) near the downstream end of the study area. 1921 logs are also overlain and underlain by fan sediment at this location. zona state plane central zone grid (FIPS zone 0202) in meters. Point coordinates include a vertical component referenced to the NAD83(1999) ellipsoid. ${ }^{8}$ Driftwood in the Palisades area occurs in several elevation groups, interpreted as deposits from the most recent historical flood events (fig. 10). Though flood waters can deposit wood and other debris during both the peak and the receding limb of the flood, the uppermost elevation (within 10-20 cm) of each 'cluster' of driftwood is inferred to represent the high water mark for historical flood events with known discharge (Topping and others, 2003). Some overlap occurs between driftwood lines deposited by floods of similar magnitude (such as the 1957 and 1958 floods). Some of this overlap is due to the fact that driftwood logs are emplaced during both the peak and the receding limb of a flood and also due to postflood natural deflation of the local ground surface by slope-wash and aeolian processes. Recognizing that some disruption of original log placement has also occurred in the past because of mining activity, camp-site arrangement, and trail maintenance, logs near camp sites, trails, and areas associated with the Tanner-McCormick mine and cabin were not included in this study. Each survey point was assigned a quality value of excellent, good, fair, or poor, based on whether evidence could be found for the logs occurring approximately in their original place of deposition (for example, forming part of a continuous log line, or having been partly buried by dune sand or debris-fan sediment; fig. 10) and on how closely the point corresponded to the elevations of other points in its elevation cluster.

Driftwood elevation data were used to compile a stagedischarge relationship, shown in figure 11. Maximum flood discharge values used in this calculation are those of Topping and others (2003): $5,940 \mathrm{~m}^{3} / \mathrm{s}\left(210,000 \mathrm{ft}^{3} / \mathrm{s}\right)$ for the 1884 flood, $4,810 \mathrm{~m}^{3} / \mathrm{s}\left(170,000 \mathrm{ft}^{3} / \mathrm{s}\right)$ for the $1921 \mathrm{flood}, 3,540 \mathrm{~m}^{3} / \mathrm{s}$ $\left(125,000 \mathrm{ft}^{3} / \mathrm{s}\right)$ for the $1957 \mathrm{flood}, 3,060 \mathrm{~m}^{3} / \mathrm{s}\left(108,000 \mathrm{ft}^{3} / \mathrm{s}\right)$ for the $1958 \mathrm{flood}$, and $2,700 \mathrm{~m}^{3} / \mathrm{s}\left(97,000 \mathrm{ft}^{3} / \mathrm{s}\right)$ for the 1983 flood. The plotted relationship in figure 11 uses only those data points that had been assigned 'good' or 'excellent' quality. Because the water surface during a flood will not be exactly horizontal, this stage-discharge curve, while approximating maximum flood-stage elevations for the Palisades area in general, may not accurately reflect exact maximum flood elevations at every specific location.

From the curve in figure 11, it is apparent that a flood with a magnitude comparable to the 1921 event would probably

\footnotetext{
${ }^{8}$ Heights given by this coordinate system, referenced to the NAD83(1999) ellipsoid, differ from "above sea level" orthometric heights, or NAVD88 elevations. Heights are referenced to the NAD83 ellipsoid instead of to sea level because the current national geoid model (GEOID03) is not sufficiently refined to model gravity anomalies in Grand Canyon to the required accuracy. As a result, the magnitude of gravitational effects on positional accuracy cannot be accurately estimated without experimental evaluation of a best-fit equipotential surface. The NAD83(1999) ellipsoid reference in the Grand Canyon area yields heights that are 23-25 $\mathrm{m}$ above heights referenced to sea level.
} 
inundate all four of the detailed stratigraphic profile locations studied at this site (land surface elevations of 798.898, $800.742,800.972$, and $800.612 \mathrm{~m}$ for sections $1,2,3$, and 4 respectively; fig. 12). At $798.898 \mathrm{~m}$, the modern land surface at the location of section 1 would be inundated by a discharge of $3,300 \mathrm{~m}^{3} / \mathrm{s}\left(117,000 \mathrm{ft}^{3} / \mathrm{s}\right)$, indicating that the fluvial sediment in unit $\mathrm{E}$ of section 1 (at a depth of $29-40 \mathrm{~cm}$ below the modern land surface) could have been deposited by the 1958 flood event, the most recent flood to reach a level above this elevation. Fluvial deposits that occur at lower elevation in section 1 lie within a zone that would have been inundated frequently (possibly annually) in predam time and so cannot be confidently attributed to flood events in specific years.

The highest occurrence of fluvial ripples in any of the measured stratigraphic sections is at an elevation of 800.652 $\mathrm{m}$ (the top of unit $\mathrm{B}$ within section 2). This is comparable to the uppermost elevation range of the 1921 flood inferred from driftwood locations in the vicinity of section 2 (fig. 11). If unit B was deposited by the 1921 flood, this would imply that unit D of section 2, the next-highest flood in that profile, would be the 1884 flood deposit. Flood deposits that underlie unit D in the stratigraphic record (none observed in this study at the location of section 2) would then be attributed to prehistoric floods.

In section 4, the uppermost fluvial deposit has a top elevation of $800.262 \mathrm{~m}$ (unit B of section 4). Given this elevation (below both the 1921 and 1884 flood maxima), the 1921 flood is inferred to be the most recent event that could have left

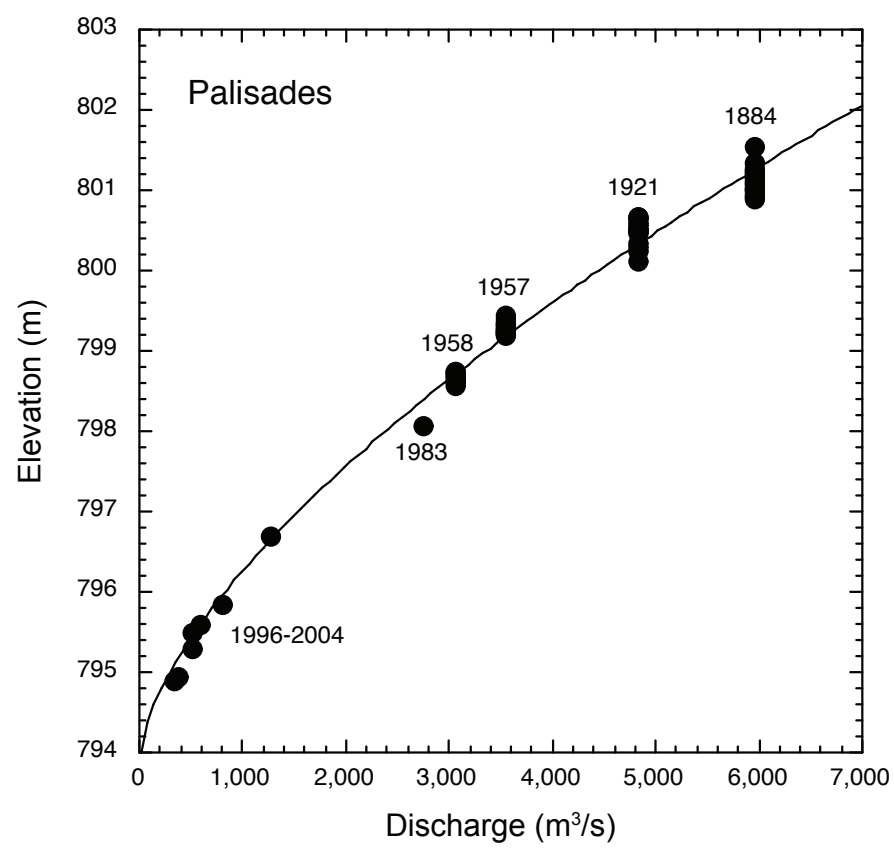

Figure 11. Stage-discharge relationship for the Palisades area, based on surveyed elevations of driftwood logs inferred to represent historical floods. Only points considered to be of 'good' or 'excellent' quality (that is, with evidence for driftwood occurring in its original position) were used to establish this relationship. this deposit. If this is the case, the next-lowest flood deposit in section 4 would be attributed to the 1884 flood: unit F, at a depth of 107-114 cm below the land surface. If this interpretation is correct, it implies that units $\mathrm{C}, \mathrm{D}$, and $\mathrm{E}$, consisting of playa and aeolian sediment, had accumulated at the location of section 4 in the 37 years between the 1884 and 1921 floods, equivalent to an accumulation rate of $0.84 \mathrm{~cm} / \mathrm{yr}$. While such a rate may seem high, it is not unreasonable given the great local variability that may occur in an environment dominated

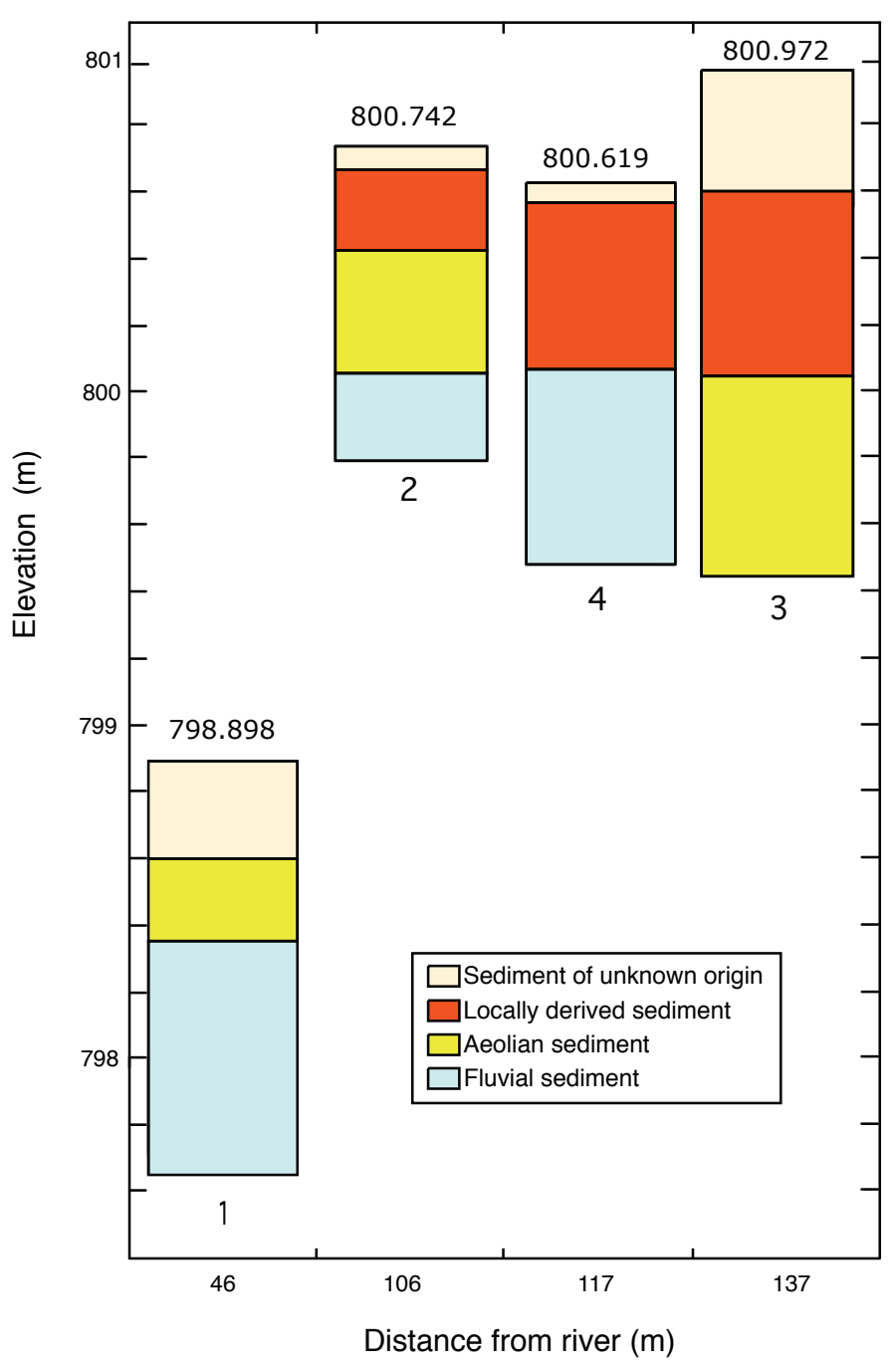

Figure 12. Proportions of fluvial, aeolian, and locally derived sediment, and sediment for which a depositional environment could not be confidently identified, in stratigraphic sections at Palisades (aeolian and fluvial sediment indicated only where confirmed by sedimentary structures). Stratigraphic section numbers are shown below the stacked-column graph for each; upper elevation (in $\mathrm{m}$ ) of each section is shown above the column. The vertical axis indicates elevation referenced to the NAD83(1999) datum for the stratigraphic sections (shown actual height). Elevations of colored bars within each section indicate proportion of that sediment type only, and do not represent actual stratigraphic position of individual horizons within that section. 
by dune migration and playa accumulation; a small number of local precipitation or high-wind events could have resulted in episodically rapid accumulation of sediment in some locations. If, alternatively, unit $\mathrm{B}$ of section 4 is interpreted to be a deposit resulting from the higher-stage 1884 flood instead of the 1921 flood, this implies that unit F must be related to a prehistoric flood event and that erosion has removed the record of the 1921 flood at the location of this profile.

\section{Palisades Site Summary}

Stratigraphic sections documented at Palisades indicate repeated inundation of this area by Colorado River floods in predam time. Fluvial deposits containing climbing ripple structures were present in three of the four vertical sections studied in detail, and the fourth (section 3) contained sediment for which fluvial deposition was suspected but could not be confirmed by sedimentary structures. The presence of spatially extensive fluvial deposits indicates that virtually all of the area between canyon walls in the Palisades region was submerged episodically during predam high flows; the upstream (northward) migration direction of fluvial ripples indicates that an eddy existed on river left in this area (compare the slackwater deposits of Kochel and Baker, 1982, and channel-widening deposits of Benito and others, 2003). The upstream-tilted water-surface slope apparent in driftwood lines from both the 1884 and 1921 floods provides additional evidence for a large eddy existing on river left in this area at discharges at or above $4,810 \mathrm{~m}^{3} / \mathrm{s}\left(170,000 \mathrm{ft}^{3} / \mathrm{s}\right)$. It is possible that fluvial deposits that underlie modern playa deposits on the eastern edge of the Palisades study area may have formed in relation to ponding of water upstream of ancient debris flows. Several active debris fans exist close to and downstream of this area, including Espejo (river mile 67.4), Comanche (mile 67.7), and Tanner (mile 69.0) Creeks. Alternatively, these fluvial deposits may have been emplaced in an eddy return channel during flood recession. Figure 12 illustrates the decreasing influence of fluvial deposition with distance from the river.

Reworking of fluvial sediment by wind in this area appears to be common. In several of the stratigraphic sections, aeolian deposits were observed between or in close association with fluvial deposits (compare Benito and others, 2003); aeolian material also was found commonly interbedded with locally derived playa sediment in sections 3 , and 4 . Playa sediment formed a volumetrically minor component of these stratigraphic sections, but the number of playa horizons indicates that such deposits frequently interrupt the record of aeolian deposition. The present-day surface geomorphology includes aeolian dunes that have been covered to varying degrees by vegetation and cryptogamic crust. Burial of driftwood logs associated with the 1884 and 1921 Colorado River floods by aeolian dunes indicates active dune migration as recently as the early $20^{\text {th }}$ century. Present morphology of most dunes in the Palisades area is consistent with relative inactivity; cryptogamic crust formation, colonization by grasses, and deflation features suggest that most dunes are relatively inactive. One exception is a dune $\sim 2 \mathrm{~m}$ high that is migrating in a northward direction and filling in a shallow branch of the main arroyo network at the location of archaeological site C:13:100 (appendix 1; fig. 38).

The influence of locally derived sediment increases landward and toward the debris fan (fig. 12). Slope-wash and/or playa sediments are readily apparent in sections 2,3 , and 4 . Driftwood logs associated with the 1884 and 1921 floods are also partly buried by debris-fan and colluvial sediments in the downstream part of the study area. Three of the nine Palisades archaeological sites (C:13:98, C:13:272, and C:13:355) are located within the range of influence of the Palisades Creek debris fan, while a fourth $(\mathrm{C}: 13: 33)$ is built on sediment derived from a second debris fan. Of the nine sites, six were apparently constructed in or on fluvial sediment at least in part, with or without aeolian reworking (C:13:99, C:13:100, C:13:272, C:13:334, C:13:336, and C:13:355). Four of the nine archaeological sites (C:13:99, C:13:100, C:13:272, and $\mathrm{C}: 13: 336)$ have been preserved at least in part by a cover of aeolian sediment, with minor contributions from aeolian sedimentary cover at two additional sites (C:13:101 and $\mathrm{C}: 13: 335)$. Erosion associated with arroyo cutting is affecting two of the sites (the large C:13:99 site in the area of the main arroyo network, and C:13:355). Exposure of the site can be attributed at least in part to aeolian deflation at five of the sites (C:13:99, C:13:100, C:13:101, C:13:272, and C:13:336). Gellis (1994) reported that camping activity may have accelerated erosion in the Palisades area; because of relocation of trails and other mitigation measures implemented by the NPS since 1994, this is not believed to be a major impact agent at these archaeological sites currently (National Park Service, 2004).

\section{Lower Comanche Area}

\section{Geomorphic Setting}

The Lower Comanche study area is shown in figure 13, with a detailed view of the arroyo in which the majority of the stratigraphic sections were located shown in figure 14. Like Palisades, Lower Comanche falls within the Furnace Flats geomorphic reach defined by Schmidt and Graf (1987). The region studied for this project lies downstream of the Comanche area discussed by Thompson and Potochnik (2000) in their survey of drainage catchment areas and alluvial terrace incision.

The canyon in this area remains wide, and Precambrian Dox Formation is exposed at the river's edge on river right. On river left in the vicinity of the study area, Pleistocene debris-flow deposits tens of meters thick are present (Machette and Rosholt, 1989; Pederson and others, 2004). Riverward of the relict debris fans, large ( $>10 \mathrm{~m}$ high) sand dunes form a large dune field (fig. 13). Many of the dunes in this field show evidence of active aeolian transport, though grasses 
and sparse mesquite have colonized the area. Several small interdune/playa areas indicate the sporadic presence of standing water, with desiccation cracks present. A shallow $(0.3 \mathrm{~m})$ test pit dug into an interdune deposit in May 2003 revealed at least two episodes of fine-grained interdune/playa sedimentation, separated by coarser aeolian sand, indicating migration of dunes over time. East of the dune field, on either side of the Beamer hiking trail, is a flat surface that shows evidence of recent standing water (abundant desiccation cracks). Precipitation appears to pond locally in the flat region, which is isolated from the well-developed arroyo drainage to the south.

The arroyo network at the southern end of the Lower Comanche area drains two minor tributaries on river left that release abundant red-colored sediment from the Dox Forma-

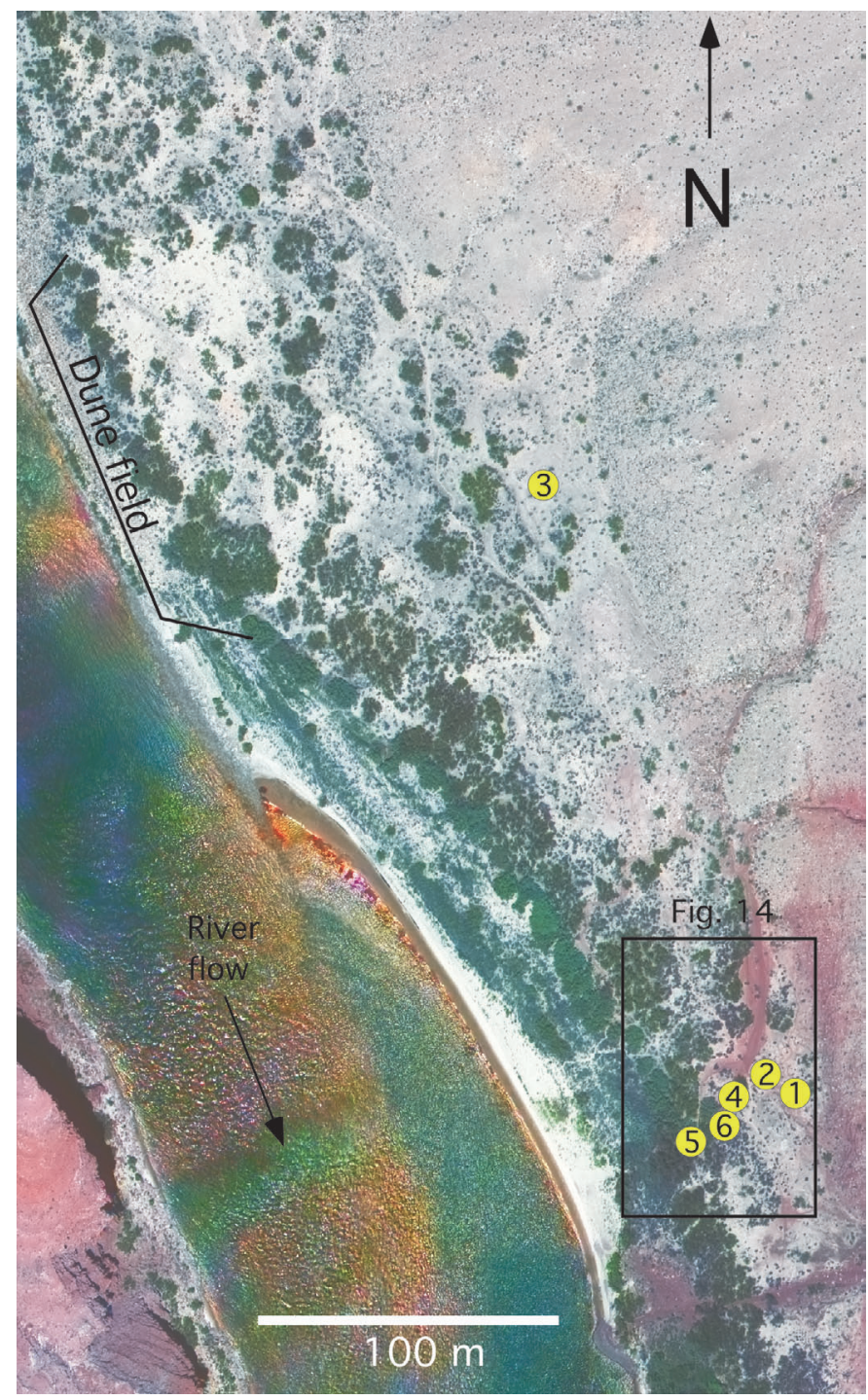

Figure 13. Large-scale aerial view of the Lower Comanche area (May 2002; Grand Canyon Monitoring and Research Center). Locations of stratigraphic sections 1 through 6 are indicated by numbered dots. The box indicates the area enlarged in figure 14 . River discharge is $226 \mathrm{~m}^{3} / \mathrm{s}$. tion. Vertical exposures of sediment in the arroyo walls were used for five of six stratigraphic sections studied at this site (discussed below).

The left margin of the river channel in this region is lined predominantly by fluvial cobble bars, with local thin sand cover. A narrow sand beach (fig. 13) is present as the river widens into an eddy at the southern end of the Lower Comanche area; the area of open sand appears to have been reduced relative to its size in 1965 aerial photos (fig. 15). One possible source of sediment reaching this channel-margin sand bar, in addition to any fluvial deposition, is aeolian transport of sand from a large sand-covered cobble bar on river right. Wind directions recorded at Lower Comanche in Spring 2004 are consistent with that possibility.

Comparison of recent (2002) aerial photographs with those taken in 1965 reveal a significant increase in vegetative

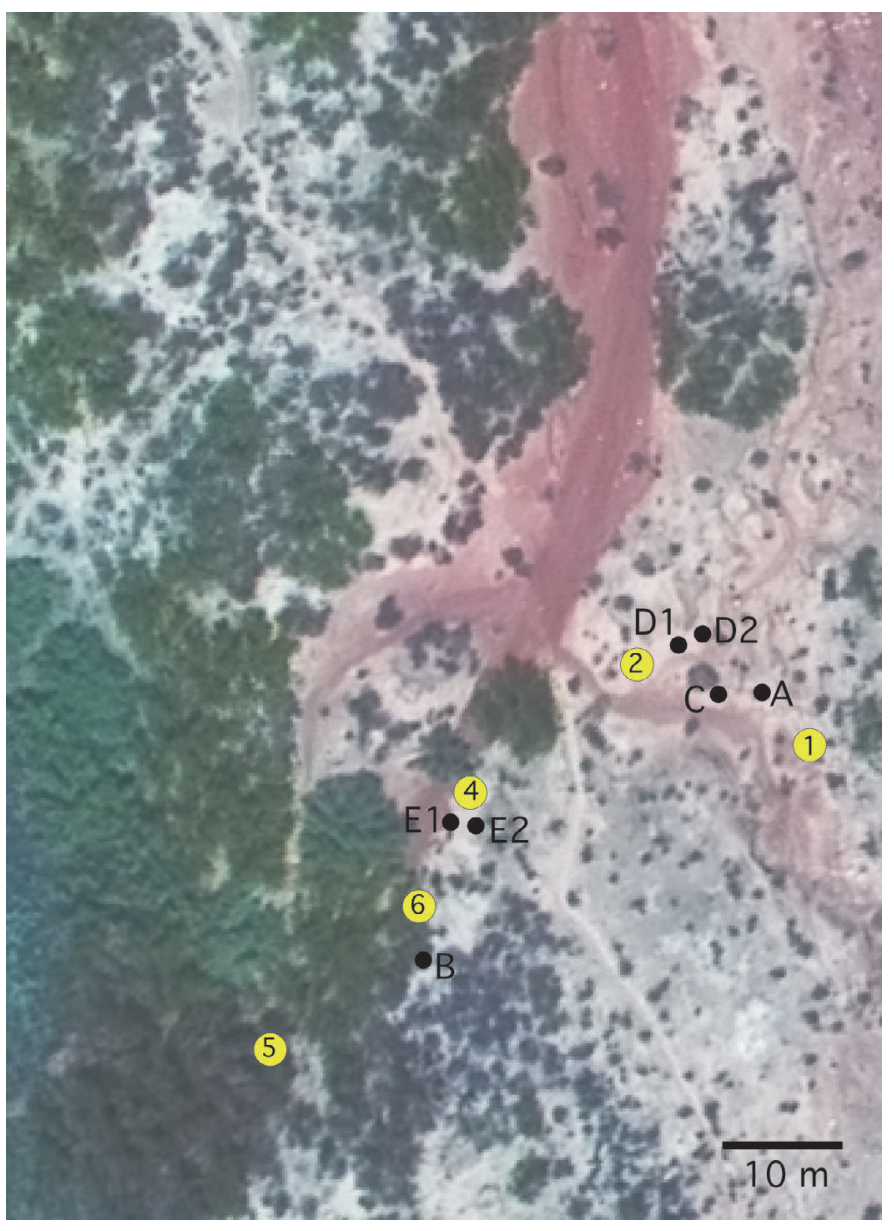

Figure 14. Aerial view of the arroyo system at Lower Comanche. The dark red sediment in the arroyo floors is locally derived material from the Dox Formation. The buff-colored, higher elevation deposits into which the arroyo has cut are dominated by fluvial and aeolian sediment. Locations of stratigraphic sections 1, 2, 4, 5, and 6 are shown with numbered dots. Small black circles (points A, B, C, D1, D2, E1, and E2) represent datums used for topographic mapping of the white layer discussed in the text. 
cover along the channel margin (figs. 13 and 15). Mesquite trees are abundant in the lower part of the main arroyo mouth.

It is possible that flow of the Colorado River in the Lower Comanche area has been affected numerous times in the past by debris flows on the Tanner debris fan, approximately $2 \mathrm{~km}$ downstream of the study region. Debris flows on the Tanner fan would be expected to cause temporary damming of the river behind it, ponding water at Lower Comanche and inundating land on river left that is included in the study area. However, activity on the Tanner debris fan that generated the largest and highest-elevation debris-flow deposits there (tens of meters above modern river level) dates from early to middle Pleistocene time (Pederson and others, 2004) and so did not affect development of the Holocene terraces discussed here.

\section{The Lower Comanche "White Layer"}

During reconnaissance work at Lower Comanche in May 2003, a resistant 0.5 - to 1.5 -cm-thick fine-grained white horizon of undetermined origin was noted to occur in an extensive area $\left(>2,000 \mathrm{~m}^{2}\right)$ of the arroyo-wall sedimentary exposure and in the dune field several hundred meters to the northwest.

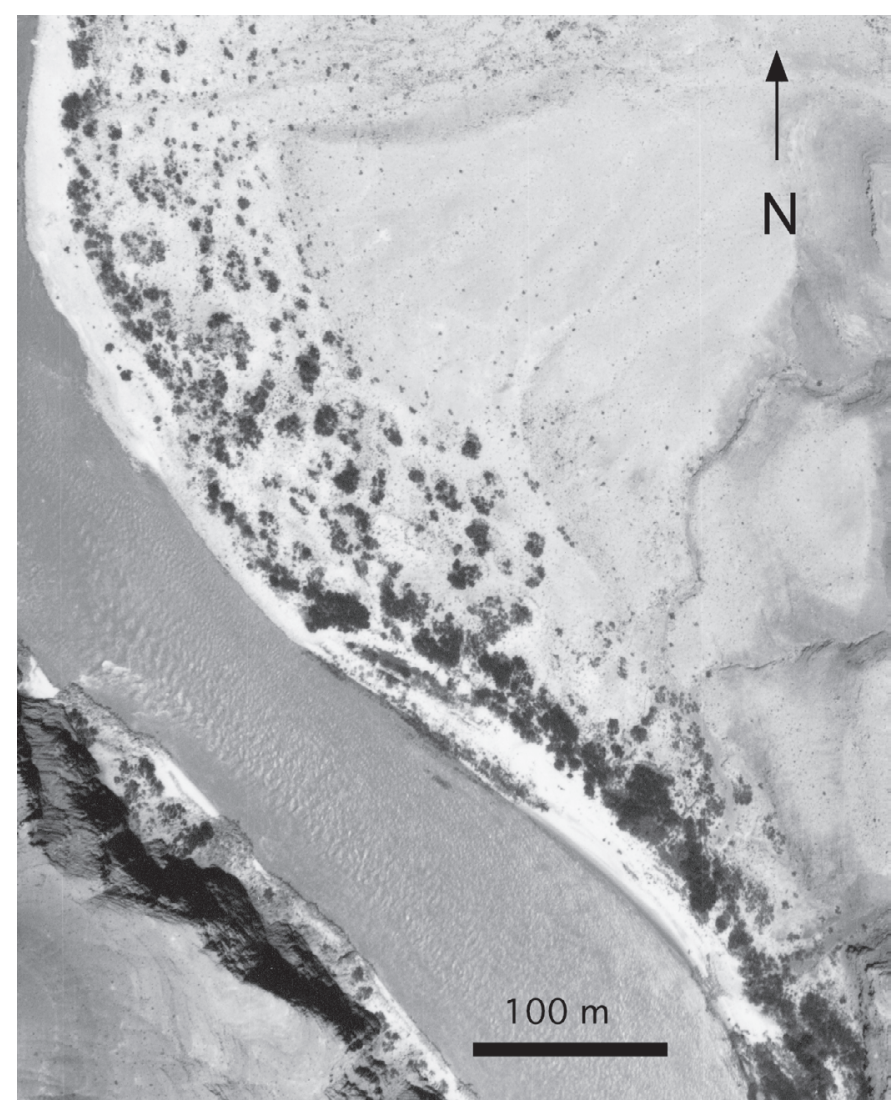

Figure 15. Aerial photograph of the Lower Comanche area taken in 1965 (Grand Canyon Monitoring and Research Center). River discharge is between 680 and $792 \mathrm{~m}^{3} / \mathrm{s}$.
Because its origin is unknown, this horizon is referred to by the informal descriptive term "white layer" in this report. Possible explanations proposed at that time for the occurrence of this horizon included volcanic ash deposition, prehistoric cultural ash material, or a caliche-type substance precipitated in place. A sample of this layer was collected in May 2003 for analysis under a petrographic microscope. Disaggregated and cemented in epoxy, the material was then thin-sectioned. In thin section, the white-layer material appeared crystalline, ruling out ash of organic origin, but its crystal character did not resemble volcanic ash under the microscope. During field work in May 2004, a sample of white-layer sediment was immersed in dilute hydrochloric acid, which produced a strong reaction. The majority of the sample was destroyed by the acid, implying a high proportion of calcium carbonate in its composition, leaving only a small amount of silt and sand behind.

This white layer consists primarily of clean, white silt and varies in thickness from 0.5 to $1.5 \mathrm{~cm}$ in all exposures where it has been observed (fig. 16). The unit commonly comprises three phases: a lowermost, seemingly purest, very white layer about $0.5 \mathrm{~cm}$ in thickness; a middle layer (frequently missing

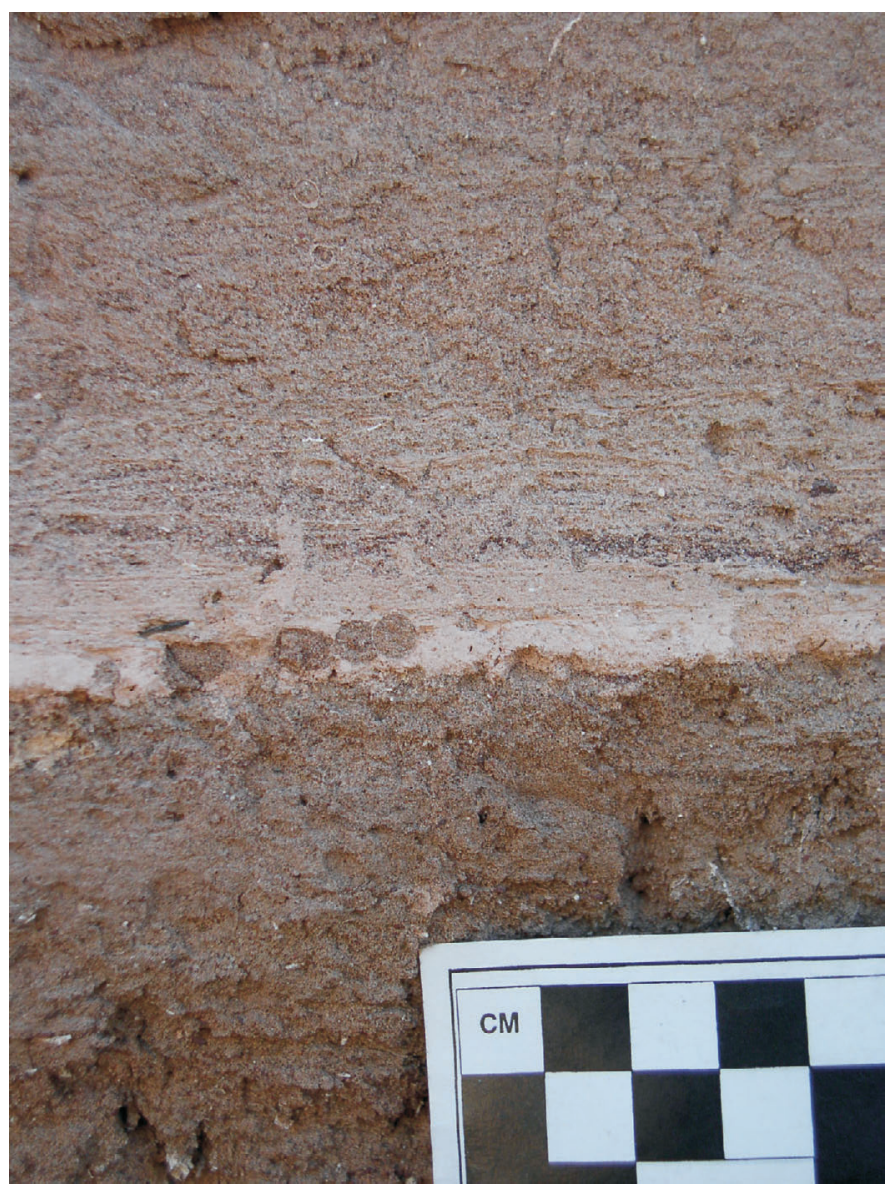

Figure 16. The white-layer horizon (center of photograph) at Lower Comanche. Several round burrows have disturbed this exposure. See text for facies description. 
and/or discontinuous) that has what appears to be bioturbated sands, apparently occurring in voids resembling insect burrows; and an uppermost, mixed and impure layer not as white as the lowermost phase. In the general area of the mouth of the unnamed tributary south of Comanche Creek, this layer appears to be restricted to low places in the topography, such as interdune areas and valley bottoms within the arroyo network. In the valley bottoms, beds pinch out toward the edges of the arroyo branches. Where present, the white layer commonly undulates with the topography of the paleosurface on which it occurs; if depositional, this would indicate that it had been deposited at a time when gullies that had previously dissected the valley floors were essentially completely healed. The texture and composition of underlying sediments does not seem to significantly influence the character or thickness of the layer. Typically, the layer unconformably overlies fine-grained alluvial and/or slope-wash deposits and is overlain by similar sediments, but locally it is overlain and underlain by relatively coarse, high-energy alluvial gravels. Its lower contact is concordant with underlying topography and is micro-irregular; the upper contact is slightly more gradational and less abrupt, but is still quite distinct. This upper contact appears to have undergone minor degrees of mixing and bioturbation. The white layer lacks desiccation cracks, oxidation, salt crystals or pseudomorphs, indications of salt-induced turbation of sediment, or root structures of obviously halophytic plants that are commonly associated with evaporite deposits. The material is significantly whiter in color than nearby relatively pure silt deposits. It is found over a wide enough range of elevation and variety of topographic settings to imply that a groundwaterrelated origin is unlikely. In at least one locality (interdune area), a number of discontinuous, very white laminae, presumably of the same material, are found within several $\mathrm{cm}$ above the primary layer.

The elevation of the top of the white layer at selected outcrop points was mapped by R. E. Hunter during this study by hand-leveling relative to the closest survey data points (at stratigraphic sections 2 and 4). The locations of these outcrop points (shown as small black circles on figure 14) were determined by tape-and-compass mapping relative to the surveyed points. The distribution of the white layer is considered to represent the topography of the surface at the time the layer was emplaced. The gully system at Lower Comanche is not sufficiently three-dimensional for a contour map of the original topography to be made, but it is apparent from this mapping exercise that the upper elevation of the white layer descends southwestward from $795.52 \mathrm{~m}$ to $794.13 \mathrm{~m}$ (points A and B on figure 14, respectively) over a distance of $37 \mathrm{~m}$ (a slope of $\left.2.15^{\circ}\right)$. This southwestward slope is the general direction in which the modern gullied land surface slopes and is probably the approximate slope direction of the original surface at the time of white-layer emplacement. In addition to the overall slope of the white layer, the exposures revealed several smaller features of its topography.

In the smallest notable topographic irregularity (point $\mathrm{C}$ on figure 14), the white layer was observed to be present in a preexisting scour deposit that measured $5 \mathrm{~cm}$ deep and $40 \mathrm{~cm}$ wide. The layer maintains its uniform thickness throughout the depression, as well as on both rims. The white layer is directly overlain by locally derived gravel that fills the scour. Although the white layer in this depression is directly underlain by silt or fine sand instead of gravel, gravel-filled scour depressions separated from one another by silt or sand occur at several horizons in the half-meter of section vertically above and below this depression. The location of point $\mathrm{C}$ was apparently a site for episodically running tributary flow, localized channel cutting, and gravel transport, while at intervening times the channel was covered by finer sediment. The white layer at this location was emplaced at a time after a channel had been cut but before the channel had been filled by gravel.

Between points D1 and D2 (fig. 14), the white layer descends eastward into a large depression filled partly by locally derived gravel. The depression, like the one at point $C$, was apparently a stream channel, although the opposite side of the channel is no longer visible because it has been eroded by the present gully system. The channel was $>1 \mathrm{~m}$ deep and several meters wide. In contrast to the small channel at point $\mathrm{C}$, this larger channel was not completely filled by gravel but instead migrated eastward as sand and silt beds prograded eastward into the channel at dips that locally approach the angle of repose. The white layer is both overlain and underlain by silt or fine sand on the flat west side of the channel margin (point D1) and on the upper slope of the channel. Near the channel center (at point D2 and northwest) the white layer is both overlain and underlain by gravel.

Between points E1 and E2 (and for some distance north and south of those points) the white layer dips westward as steeply as $25^{\circ}$, descending nearly $0.5 \mathrm{~m}$ in a distance of $1.0 \mathrm{~m}$. If the exposures had extended farther in an east-west direction, even greater elevation change might have been documented, as the dip angles were not observed to flatten out in either direction. In this area, the white layer is both overlain and underlain by silt or fine sand. It could not be determined whether the topographic irregularity in this area was due to a channel to the west or a dune form to the east. This site is located at the eastern edge of the present arroyo, which may have existed for a long time.

In all of these topographic irregularities (points C, D1-D2, and E1-E2), the uniform thickness of the white-layer horizon is suggestive of deposition of suspended sediment in a relatively quiescent fluid (water or air) whose vertical extent was great compared to the vertical extent of the topographic irregularities. Although recent studies have not shown major post-Pleistocene activity of the Tanner debris fan, $2 \mathrm{~km}$ downstream of Lower Comanche (Pederson and others, 2004), it is possible that a relatively minor Tanner debris flow caused short-lived impoundment of water in this area; otherwise, an airfall origin of the white layer seems more likely. One problem with an airfall explanation is that the relations at point $\mathrm{C}$ would require that the small channel was first cut by water, then dried out and coated by the airfall layer and finally filled with tributary gravel without disruption of the fine-grained white-layer material below. 
At this time, the origin of the white-layer horizon is undetermined. Deposition as a pedogenic horizon is considered unlikely, because of the uniformity of thickness, the consistency of its characteristics in sediments of significantly variable textures and depths, the abrupt character of its lower boundary, and the topography of the bed. Although pedogenic $\mathrm{CaCO}_{3}$ can occur in lenticular masses having abrupt upper and lower contacts, this typically is not found in early-stage pedogenic carbonate accumulation. Likewise, thickness and degree of cementation typically vary over the catena; this horizon does not resemble pedogenic horizons observed by members of this research group in other soils or Holocene deposits from desert environments. Similarly, deposition in an evaporitic environment can likely be eliminated on the basis of the absence of desiccation features, oxidation, soil weathering, and groundwater phenomena, and the relation to topography. The wide distribution, topography, and elevational range of the deposit, and the powdery character of the (apparently $\mathrm{CaCO}_{3}$ ) material indicate that deposition in standing water is unlikely. Likewise, the fine grain size and physical characteristics of the deposit appear to eliminate deposition by running water (other than, perhaps, minor redeposition in a slopewash environment). Physical attributes of this horizon resemble those of air-fall deposits such as volcanic ash (including the fact that it is significantly purer at the bottom), though its dominantly carbonate composition does not. One major difference between the white layer and known volcanic ash layers, however, is the apparent degree of reworking and redeposition near the toes of alluvial slopes and alluvial fans that is usually observed in ash deposits and is absent in the white layer.

\section{Archaeological Significance}

Multiple cultural features on river left in the Lower Comanche region have been dated to the Late PI - Early PII Formative period (Fairley and others, 1994; National Park Service, 2004). Additional sites contain artifacts that are likely related to prehistoric and early historic Hopi habitation (Fairley and others, 1994), and at least one site is of unknown cultural affiliation. This area is significant in that it contains a higher concentration of roasting features than any other area in the eastern canyon. The sites are devoid of any Puebloantype structures. Archaeologists infer that this area could have been occupied by non-Puebloan people; the features present at Lower Comanche are more representative of Cohonina or prehistoric Puebloan occupation. This area appears to have been used for processing of food and not for direct habitation; living areas were perhaps located across the river, upstream, or downstream of this region.

Monitoring reports from NPS that date back to the 1980 s have identified aeolian deflation, surface erosion, and gully incision as the greatest impact agents at archaeological sites in the Lower Comanche area (National Park Service, 2004). Because the majority of the sites are located in the large dune field, aeolian erosion by deflation and dune migration are par- ticularly influential. The condition of archaeological sites at Lower Comanche has also been impacted to a lesser degree by visitors; the Beamer hiking trail passes directly through this area.

\section{Stratigraphic and Geomorphic Analyses}

Detailed stratigraphic logs for the Lower Comanche area are described in appendix 2 (figs. 40 through 46). Stratigraphic sections $1,2,4,5$, and 6 are located in vertical exposures of sediment that form the walls of the arroyo network upstream of the tributary drainage. Section 3 is a pit dug into a flat land surface $\sim 270 \mathrm{~m}$ north of the arroyo area where the other five sections were recorded. Geomorphic characteristics in the immediate area surrounding each archaeological site are discussed in appendix 2 (figs. 47 through 49). Stratigraphic data and geomorphic observations are summarized in the section below titled "Lower Comanche Site Summary."

\section{Grain-Size Analyses}

The results of grain-size analyses from sediment samples collected from section 2 at Lower Comanche are shown in figure 17. When plotted superimposed on fields that represent the range of grain-size distributions for fluvial and aeolian samples whose depositional environment could be ascertained by field observation, both samples from section 2 (units $\mathrm{C}$ and F) plot within the fluvial field. Unit $\mathrm{C}$ was interpreted in the field as dominated by tributary alluvium, and unit $\mathrm{F}$ as the edge of a channel-fill horizon. The similarity in particlesize characteristics between these samples and known fluvial deposits indicates that these units may also include (and may actually be dominated by) interbedded or reworked Colorado River sediment, a result of the complex interaction between fan and fluvial processes. Two of the three samples from section 6 at Lower Comanche whose depositional environment was uncertain in the field also fall into the 'fluvial' range (fig. 18). A sample collected from unit B of section 6 , a horizon where faint fluvial climbing ripples appeared to be present, and a sample from unit $\mathrm{F}$ of section 6 , where faint fluvial climbing ripples appeared to be present in the upper part of the deposit, both plot within the fluvial field. These samples are finer grained than a sample from unit E of section 6, which was determined in the field to be a flood deposit on the basis of readily apparent fluvial climbing ripples.

\section{Driftwood Elevation Survey: Lower Comanche Stage-Discharge Relationship}

The location and elevation of driftwood logs were surveyed in the Lower Comanche area on both banks of the river. In the lower elevation areas on river left at Lower Comanche (near sections 5 and 6 described above), dense vegetation 
limited the extent of the driftwood survey work. Data were not collected in the vicinity of the popular camp on river right known as the upper Tanner camp, to avoid sampling an area where logs had been rearranged to form camp sites and to avoid sampling logs that have moved downslope due to aeolian deflation. The uppermost $10-20 \mathrm{~cm}$ within each surveyed 'cluster' of driftwood were used to compile a stage-discharge relationship (fig. 19). Maximum flood discharge values used in this calculation are those of Topping and others (2003): 5,940 $\mathrm{m}^{3} / \mathrm{s}\left(210,000 \mathrm{ft}^{3} / \mathrm{s}\right)$ for the 1884 flood, $4,810 \mathrm{~m}^{3} / \mathrm{s}(170,000$ $\left.\mathrm{ft}^{3} / \mathrm{s}\right)$ for the $1921 \mathrm{flood}, 3,540 \mathrm{~m}^{3} / \mathrm{s}\left(125,000 \mathrm{ft}^{3} / \mathrm{s}\right)$ for the 1957 flood, $3,060 \mathrm{~m}^{3} / \mathrm{s}\left(108,000 \mathrm{ft}^{3} / \mathrm{s}\right)$ for the 1958 flood, and 2,700 $\mathrm{m}^{3} / \mathrm{s}\left(97,000 \mathrm{ft}^{3} / \mathrm{s}\right)$ for the 1983 flood. As with the Palisades data (fig. 11), the plotted relationship for Lower Comanche shown in figure 19 uses only those data points that had been

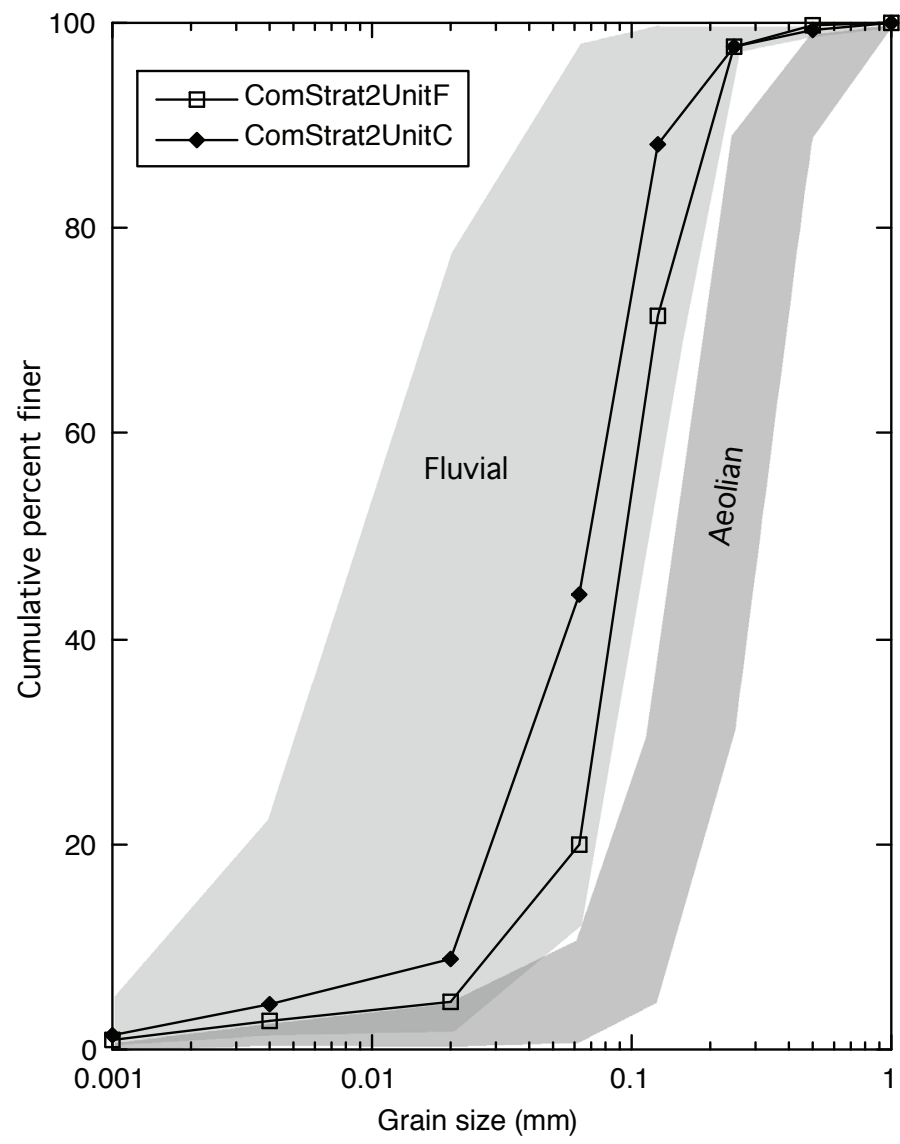

Figure 17. Grain-size analyses for units $C$ and $F$ in section 2, Lower Comanche, superimposed on fields that show the range of grain-size distribution for samples of known fluvial ( $n=27$, light gray field) and aeolian ( $n=9$, dark gray field) origin (from the presence of diagnostic sedimentary structures and/or geomorphic features). Although these two samples appeared in the field to be largely composed of locally derived sediment, the fact that both plot within the fluvial field indicates that fluvial sediment may form a substantial amount of these units (by interaction between fluvial and fan processes, leading to interbedding of sediment from each source). See appendix 2 for sample descriptions. assigned 'good' or 'excellent' quality in terms of the apparent original placement of driftwood logs and the agreement between that point and the elevation 'cluster' for that flood. Because the water surface during a flood is unlikely to be horizontal, this stage-discharge curve represents approximate flood elevation maxima for the Lower Comanche region but is unlikely to accurately represent local conditions in specific areas within this region.

Of the six stratigraphic sections studied at Lower Comanche, only sections 5 and 6 contained unambiguous fluvial deposits (with distinct fluvial sedimentary structures). Using the stage-discharge relationship from figure 19, it is apparent that the highest elevation fluvial deposits observed in this area $(\sim 795 \mathrm{~m}$ in unit $\mathrm{C}$ of section 6 , and possibly unit $\mathrm{B}$ of this same profile) lie above the inferred 1921 flood limit. These uppermost fluvial deposits in section 6 could therefore be consistent with deposition during the 1884 flood. This would imply that other possible flood deposits lower in the section 6 stratigraphy (units E, F, H, and J) were left by prehistoric flood events. These stage-discharge relationships assume that the bed of the river (and surface elevation of river flows, for any given discharge) were the same as the modern state; it is possible that paleoenvironmental factors (for example, short-lived ponding behind debris fans, channel migration) could have

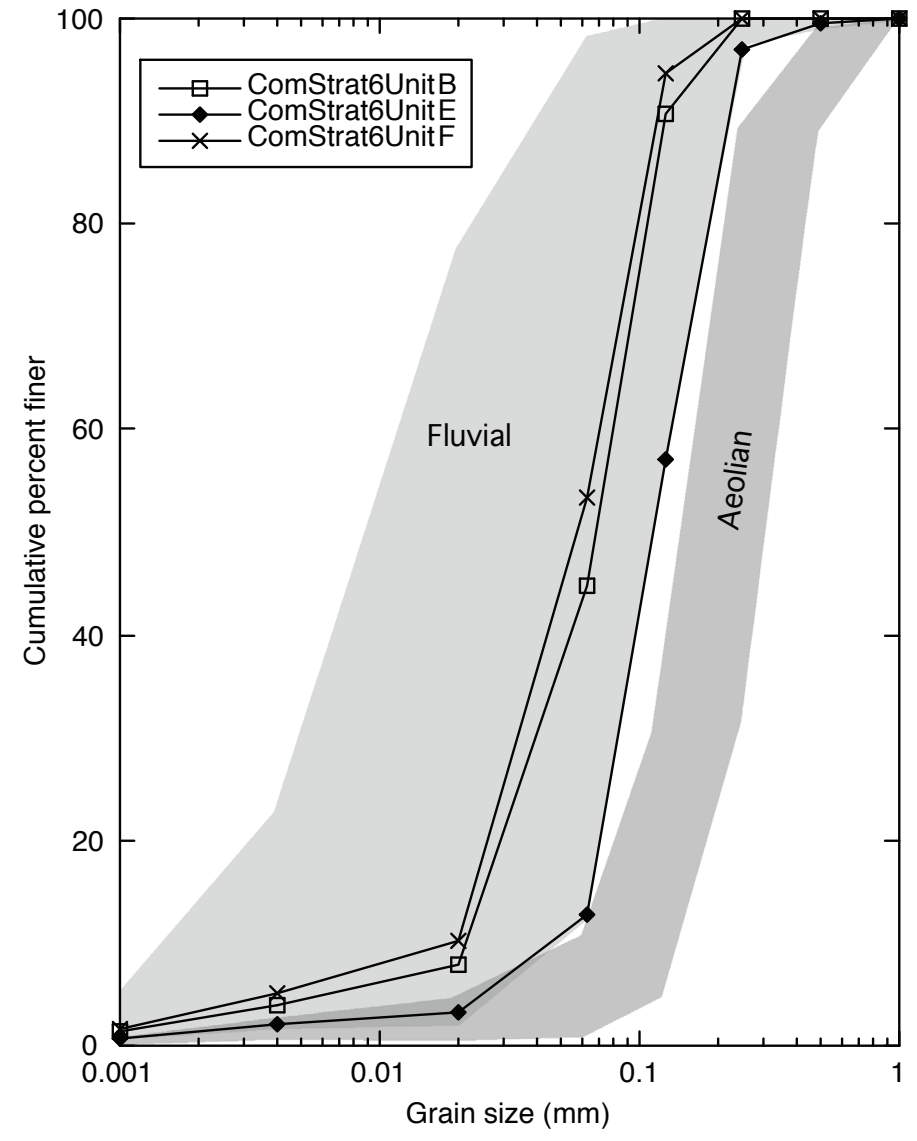

Figure 18. Grain-size analyses for units $B, E$, and $F$ in section 6 at Lower Comanche. See appendix 2 for sample descriptions. 
dictated a stage-discharge relationship at the time of deposition that is different from that of today.

The elevation of the land surface at section 5 (793.395 $\mathrm{m}$ ) is low enough that this location could be inundated by a flow comparable to or slightly less than that of the 1921 flood, and possibly by the peak of the 1957 flood. At the other stratigraphic sections, much greater floods (with discharge higher than can be accurately estimated using this stage-discharge relationship) would be required to deposit sediment on the existing land surface (surface elevations are $796.710 \mathrm{~m}$ at section 1, $796.147 \mathrm{~m}$ at section 2,797.480 $\mathrm{m}$ at section 3, $795.874 \mathrm{~m}$ at section 4 , and $795.525 \mathrm{~m}$ at section 6 ). The floor of the arroyo, in contrast, would be inundated by a discharge of $\sim 5,100 \mathrm{~m}^{3} / \mathrm{s}\left(180,000 \mathrm{ft}^{3} / \mathrm{s}\right)$ at the location of section 6 , assuming that the regional average conditions represented by this stage-discharge relationship would hold. At four times the level of the 1996 BHBF flood experiment, such a discharge (or greater) would be needed to promote restorative fluvial sediment deposition in this arroyo network.

\section{Lower Comanche Site Summary}

Stratigraphic sections described in the southern, arroyoincised Lower Comanche area indicate multiple episodes

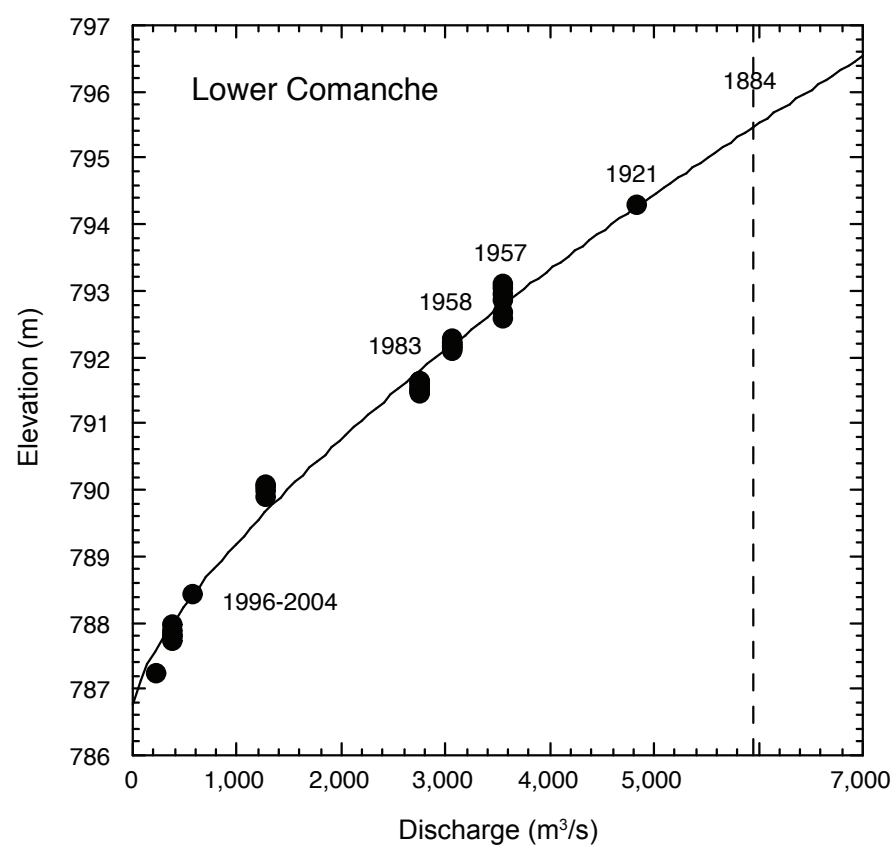

Figure 19. Stage-discharge relationship for the Lower Comanche area, based on surveyed elevation of driftwood logs inferred to represent historical floods. Only points considered to be of 'good' or 'excellent' quality were used to establish this relationship. The 1921 point that was surveyed comes from a cluster of logs $\sim 1.2 \mathrm{~m}$ above a well-defined 1957 driftwood assemblage. No wood was identified that could confidently be identified as an 1884 deposit; the dashed line shows the 1884 flood discharge as it would intersect with the extrapolated stage-discharge curve. of fluvial sedimentation followed by reworking at the land surface. Aeolian sedimentary structures are present in some of the fine-grained deposits. The abundant buff-colored silt and sand material in sections 1, 2, and 4 could be interpreted as tributary alluvium derived from aeolian deposits upstream and on valley slopes during local runoff events, or as sediment derived from the Colorado River (fluvial or reworked aeolian) that may have interbedded with tributary sediment as fluvial and fan processes intersect. Results of grain-size analyses of two samples from section 2 favor the interpretation of reworked Colorado River sediment. The importance of

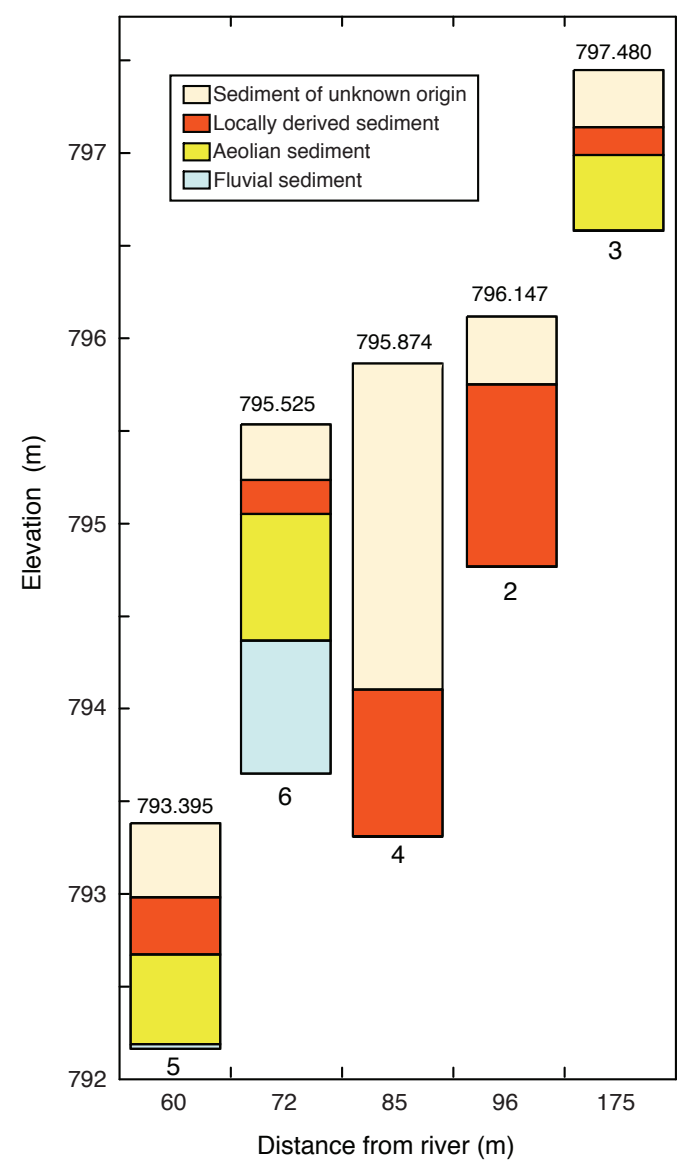

Figure 20. Proportions of fluvial, aeolian, and locally derived sediment, and sediment for which a depositional environment could not be confidently identified, in stratigraphic sections at Lower Comanche (aeolian and fluvial sediment indicated only where confirmed by sedimentary structures). Stratigraphic section numbers are shown below the stacked-column graph for each; upper elevation (in $\mathrm{m}$ ) of each section is shown above the column. The vertical axis indicates elevation referenced to the NAD83(1999) datum for the stratigraphic sections (shown actual height). Elevations of colored bars within each section indicate proportion of that sediment type only, and do not represent actual stratigraphic position of individual horizons within that section. 
various depositional environments does not show a clear trend with distance from the river (fig. 20) because much of the total stratigraphic thickness studied had no diagnostic sedimentary structures. Well-defined Colorado River flood deposits (those that contain fluvial sedimentary structures) were observed only in sections 5 and 6, the two closest to the river. Locally derived sediment, predominantly Dox sandstone and shale clasts, is present in all of the sections described (fig. 20). Numerous channel-fill structures are apparent in arroyo wall exposures (sections 1, 2, 4, and surrounding area), indicating paleogully development similar to that in the modern arroyo network. Data from section 3 indicate that repeated wetting episodes have occurred on the large flat area west of the main dune field, interpreted as ponding due to precipitation runoff that carries locally derived sediment.

The majority of archaeological sites at Lower Comanche are affected to a great degree by aeolian processes in the main dune field. Five of the six cultural sites in this area are located within this dune field (C:13:274, C:13:333, C:13:335, $\mathrm{C}: 13: 337$, and $\mathrm{C}: 13: 373)$. Four of those five were originally situated on aeolian sediment (C:13274, C:13:333, C:13:335, and $\mathrm{C}: 13: 373)$, with the fifth $(\mathrm{C}: 13: 337)$ built on an interdune/playa surface within the dune field. Four of the six sites (C:13:274, C:13:333, C:13:335, and C:13:373) show evidence of at least partial burial by aeolian sediment; two of those four (C:13:274 and C:13:373) have only minor sediment cover. Three of the five sites within the dune field are affected by aeolian deflation (C:13:274, C:13:333, and C:13:335), and one of those ( $\mathrm{C}: 13: 333)$ is exposed as a result of dune migration. One of the sites in the dune field, $\mathrm{C}: 13: 333$, has begun to be affected by gully incision that reaches into the upper elevations of a dune $\sim 10 \mathrm{~m}$ high. Dune migration and aeolian sediment transport are expected to continue to affect these five sites; it is likely that new artifacts will become exposed as dune migration continues, while others are reburied by wind-blown sand. The one site not located in the dune field (C:13:273) is affected significantly by arroyo incision and local runoff (Gellis, 1994; National Park Service, 2004). Arroyo-related erosion is severe at Feature 3 of that site and is predicted to undercut more of Features 1 and 3 as backwasting of the gully walls progresses. The site is also impacted to a lesser degree by visitor use of the Beamer hiking trail.

Much of the fine-grained (silt to fine sand) material in stratigraphic sections at Lower Comanche does not contain preserved diagnostic sedimentary structures. Degradation of original structures is attributed primarily to bioturbation, in the form of animal burrowing and the growth of plant roots. In the absence of lithic grains that imply a local sediment source, such fine-grained deposits are generally interpreted as having been originally derived from Colorado River deposits (and later having been subject to aeolian and tributary-flood reworking). Without sedimentary structures, it is not possible to confidently ascertain whether such deposits remain in their original position as fluvial layers or have been transported and redeposited by wind. Although grain-size analysis may in some cases distinguish between these options, the range of grain sizes present within verifiable fluvial deposits is great enough that caution should be used in assigning depositional environment solely on this basis (see dicussion in section titled "Methods").

It is worthwhile to consider the possibility that debris flows on the large Tanner debris fan ( $\sim 2 \mathrm{~km}$ downstream) could have affected river discharge levels at Lower Comanche (R. H. Webb, written commun. with H. C. Fairley, 2004). While none of the strata identified during this work explicitly suggest quiescent ponding or lacustrine sedimentation, it is possible that elevations of observed fluvial strata may be higher than comparable discharge would reach today, because of prehistoric damming behind the Tanner fan. This possibility could be addressed more fully if a suite of dates were available from fluvial deposits at this site and from debris flow events at Tanner.

The origin of the so-called white layer remains to be determined. It would be advantageous to analyze a sample by $\mathrm{x}$-ray diffraction, which could provide more information on its composition, and consequently on its emplacement.

\section{Arroyo Grande Area}

\section{Geomorphic Setting}

The left bank of the Colorado River in the area known as Arroyo Grande is part of the Area of Cooperation (AOC) between the Hualapai Nation and the National Park Service in western Grand Canyon (Memorandum of Understanding by and among the Hualapai Tribe, Grand Canyon National Park, and Lake Mead National Recreation Area, October 2000). The river in this reach is located along the trend of the major Hurricane Fault system (Huntoon and others, 1981), which locally offsets Precambrian schist and gneiss along river left. Schist and amphibolite-grade gneiss dominate locally derived sediment in the study area.

The study site discussed here (fig. 21) is approximately $1 \mathrm{~km}$ north of the limit of mapping work done by Hereford and others (2000) at Granite Park. Many of the alluvial terraces and other geomorphic features identified at Granite Park by Hereford and others (2000) are present at Arroyo Grande, including designations of the upper mesquite terrace (map unit 'umt'), lower mesquite terrace (map unit 'lmt') and predam alluvium (map unit 'pda') deposits considered by Hereford and others (2000) to be equivalent to those mapped by Hereford (1993) and Hereford and others (1996) at Palisades. In the Arroyo Grande region, the oldest two alluvial terrace units defined by Hereford (1993) and Hereford and others (1996, 2000), the 'pda' map unit and the local equivalent of what was called the striped alluvium ('sa') unit at Palisades by Hereford (1993), are both truncated and overlain by the 'umt' alluvium. This younger 'umt' deposit typically occurs at lower elevation than the older 'sa' and 'pda' in the eastern canyon; in this area of the western canyon, where 'umt' forms a cap over the older alluvial deposits, the covering of Pueblo II age cultural sites 
by subsequent flood deposits may explain the relative rarity of exposed PII sites in the western canyon (Fairley, 2003, p. 112).

As the name suggests, the Arroyo Grande area is characterized by a wide, deep arroyo network (figure 22) that has incised these terrace deposits, exposing cultural material and stratigraphy in the arroyo walls. The arroyo network is as much as $5 \mathrm{~m}$ deep in places. A smaller, secondary arroyo is present downstream of the primary system (figure 21), which has incised $<0.5$ $\mathrm{m}$ into the uppermost alluvial terrace and more than $1 \mathrm{~m}$ into the lower terrace units. A nickpoint near the location of section 5 described at this site suggests that incision of the uppermost terrace will soon increase.

The main arroyo at Arroyo Grande is considered to be a predam feature, because it is present in aerial photographs from 1965 (fig. 23). The extent of arroyo development appears (at least qualitatively) to have increased since 1965 , from examination of stereo pairs of 1965 photographs, but the scale of those images is such that more detailed measurements of arroyo features in 1965 would not be reliable. Repeated ground-based and photogrammetric mapping by Pederson and others (2003) found little change in the depth and configuration of arroyos at Arroyo
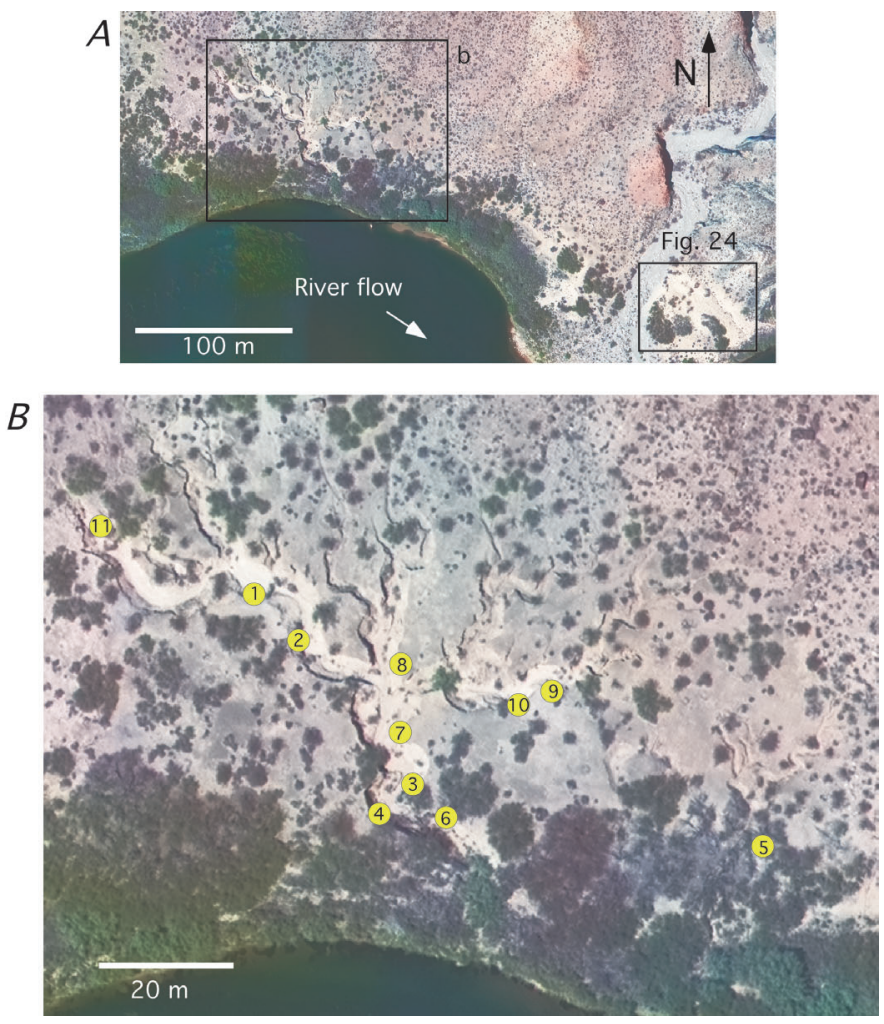

Figure 21. Aerial view of the Arroyo Grande area (photographs from the Grand Canyon Monitoring and Research Center, taken in May 2002). Larger-scale view $(A)$ shows locations of aerial views in $B$, and of the dune shown in an oblique view in figure 24. Locations of stratigraphic sections 1 through 11 are shown in $B$. In $B$, a smaller, secondary arroyo network is visible to the east of the main arroyo (section 5 is in the secondary arroyo. River discharge is $226 \mathrm{~m}^{3} / \mathrm{s}$.
Grande before and after the 2002 monsoon season, the only exception being the partial filling of a minor rill with aeolian sediment between February and October 2002.

The mouth of the primary arroyo drains into the river near the center of a large eddy on river left (fig. 21). Comparison of recent aerial photographs with those from 1965 shows that the extent of riparian vegetation has greatly increased during the past 40 years, and that the area of open sand in the main eddy and along the channel margin has decreased (figs. 21 and 23). Aerial photographs taken immediately before the 1996 flood experiment and again six months after the flood show that a sand bar $\sim 5 \mathrm{~m}$ wide (measured at a river discharge of $220 \mathrm{~m}^{3} / \mathrm{s}$ $\left[8,000 \mathrm{ft}^{3} / \mathrm{s}\right]$ ) formed during the flood at the arroyo mouth in the eddy on river left.

The terrace surfaces into which the arroyos cut have undergone deflation by wind, evidenced by pedestal development of pebbles and cultural artifacts of up to $5 \mathrm{~cm}$ above the surrounding land surface. Coppice dunes are common on the terraces, although well developed cryptogamic crust and colonization by grasses, mesquite, and other vegetation indicate relatively inactive dunes at this time. A large, active sand dune is present at the extreme downstream end of the Arroyo Grande area, $280 \mathrm{~m}$ downstream of the center of the main arroyo network (fig. 24).
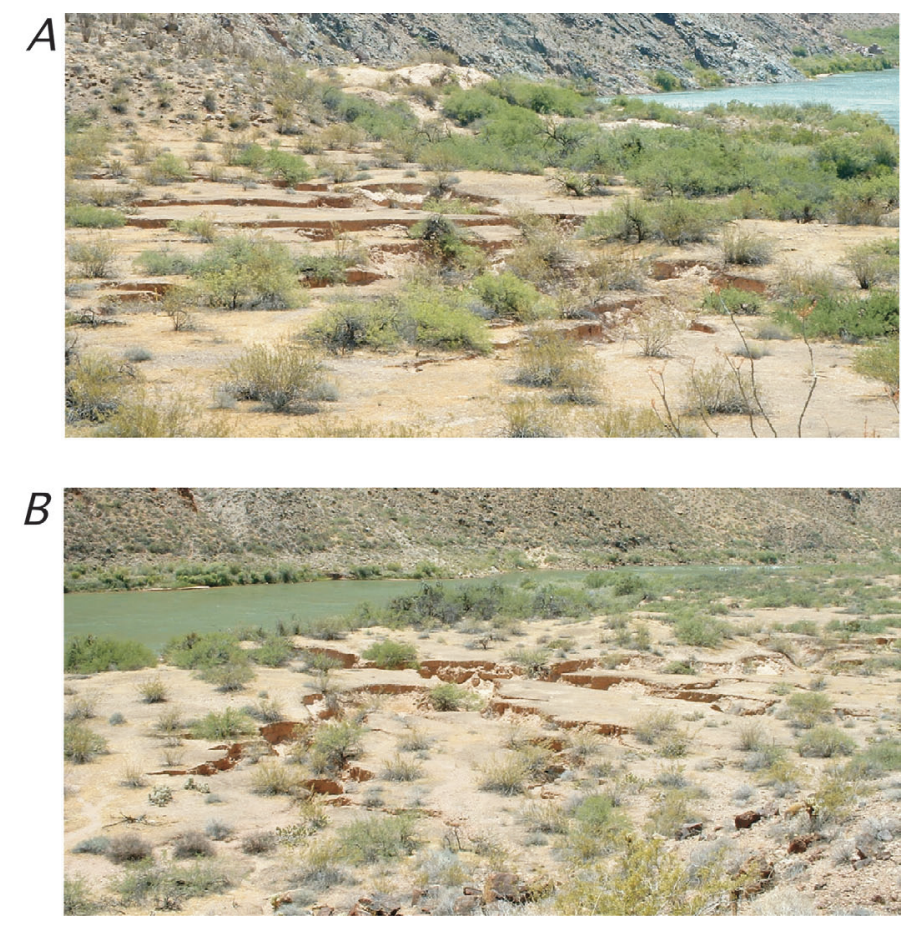

Figure 22. The main arroyo network at Arroyo Grande, viewed from the north $(A)$ and south $(B)$. The large sand dune in the distance in $A$ (at the downstream end of this area) is migrating to the north, toward the arroyo network, but its sand is trapped by a wide drainage (not visible) between the dune and the arroyo, which prevents much of this sand from reaching the terrace into which the arroyo has incised. Note the thick zone of riparian vegetation. 
The orientation of this dune's slip face indicates that it is migrating in an upstream direction, such that sand is being transported into the wide bed of the tributary that lies between this large dune and the terraced area into which the main arroyo has cut. This large tributary likely intercepts most of the sand that migrates into it from the large dune, preventing the dune from acting as a significant source of aeolian sand for the Arroyo Grande terrace.

It is probable that flow of the Colorado River in the Arroyo Grande area has been affected multiple times in the past by debris flows on the debris fan at Granite Park, $2 \mathrm{~km}$ downstream of the study region. At least four episodes of debris flow activity are recognizable in the geomorphology at Granite Park (Hereford and others, 2000), the most recent of those occurring in 1994. Debris flows at Granite Park would be expected to cause temporary damming of the river behind it, ponding water on the terraced areas at Arroyo Grande and inundating land on river left that is included in the study area.

\section{Archaeological Significance}

Four archaeological site complexes are present in the delta and terrace regions of the Arroyo Grande area. An additional three sites are located at higher elevation, near the basalt cliffs that define the lower canyon wall on river left. The largest of the sites is the area immediately affected by the large arroyo network, NPS site number G:03:064 (Fairley and others, 1994). This site, one of the largest and most significant in the western Grand Canyon, contains 16 known features exposed on the land surface with several additional hearths, charcoal lenses,

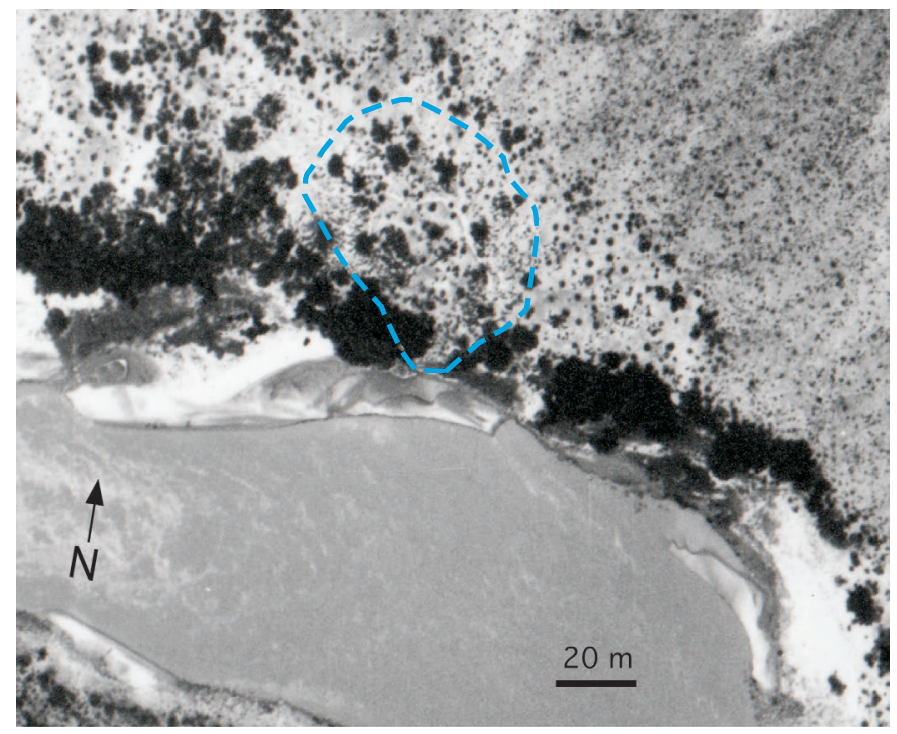

Figure 23. Aerial photograph of the Arroyo Grande area (taken in 1965; Grand Canyon Monitoring and Research Center). The dashed line shows the approximate perimeter of the main arroyo. River discharge is between 680 and $792 \mathrm{~m}^{3} / \mathrm{s}$. and one metate exposed within the drainage network itself. The arroyo system that cuts through this large site is as much as $5 \mathrm{~m}$ deep in places and has contributed to significant erosion of these cultural features. NPS identifies this site as being in immediate danger of severe loss due to arroyo incision of the terrace on which the features are located (National Park Service, 2004). Features that are exposed on the surface today date primarily from the protohistoric and early historic era (Pai and Paiute occupation), whereas older dates (PI-III Formative) have been identified for features that are exposed at lower stratigraphic levels (as much as $3 \mathrm{~m}$ below the modern surface) within the arroyo walls (Fairley and others, 1994).

Numerous artifacts that have been documented on the land surface indicate the cultural importance of this area. Several of the roasting features at this site are greater than six meters in diameter, implying extensive and repeated use over time. The artifact assemblage indicates that the occupants of this area participated in an extensive trade network. Imported artifacts include obsidian, Hopi pottery, and marine shell material.

Arroyo Grande is a very important area in the historic archaeological record because there are several ethnographic accounts from the Paiute and Hualapai of how the area was used; known uses include religious practice and ceremonies, trade, complex social interaction including information exchange, and crossing of the river. Tribes continue today to view this area as a very significant part of their past, present, and future.

\section{Stratigraphic and Geomorphic Analyses}

Detailed stratigraphic logs for the Arroyo Grande study area are described in appendix 3 (figs. 50 through 65). With

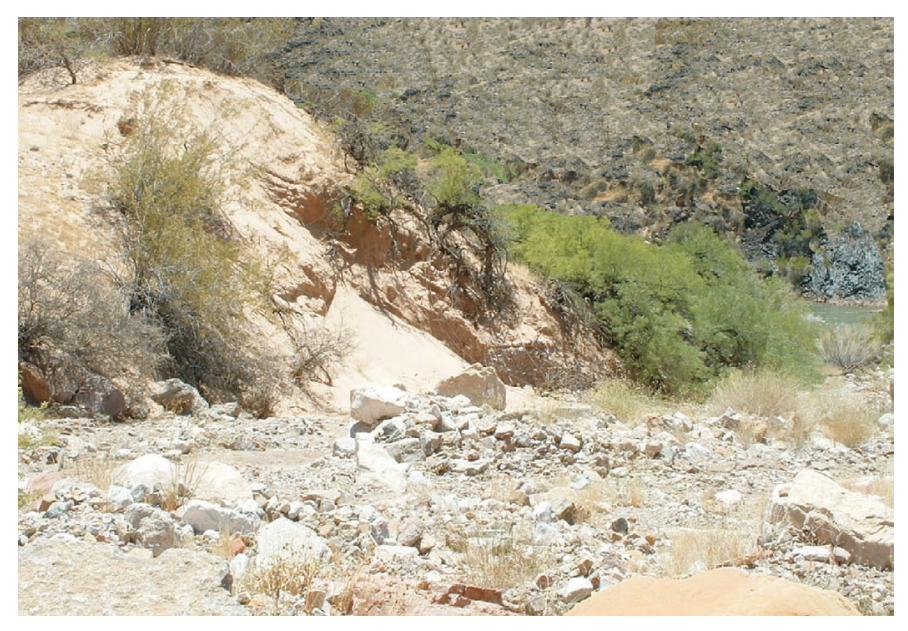

Figure 24. Photograph taken from within a wide drainage at the downstream end of the Arroyo Grande area, on river left (facing toward the river). The large sand dune is migrating northwest (upcanyon; toward the right of the photograph), but interception of sand by this drainage prevents much of it from reaching the terrace into which the deep arroyo network is cut. 
the exception of section 5, all stratigraphic descriptions from Arroyo Grande were obtained within the main arroyo network. Section locations were distributed such that representative samples of the along-shore and across-shore stratigraphy would be included. Section 5 was described from a wall of the secondary arroyo network that lies downstream of the major arroyo. No artificial trenches or pits were dug for this work; all stratigraphic information was obtained using the existing arroyo walls. After completion of the work, stratigraphic sections were disguised with loose sediment from the arroyo floor to conceal the work areas. Dispersed ash and charcoal are common in Arroyo Grande stratigraphy; this is believed to be the result of grass fires (discussed in more detail below). Unless specifically noted, mention of charcoal in the stratigraphic descriptions to follow does not refer to charcoal deposits of cultural significance (such as hearths or roasting pits). Geomorphic characteristics in the immediate area surrounding each of the features of site G:03:064 are discussed in appendix 3 (figs. 66 through 68). Stratigraphic data and geomorphic observations are summarized in the Arroyo Grande Site Summary section below.

\section{Grain-Size Analyses}

Samples were collected from selected stratigraphic units at Arroyo Grande to obtain grain-size data for several fluvial, aeolian, and slope-wash deposits. As discussed above in the section titled "Methods," considerable variation in grain size and other sedimentary characteristics may occur between deposits generated by the same type of depositional event. However, these analyses provide a reference framework for comparing characteristics of different depositional environments relative to each other within each section, and for evaluating sedimentary dynamics within specific flood events. Grain-size data from Arroyo Grande samples are shown in figures 25 through 29. Figure 30 shows grain-size trends within four individual flood units from which multiple samples were taken at different depths within the flood deposit.

Results of grain-size analyses for samples taken from section 1 ( $a$ and $b$ ) at Arroyo Grande are shown in figure 25. The lowermost sample from the section $1 \mathrm{~b}$ stratigraphy, sample AG Strat $1 \mathrm{~b} \# 2$, shows the very fine grained nature of the basal part of this flood deposit, which contains more than 74 percent silt and clay. The deposit coarsens upward (see also fig. 30), similar to flood deposits described by Rubin and others (1998), which can indicate sediment-supply limitation during the flood that produced the deposit. The aeolian unit (sample AG Strat 1a \#1) that overlies the flood sampled in section $1 \mathrm{~b}$ is distinctly coarser than any of the samples from the fluvial deposit (fig. 25). In cases where aeolian deposits are produced by aeolian reworking of fluvial sediment, it is expected that the aeolian deposits will, in general, be coarser than the fluvial source sediment because of winnowing and removal of fines by wind. Sample AG Strat 1b \#6, which was considered in the field to be most likely from the upper part of the flood deposit but possibly part of the overlying aeolian unit, has a grain-size distribution more consistent with the upper part of the flood layer than the overlying aeolian sand (fig. 25).

Data from two flood deposits within section 5 are shown in figure 26. It is apparent from this plot that unit $\mathrm{H}$ contains distinctly coarser sediment than unit $\mathrm{C}$. Unit $\mathrm{H}$ coarsens upward (fig. 30), suggesting that sediment supply was limited during the flood that deposited this unit (Rubin and others, 1998). Unit C, in contrast, fines upward, indicating that sediment-supply limitation was less significant or absent during this flood; this is the same flood unit in which rapid sediment deposition is inferred from vertically climbing eddy-pulsation ripples (figs. 55, 56).

Grain-size data from seven stratigraphically sequential samples within section 6 are shown in figure 27. Samples AG Strat 6 \#1 and AG Strat 6 \#7 were collected from subaerial strata that underlie and overlie a flood deposit from which the intermediate five samples were obtained. The lower of the two subaerial deposits (AG Strat $6 \# 1$ ) is coarser than the upper (AG Strat 6 \#7), and both of them are coarser than any of the sampled flood sediment between them. These subaerial deposits include locally derived slope-wash sediments as well as charcoal and ash material. Charcoal and ash particles were present in small enough amounts that their presence is not believed to have significantly affected analyses of these samples on the Coulter LS 100Q laser particle-size analyzer. The fluvial deposit (AG Strat 6 \#2 through \#6; fig. 30) first coars-

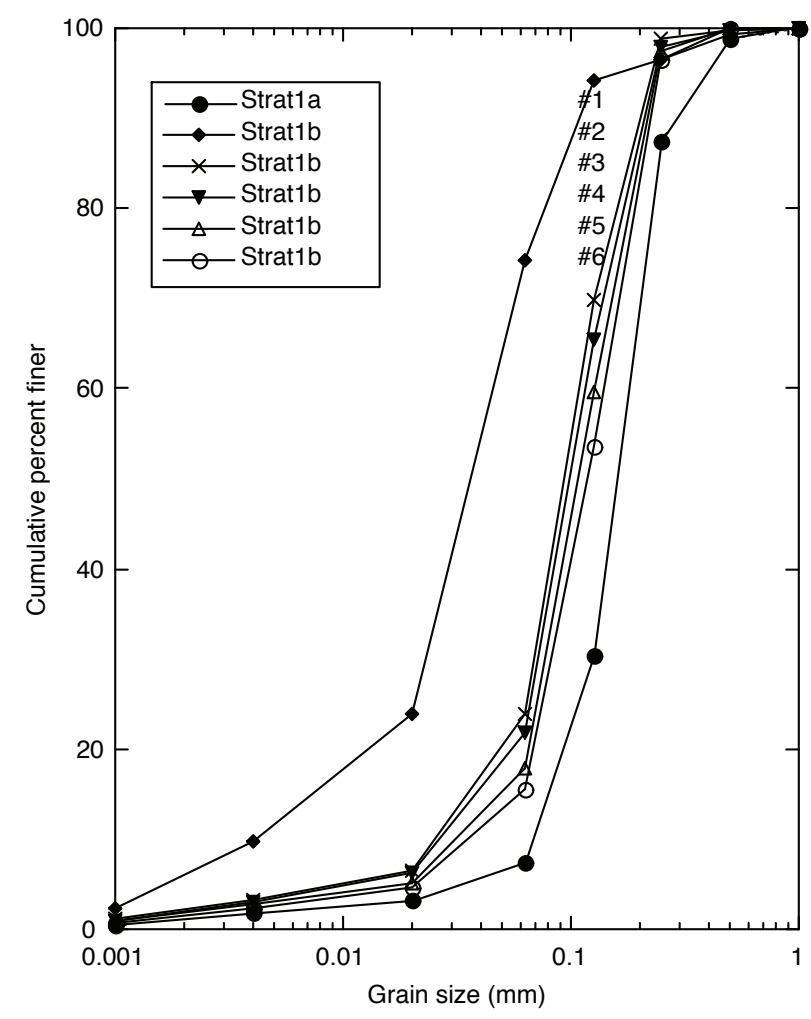

Figure 25. Grain-size data from sections 1a (sample \#1) and 1b (\#2 through \#6), Arroyo Grande. See appendix 3 for sample descriptions. 


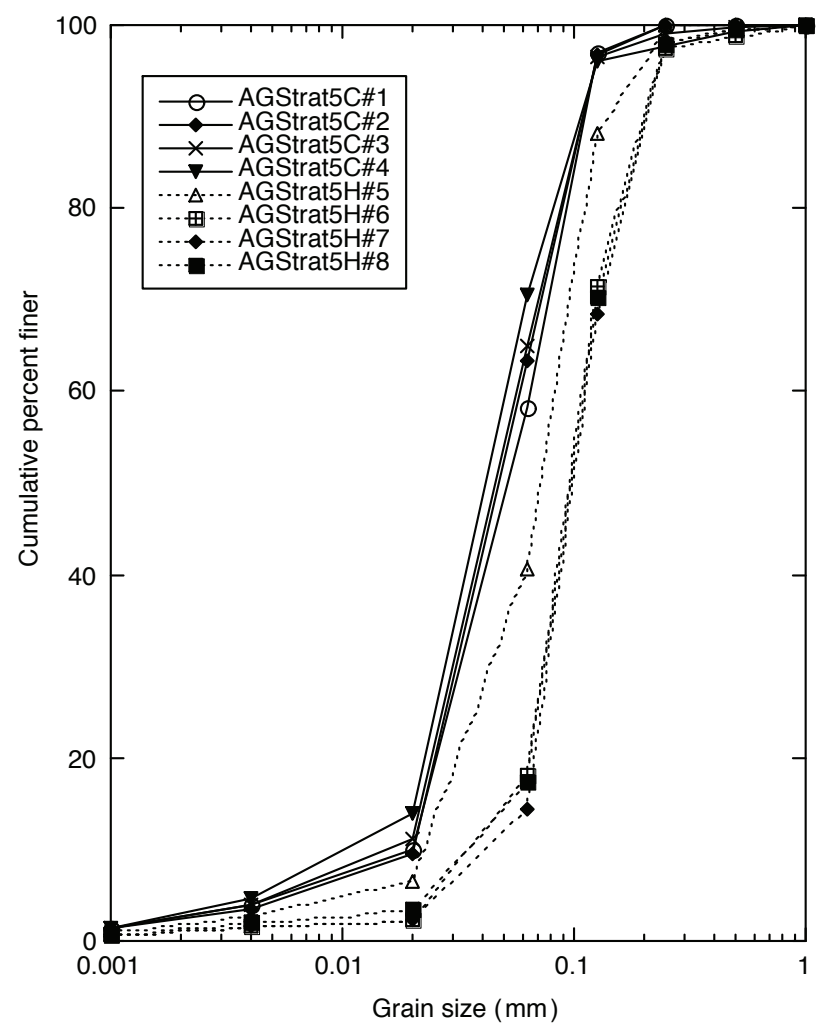

Figure 26. Grain-size data from four samples taken from each of two floods within section 5 at Arroyo Grande (unit $\mathrm{C}$ and unit H). See appendix 3 for sample descriptions.

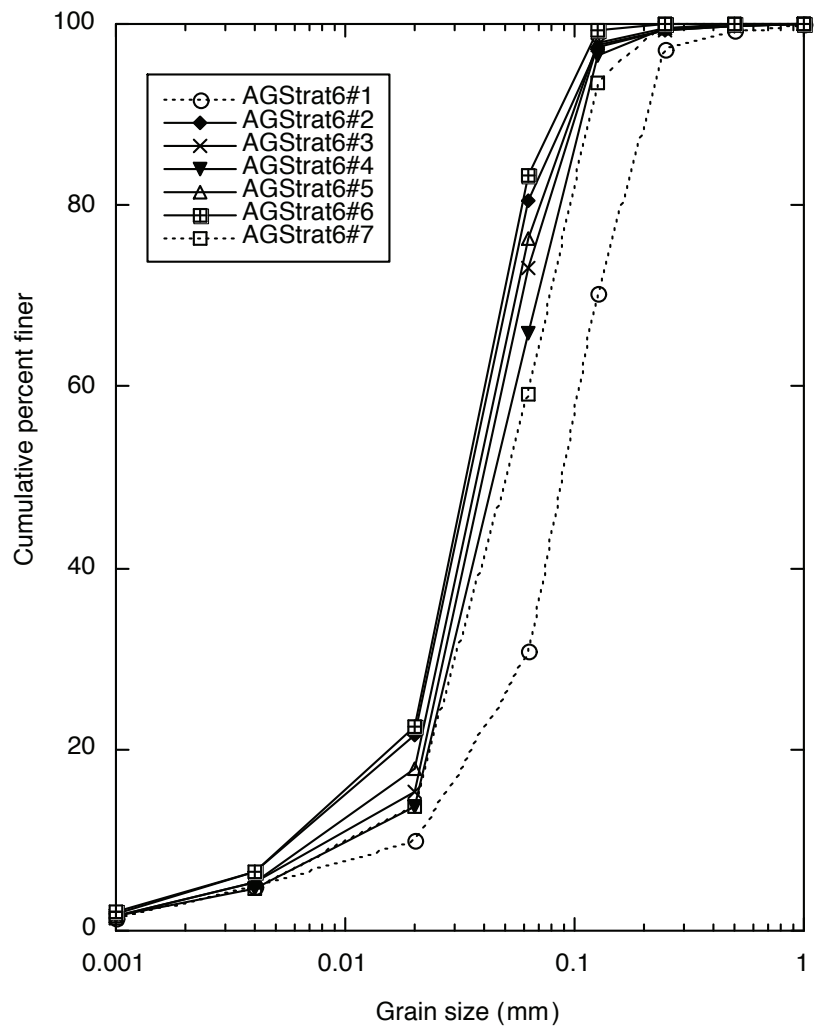

Figure 27. Grain-size data from subunit $\mathrm{G} 3$ within section 6 , Arroyo Grande. See appendix 3 for sample descriptions.

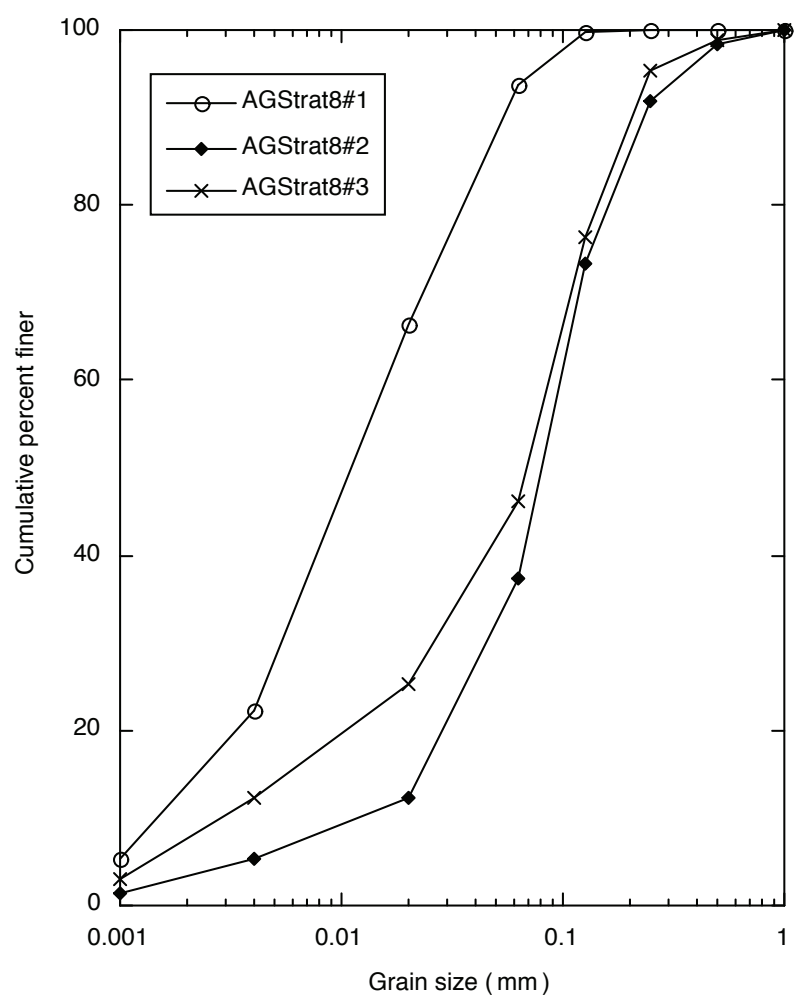

Figure 28. Grain-size data for samples from section 8, Arroyo Grande. See appendix 3 for sample descriptions.

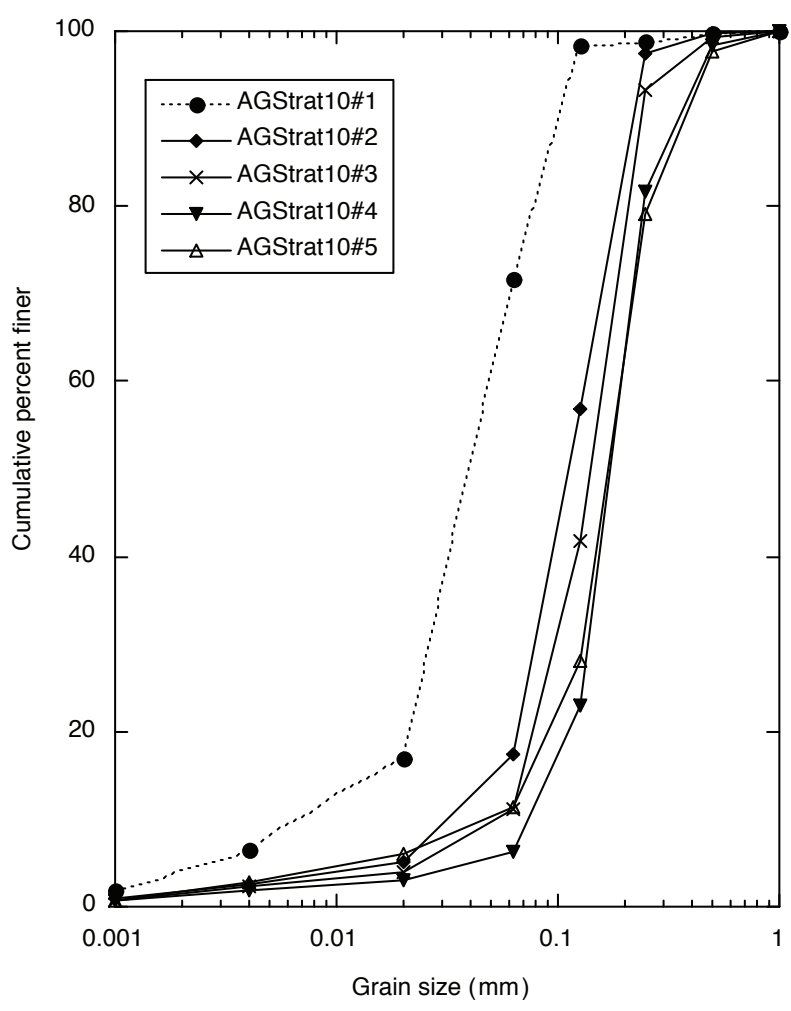

Figure 29. Grain-size data for samples from section 10, Arroyo Grande. See appendix 3 for sample descriptions. 
ens upward and then fines again near its top. Such a grain-size progression is consistent with a deposit that mimics suspendedsediment characteristics of the flood hydrograph in the absence of significant sediment-supply limitation.

Three samples from section 8 show the different grain-size distributions that characterize various parts of a flood/landsurface 'couplet' deposit within this section (fig. 28). Sample AG Strat 8 \#1, from the basal part of a fluvial deposit, contains nearly 94 percent silt and clay. Sample AG Strat 8 \#2 was taken higher up in the same couplet from sediment that was interpreted in the field as either the upper part of the fluvial layer or part of the subaerial unit that overlies the fluvial part of this couplet. This sample is coarser than the base of the deposit, containing 37 percent silt and clay. Because this sample was also found to be slightly coarser than sediment that was clearly part of the subaerial portion of this couplet (sample AG Strat 8 \#3, which contained 46 percent silt and clay; fig. 28), sample AG Strat 8 \#2 can be more reasonably interpreted as subaerial material (having undergone winnowing and possibly incorpora-
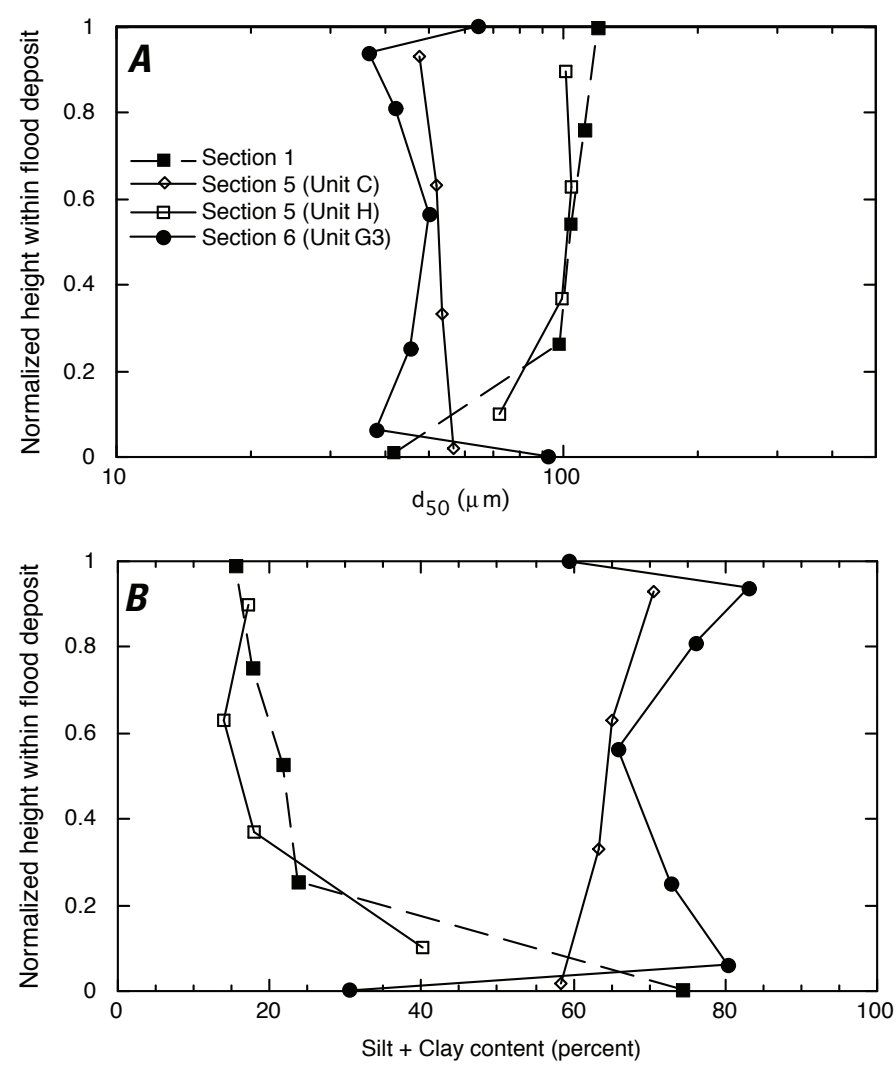

Figure 30. Grain-size trends upsection for four flood units sampled at Arroyo Grande. $A$, Median grain size vs. normalized height within the flood deposit. $B$, Combined silt and clay content vs. normalized height. Two of the floods, unit $\mathrm{H}$ of section 5 and the flood within section $1 \mathrm{~b}$, coarsen upward. Unit $C$ of section 5 fines upward. The flood sampled within section 6 (subunit G3) first coarsens upward then fines upward. Samples from coarser subaerial strata immediately above and below section 6 (subunit G3) are also shown (at normalized heights 1 and 0 on the line for this sample, respectively). See appendix 3 for sample descriptions. tion of locally derived sediment) rather than as the upper part of an intact fluvial layer.

Results of grain-size analyses on five samples collected from section 10 are shown in figure 29. Samples AG Strat 10 $\# 1,2$, and 3 were collected from sediment in this section that was clearly fluvial in origin, containing well-defined fluvial sedimentary structures. Sample AG Strat 10 \#1, a white silt that forms the base of that flood deposit, is much finer than the other samples from this section, containing 72 percent silt and clay. The uppermost two samples from section 10 were considered in the field to be of uncertain depositional origin, though an aeolian interpretation was favored on the basis of sedimentary structures. It is apparent from figure 29 that these two samples, AG Strat 10 \#4 and \#5, are coarser than the samples of fluvial sediment at this site, which would be consistent with an aeolian origin for these two. These two samples have grain-size distributions comparable to samples of known aeolian affinity, though in the finer grain sizes they plot within the region of overlap between fluvial and aeolian grain-size fields. On the basis of both field observations and grain-size data, an aeolian origin is most likely for these two samples.

\section{Arroyo Grande Site Summary}

In the stratigraphic sections examined at Arroyo Grande, it is apparent that Colorado River flood deposits dominate the stratigraphic record of the area in which the features of archaeological site G:03:064 are located. The number and total thickness of fluvial deposits increase toward the river; the best preserved record of flood deposition occurs here in sections 5 and 6, closest to the river (see, for example, fig. 31). All profiles show some evidence of subaerial reworking and incorporation of locally derived (slope-wash) sediment between flood events (compare Benito and others, 2003); poorly sorted sediment with abundant lithic grains typically characterize interflood sedimentation and may occur as channel-fill lenses. The frequent occurrence of fluvial deposits overlain by these subaerial sedimentary packages led to the description, in the field, of 'flood couplets' that each contain a lower fluvial and upper subaerial member (see figs. 58, 59). The fluvial portion of flood couplets commonly, but not always, was seen to begin with a light-colored, very fine grained silt and clay layer. Within four flood units from which multiple samples were taken at different depths, two were found to coarsen upward (section 1b, and unit $\mathrm{H}$ of section 5), one was found to fine upward (unit $\mathrm{C}$ of section 5) and one had no distinct trend, first coarsening and then fining upward (subunit G3 of section 6).

A stage-discharge relationship similar to those shown in figures 11 and 19 was not developed for the Arroyo Grande area because of limited access to driftwood on the densely vegetated lower terraces on river left. Two driftwood logs on river right that are believed to be associated with the 1957 flood (they are, in any case, not likely to be older than 1921, given their relatively good condition) yielded elevations of 428.5 and $428.7 \mathrm{~m}$. The highest fluvial deposits observed at Arroyo 
Grande are within 2-3 $\mathrm{m}$ of this and therefore would not have required a flood discharge substantially larger than that of the 1921 flood $\left(4,810 \mathrm{~m}^{3} \mathrm{~s}, 170,000 \mathrm{ft}^{3} / \mathrm{s}\right)$.

The influence of locally derived sediment was seen to increase with distance away from the river (fig. 31), making up the great majority of section 11 and forming a substantial component of the stratigraphy at sections 7,8 , and 9 . Channel-fill deposits, such as those observed in sections 4 and 11, indicate multiple episodes of gully formation and subsequent filling.

Aeolian sediment constitutes a relatively minor volume in the sections studied; deposits that were clearly aeolian in

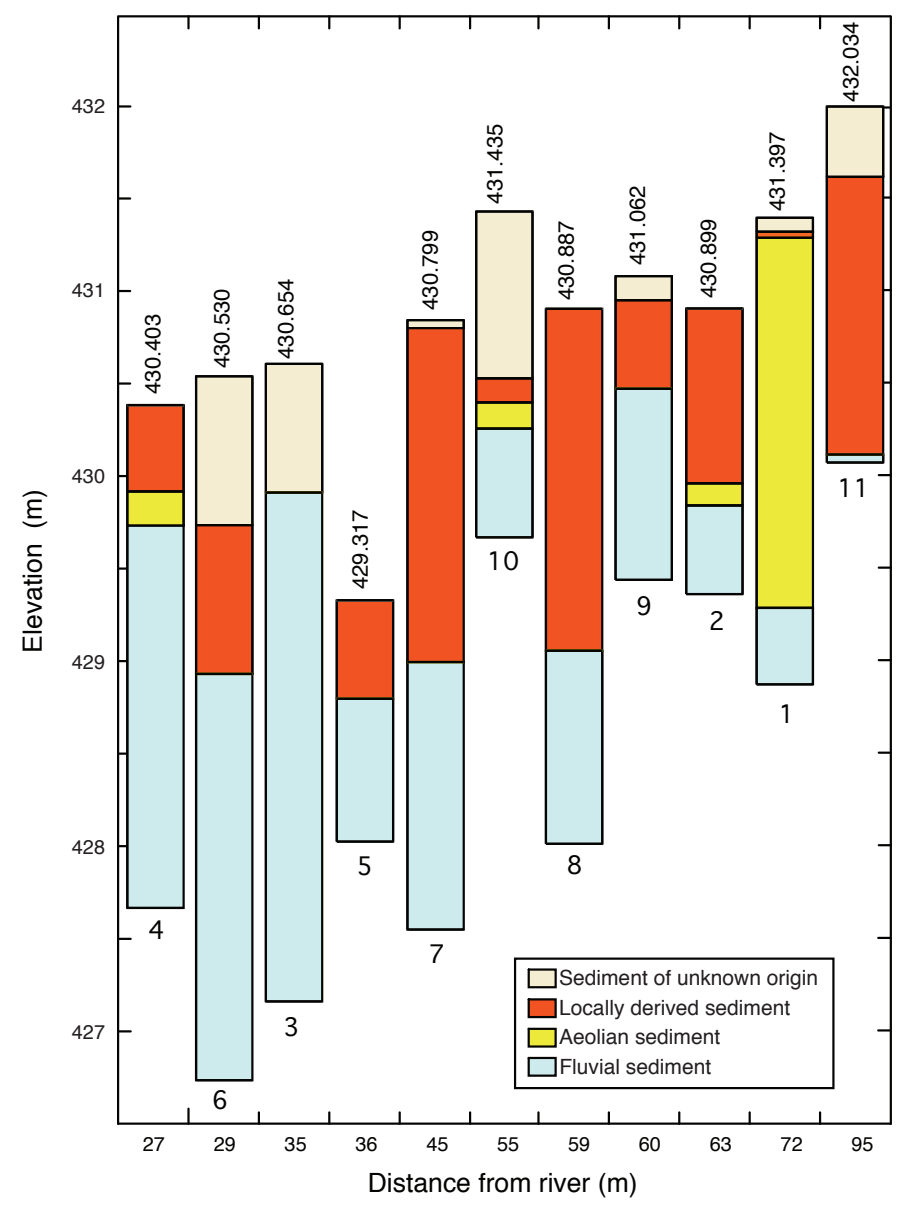

Figure 31. Proportions of fluvial, aeolian, and locally derived sediment, and sediment for which a depositional environment could not be confidently identified, in stratigraphic sections at Arroyo Grande (aeolian and fluvial sediment indicated only where confirmed by sedimentary structures). Stratigraphic section numbers are shown below the stacked-column graph for each; upper elevation (in m) of each section is shown above the column. The vertical axis indicates elevation referenced to the NAD83(1999) datum for the stratigraphic sections (shown actual height). Elevations of colored bars within each section indicate proportion of that sediment type only, and do not represent actual stratigraphic position of individual horizons within that section. Relative proportion of fluvial sediment can be seen to decrease with distance from the river, as locally derived and aeolian sediment are more volumetrically significant at distances far from the river and at higher elevation. nature (from the presence of sedimentary structures) occurred at sections 1,2, and 10; where present, these aeolian dune deposits exhibited fairly deep roots, extending as much as $2 \mathrm{~m}$ beneath the land surface. The most likely sediment source for the small coppice dunes, now deflated, that are visible on the land surface today (for example, fig. 66) is the reworking of the extensive fluvial deposits that created the terrace morphology in this area.

The presence of abundant charcoal and ash material in many of the stratigraphic horizons that represent subaerial exposure is most probably attributable to frequent grass fires in the area. It is likely that these were deliberately set by the inhabitants of the area, although lightning strikes could also have caused occasional fires. The Hualapai and Paiute Tribes, which have ancestral ties to the Arroyo Grande region, both carry cultural traditions that include the deliberate setting of grass fires. Loretta Jackson, Tribal Historic Preservation Officer for the Hualapai, has related that Hualapai tribal elders know of grass fires commonly set to initiate seed germination (L. Jackson, oral commun. with L. M. Leap, 2004). Ila Bullets, of the Kaibab Band of Paiutes, reports that grass fires were commonly initiated to facilitate seed collection and crop management and to prevent other, larger fires from starting. The setting of grass fires was practiced at certain prescribed times of year, and continues today (I. Bullets, oral commun. with L. M. Leap, 2004). Other possible reasons for deliberately set fires include hunting and escape/warfare (see, for example, Powell, 1878; Beaglehole, 1936; Drucker, 1941; Kelly and Fowler, 1986; Boyd, 1999).

The features that form site G:03:064, all of which occur on or just beneath the land surface, are built primarily on fluvial sediment, though several (features 1, 2, 4, 5, and 6) are located in the area where small coppice dunes, now deflated, occur (fig. 66). Several cultural hearth features, which are not included as features in G:03:064, are visible in the walls of the arroyo, having been built on fluvial and slope-wash sediment and subsequently buried by both fluvial and locally derived material. By far the greatest threat to cultural features at Arroyo Grande, both the surface features that make up G:03:064 and the older subsurface hearths, is arroyo incision. The steep arroyo walls consist of relatively poorly consolidated fluvial and aeolian sediment throughout most of the arroyo network; back-wasting of the walls continues to undercut features such as that shown in figure 67. Toward the distal ends of the arroyo arms, incision is taking place into more resistant, coarser grained sediment (the slope-wash and talus deposits near the cliff wall), which limits the rate at which incision can occur. All but one of the features associated with G:03:064 are located on the fluvial/aeolian terrace surface, however, and not in the slopewash-dominated area far from the river, resulting in the imminent threat to these features from arroyo incision. The smaller, secondary arroyo network that lies downstream of the primary arroyo (in the area where section 5 was measured) has begun to incise into the uppermost fluvial terrace to its north. Incision of the upper terrace by the secondary arroyo is expected to accelerate after the $\sim 1.5$-m-deep nickpoint that is currently located 
at the site of section 5 retreats further and meets the upper terrace. The proximity of this nickpoint to the upper terrace at this time $(2 \mathrm{~m})$ implies that perhaps two or three intense rain storms could allow the nickpoint to move into the upper terrace area.

Although no samples were collected from Arroyo Grande for radiocarbon dating, numerous stratigraphic horizons in the arroyo walls contain sufficient ash material for radiocarbon dating purposes. Any future efforts to conduct radiocarbon dating work on charcoal (either cultural or noncultural ash, such as the apparent grass-fire horizons represented in several stratigraphic sections) could provide valuable age data that could be used to refine the flood history of this area, as well as providing dates for various stages of cultural occupation.

\section{Discussion and Conclusions}

These investigations of Holocene stratigraphy in archaeologically significant areas have been designed as a cooperative effort by geologists and archaeologists to collect data to help guide managers on future efforts to preserve archaeological sites in Grand Canyon. Developing a strategy for preservation of such cultural resources requires a detailed understanding of sedimentary and geomorphic processes with multiple time scales considered. In the shorter term, field evaluation of geomorphic processes (such as gully incision and dune migration) is essential to the success of erosion-mitigation efforts at archaeological sites (for example, checkdam construction, slope stabilization). The time scales on which these processes and mitigation methods are relevant in a particular location may vary from less than an hour (the duration of a rainfall event that can carve a new gully or further incise an existing one) to decades or more (the time scale on which the migration distance of large aeolian dunes becomes important). To develop a far-sighted, longer term approach to in situ preservation of sites throughout the river corridor, it is necessary to document in detail the geomorphic and stratigraphic context in which these sites were built and in which they were preserved. Such information is essential to the formulation of management decisions, including those that involve dam operation, with the aim of maintaining and restoring sedimentary deposits in which sites are located. The time scale on which these research topics remain relevant ranges from days (during which the effect of flow fluctuations, including a beach/habitat-building flow [BHBF], may be measured) to many years or decades, as anthropogenic impact on the river corridor continues.

In her recent comprehensive assessment of culturalresource issues in the river corridor, and of the research approach that is needed to best address the preservation of archaeological sites, Fairley (2003) has posed a series of research questions that encompass complex multi-dimensional aspects of geomorphic process and history, paleoclimate and ecology, and cultural interaction with the Grand Canyon landscape. Four of those research questions are particularly relevant to the present study:
(1) What do the sedimentary structures and grain sizes in Holocene deposits reveal about the relative dominance of aeolian versus fluvial processes in prehistory, and how might these processes have influenced the preservation or erosion of archaeological sites in the past?

(2) What types of geomorphic processes were active on the landscape before settlement, and what processes created the landscape on which sites were subsequently located?

(3) How have postdepositional processes altered or removed portions of the archaeological record at sites?

(4) What do postdepositional sediments [those that postdate site formation] reveal about landscape changes since the time of occupation?

Stratigraphic and geomorphic data such as those collected during this investigation are essential to formulating answers to these and other research questions, which seek to better define the context in which prehistoric people lived in Grand Canyon. Understanding the complex interaction between the people who lived along the river corridor and their physical environment has great significance for enhancing archaeological studies of this area. The same types of data in turn form the basis by which management decisions must be made that have the potential to preserve or restore archaeologically significant sediment deposits.

During the course of this study, the importance of answering the four research questions listed above on a site-by-site basis became particularly apparent. The relative dominance of fluvial, aeolian, and slope-wash sedimentation can differ widely between study sites and can vary substantially between stratigraphic sections within any one study site. It is difficult, and not necessarily informative, to form regionally generalized conclusions about the geomorphic processes that created the landscape before and after settlement, or to generalize the effects of postoccupation processes on archaeological site preservation, without actual detailed field study at a site in question. For example, the answers to these questions attained by our work at Arroyo Grande (dominance of fluvial and slope-wash deposition in various areas of site G:03:064, with arroyo incision having removed portions of features) cannot be assumed to affect other sites in western Grand Canyon, or even sites directly across the river, in exactly the same manner.

\section{Observations Related to Aeolian Sediment}

Because this research team was originally assembled for the specific purpose of investigating the role of aeolian sediment in the preservation of archaeological sites, we offer conclusions on that topic based on information obtained during this stratigraphic study and from earlier reconnaissance work done in 2003. As an initial reconnaissance effort for this project, personnel from the USGS, NPS, Hopi and Hualapai Tribes, GCMRC, and the Western Area Power Authority (WAPA) participated in a river trip from May 4 to 19, 2003. NPS archeologists J. R. Balsom, L. M. Leap, and J. L. Dierker directed visitation of 38 archeological sites at which earlier 
monitoring work by NPS had indicated that aeolian sediment may have been significant, either as the material underlying the site or forming a protective cover. At each site, the sedimentologists made initial assessments of the depositional environments (aeolian vs. fluvial) on which the sites were located. Although a few of these sites are underlain by sediment deposited by slope-wash processes or by side-canyon floods, most sites were built on (or buried by) sand that was transported by wind from Colorado River deposits. Following the May 2003 reconnaissance trip, the list of study sites was narrowed to identify areas of highest priority that would then be examined within our budget and time constraints. The Palisades, Lower Comanche, and Arroyo Grande investigations described in this report were three of those areas selected for further study.

Observations made during the May 2003 reconnaissance trip included the following:

1. A preliminary estimate is that roughly 90 percent of the sediment beneath or above these particular archaeological sites is Colorado River sand that was transported from fluvial deposits at the river margins by wind. A few sites were built on or buried by sediment deposited directly by large floods of the Colorado River. (These sites were selected for the purposes of this reconnaissance trip and are not typical of all sites.)

2. Aeolian transport appears to be limited largely by factors such as sediment supply and vegetation, rather than by wind. Reduction in the size of sand bars, increased vegetative cover, and increased submergence of bars can be expected to reduce aeolian transport of sand to the nearby dune fields that contain archaeological sites. Reduced aeolian transport can be expected to facilitate the growth of existing arroyos and establishment of new arroyos. At many of the sites visited in May 2003, damage to archaeological sites by arroyo development and incision is apparent. Data and photographs collected by NPS archaeologists at repeated visits to many sites over a time frame of more than a decade support this observation.

3. Some archaeological sites are threatened by small drainages that might be repaired by modest increases in aeolian sand deposition. Examples include sites visited at Lower Tanner and Palisades, where construction of brush check dams by archeological teams has slowed the incision of some gully systems; an increase in transport of aeolian sand to such areas is anticipated to further stabilize such archaeological features. Other sites (such as Arroyo Grande) are threatened by very large drainages that could only be filled by increases in aeolian transport larger than might reasonably be expected in the short term.

4. The side walls of some drainages showed sedimentary structures recording prior gully erosion and prior filling by aeolian sand, but these structures showed filling of paleogullies that were smaller than the modern active arroyo channels.
Beginning in November 2003, six months after this reconnaissance river trip, several members of the research group (Draut, Rubin, Dierker, Fairley) installed weather stations at six locations along the river corridor that collect a continuous record of wind conditions and precipitation in the vicinity of selected archaeological sites. The purpose of these stations is to document wind speed/direction and measure aeolian sediment-transport rates using anemometers and sand traps. The work plan for these instrument stations calls for their continued operation until December 2005, after which time they are scheduled to be removed. Data collected at these weather stations will be discussed in a separate report.

Because the relative significance of various sedimentary and geomorphic processes can differ widely between sites, specific causes of archaeological-site erosion, and specific measures needed to rectify erosion, must be determined on a site-by-site basis. We propose a series of questions that must be answered to determine the extent to which aeolian sediment deposition affects the preservation potential of archaeological sites. The first two questions in this series are:

(1) What is the depositional context of sediment on which the site is built?

(2) What is the depositional context of sediment that has buried/protected the site?

These two questions require detailed field analyses of the stratigraphic and geomorphic context of each site, using the methods described in this report for the work at Palisades, Lower Comanche, and Arroyo Grande. The results described in this report are intended to answer these research questions for the three locations considered. To move toward developing a plan for mitigation of archaeological-site degradation, additional questions follow. If the answer to question 2 is aeolian sediment, one asks:

(3) Is there evidence for loss of aeolian sediment that previously covered the site?

Establishing whether or not aeolian-sand cover has been lost from a site provides a means by which to gauge the risk or degree of site degradation. If no loss of aeolian sediment is suspected at a particular site, that site may not be at immediate risk of artifact loss; in such a case, it may not be necessary to continue with the remaining questions that identify the degree of sensitivity to dam operations that could have contributed to degradation. A loss of aeolian sediment at a site could be most accurately documented using repeated high-resolution survey mapping to quantify aeolian deflation and/or gully incision. If such methods are not available, loss of aeolian sediment can be qualitatively inferred using repeated ground-based photography and geomorphic and sedimentary evidence of deflation. Evidence for deflation can include pedestal development, lag deposits on the land surface, and exhumation of plant roots. Deflation of aeolian sand in an area that had formerly experienced aeolian deposition can result from continued wind action 
accompanied by reduced sediment supply in the source area from which the sand is derived. Therefore, if it can be established that degradation of the archaeological site is related to a loss of aeolian sediment cover, the next question that arises is:

(4) What is the source of the aeolian sediment that has buried the site?

Positive identification of the source area for aeolian sediment can best be made by documenting wind conditions at this location over a representative period of time. In this river corridor, the most prominent sources of new sediment from which the wind can mobilize sand are sand bars created by fluvial deposition of sediment (see, for example, Schmidt, 1990). It is also possible for large aeolian dune fields (which have developed by accumulation of windborne sand from fluvial deposits) to serve as source areas for other, secondary aeolian deposits located farther from the river. Records of wind speed and direction can be used to generate vector sums that demonstrate the potential for aeolian transport of sediment over time; this is the primary objective of data collection at the weather stations now in operation at six locations along the river corridor (mentioned above). Because wind conditions may vary widely from season to season, and even from year to year, the longer the time interval from which data are used, the more accurate net sediment-transport calculations and predictions will be. Once a source area has been identified on the basis of local wind conditions, it is necessary to ask:

(5) Has there been a demonstrated reduction in the source area from which this aeolian sand is derived?

Aerial photography and repeated high-resolution mapping can be used to identify historical changes in the amount of sand available in the source area for aeolian transport. A demonstrated reduction in the open-sand area at the source indicates that less sand would therefore be available for transport toward and redeposition at the archaeological site in question. The definition of "open sand" (sand that is available to be transported by wind) is somewhat loose, because multiple factors affect the entrainment of sand by wind to varying degrees. Aeolian sand transport is limited by the presence of vegetation (Olson, 1958; Bressolier and Thomas, 1977; Ash and Wasson, 1983; Wasson and Nanninga, 1986; Buckley, 1987; Bauer and others, 1996), interstitial moisture in the sediment (Sarre, 1988, 1989; McKenna Neuman and Nickling, 1989; Namikas and Sherman, 1995; Wiggs and others, 2004), trapping of sand by gullies (Bauer and others, 1996), nonerodible surface objects such as rocks (for example, Gillette and Stockton, 1989), and cryptogamic soil crusts (Leys and Eldridge, 1998; Belknap, 2001; Goossens, 2004). A reduced potential for aeolian entrainment of sand from a given source area could therefore be manifested in the form of increased vegetation on the source-area sand bar, an increase in the moisture content of the exposed sand area (caused either by flow fluctuations or precipitation), increased exposure of rocks that obstruct wind, or development of cryptogamic soil crust on the source-area sediment. If a loss of open sand in the identified source area is inferred, one needs to ask:

(6) Could renewed deposition of aeolian sand have a substantial restorative effect on this site?

Sites at which renewed aeolian deposition would "substantially" improve the preservation of cultural features would be those at which the greatest threat of degradation is from deflation of sediment cover by wind, from incision by gullies small enough to be healed by wind-blown sand (those on the order of $<1 \mathrm{~m}$ wide, judging by occasional exposures of filled gullies observed on the land surface and in stratigraphic sections by this research group; see also Thompson and Potochnik, 2000). Aeolian sedimentation is not expected to protect (in terms of its ability to prevent complete loss of the site) archaeological features that are more threatened by incision of a major gully, arroyo, or side-canyon channel than they are by the loss of aeolian sediment.

In the case of sites that have been compromised by migration of aeolian dunes, leading to the destabilization of surfaces on which the sites were formed (for example, fig. 48), renewed deposition of aeolian sand during dune migration could rebury artifacts but would not lead to preservation of the site in its original, intact state if artifacts have migrated downslope. If the answer to question 6 is 'yes,' a final additional question that begins to involve larger-scale management decisions should be asked:

\section{(7) How could this be accomplished?}

This final question is obviously broad, but given that increased deposition of aeolian sediment at a particular site would (in our line of reasoning) be linked to an increase in sand available for aeolian transport from the source area, the question could be rephrased to ask, how could the source area for aeolian sediment at this site be enhanced? Because riverlevel sand bars constitute the largest source of new sediment that could be mobilized by wind, an increase in the area of open sand available on river-level sand bars would enhance the potential for aeolian sand transport and redeposition in the vicinity of the archaeological site considered. In Grand Canyon, management options include restoration of open-sand area on river-level sand bars throughout the river corridor using BHBF flows (Bureau of Reclamation, 1995). Behavior of a particular sand bar that is of interest as an aeolian-sediment source during a BHBF flow may be gauged using aerial photographs or mapping conducted before and after the 1996 $\mathrm{BHBF}$. However, future BHBF flows may induce local aggradation or degradation patterns that are not identical to those of the 1996 flow, if sediment concentration and flow operation are different from the 1996 controlled flood experiment.

Additional management considerations related to the observations of this study are discussed below, as they involve processes not limited to aeolian sedimentation. 


\section{Potential Implications for Management Objectives}

Observations from the three study areas discussed here lead to several implications for management action that could potentially help to restore the condition of some archaeological sites. First, based on observations relevant to question 1 above, large areas of fluvial deposits, such as those at Palisades and Arroyo Grande, form the most substantial substrate on which archaeological sites are located (see Hereford and others, 1996). The river discharge level represented by high-elevation flood deposits such as the well-defined fluvial terraces at Palisades and Arroyo Grande is substantially above the $1,270 \mathrm{~m}^{3} / \mathrm{s}(45,000$ $\left.\mathrm{ft}^{3} / \mathrm{s}\right) 1996$ BHBF flow and of the 2004 flood experiment $(1,160$ $\left.\mathrm{m}^{3} / \mathrm{s} ; 41,000 \mathrm{ft}^{3} / \mathrm{s}\right)$. In order to effect large-scale restoration of the fluvial terraces in these two (and other) areas, a flow level comparable to or exceeding the 1921 flood stage $\left(4,810 \mathrm{~m}^{3} / \mathrm{s}\right.$, or $170,000 \mathrm{ft}^{3} / \mathrm{s}$ ) would likely be needed. In order to produce the desired deposition instead of erosion, a flood of this magnitude would also require very high sediment concentrations in the flow (see modeling work of Wiele and Franseen, 1999). An experimental flow of this magnitude is not currently within the management considerations of the Glen Canyon Dam Adaptive Management Program, and it is likely that sediment concentrations would be too low in a flow with such high discharge to have a substantial restorative effect. Were a sediment-rich, highdischarge flood to occur, a large volume of new high-elevation fluvial deposits could then act as a source for aeolian sediment, which could help preserve and protect archaeological sites in areas dominated by aeolian sediments (such as the large dune field at Lower Comanche or smaller coppice dune accumulations that overlie fluvial terrace sediment at Palisades and Arroyo Grande). Generating a major new fluvial deposit as a source for aeolian sand is anticipated to produce a much greater benefit to the condition of aeolian deposits than creating smaller sources of aeolian sand by simpler methods (for example, removing vegetation from selected channel-margin sand bars).

As discussed by previous researchers, Glen Canyon Dam operations are considered to have a potentially large effect on the condition of fluvial deposits (see, for example, Hereford and others, 1993a). By extension (Thompson and Potochnik, 2000), the operation of the dam has the potential to affect the condition of aeolian deposits as well. In contrast to fluvial and aeolian sediment sources, deposition of locally derived sediment has the least potential to be affected by Glen Canyon Dam operations. Local sediment delivery occurs at the sites studied in the form of slope-wash events, playa deposition, and distal debris-flow runoff. All of these processes occur irrespective of processes controlled by dam operations. It is possible, however, that the deposits produced by local sedimentation events may vary in their extent and location from the predam condition if, as Hereford and others (1993) and Thompson and Potochnik (2000) proposed, the base level onto which local sediment is delivered has been altered by dam operations. If the configuration of aeolian dunes in a dune field (such as the one at Palisades) has changed, or if a new gully has breached the dune field, local slope-wash events may produce additional gully incision that drains to the river rather than collecting in ponded areas to produce the playa deposits commonly seen at Palisades. The loss of locally derived sediment would have the greatest effect farthest from the river, where the proportion of local sediment is highest (see discussion of Palisades and Arroyo Grande stratigraphic sections, above).

With respect to the archaeological sites investigated during this work, locally derived sediment was not found to play a volumetrically significant role in site preservation relative to the protective cover provided by thicker fluvial and aeolian deposits. However, this research group has observed exposures in other areas of the river corridor in which aeolian and locally derived (slope-wash and debris-flow) sediments interbed, such that a thin cover of coarse, poorly sorted local sediment forms a resistant cap that protects more easily erodible aeolian sediment beneath (Hereford and others, 1996). Examples include exposures at the mouths of small tributaries at river mile 60.7 and at Monument Creek, river mile 93.9. By extrapolation, the potential reduction in local sediment delivery that could follow a reconfiguration of local drainage patterns might lead eventually to reduced preservation of aeolian sediment.

\section{Future Research Directions}

It is apparent from the results presented here that sedimentary and geomorphic processes that affect archaeological site stability and preservation can vary widely even within a relatively small area. At Lower Comanche, some cultural features face erosion because of arroyo incision, while others have become (or have the potential to become) unstable because of dune migration processes. Treatment procedures designed to mitigate erosion at archaeological sites such as these, and others, depend greatly on site-specific parameters. Mitigation measures that increase the preservation potential of one site may be ineffective at others. To this end, the formulation of successful mitigation strategies must depend on detailed cooperative field investigations involving both archaeologists and geologists.

Such a joint research approach could be used to further elaborate on the sequence of events that has led to the repeated fluvial-subaerial 'flood couplet' stratigraphy described at Arroyo Grande. Radiocarbon dating of charcoal and ash material in many of the stratigraphic horizons that represent subaerial exposure, both in cultural features (hearths) and in dispersed occurrences that likely represent grass fires, could be used to establish a chronology for flood events in the western canyon. The potential for detailed dating work in these deposits warrants further investigation, if this can be accomplished without unacceptable risk to the integrity of cultural material and if the collection of carbon samples from this particular area would be acceptable to the Hualapai Nation. The frequency of flood events, and of burning incidents during interflood times, has the potential to produce a high-resolution record of flood occurrence and to elu- 
cidate the timing of human occupation at this site (if grass fires were indeed deliberately set), issues discussed by Fairley (2003) as relevant to understanding human interaction with the prehistoric Grand Canyon landscape.

As Fairley (2003) has stated, cultural resource management in Grand Canyon National Park could benefit from more detailed quantification of erosion of archaeologically significant sediment deposits. Resolution of dam-induced erosional effects, a key component of both geomorphic and cultural-resource investigations, could be greatly facilitated if quantitative records of erosion rates were available from the predam time, but such data are not available, nor are erosion rates systematically quantified on a regional scale during geomorphic or archaeological monitoring work today. Erosion rates and processes could be definitively established through the more widespread use of repeated high-resolution survey mapping (which has been done at a number of locations by NPS and other research groups, as exemplified by Yeatts, 1996), the use of long-term camera placement, and the continued use of instrument stations to measure precipitation, wind magnitude and intensity, and aeolian sediment-transport rates. The Thompson and Potochnik (2000) restorative base-level hypothesis, and their predictive model for terrace erosion, could be tested systematically in representative river- and terrace-based drainage systems using similar methods. The strengthening or refutation of the restorative base-level hypothesis through quantitative testing of this model could generate significant progress in formulation of management strategies for the river corridor, given the implications of this model for relating geomorphic processes and archaeological site preservation to dam operations.

\section{Acknowledgements}

This project has been sponsored by the U.S. Geological Survey and Bureau of Reclamation through the Grand Canyon Monitoring and Research Center (GCMRC). Permission to conduct the research was granted by Grand Canyon National Park under Research and Collecting Permit GRCA-2003-SCI0101. We are grateful to Loretta Jackson, Hualapai Tribal Historic Preservation Officer, for authorizing the work to occur at Arroyo Grande. We thank boatmen Brian Dierker, Steve Jones, and Kirk Burnett for their valuable logistical support during river trips in May 2003 and May 2004, and Carol Fritzinger of GCMRC for coordinating those trips. Jan Balsom, Chief of Cultural Resources at Grand Canyon National Park, has been instrumental in the development and planning of this research. Michelle Rubin provided field assistance during the 2003 and 2004 river trips. Mike Dai and Tom Porter of the Arizona Water Resources District assisted with surveying operations and logistics at Arroyo Grande. Nancy Andrews of NPS contributed to the data preparation for monitoring work at archaeological sites. Erin Todd analyzed a sample of the Lower Comanche white layer under a petrographic microscope. This work has benefited from insightful discussion and comments by Ted Melis, Mary Barger, Loretta Jackson, and Richard Hereford. We thank Curt
Storlazzi and Jon Warrick for their technical reviews of this manuscript, and Peter Stauffer for thorough editorial reviews and revision.

\section{References}

Andrews, E.D., 1986, The Colorado River - a perspective from Lees Ferry, Arizona, in Wolman, M.G., and Riggs, H.C., eds., Surface water hydrology: Geological Society of America, Decade of North American Geology, v. O-1, p. 304-310.

Ash, J.E., and Wasson, R.J., 1983, Vegetation and sand mobility in the Australian desert dunefield: Zeitschrift für Geomorphologie Suppl.-Bd. 45, p. 7-25.

Balsom, J.R., and Larralde, S. (eds.), 1996, Mitigation and monitoring of cultural resources in response to the experimental habitat building flow in Glen and Grand Canyons, spring 1996: Report submitted to the Bureau of Reclamation (Grand Canyon Monitoring and Research Center), Flagstaff, Ariz., December 1996.

Bauer, B.O., Davidson-Arnott, R.G.D., Nordstrom, K.F, Ollerhead, J., and Jackson, N.L., 1996, Indeterminacy in aeolian sediment transport across beaches: Journal of Coastal Research, v. 12, p. 641-653.

Beaglehole, E., 1936, Hopi hunting and hunting ritual: New Haven, Conn., Yale University Press, Yale University Publications in Anthropology No. 4.

Belknap, J., 2001, Biological soil crusts and wind erosion, in Biological soil crusts - structure, function, and management: New York, Springer-Verlag, p. 339-347.

Benito, G., Sánchez-Moya, Y., and Sopeña, A., 2003, Sedimentology of high-stage flood deposits of the Tagus River, central Spain: Sedimentary Geology, v. 157, p. 107132.

Beus, S.S., Carothers, S.W., and Avery, C.C., 1985, Topographic changes in fluvial terrace deposits used as campsite beaches along the Colorado River in Grand Canyon: Journal of the Arizona-Nevada Academy of Science, v. 20, p. 111-120.

Boudreau, B.P., 1994, Is burial velocity a master parameter for bioturbation?: Geochimica et Cosmochimica Acta, v. 58, p. 1243-1249.

Boyd, R.T., ed., 1999, Indians, fire, and the land. Corvallis, Oreg.: Oregon State University Press.

Bressolier, C. and Thomas, Y.-F., 1977, Studies on wind and plant interactions on French Atlantic coastal dunes: Journal of Sedimentary Petrology, v. 47, p. 331-338.

Buckley, R., 1987, The effect of sparse vegetation on the transport of dune sand by wind: Nature v. 325, p. 426-428.

Budhu, M., and Gobin, R., 1994, Instability of sandbars in Grand Canyon: Journal of Hydraulic Engineering, v. 120, p. 918-933.

Bureau of Reclamation, 1995, Operation of Glen Canyon Dam - final environmental impact statement: U.S. Department of the Interior, Bureau of Reclamation, Upper Colorado Region, Salt Lake City, Utah, 337 pages plus appendices. 
Carothers, S.W., and Brown, B.T., 1991, The Colorado River through Grand Canyon: Tucson, Ariz., University of Arizona Press, 235 pages.

Coder, C.M., 1994, Historical archaeology, in Fairley, H.C., Bungart, P.W., Coder, C.M., Huffman, J., Samples, T.L., and Balsom, J.R., The Grand Canyon river corridor survey project, archaeological survey along the Colorado River between Glen Canyon Dam and Separation Canyon: Cooperative Agreement No. 9AA-40-07920, Grand Canyon National Park, Prepared in cooperation with the Bureau of Reclamation, Glen Canyon Environmental Studies, Flagstaff Ariz., p. 113-146.

Coder, C.M., Leap, L.M., Andrews, N.B., Kline, D., and Hubbard, D.C., 1994a, Summary Report for 1992-GCES monitoring of archaeological sites from Lees Ferry to Separation Canyon, Grand Canyon National Park: Report prepared by Grand Canyon National Park and Northern Arizona University, Submitted to the Bureau of Reclamation, Upper Colorado Region, Salt Lake City, Utah. Grand Canyon National Park, River Corridor Monitoring Project, Report \#6.

Coder, C.M., Leap, L.M., Andrews, N.B., and Hubbard, D.C., 1994b, 1993 Summary report-monitoring of archaeological sites along the Colorado River Corridor in Grand Canyon National Park: Report prepared by Grand Canyon National Park and Northern Arizona University, submitted to the Bureau of Reclamation, Upper Colorado Region, Salt Lake City, Utah, Grand Canyon National Park, River Corridor Monitoring Project, Report \#12.

Coder, C.M., Leap, L.M., Andrews, N.B., and Hubbard, D.C., 1995, 1994 Summary report — monitoring of archaeological sites along the Colorado River corridor in Grand Canyon National Park: Report prepared by Grand Canyon National Park and Northern Arizona University, submitted to the Bureau of Reclamation, Upper Colorado Region, Salt Lake City, Utah, Grand Canyon National Park, River Corridor Monitoring Project, Report \#18.

Dierker, J.L., Leap, L.M., and Andrews, N.B., 2001, 2001 archaeological site monitoring and management activities along the Colorado River in Grand Canyon National Park: Report prepared by Grand Canyon National Park and Northern Arizona University, submitted to the Bureau of Reclamation, Upper Colorado Region, Salt Lake City, Utah, Grand Canyon National Park, River Corridor Monitoring Project, Report \#75.

Dierker, J.L., Leap, L.M., and Andrews, N.B., 2002, 2002 archaeological site monitoring and management activities along the Colorado River in Grand Canyon National Park: Report prepared by Grand Canyon National Park and Northern Arizona University, submitted to the Bureau of Reclamation, Upper Colorado Region, Salt Lake City, Utah, Grand Canyon National Park, River Corridor Monitoring Project, Report \#87.

Dolan, R., Hayden, B., Howard, A., and Johnson, R., 1977, Environmental management of the Colorado River within the Grand Canyon: Environmental Management, v. 1, p. 391-400.
Dott, R.H. Jr., and Bourgeous, J., 1982, Hummocky stratification - significance of its variable bedding sequences: Geological Society of America Bulletin, v. 93, p. 663-680.

Douglas, M.E. and Marsh, P.C., 1996, Population estimates/ population movements of Gila cypha, an endangered cyprinid fish in the Grand Canyon region of Arizona: Copeia, v. 1, p. 15-28.

Drucker, P., 1941, Culture element distributions, XVII, YumanPiman: University of California Anthropological Records, Vol. 6.

Fairley, H.C., 2003, Changing river; time, culture, and the transformation of landscape in the Grand Canyon-a regional research design for the study of cultural resources along the Colorado River in lower Glen Canyon and Grand Canyon National Park, Arizona: Statistical Research, Inc., prepared for the U.S. Geological Survey, Grand Canyon Monitoring and Research Center, Flagstaff, Ariz., Technical Series 79, 179 pages.

Fairley, H.C., Bungart, P.W., Coder, C.M., Huffman, J., Samples, T.L., and Balsom, J.R., 1994. The Grand Canyon river corridor survey project; archaeological survey along the Colorado River between Glen Canyon Dam and Separation Canyon: Cooperative agreement No. 9AA-40-07920, Grand Canyon National Park, prepared in cooperation with the Bureau of Reclamation, Glen Canyon Environmental Studies, Flagstaff, Ariz., 276 pages.

Gellis, A., 1994, Trip report on erosion at selected archaeological sites, Grand Canyon National Park, Arizona: U.S. Geological Survey, New Mexico District Office, December 1994.

Gillette, D.A., and Stockton, P.H., 1989, The effect of nonerodible particles on wind erosion of erodible surfaces: Journal of Geophysical Research, v. 94, D10, p. 1288512893.

Goossens, D., 2004, Effect of soil crusting on the emission and transport of wind-eroded sediment; field measurements on loamy sandy soil: Geomorphology, v. 58, p. 145-160.

Grams, P.E., and Schmidt, J.C., 1999, Integration of photographic and topographic data to develop temporally and spatially rich records of sand bar change in the Point Hansbrough and Little Colorado River confluence study reaches: Report submitted to Grand Canyon Monitoring and Research Center, Flagstaff, Ariz., 84 pages.

Harms, J.C., Southard, J.B., Spearing, D.R., and Walker, R.G., 1975, Depositional environments as interpreted from primary sedimentary structures and stratification sequences: Society of Economic Paleontologists and Mineralogists Short Course No. 2, 161 pages.

Hazel, J.E. Jr., Kaplinski, M., Parnell, R., Manone, M., and Dale, A., 1999, Topographic and bathymetric changes at thirty-three long-term study sites, in Webb, R.H., Schmidt, J.C., Marzolf, G.R., and Valdez, R.A., eds., The controlled flood in Grand Canyon: Washington, D. C., American Geophysical Union: Geophysical Monograph 110, p. 161183.

Hazel, J.E., Kaplinski, M., Manone, M., and Parnell, R., 2000, 
Monitoring arroyo erosion of pre-dam river terraces in the Colorado River ecosystem, 1996-1999, Grand Canyon National Park, Arizona: Northern Arizona University, Department of Geology, Draft final report to the Grand Canyon Monitoring and Research Center, cooperative agreement CA 1425-98-FC-40-22630, 29 pages.

Hereford, R., 1993, Map showing surficial geology and geomorphology of the Palisades Creek archaeological area, Grand Canyon National Park, Arizona: U.S. Geological Survey Open-File Report 93-553, scale 1:4,600.

Hereford, R., Fairley, H.C., Thompson, K.S., and Balsom, J.R., 1993, Surficial geology, geomorphology, and erosion of archeological sites along the Colorado River, eastern Grand Canyon, Grand Canyon National Park, Arizona: U.S. Geological Survey Open-File Report 93-517.

Hereford, R., Thompson, K.S., Burke, K.J. and Fairley, H.C., 1996, Tributary debris fans and the late Holocene alluvial chronology of the Colorado River, eastern Grand Canyon, Arizona: Geological Society of America Bulletin, v. 108, p. 3-19.

Hereford, R., Burke, K.J., and Thompson, K.S., 2000, Quaternary geology and geomorphology of the Granite Park area, Grand Canyon, Arizona. US Geological Survey Geologic Investigations Series I-2662, scale 1:2,000.

Hunter, R.E., 1977a, Terminology of cross-stratified sedimentary layers and climbing ripple structure: Journal of Sedimentary Petrology, v. 47, p. 697-706.

Hunter, R.E., 1977b, Basic types of stratification in small eolian dunes: Sedimentology, v. 24, p. 361-387.

Huntoon, P.W., Billingsley, G.H., and Clark, M.D., 1981, Geologic map of the Hurricane Fault Zone and vicinity, western Grand Canyon, Arizona: Grand Canyon, Ariz., Grand Canyon Association, scale 1:48,000.

Huntoon, P.W., Billingsley, G.H., Sears, J.W., Ilg, B.R., Karlstrom, K.E., Williams, M.L., and Hawkins, D., 1996, Geologic map of the eastern part of the Grand Canyon National Park, Arizona: Grand Canyon, Ariz., Grand Canyon Association and the Museum of Northern Arizona, Flagstaff, Ariz., (fourth edition), scale 1:62,500.

Kaplinski, M., Hazel, J.E., Jr., and Beus, S.S., 1995, Monitoring the effects of interim flows from Glen Canyon Dam on sand bars in the Colorado River corridor, Grand Canyon National Park, Arizona: Final report to Glen Canyon Environmental Studies, Northern Arizona University, Flagstaff, Ariz., 62 pages.

Kearsley, L.H., Schmidt, J.C., and Warren, K.D., 1994, Effects of Glen Canyon Dam on Colorado River sand deposits used as campsites in Grand Canyon National Park, USA: Regulated Rivers, Research and Management, v. 9, p. 137149 .

Kelly, I.T., and Fowler, C.S., 1986, Southern Paiute, in d'Azevedo, W.L., ed., Handbook of North American Indians, Vol 11-Great Basin: Washington, D.C., Smithsonian Institution, p. 368-397.

Kochel, R.C., and Baker, V.R., 1982, Paleoflood hydrology: Science, v. 215, p. 353-361.
Leap, L.M., 1995, Testing results from C:13:273 and C:13:339 to recommend clearance for Beamer trail maintenance in the Colorado River corridor, Grand Canyon National Park: River Corridor Monitoring Project, Report \#23 (copies available from Grand Canyon National Park).

Leap, L.M., and Coder, C.M., 1995, Erosion control project at Palisades delta along the Colorado River corridor, Grand Canyon National Park: River Corridor Monitoring Project Report prepared for the Bureau of Reclamation, Salt Lake City, Utah, Grand Canyon National Park, River Corridor Monitoring Project, Report \#29.

Leap, L.M., and Kunde, J.L., 2000, 2000 summary report; archaeological site monitoring and management along the Colorado River corridor in Grand Canyon National Park: Report prepared by Grand Canyon National Park and Northern Arizona University, submitted to the Bureau of Reclamation, Upper Colorado Region, Salt Lake City, Utah, Grand Canyon National Park, River Corridor Monitoring Project, Report \#73.

Leap, L.M., Andrews, N.B., and Kunde, J.L., 1996, 1996 summary report; monitoring of archaeological sites along the Colorado River corridor in Grand Canyon National Park: Report prepared by Grand Canyon National Park and Northern Arizona University. Submitted to the Bureau of Reclamation, Upper Colorado Region, Salt Lake City, Utah, Grand Canyon National Park, River Corridor Monitoring Project, Report \#37.

Leap, L.M., Andrews, N.B., Hubbard, D.C., and Kunde, J.L., 1997, 1997 summary report; archaeological site monitoring and management along the Colorado River corridor in Grand Canyon National Park: Report prepared by Grand Canyon National Park and Northern Arizona University, submitted to the Bureau of Reclamation, Upper Colorado Region, Salt Lake City, Utah, Grand Canyon National Park, River Corridor Monitoring Project, Report \#50.

Leap, L.M., Burchett, T., Kunde, J.L., Andrews, N.B., and Hubbard, D.C., 1998., 1998 summary report; archaeological site monitoring and management along the Colorado River corridor below Glen Canyon Dam: Report prepared by Grand Canyon National Park and Northern Arizona University, submitted to the Bureau of Reclamation, Upper Colorado Region, Salt Lake City, Utah, Grand Canyon National Park, River Corridor Monitoring Project, Report \#57.

Leap, L.M., Kunde, J.L., Hubbard, D.C., Andrews, N.B., Downum, C.E., Miller, A.R., and Balsom, J., 2000, Grand Canyon Monitoring Project 1992-1999; synthesis and annual report FY99: Report prepared by Grand Canyon National Park and Northern Arizona University, submitted to the Bureau of Reclamation, Upper Colorado Region, Salt Lake City, Utah, Grand Canyon National Park, River Corridor Monitoring Project, Report \#66.

Leap, L.M., Dierker, J.L. and Andrews, N.B., 2003, Fiscal year 2003 archaeological site monitoring and management activities along the Colorado River in Grand Canyon National Park: Report prepared by Grand Canyon National Park and Northern Arizona University, submitted to the Bureau of 
Reclamation, Upper Colorado Region, Salt Lake City, Utah, Grand Canyon National Park, River Corridor Monitoring Project, Report \#89.

Leys, J.F., and Eldridge, D.J., 1998, Influence of cryptogamic crust disturbance to wind erosion on sand and loam rangeland soils: Earth Surface Processes and Landforms, v. 23, p. 963-974.

Machette, M.A., and Rosholt, J.N., 1989, Quaternary terraces in Marble Canyon and eastern Grand Canyon, Arizona, in Elston, D.P., Billingsley, G.H. and Young, R.A., Geology of Grand Canyon, Northern Arizona (with Colorado River guides): Washington, D.C., American Geophysical Union, Field trip guidebook T115/315.

Matthews, R.J., 1997, Results of macrobotanical analysis for five sites in the Grand Canyon: San Juan College, Cultural Resources Management Program, submitted to Grand Canyon National Park, River Corridor Monitoring Project, Report \#80.

McKee, E.D., 1938, Original structures in Colorado River flood deposits of Grand Canyon: Journal of Sedimentary Petrology, v. 8, p. 77-83.

McKee, E.D., 1979, Sedimentary structures in dunes, in McKee, E.D., ed., A study of global sand seas: U.S. Geological Survey Professional Paper 1052, p. 83-134.

McKenna Neuman, C., and Nickling, W.G., 1989, A theoretical and wind-tunnel investigation of the effect of capillary water on the entrainment of sediment by wind: Canadian Journal of Soil Science, v. 69, p. 79-96.

Namikas, S.L., and Sherman, D.J., 1995, A review of the effects of surface moisture content on aeolian sand transport, in Tchakerian, V., ed., Desert aeolian processes: London, Chapman and Hall, p. 269-293.

National Park Service, 2004, U.S. Department of the Interior, National Park Service, Intermountain Antiquities computer system archaeological site database, Grand Canyon National Park.

Neal, L.A., Gilpin, D., Jonas, L., and Ballagh, J.H., 2000, Cultural resources data synthesis within the Colorado River corridor, Grand Canyon National Park and Glen Canyon National Recreation Area, Arizona: SWCA, Inc. Cultural Resources Report 98-85 submitted to Grand Canyon Monitoring and Research Center.

Noble, L.F., 1914, The Shinumo quadrangle, Grand Canyon district, Arizona: U.S. Geological Survey Bulletin 549, 100 pages.

O'Connor, J.E., Ely, L.L., Wohl, E.E., Stevens, L.E., Melis, T.M., Kale, V.S., and Baker, V.R., 1994, A 4500-year record of large floods on the Colorado River in the Grand Canyon, Arizona: Journal of Geology, v. 102, p. 1-9.

Olson, J.S., 1958, Lake Michigan dune development 1; windvelocity profiles: Journal of Geology, v. 66, p. 254-263.

Pederson, J.L., Peterson, P.A., Macfarlane, W.W., Gonzales, M.F., and Kohl, K., 2003, Mitigation, monitoring, and geomorphology related to gully erosion of cultural sites in Grand Canyon: Logan, Utah, Utah State University, Department of Geology, Report to Grand Canyon Monitoring and Research Center, November 2003, 243 pages.

Pederson, J.L., Anders, M., and Rittenour, T., 2004, Linkages and lag times between the desert hillslopes and streams of Grand Canyon during responses to glacial-interglacial climate changes: Geological Society of America Abstracts with Programs 36 (5), Abstract 164-4.

Powell, J.W., 1878, Report on the lands of the arid region of the United States, with a more detailed account of the lands of Utah: Washington, D.C., U.S. Government Printing Office, reprinted in 1962 (Wallace Stegner, ed.) by The Belknap Press of Harvard University, Cambridge, Mass.

Rubin, D.M., 1987, Cross-bedding, bedforms, and paleocurrents: Society of Economic Paleontologists and Mineralogists, Concepts in sedimentology and paleontology, v. 1, 187 pages.

Rubin, D.M., and Hunter, R.E., 1982, Bedform climbing in theory and nature: Sedimentology, v. 29, p. 121-138.

Rubin, D.M., and Hunter, R.E., 1987, Field guide to sedimentary structures in the Navajo and Entrada Sandstones in southern Utah and northern Arizona: Arizona Bureau of Geology and Mineral Technology, Special Paper 5, 126-139.

Rubin, D.M., and McDonald, R.R., 1995, Nonperiodic eddy pulsations: Water Resources Research, v. 31, p. 1595-1605.

Rubin, D.M. and Topping, D.J., 2001, Quantifying the relative importance of flow regulation and grain size regulation of suspended sediment transport a and tracking changes in grain size of bed sediment b: Water Resources Research, v. 37, p. 133-146.

Rubin, D.M., Schmidt, J.C., and Moore, J.N., 1990, Origin, structure, and evolution of a reattachment bar, Colorado River, Grand Canyon, Arizona: Journal of Sedimentary Petrology, v. 60, p. 982-991.

Rubin, D.M., Schmidt, J.C., Anima, R.A., Brown, K.M., Hunter, R.E., Ikeda, H., Jaffe, B.E., McDonald, R.R., Nelson, J.M., Reiss, T.E., Sanders, R., and Stanley, R.G., 1994, Internal structure of bars in Grand Canyon, Arizona and evaluation of proposed flow alternatives for Glen Canyon Dam: U.S. Geological Survey Open-File Report 94-594, 34 pages.

Rubin, D.M., Nelson, J.M., and Topping, D.J., 1998, Relation of inversely graded deposits to suspended-sediment grainsize evolution during the 1996 flood experiment in Grand Canyon: Geology, v. 26, p. 99-102.

Rubin, D.M., Topping, D.J., Schmidt, J.C., Hazel, J., Kaplinski, M., and Melis, T.S., 2002, Recent sediment studies refute Glen Canyon Dam hypothesis: EOS, Transactions of the American Geophysical Union, v. 83, p. 277-278.

Sarre, R.D., 1988, Evaluation of aeolian sand transport equations using intertidal zone measurements, Saunton Sands, England: Sedimentology, v. 35, p. 671-679.

Sarre, R.D., 1989, Aeolian sand drift from the intertidal zone on a temperate beach; potential and actual rates: Earth Surface Processes and Landforms, v. 14, p. 247-258.

Schmidt, J.C., 1990, Recirculating flow and sedimentation in the Colorado River in Grand Canyon, Arizona: Journal of Geology, v. 98, p. 709-724.

Schmidt, J.C., and Graf, J.B., 1987, Aggradation and 
degradation of alluvial sand deposits, 1965 to 1986, Colorado River, Grand Canyon National Park, Arizona: U.S. Geological Survey Open-File Report 87-555, 120 pages.

Schmidt, J.C., and Leschin, M.F., 1995, Geomorphology of post-Glen Canyon Dam fine-grained alluvial deposits of the Colorado River in the Point Hansbrough and Little Colorado River confluence study reaches in Grand Canyon National Park, Arizona: Report prepared for the U.S. Bureau of Reclamation, Glen Canyon Environmental Studies, 47 pages. Schmidt, J.C., Topping, D.J., Grams, P.E., and Hazel, J.E., 2004, System-wide changes in the distribution of fine sediment in the Colorado River corridor between Glen Canyon Dam and Bright Angel Creek, Arizona: Final report submitted to Grand Canyon Monitoring and Research Center by the Department of Aquatic, Watershed, and Earth Resources, Utah State University, 107 pages.

Smith, S.J., 1997, Pollen analysis for four sites in Grand Canyon National Park, Arizona: Northern Arizona University, Laboratory of Paleoecology, submitted to Grand Canyon National Park, River Corridor Monitoring Project, Report \#77.

Stevenson, G.M., and Beus, S.S., 1982, Stratigraphy and depositional setting of the upper Precambrian Dox Formation in Grand Canyon: Geological Society of America Bulletin, v. 93, p. 163-173.

Stokes, W.L., 1968, Multiple parallel-truncation bedding planes: a feature of wind-deposited sandstone formations: Journal of Sedimentary Petrology, v. 38, p. 510-515.

Thompson, K.S., and Potochnik, A.R., 2000, Development of a geomorphic model to predict erosion of pre-dam Colorado River terraces containing archaeological resources: SWCA, Inc. Cultural Resources Report 99-257, submitted to the Grand Canyon Monitoring and Research Center.

Topping, D.J., Rubin, D.M., and Vierra, L.E. Jr., 2000a, Colorado River sediment transport 1. Natural sediment supply limitation and the influence of Glen Canyon Dam: Water Resources Research, v. 36, p. 515-542.

Topping, D.J., Rubin, D.M., Nelson, J.M., Kinzel III, P.J., and Corson, I.C., 2000b, Colorado River sediment transport 2. Systematic bed-elevation and grain-size effects of sand supply limitation: Water Resources Research, v. 36, p. 543570.

Topping, D.J., Schmidt, J.C., and Vierra, L.E. Jr., 2003, Computation and analysis of the instantaneous-discharge record for the Colorado River at Lees Ferry, Arizona-May 8, 1921 through September 30, 2000: U.S. Geological Survey Professional Paper 1677, 118 pages.

Turner, R.M., and Karpiscak, M.M., 1980, Recent vegetation changes along the Colorado River between Glen Canyon Dam and Lake Mead, Arizona: U.S. Geological Survey Professional Paper 1132, 125 pages.
Valdez, R.A., and Ryel, R.J., 1995, Life history and ecology of the humpback chub (Gila cypha) in the Colorado River in Grand Canyon, Arizona: Bio/West Inc., Report No. TR-25008 , submitted to the Bureau of Reclamation, contribution number 0-CS-40-09110.

Walker, R.G., 1963, Distinctive types of ripple-drift crosslamination: Sedimentology, v. 2, p. 173-188.

Wasson, R.J., and Nanninga, P.M., 1986, Estimating wind transport of sand on vegetated surfaces: Earth Surface Processes and Landforms, v. 11, p. 505-514.

Webb, R.H., Wegner, D.L., Andrews, E.D., Valdez, R.A., and Patten, D.T., 1999, Downstream effects of Glen Canyon Dam on the Colorado River in Grand Canyon-a review, in Webb, R.H., Schmidt, J.C., Marzolf, G.R., and Valdez, R.A., eds., The controlled flood in Grand Canyon: Washington, D.C., American Geophysical Union, Geophysical Monograph 110, p. 1-21.

Wheatcroft, R.A., 1990, Preservation potential of sedimentary event layers: Geology, v. 18, p. 843-845.

Wiele, S.M., and Franseen, M., 1999, Modeling of mainstem flow and sediment dynamics at selected cultural resource locations: Report to the Grand Canyon Monitoring and Research Center, Flagstaff, Ariz., 24 pages.

Wiele, S.M., and Franseen, M.A., 2001, Sand transport and bed evolution modeling applications in the Colorado River, Grand Canyon: in Glysson, G.D., ed., Proceedings of the Seventh Federal Interagency Sedimentation Conference, March 2529, 2001, Reno, Nevada, p. 115-119.

Wiele, S.M., Graf, J.B., and Smith, J.D., 1996, Sand deposition in the Colorado River in the Grand Canyon from flooding of the Little Colorado River: Water Resources Research, v. 32, p. 3579-3596.

Wiggs, G.F.S., Baird, A.J., and Atherton, R.J., 2004, The dynamic effects of moisture on the entrainment and transport of sand by wind: Geomorphology, v. 59, p. 13-30.

Yeatts, M., 1996, High elevation sand deposition and retention from the 1996 spike flow-an assessment for cultural resources stabilization, in Balsom, J.R., and Larralde, S. eds., Mitigation and monitoring of cultural resources in response to the experimental habitat building flow in Glen and Grand Canyons, Spring 1996: Report submitted to the Bureau of Reclamation (Grand Canyon Monitoring and Research Center), Flagstaff, Ariz., December 1996, p. 124-158.

Yeatts, M., 1997, High elevation sand retention following the 1996 spike flow: Report to the Grand Canyon Monitoring and Research Center, Flagstaff, Ariz., 15 pages.

Yeatts, M., 1998, 1997 data recovery at five sites in the Grand Canyon-Final report: Report submitted to Grand Canyon National Park, River Corridor Monitoring Project, Report \#60. 


\section{Appendix 1: Descriptions of Stratigraphic Sections and Geomorphology at Archaeological Site Locations, Palisades Area}

\section{Stratigraphic Sections}

\section{Palisades, Section 1}

Stratigraphic heights in this exposure were originally measured in $\mathrm{cm}$ above a datum at the west end of the outcrop (on the arroyo floor). They have been converted here to $\mathrm{cm}$ below the ground surface, with the original measurements from R. E. Hunter's notes listed in parentheses. A stratigraphic diagram for section 1 is shown in figure 32 .

0 - $6 \mathrm{~cm}(116-124 \mathrm{~cm})$, Unit A: Ground surface sediment.

$6-14 \mathrm{~cm}(110-120 \mathrm{~cm})$, Unit B: This unit consists of poorly exposed sandy silt, sloping toward the arroyo.

$14-25 \mathrm{~cm}(99-110 \mathrm{~cm})$, Unit C: This very fine silty sand unit contains silt laminae.

$25-29 \mathrm{~cm}(95-99 \mathrm{~cm})$, Unit D: Unit D is a reddish silt.

$29-40 \mathrm{~cm}(85-95 \mathrm{~cm})$, Unit E: This horizon is a very fine silty sand with fluvial ripple bedding.

$40-53 \mathrm{~cm}(71-84 \mathrm{~cm})$, Unit F: Planar lamination in this fine sand indicates probable aeolian deposition. One sample was collected from this layer for grain size analysis: $\mathrm{Pal}$ Strat 1, Unit F.

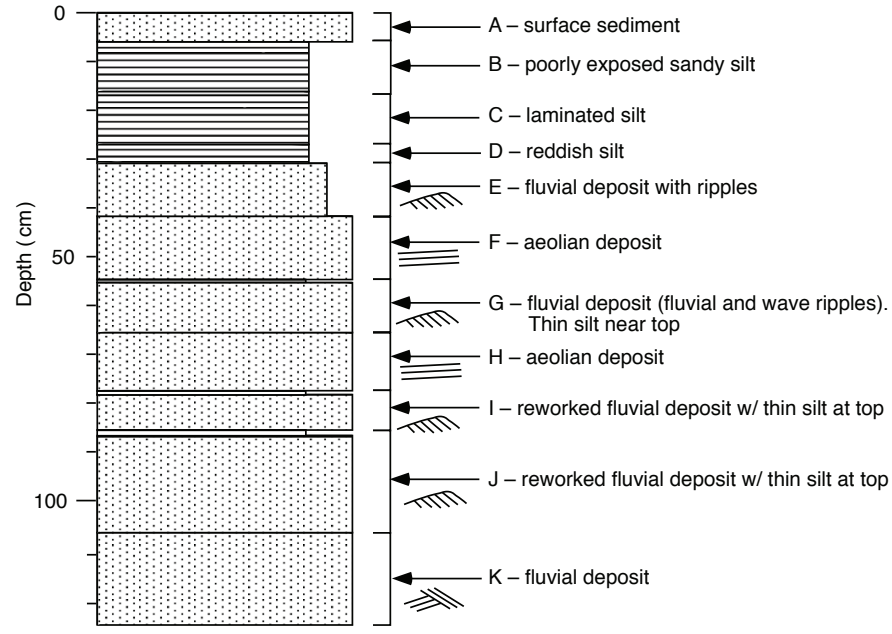

Figure 32. Stratigraphic diagram for section 1 at Palisades.
$53-64 \mathrm{~cm}(60-71 \mathrm{~cm})$, Unit G: This unit consists of very fine to medium sand, with fluvial ripple bedding apparent. Eddy pulsation ripples (Rubin and McDonald, 1995) occur at $54 \mathrm{~cm}$ below the ground surface $(70 \mathrm{~cm}$ original recorded depth). At $56 \mathrm{~cm}$ below the surface $(68 \mathrm{~cm}$ originally recorded depth) a gray muddy silt occurs that is $3 \mathrm{~mm}$ thick. One sample was collected from unit $\mathrm{G}$ for grain size analysis: Pal Strat 1, Unit G.

$64-76 \mathrm{~cm}(48-60 \mathrm{~cm})$, Unit H: This horizon consists of fine sand with planar laminations and is interpreted as an aeolian deposit.

$76-84 \mathrm{~cm}(40-48 \mathrm{~cm})$, Unit I: This is a fine- to mediumgrained sand with occasional small pebbles and fluvial ripple bedding. The uppermost part of unit I contains a 1$\mathrm{cm}$-thick gray silt layer with ripple structures.

$84-105 \mathrm{~cm}(19-40 \mathrm{~cm})$, Unit J: Unit J is a very fine to medium sand, with occasional small pebbles and fluvial ripple structures. A 3-mm-thick reddish silt is present at the top of this horizon.

$105-124 \mathrm{~cm}(0-19 \mathrm{~cm})$, Unit K: This lowermost unit contains fine to medium sand with planar lamination and cross-lamination in sets as thick as $10 \mathrm{~cm}$. At the base of the section, the tops of scattered cobbles are exposed.

Section 1 summary.-This low-elevation exposure in the wall of the main arroyo trunk indicates multiple episodes of fluvial deposition and aeolian reworking of that sediment. Occasional pebbles incorporated into the upper parts of fluvial deposits are interpreted to reflect reworking processes at the land surface.

\section{Palisades, Section 2}

A stratigraphic diagram for section 2 is shown in figure 33 . Measurements are in $\mathrm{cm}$ below the ground surface.

0-9 cm (Unit A): This uppermost unit is an aeolian sand with soft, single-grain dry consistency, very friable when moist. Its lower contact is abrupt and smooth.

$9-13 \mathbf{~ c m}$ (Unit B): Unit B sediment is soft to slightly hard when dry, very friable when moist. Its lower boundary is abrupt and wavy. Fluvial climbing ripples are visible (see discussion of stage-discharge relationship for the Palisades area in main text). This unit consists of Colorado River flood sand.

$13-36 \mathrm{~cm}$ (Unit C): This unit is tan colored with a slightly reddish color in the lower $10 \mathrm{~cm}$. Soft, single-grain in the upper part when dry, slightly hard in lower portion when dry; unit $\mathrm{C}$ is friable throughout when moist. There are thin, indistinct bedding planes visible; these dip mainly in 
the onshore direction and slightly downstream. Unit $\mathrm{C}$ is interpreted as aeolian sand.

$\mathbf{3 6}-\mathbf{5 5} \mathbf{~ c m}$ (Unit D): Unit D is a reddish fine sand, with fluvial climbing ripples faintly visible. Sediment is hard to very hard when dry, friable when moist, and weakly cemented. Salt weathering is visible in the upper part of this horizon. Ripple migration direction has an offshore component; this is interpreted as a Colorado River fluvial deposit.

$55-58 \mathbf{~ c m}$ (Unit E): This is a very light colored fine sandy silt, deposited in water. Lenses of cross-laminated sand are present.

$58-70 \mathbf{~ c m}$ (Unit F): Unit $F$ is poorly sorted with granules and coarse sand in its lower part, grading to fine sand with silt interbeds in the upper part. This horizon is tan colored, and appears to be the product of local deposition (slope-wash deposit).

$70-81 \mathrm{~cm}$ (Unit G): This very poorly sorted, matrixsupported horizon contains dominantly fine sand but with clasts up to granule sizes; occasional small pebbles are present. Sediment is red and hard to very hard when dry, friable when moist. Sediment is locally derived; unit $\mathrm{G}$ may represent local distal debris-flow sedimentation. This

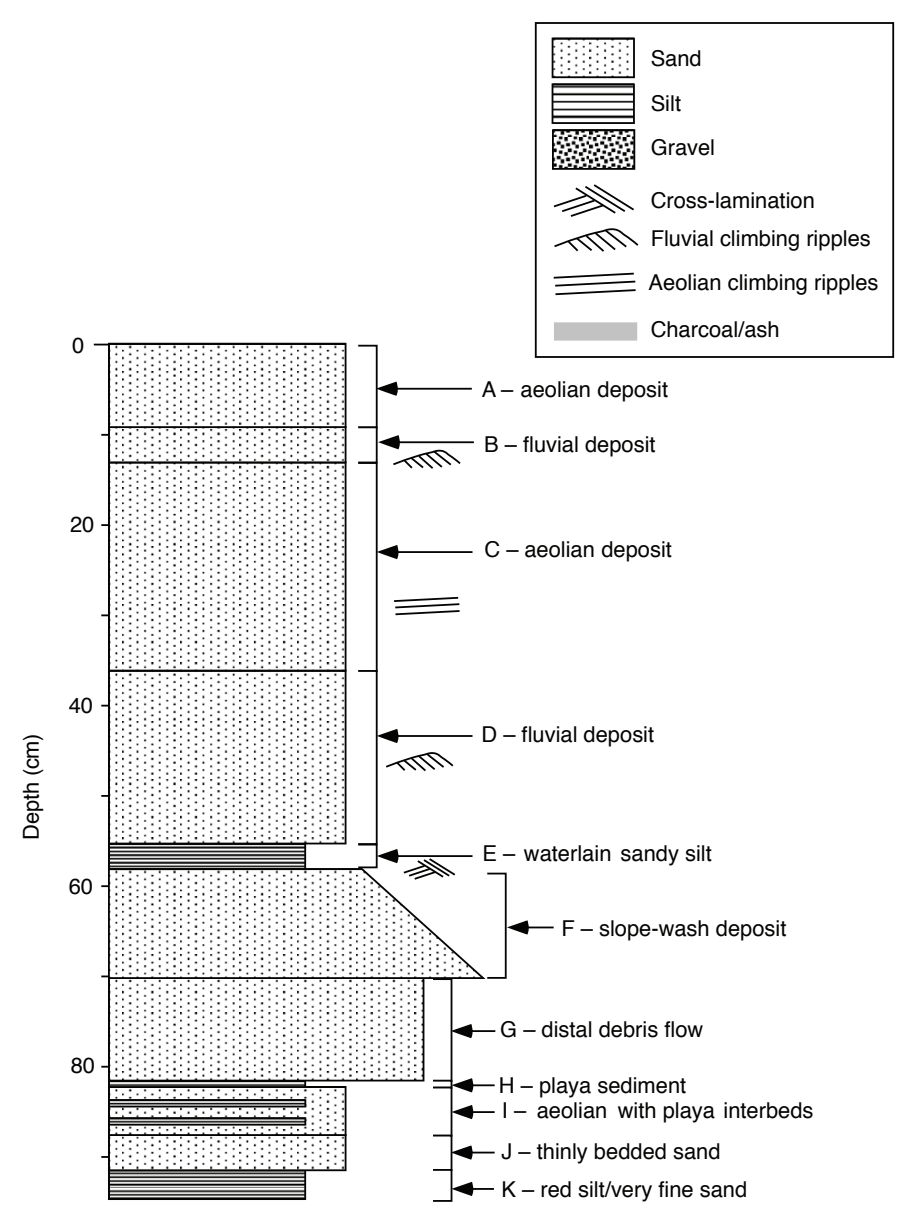

Figure 33. Stratigraphic diagram for section 2 at Palisades. unit may correspond to unit $\mathrm{F}$ of section 3 and unit $\mathrm{E}$ of section 4 .

$81-82$ cm (Unit H): This horizon consists of muddy silty clay deposits. A 1-cm-thick lens of paper-thin laminae is present. Unit $\mathrm{H}$ was interpreted in the field as playa sediment.

$82-87$ cm (Unit I): This is a very fine sand, horizontally bedded with red silty clay interbeds. Unit I is interpreted as aeolian deposition with episodic brief playa inundation.

$87-91$ cm (Unit J): Unit J is a fine sand, thinly bedded and lenticular.

91 -94+ cm (Unit K, to base of section): This is a reddishcolored very fine sand and silt, with no sedimentary structures visible.

Section 2 summary.-This stratigraphic section consists of aeolian, fluvial, possible playa, locally derived slope-wash and distal debris-fan deposits. Aeolian sediment makes up the greatest thickness within this section ( $\sim 39$ percent), with fluvial and slope-wash/distal debris-fan sediment contributing $\sim 28$ percent and $\sim 25$ percent respectively. Multiple episodes of aeolian deposition followed by deposition of locally-derived sediment are evident from interbedding of those deposits (for example, units $\mathrm{H}$ and I). Aeolian deposition (with subsequent deflation and arroyo cutting) has been active most recently at this location. The most likely source for aeolian sediment at this location is reworked fluvial sediment. Two flood deposits are preserved in this section (units B and D), with a third waterlain deposit (unit E) possibly also representing a Colorado River flood.

\section{Palisades, Section 3}

A stratigraphic diagram for section 3 is shown in figure 34 . Measurements are in $\mathrm{cm}$ below the ground surface.

0 - 30 cm (Unit A): This is a clean, fine to medium sand with well defined thin bedding, an aeolian deposit. There are several very thin, irregular red silt beds that may represent playa-wetting events. The lower contact is very irregular; disruption of the contact may be related to formation of salt crust.

$30-39$ cm (Unit B): Unit B is a fine to medium sand of uncertain depositional origin, alternating with thin silty clay beds. These may be locally reworked fluvial sands, interrupted by what appears to be occasional playa inundation. The upper contact of unit B is very irregular. Occasional vertical, silty-clay-filled desiccation structures originate from the upper contact.

39 - 46 cm (Unit C): This horizon consists primarily of fine sand, with occasional clay laminae that are thought to represent playa wetting. Occasional vertical, silty clay-filled desiccation structures originate from the upper contact of unit $\mathrm{C}$.

$46-73 \mathrm{~cm}$ (Unit D): Unit D is primarily a fine sand; its 
redness and clay content increase up-section. Very thin beds of silty clay are present at a depth of $54 \mathrm{~cm}$ that likely represent playa sedimentation. The lower contact of this unit is abrupt, erosional, and very prominent. Unit D is interpreted as an aeolian deposit.

$73-95 \mathrm{~cm}$ (Unit E): This is a cemented red sand that initially appears massive but, after drying, shows very faint bedding and cross lamination. A thin, white bed of silty fine sand occurs at approximately $85 \mathrm{~cm}$. This depositional unit is truncated in the landward direction. There is a charcoal concentration at approximately $76-77 \mathrm{~cm}$ that contains diffuse ash material (not a cultural hearth feature). The red color and the presence of charcoal indicate that this unit is most likely the result of locally derived sediment deposition (possibly a playa layer).

$95-108 \mathrm{~cm}$ (Unit F): The sediment in this horizon fines upward from coarse sand and gravel to a medium sand. Minor charcoal is present. This horizon is likely equivalent to unit $\mathrm{E}$ of section 4, which occurs at a comparable depth below the land surface at that site. This unit may also correlate with unit $\mathrm{G}$ of section 2 . Unit $\mathrm{F}$ is most probably a distal debris-flow deposit.

$108-124 \mathbf{~ c m}$ (Unit G): This is a fine sand interbedded with thin, red, silty sands. Desiccation fractures originate in

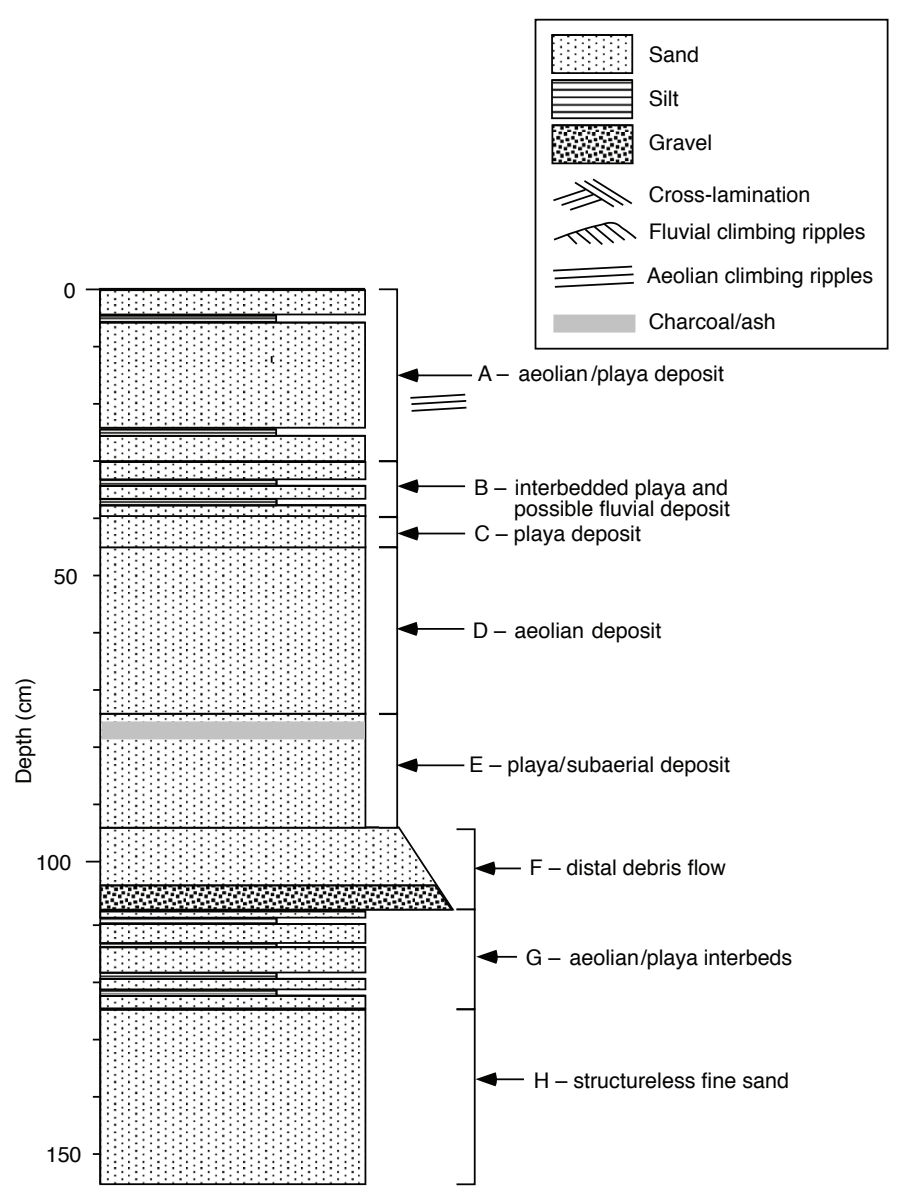

Figure 34. Stratigraphic diagram for section 3 at Palisades. at least five levels within this unit. Lenticular bodies of cross-laminae are present. Thicker sandy beds appear to be aeolian, with small rivulets crossing the playa area.

$124-156+\mathbf{c m}$ (Unit $\mathbf{H}$, to base of section): This is a fine sand, in which no sedimentary structures are evident. Its origin is uncertain. One sample was collected from this horizon: Pal Strat 3, Unit H (145 cm depth).

Section 3 summary. - This stratigraphic section is located farther from the river than any other section studied at Palisades. The stratigraphy in section 3 contains numerous deposits of locally derived sediment, in the form of multiple thin playa beds and coarser distal debris-flow deposits. Playa sedimentation is represented by a volumetrically minor part of this section but has occurred frequently, judging from the interbedding of playa units with aeolian and possible fluvial strata. There is no unambiguous evidence for interpreting a Colorado River flood deposit in this section on the basis of sedimentary structures; flood events may be represented here by thin sand beds (distal flood deposits) that interbed with the playa horizons (units $\mathrm{B}, \mathrm{C}, \mathrm{G}$, and possibly $\mathrm{H}$ ).

\section{Palisades, Section 4}

Units $\mathrm{A}, \mathrm{B}$, and the upper part of unit $\mathrm{C}$ in section 4 are shown in figure 35. A stratigraphic diagram for section 4 is shown in figure 36. Measurements are in $\mathrm{cm}$ below the ground surface.

0 - 35 cm (Unit A): Unit A contains two very red, mud-rich beds (clay loam) separated by clean, fine-grained sand. The uppermost 10-12 $\mathrm{cm}$ of unit A are vesicular. This uppermost horizon in this section consists of playa deposits.

$35-76 \mathbf{c m}$ (Unit B): Fluvial climbing ripples occur in the upper $7 \mathrm{~cm}$ of unit B (35-42 $\mathrm{cm}$ depth below the land surface). Between 37 and $39 \mathrm{~cm}$, the ripple migration direction is upstream, indicating flow in an eddy. At $67 \mathrm{~cm}$, the ripple migration direction is dominantly offshore, with a downstream component. This unit is a Colorado River alluvial deposit. Three sediment samples were collected from this unit: Pal Strat 4, Unit B \#1 (75 cm depth); Pal Strat 4, Unit B \#2 (67 cm depth); Pal Strat 4, Unit B \#3 (48 cm depth).

76 - 86 cm (Unit C): Unit C consists of dark brown muds, interpreted as possible nearshore deposition.

$86-92 \mathrm{~cm}$ (Unit D): This unit is a clean, light-colored fine sand; its depositional environment is ambiguous.

$92-107 \mathrm{~cm}$ (Unit E): Unit E is a bright red, poorly sorted horizon of clay to very coarse sand. This may correspond to red gravelly sand distal debris-flow deposits observed elsewhere (for example, unit $\mathrm{F}$ of section 3, and possibly also unit $\mathrm{G}$ of section 2). One sample was collected from unit E: Pal Strat 4, Unit E (99 cm depth).

$107-114+\mathbf{c m}$ (Unit F, to base of section): This basal unit 


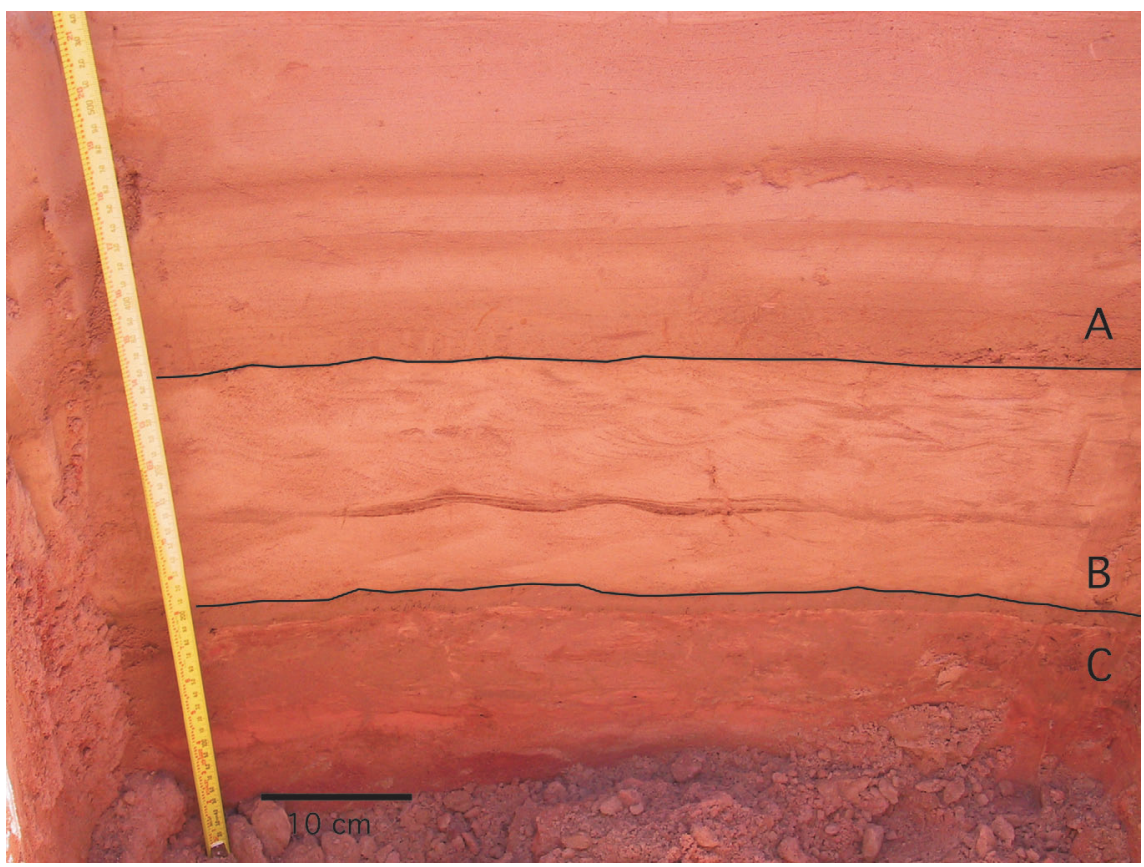

Figure 35. Photograph of part of section 4 measured at Palisades. Unit A represents multiple episodes of playa deposition. Unit B is a Colorado River flood deposit (note fluvial climbing ripples). Unit $\mathrm{C}$ contains dark brown muds that may represent nearshore deposition.

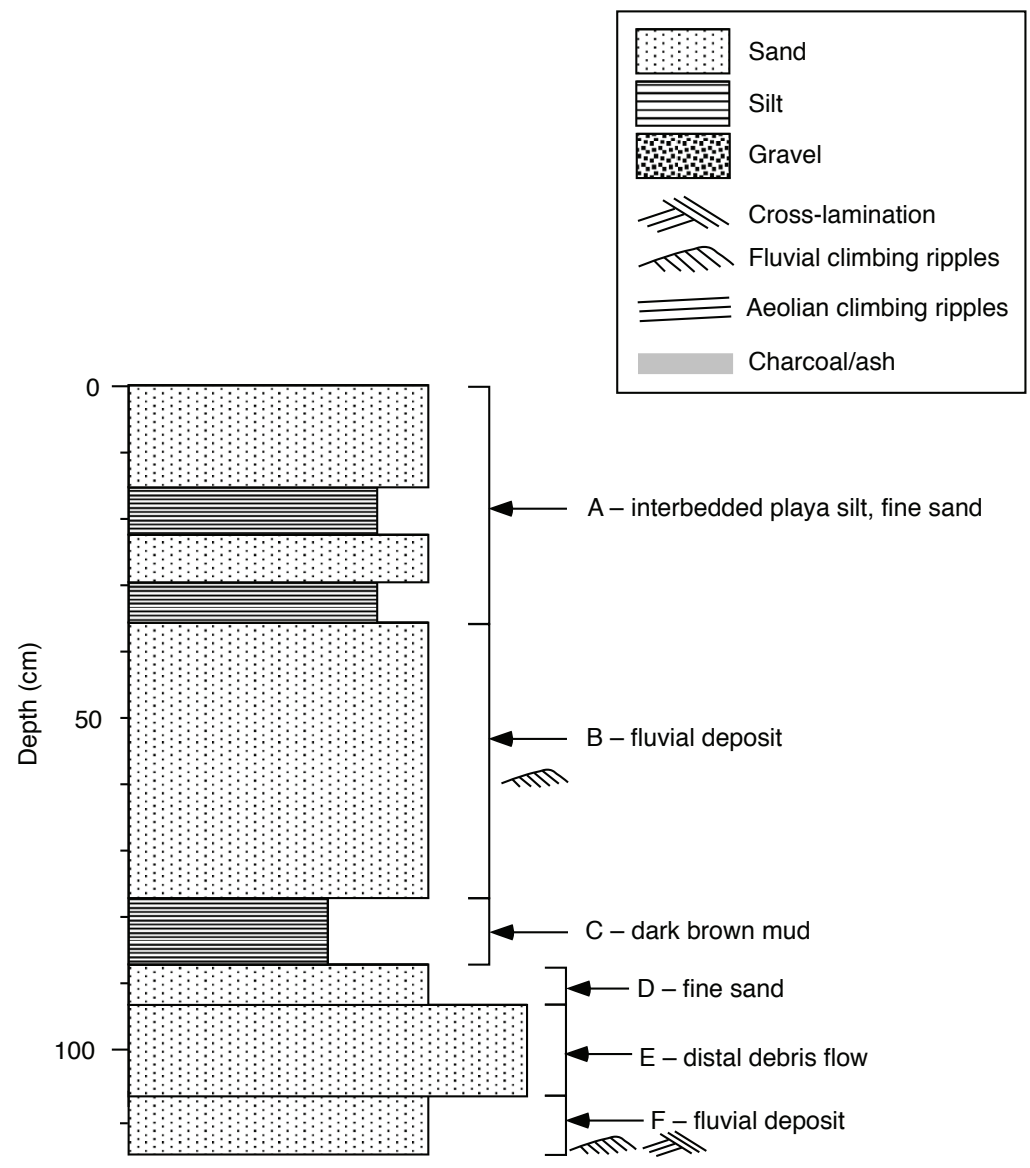

Figure 36. Stratigraphic diagram for section 4 at Palisades. 
is a very fine tan-colored sand or sandy silt. Horizontal laminations and cross-laminations are present, with fluvial climbing ripples. This is a Colorado River fluvial deposit. One sample was collected from this unit: Pal Strat 4, Unit F (114 cm depth).

Section 4 summary.-Section 4 contains two Colorado River flood deposits with well-defined fluvial climbing ripples (units B and F). Two additional floods may be present in this deposit (units $\mathrm{C}$ and $\mathrm{D}$ ); alternatively, units $\mathrm{C}$ and $\mathrm{D}$ may represent different phases of deposition during one flood event. Locally derived sediment also contributes significantly to this profile, with a distal debris-flow deposit (unit F) and a 35-cm-thick upper horizon (unit A) that represents multiple episodes of playa sedimentation.

\section{Palisades, Section 5}

Section 5 was a test pit $0.8 \mathrm{~m}$ deep, located on the edge of the playa area. A detailed stratigraphic log was not made for this pit. It was noted that the sediment in section 5 was very different in appearance from that of section 4 , approximately $70 \mathrm{~m}$ away. In contrast to the red-colored, playa-dominated sediment in the upper part of section 4 , section 5 contained poorly consolidated, pale beige-colored sediment. No sedimentary structures were visible. This deposit was interpreted as a remnant of a fluvial terrace that is now surrounded by playa deposits; Hereford (1993) mapped a sediment deposit $\sim 20 \mathrm{~m}$ from the section 5 location as a remnant of the 'ap' fluvial terrace.

\section{Stratigraphy and Geomorphology at Archaeo- logical Site Locations}

All archaeological sites discussed in this report are referred to by the site number assigned by NPS.

C:13:033-This site is constructed on debris-fan sediment originating from the unnamed tributary that debouches into the Colorado River on river left $400 \mathrm{~m}$ north of the Palisades Creek mouth. One small area of aeolian sand cover (maximum $10 \mathrm{~cm}$ thick, covering $\sim 2 \mathrm{~m} 2$ ) is present immediately north of the room structure, apparently in the lee of the northern wall of the structure. With the exception of this small patch of sand, the remainder of the area consists of gravel, cobbles, and boulders related to the leveed debris fan immediately upslope and to the north of the site. The site is not buried by debris-flow sediment and apparently postdates the most recent debris-flow deposition in its immediate vicinity.

\section{C:13:098-This is the historic-era site that contains the} Tanner-McCormick Mine and associated living structure and artifacts. A test pit was not attempted at this site. On the basis of field observations and aerial photographs, this site is within the boundary of the Palisades Creek debris fan. The area where this site lies was mapped by Hereford (1993) as within the geomorphic unit designated as 'dfi' (debris fan of intermediate age).

C:13:099- This is the lowest elevation archaeological site identified at Palisades. Clasts at the distal margin of the Palisades Creek debris fan (reddish gravel-rich colluvium) reach almost to the edge of this site. Immediately up-arroyo of feature 1 (next to NPS Cross-section \#3 across the arroyo) are very fine-scale fluvial ripples. The upper portion of this flood deposit has been modified by aeolian processes and now forms a small dune surface (figure 37) such that $\sim 5 \mathrm{~cm}$ of aeolian sediment overlies $\sim 6 \mathrm{~cm}$ of undisturbed fluvial deposit, which in turn overlies red-orange sediment interpreted as distal-debris-flow sediment. The fluvial sediment appears to be just overlying potsherds eroding out of the arroyo wall. The original depth of the archaeological material is difficult to determine. Feature 1 is built on Colorado River flood sediment and is buried by aeolian sediment (well-defined aeolian climbing-ripple structures are visible). Feature 3 (partly missing because of erosion) is located in a gravel unit that represents distal debris-flow sediment from Palisades Creek. Feature 5 is built on red gravelly slope-wash sediment directly, but has an apparently younger dune partly covering it (it is built on slopewash sediment but buried by aeolian sand, which is now undergoing deflation). Sediment that partly buries feature 5 is structureless medium-grained sand. It is likely that this site was reoccupied (and feature 5 constructed) after debrisflow sediment partly buried older occupation sites (such as feature 3). A driftwood line just below (riverward of) the

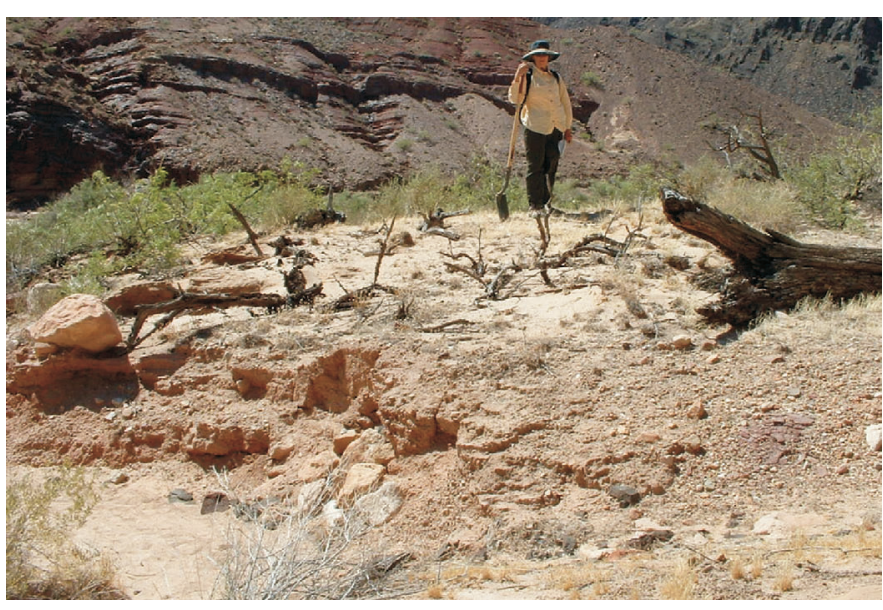

Figure 37. Juxtaposition of aeolian and fluvial sediment at archaeological site $\mathrm{C}: 13: 99$, Palisades. The arroyo wall exposed in the foreground has incised into several features of this site. A thin cover of light-colored aeolian sediment has buried artifacts at this location. The site was formed on top of fluvial sediment and distal colluvium from the Palisades Creek debris fan, both of which are exposed in the arroyo wall. 
site, adjacent to feature 5 , has an elevation consistent with that of the 1958 Colorado River flood (3,060 m3/s; 108,000 $\mathrm{ft} 3 / \mathrm{s})$. Summary: several features are partly buried by aeolian sediment, but were built on material that originated from Colorado River floods and distal colluvium from the nearby debris fan. The site is affected by arroyo incision (artifacts exposed in the northernmost branches of the main arroyo system).

C:13:100-This site occupies a partially deflated coppice dune area in the region mapped as 'ec' (eolian, coppice) by Hereford (1993) and is within the limit of the driftwood line believed to represent the 1921 Colorado River flood $(4,810 \mathrm{~m} 3 / \mathrm{s} ; 170,000 \mathrm{ft} 3 / \mathrm{s})$. No clear sedimentary structures were apparent in most of the sand/silt material that has filled in structures at this site, but in the northernmost structure, parallel-bedded sediment indicates likely aeolian deposition. Aeolian reworking of flood-derived sediment is likely. Feature 4 (vertical walls of sandstone from the Dox Formation outlining room blocks) is exposed in a shallow arm of the main arroyo network. A driftwood log directly above this wall, exposed in the gully that is being filled by migrating dune sand, is at the same elevation as the 1921 driftwood line surveyed during this work. Aeolian sediment is filling in the arroyo as a sand dune approximately $2 \mathrm{~m}$ high is actively migrating to the north (approximately up-canyon; figure 38). Feature 7 was identified eroding out of an incision into fluvial/aeolian sediment in the area mapped as 'lmt' by Hereford (1993) and is apparently both built on and buried by fluvial sediment that has undergone aeolian modification. C:13:101-This site is located on an apparent fluvial cobble

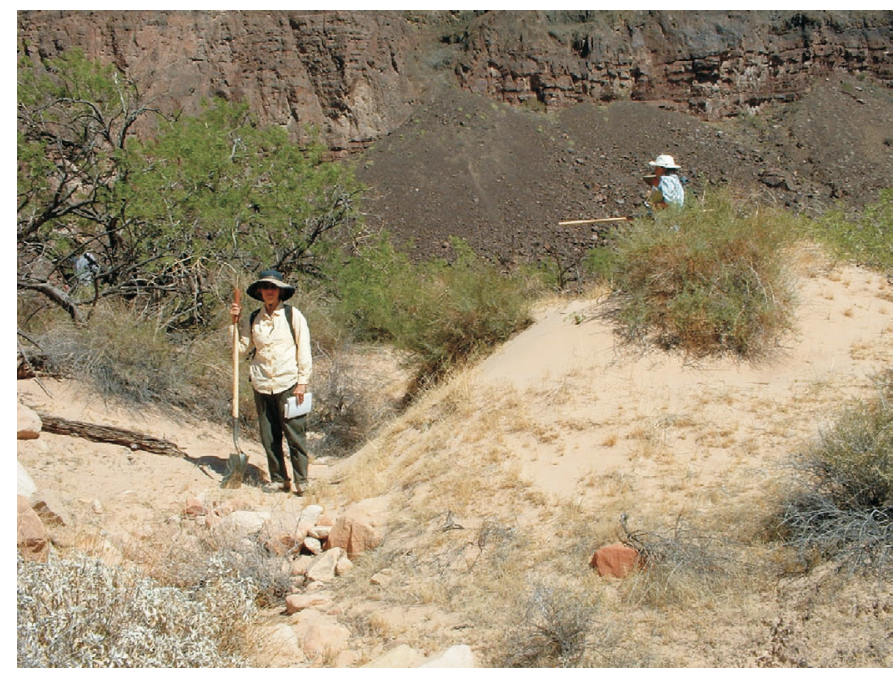

Figure 38. Sand dune migrating northward (upcanyon; toward the left in this east-facing photograph), filling a small gully at the location of archaeological site C:13:100, Palisades. A driftwood log (far left of photo), partially buried by aeolian sand on which vegetation has grown, lies at the same elevation as a driftwood line identified as the 1921 flood stage. bar just riverward of the former location of the Beamer Trail. Driftwood present at this site is at an elevation consistent with the 1957 Colorado River flood event $(3,540$ $\mathrm{m} 3 / \mathrm{s} ; 125,000 \mathrm{ft} 3 / \mathrm{s}$ ). Riverward of this site (and the old Beamer Trail) is a relatively flat area with thin sedimentary cover over the river cobbles that probably represents a flood surface. Immediately landward of this site and the old Beamer Trail are aeolian dunes that have apparently undergone deflation. Sedimentary structures in one dune that is adjacent to the former Beamer Trail indicate aeolian stratification dipping to the north. This dune sediment consists of well-sorted fine to medium sand, and the north-dipping aeolian climbing ripples indicate northward dune migration. New artifacts have been exposed as dune migration and deflation occur. The depositional environment of sediment on which the site was constructed cannot be confidently ascertained, although rounded fluvial cobbles appear to underlie many of the artifacts riverward of the old Beamer Trail. Artifacts are buried by little or no sediment; where overlying sediment is present, it occurs in the form of small coppice dunes.

\section{C:13:272 - Gravel, cobbles, and boulders related to the} Palisades Creek debris fan appear to underlie features at this site, though sand and silt form an extensive cover of variable thickness over these larger clasts (figure 39).

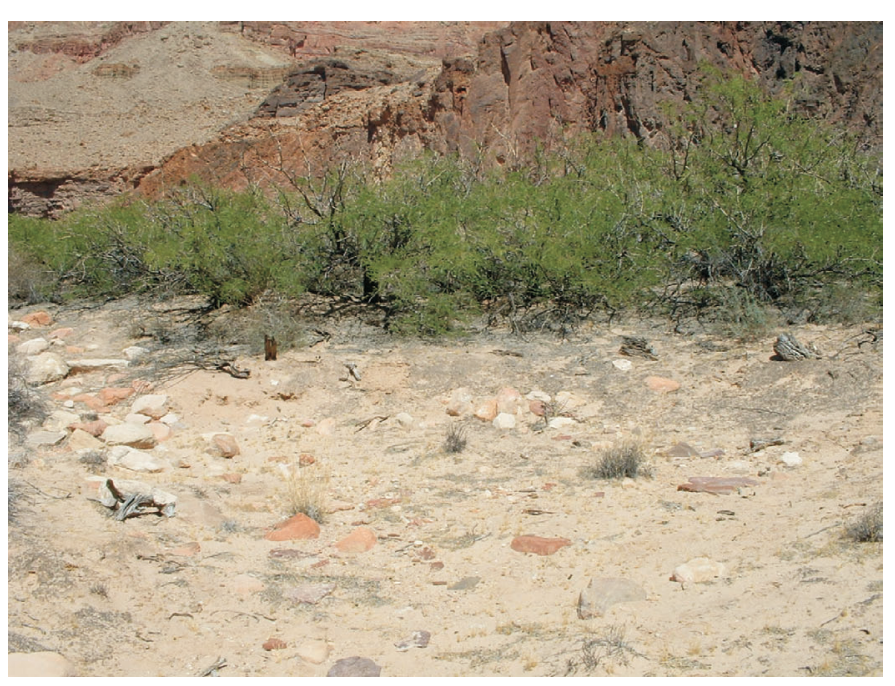

Figure 39. Thin sedimentary cover at archaeological site C:13:272, at Palisades. In the foreground are cobbles associated with a habitation structure at this site. Mesquite in the background has grown on sediment that partly covers the site. Sedimentary structures are absent in this sediment; its color and consistency suggest a fluvial origin rather than locally derived material from the Dox Formation (Stevenson and Beus, 1982). Aeolian reworking is evident in this deposit; a partly buried driftwood log is exposed at the northern end of this site in the same sedimentary unit. The sedimentary cover is inferred to be a fluvial deposit that has been reworked by wind into coppice dunes on which the mesquite has grown. This is within the 'Imt' (lower mesquite terrace) unit mapped by Hereford (1993). 
Features are apparently constructed on the distal debrisflow sediment, though possibly on the finer sand that covers the boulders and cobbles and provides a more habitable surface. The majority of the area covered by this site is within the 'Imt' unit mapped by Hereford (1993). Sand and silt have filled in several room-block features at this site. Sand and silt deposits in this area probably originated from Colorado River fluvial deposition during floods but have been modified by aeolian activity, evident from the modern dune morphology. No sedimentary structures are visible in the cryptogamic, bioturbated sediment that covers features of this site, but the surficial geomorphology is indicative of small (up to $1 \mathrm{~m}$ high) aeolian dunes that have undergone deflation, colonization by grasses and mesquite, and cryptogamic crust development. The color and consistency of the sediment cover suggests a fluvial origin, but the degree of sorting and the relatively coarse grain size (dominantly fine sand, with little silt present) are suggestive of aeolian reworking. This site lies immediately riverward of a driftwood line believed to represent the landward extent of the 1957 Colorado River flood (3,540 m3/s; 125,000 $\mathrm{ft} 3 / \mathrm{s})$. Logs from this driftwood line are partly buried by cryptogamic surficial sediment apparently related to migration of aeolian sand dunes.

C:13:334-This site is exposed on the surface of the playa deposits at the landward side of the Palisades area, although the artifacts appear to have eroded out of a remnant of a sediment deposit at slightly higher elevation than the current playa surface (mapped as 'ap' terrace by Hereford, 1993). There is little to no aeolian sediment cover apparent at the artifact location.

C:13:336-An exposure of sediment in a gully wall adjacent to this site revealed fluvial ripple structures; the elevation at this location is between the $1957(3,540 \mathrm{~m} 3 / \mathrm{s} ; 125,000$ $\mathrm{ft} 3 / \mathrm{s})$ and $1884(5,940 \mathrm{~m} 3 / \mathrm{s} ; 210,000 \mathrm{ft} 3 / \mathrm{s})$ driftwood limits (with logs at the inferred 1884 flood level partly buried immediately landward of the site; 1921 driftwood is not clearly present at this location). Aeolian modification of this flood sediment is apparent, with coppice dunes on the surface (consistent with the 'ec' map unit (eolian, coppice) in this area by Hereford, 1993). The deflated morphology and cryptogamic crust on these dunes indicate relative inactivity at this time. The nature of the sediment on which the site was originally constructed is not clear, as the site consists largely of artifacts scattered on the ground surface. Burial by fluvial sediment (with discharge at the 1921 levels and greater) is inferred, as is subsequent aeolian modification of flood-deposited sediment. A minor contribution by fine-grained, pinkish interdune/playa sediment is apparent in the sediment cover also.

C:13:355-This site is located just south of an arroyo network between the Palisades Creek debris fan and the debris fan of the unnamed tributary $400 \mathrm{~m}$ north of Palisades Creek.
Sediment in the arroyo walls is largely structureless and affected by significant bioturbation, but locally it contains fluvial climbing ripples that indicate deposition during Colorado River flood events. The high silt content and light color of the majority of the structureless areas of arroyowall sediment indicates derivation from the Colorado River, but without sedimentary structures this cannot be confirmed for much of the deposit. Slope-wash gravel and distal debris-flow sediment is also apparent in the arroyo walls, in greater proportions at the eastern (landward) end of the arroyo. The mouth of this arroyo enters the Colorado River in the large eddy on river left where a large sand bar is commonly present. Access to the arroyo mouth is restricted by very heavy vegetation. Two of the four features of site C:13:355 (features 1 and 4) were constructed on distal debris-flow sediment from Palisades Creek, with very minor modification on the surface by likely aeolian sediment (10$12 \mathrm{~cm}$ thick). This thin aeolian sediment deposit at the site shows no sedimentary structures and is heavily cryptogamic, indicating very little active aeolian transport at this time. Feature 2 is similarly built on colluvial gravels and cobbles, near Feature 1. One additional feature of this site (feature 3) is located at lower elevation and is now affected by incision of the arroyo network mentioned above. Feature 3 is eroding out of an arroyo wall that contains thinly bedded fluvial ripples in cross-section. Radiocarbon samples collected from feature 3 by R. Hereford during excavation of this site yielded dates of A.D. 1030-1240, 1010-1210, and 14501640 (Hereford, 1993). At this location, the stratigraphy of the arroyo walls also shows slope-wash and possible debrisflow gravels in addition to the fluvial sediment. Feature 3 appears to have been built on and buried by fluvial sediment, in an area affected by slope-wash and debris-flow deposition.

\section{Appendix 2: Descriptions of Stratigraphic Sections and Geomorphology at Archaeological Site Locations, Lower Comanche Area}

\section{Stratigraphic Sections}

\section{Lower Comanche, Section 1}

Section 1 is located beside an archaeological site that contains a roasting mound eroding into the arroyo drainage. The face of this stratigraphic exposure was not cleaned off or studied in detail, to avoid damaging the feature. From existing exposure, it is apparent that section 1 contains slumping aeolian sediment that overlies poorly sorted sand and gravel channel-fill sediment dominated by sandstone clasts from the Dox Formation. The inferred aeolian sediment is approximately laterally continuous with the aeolian deposits described in section 2 . 


\section{Lower Comanche, Section 2}

The photograph in figure 40 shows the arroyo wall where section 2 was described. Figure 41 shows the stratigraphic $\log$ for section 2. Measurements are in $\mathrm{cm}$ below the ground surface.

Surface: The surface has a crust $2 \mathrm{~mm}$ thick with cryptogams. It is very thinly bedded, with both horizontal and inclined beds. Surface material is fine sand, slightly hard, and is interpreted as slope-wash sediment and tributary alluvium, with a minor aeolian component.

$0-15 \mathbf{~ c m}$ (Unit A): Unit A contains primarily fine sand, with silt. No ripple structures are visible; bedding is dominantly horizontal, though some is inclined, and varies from indistinct to clear. The lower contact is abrupt and flat. This layer is interpreted as reworked slope-wash sediment and tributary alluvium, possibly with a minor aeolian component.

$\mathbf{1 5}-\mathbf{5 1} \mathbf{~ c m}$ (Unit B): Bedding in unit B varies from clear to indistinct. Sediment is very thinly bedded sand and silt, with bedding horizontal to subhorizontal. No cross-stratification is present. Three substrata exist within this horizon: $15-28$ cm (Subunit B1): Fine sand, with indistinct bedding.

$28-40 \mathrm{~cm}$ (Subunit B2): This stratum has numerous silt laminae; bedding is subhorizontal. Silt is very soft and friable, with numerous 1-mm-wide rootlet pores filled with calcium carbonate.

$\mathbf{4 0}-\mathbf{5 1} \mathbf{~ c m}$ (Subunit B3): Very slightly harder than B2, this substratum has indistinct bedding. It consists of fine sand with a minor component of medium sand. The lower boundary is abrupt and flat.

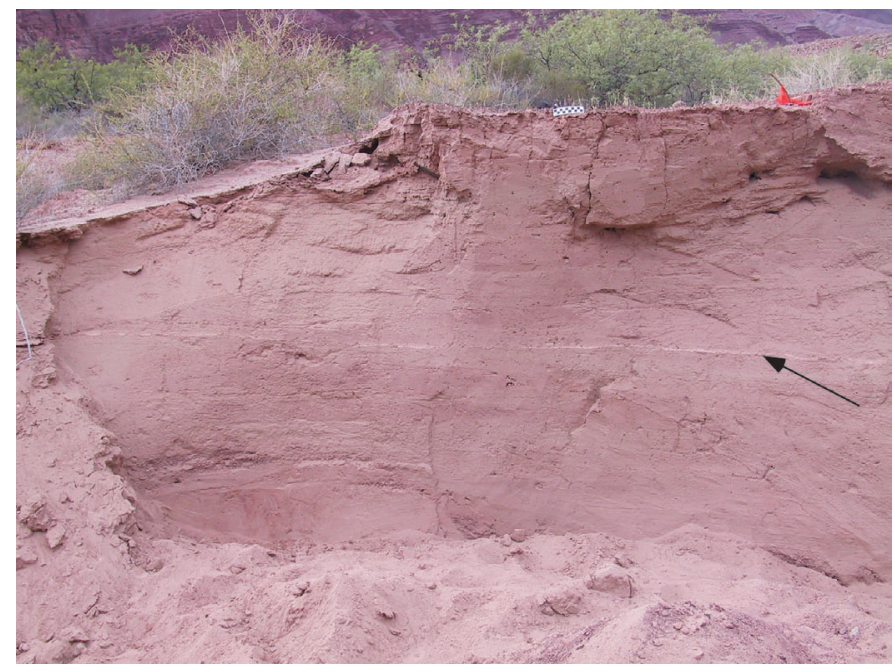

Figure 40. Stratigraphic section 2 at Lower Comanche, an exposure in the arroyo wall. The white layer is visible at a depth of 78 to $79 \mathrm{~cm}$ below the surface (arrow).
$51-78$ cm (Unit C): Unit C contains distinctly laminated and indistinctly bedded sediment. Individual beds vary in color between tan and reddish. In indistinctly bedded strata, the texture is fine sand with a minor medium-sand component. There are occasional to many 1-mm-wide carbonate-filled rootlet pores. Indistinctly bedded horizons are redder and contain small, fine-sand-size lithic fragments from the Dox Formation. These are less well sorted. Distinctly laminated beds are light in color with numerous paper-thin laminae. They are relatively well sorted and contain numerous carbonate-filled rootlet pores. These appear to be tributary alluvial deposits. Laminae are subhorizontal, subparallel, and locally cross-stratified, but no climbing ripples are observed. Occasional charcoal fragments occur that are as much as $3 \mathrm{~mm}$ in diameter. Laterally, unit $\mathrm{C}$ grades into channel facies, filled with channel-fill gravels derived from the Dox Formation. The lower contact is abrupt, and erosional. One sample was collected from unit $\mathrm{C}$ for grain-size analysis: Com Strat 2, Unit C (sample depth not recorded).

$78-79 \mathrm{~cm}$ (Unit D): This is the white layer observed throughout the Lower Comanche study area. In this locality, this stratum does not display the three phases observed elsewhere, but rather consists of a thin single bed that

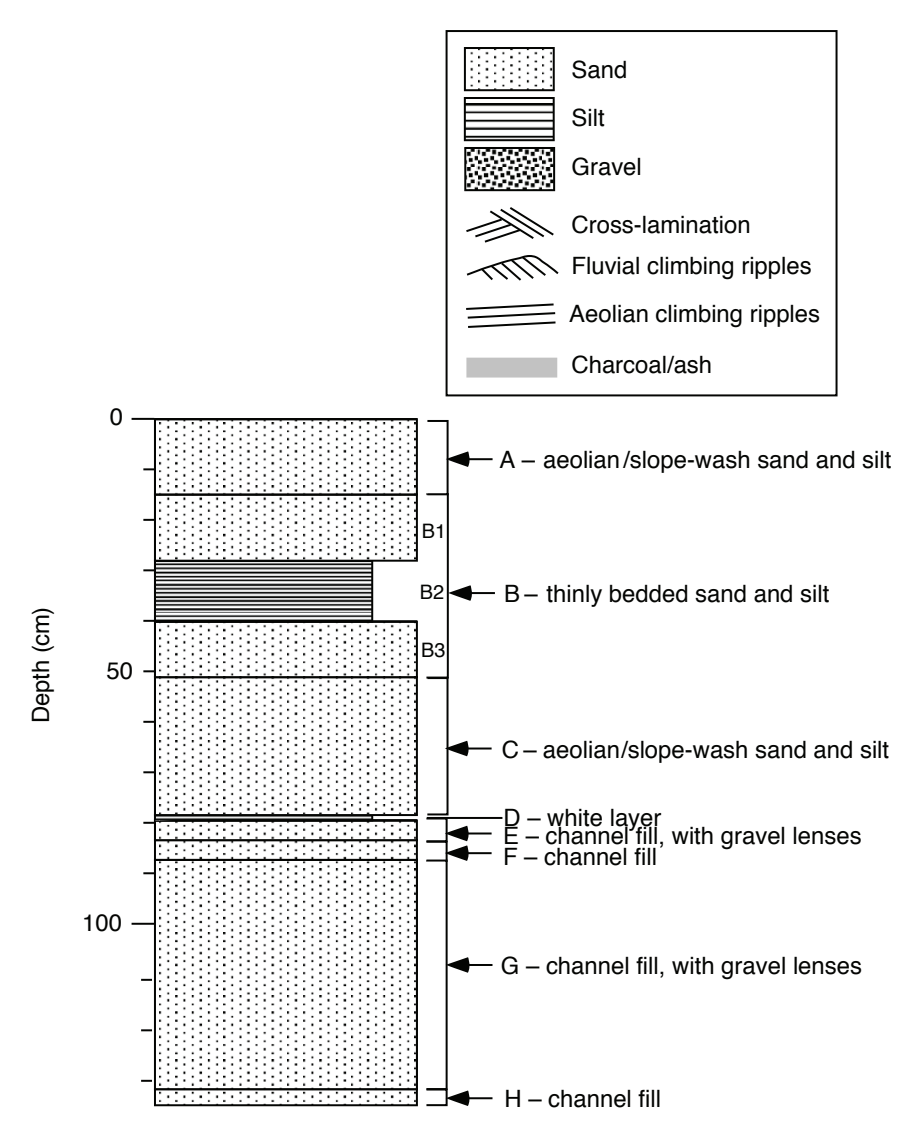

Figure 41. Stratigraphic diagram for section 2 at Lower Comanche. 
pinches out laterally into gravelly alluvium. This surface locally has $20-30 \mathrm{~cm}$ of topographic variation in this exposure. The lower boundary appears to be conformable, and there is no evidence of erosional activity (truncation of laminae). The upper surface is, however, eroded, which probably accounts for the absence of the upper two phases of this white-layer unit. Its thickness varies between 0.5 and $1.5 \mathrm{~cm}$ locally.

$79-83 \mathrm{~cm}$ (Unit E): This is one of several westward (riverward)-migrating channels representing paleoarroyo features in this locality. Thinly bedded silt laminae are present, primarily horizontal, though inclined at the edge of the channel. Silty fine sand occurs where this stratigraphic section was measured, but this interbeds laterally with channel gravels locally derived from the Dox Formation. The lower contact of unit $\mathrm{E}$ is abrupt, representing one stage in channel filling, but does not appear to be significantly erosive. This unit, which occurs as a horizon as much as 50 $\mathrm{cm}$ thick in a nearby channel-fill exposure, is the edge of channel-fill deposits.

$83-87$ cm (Unit F): The facies within unit F strongly resembles unit $\mathrm{E}$ above (channel-fill material), with the exception that cross-stratification is observed in the channelfill deposits. This stratum also grades locally into channel deposits derived from the Dox Formation and locally reaches $50 \mathrm{~cm}$ in thickness. One sample was collected from unit $\mathrm{F}$ for grain-size analysis: Com Strat 2, Unit F (sample depth not recorded).

$87-132$ cm (Unit G): The texture of unit G is primarily fine sand but with occasional small pebble-gravel lenses. The lowermost deposits of this stratum (which are generally not observed) are gravel. Sediments at the top and bottom of unit $\mathrm{G}$ appear to be slightly cemented and are redder in color than the lower deposits of this unit. This horizon represents channel fill and in places is significantly thinner than at the recorded section location.

$132-135+\mathbf{c m}$ (Unit H, to base of section): This lowermost stratum contains very fine sandy channel-margin deposits. These are thinly bedded, with laminae in some places and indistinct bedding in others. These sediments are interpreted as tributary alluvium and appear to have been modified by wetting and drying related to ground water, producing contorted liesegang-like oxidation bands in some areas. This would imply a relatively high water table, which is difficult to explain in this particular location.

Section 2 summary.-This profile represents various facies of tributary alluvium deposited in and adjacent to a series of eastward (shoreward)-migrating channels, which may interbed with sediment originally derived from fluvial and/or aeolian deposits. The white-layer horizon was deposited at a time when the deepest channels had largely filled but a gravel-bottomed channel still persisted adjacent to the bedrock valley wall. Additional tributary alluvium was deposited above the white layer, although associated channels are not as apparent or as deep as those from earlier times (at least until the modern arroyo-cutting episode). Sediments contained within this alluvial stack are unusually fine, and, with the exception of gravel-bottomed channels, contain very limited amounts of bedrock-derived sediment. The source of alluvial sediments is believed to be reworked aeolian deposits from upstream and valley-slope areas. The relationship of these sediments to modern coppice accumulations is not clear.

\section{Lower Comanche, Section 3}

The pit from which section 3 was described is shown in figure 42. Figure 43 shows the stratigraphic profile for section 3. Measurements are in $\mathrm{cm}$ below the ground surface.

Surface: This profile is a pit dug into a flat land surface with sparse vegetation. The surface shows evidence of recently ponded water (abundant mudcracks) over a large area, and crust formation 2-2.5 mm thick. Minor mud curls are present; cryptogamic development is present but weak, and short grasses (cheat grass) have colonized the area.

0-5 cm (Unit A): Uppermost sediment in this section contains soft, very friable (to single grains) coarse, weakly subangular, blocky fine sandy silt. Sand content is estimated to be approximately 25-30 percent, with the remainder silt. Considerable bioturbation, primarily by rootlet growth, has obscured most sedimentary structures. Minor crosslamination is visible, but this unit is generally massive. The lower contact is clear to sharp, and wavy. An aeolian origin is inferred; the unit appears to be a loose aeolian cover on the surface.

$5-20 \mathrm{~cm}$ (Unit B): Unit B is a silty fine sand that contains subhorizontal, paper-thin laminae throughout that may be related to wetting episodes. Sand content is estimated to be $\sim 75$ percent, with the remainder silt. Sediment is friable, and is slightly more consolidated than unit A. No crossbedding is visible. The lower contact is somewhat arbitrary, and has been placed at $20 \mathrm{~cm}$, in a zone where silt laminae become more prominent and frequent. These laminae may be remnants of a wetted surface, weathering out to appear more consolidated than the sediment above or below. Unit $\mathrm{B}$ is interpreted as a likely aeolian deposit on the basis of its texture and lamination. This may represent aeolian deposition with periodic wetting.

20 - 40 cm (Unit C): Lamination in unit $C$ shows some disturbance attributed to bioturbation in the upper $3 \mathrm{~cm}$ of this horizon. There is a broad channel in unit $\mathrm{C}$ with a maximum depth of $8 \mathrm{~cm}$ that has lamination in the channelfill sediment (cross-lamination is not present). Scattered pebbles and granules occur in the channel-fill material, which may represent a deflation or lag deposit. Silt laminae are present at the base of the channel fill, but they become indistinct toward its edges. Sediment in the channel is dominantly soft, fine sand and silt with occasional pebbles and granules. Bedding both inside and outside the channel 
fill is very thin to laminated, and approximately horizontal. There is a poorly defined central zone within unit $\mathrm{C}$ (outside and below the channel) $\sim 7 \mathrm{~cm}$ thick that is slightly more consolidated and massive than the sediment above and below. This central consolidated sediment has indistinct minor lamination. Unit $\mathrm{C}$ contains $\sim 25$ percent fine sand, with the remainder silt (and rare pebbles). The unit coarsens downward, with the lowermost third of unit $\mathrm{C}$ significantly

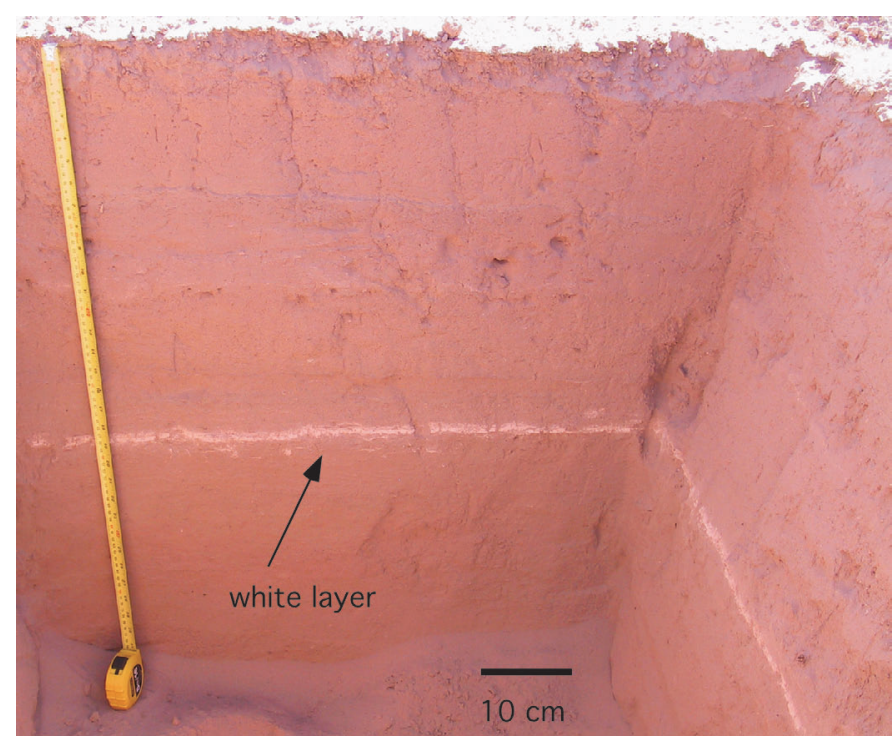

Figure 42. Section 3 at Lower Comanche. The white layer is visible, spanning a depth of 46 to $48 \mathrm{~cm}$ below the land surface.

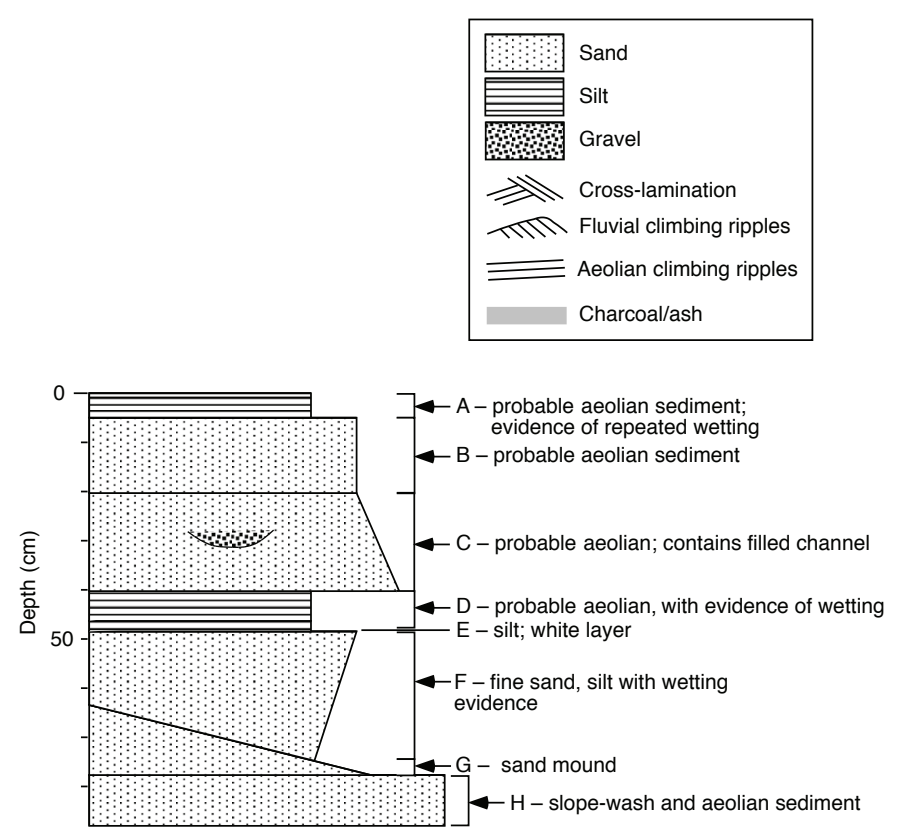

Figure 43. Stratigraphic diagram for section 3 at Lower Comanche. coarser than the sediment above it (fine to medium sand). Indistinct very thin subhorizontal bedding is apparent in this lower portion of unit $\mathrm{C}$; silt laminae are fewer than in the upper part of the unit. The lower fine and medium sand is very soft and friable (to single grains). The unit's lower boundary is defined at several prominent silt laminae that are better consolidated than the sediment above or below.

$40-46$ cm (Unit D): Bedding in unit D is much more distinct than in overlying unit $\mathrm{C}$, with numerous subhorizontal paper-thin silt laminae. This horizon is very silty; no crosslamination is apparent. Some of the laminae in the lowest $2 \mathrm{~cm}$ of unit D consist of material from the white-layer horizon. Laminae increase in frequency downsection just above the white layer. The boundary with the white layer (unit $\mathrm{E}$ below) is somewhat abrupt but gradational. Unit $\mathrm{D}$ appears to be aeolian, but deposited when standing or slowmoving water was present (judging from well-defined silt lamination and texture).

$46-48 \mathrm{~cm}$ (Unit E): Unit $\mathrm{E}$ in this section is the white layer observed elsewhere in the Lower Comanche area. Section 3 is the northernmost location where it has been documented during this study. The top part of the horizon here is very well laminated. Its base is sharp in terms of composition, but deposition within this unit appears gradational. The three phases identified in this white layer in the more southern stratigraphic sections at Lower Comanche are also present in section 3 (a central, slightly darker, sandier layer is present within it). The lowest phase of the white layer contains small micropores from rootlet channels (scale 1-3 mm), with vegetation occupying the channels. Its total thickness is 1.5 to $2.0 \mathrm{~cm}$. The sediment is friable, very fine and powdery when crumbled; grain size is visually estimated to be fine silt. Small fragments of mica are visible within it.

48 - 63 (77) cm (Unit F): This sediment immediately below the white layer is silty fine sand. The upper $8 \mathrm{~cm}$ of unit $\mathrm{F}$ is similar to unit $\mathrm{D}$, with frequent paper-thin silt laminae that decrease in frequency downsection. In places, some of those silt laminae appear to be composed of silt similar to that of the white layer (unit E). The contact between units $\mathrm{E}$ and $\mathrm{F}$ does not appear to be burrowed; the silt laminae in uppermost unit $\mathrm{F}$ may possibly be related to an early stage in the deposition of the white layer. The lamination immediately below the white layer is interpreted to reflect frequently wetted sediment. The rest of unit $\mathrm{F}$ (below the 8 $\mathrm{cm}$ laminated upper region) appears much more massive; lamination disappears, and the sediment becomes slightly more consolidated and fines downward into fine sandy silt. The lower contact of unit $\mathrm{F}$ is inclined, as a small mound is apparent in the contact between units $F$ and $G$ in the southern corner of the section 3 pit. Where unit $\mathrm{F}$ overlies this mound, that unit is thinnest ( $15 \mathrm{~cm}$ thick); its maximum thickness (at the northern corner of the pit, away from the mound) is $29 \mathrm{~cm}$.

$63-77 \mathrm{~cm}$ (Unit G): This fine to medium sand unit is present only in the southern corner of the pit, as a mound up to 14 
$\mathrm{cm}$ thick. The mound that defines unit $\mathrm{G}$ is significantly coarser than overlying unit $\mathrm{F}$. The contact between units $\mathrm{F}$ and $\mathrm{G}$ at this mound surface is abrupt and inclined. Unit $\mathrm{G}$ is massive but contains at least one inclined bedding plane (dipping off the mound, subparallel to its upper surface). Unit $\mathrm{G}$ fines downward. Its lower contact with unit $\mathrm{H}$ is abrupt and inclined toward the north (dipping off the mound).

$77-87+\mathbf{c m}$ (Unit $\mathrm{H}$, to base of exposure): Unit $\mathrm{H}$ is a poorly sorted fine to very coarse sand that contains some clasts as large as granule size. Numerous lithic clasts are present; sandstone clasts from the Dox Formation can be identified, among other lithologies. Some stratification is present, but it is poorly defined. This unit is inferred to be a combination of aeolian and slope-wash sediment.

Section 3 summary.-This profile represents episodes of aeolian and slope-wash sediment deposition and reworking, affected by repeated wetting events. The flat land surface into which this pit was dug is still an area that collects standing water, as evidenced by abundant mudcracks over a large area on the modern land surface. This location represents the northernmost site where the white-layer horizon has been observed.

\section{Lower Comanche, Section 4}

The stratigraphic diagram for section 4 is shown in figure 44 . Measurements are in $\mathrm{cm}$ below the ground surface.

Surface: Section 4 is located $\sim 10 \mathrm{~m}$ shoreward of section 6 . Section 4 is exposed in a wall of the arroyo; fluvial deposits in the upper part of section 6 can be observed to pinch out in a shoreward direction before reaching the location of section 4.

$0-13 \mathbf{~ c m}$ (Unit A): The uppermost horizon consists of buffcolored sand and silt, with no discernible sedimentary structures.

$13-55 \mathbf{~ c m}$ (Unit B): Unit B is a silty sand, with faint parallel bedding. Its color is slightly pinker than that of units $\mathrm{A}$ and $\mathrm{C}$, above and below it, respectively.

$55-93 \mathbf{~ c m}$ (Unit C): Unit C is a buff-colored sandy silt with some parallel bedding structures.

$93-94 \mathrm{~cm}$ (Unit D): Unit D is the white layer observed in other areas at Lower Comanche, of unknown origin.

$94-151 \mathrm{~cm}$ (Unit E): Unit E is a buff-colored silty fine sand, with some parallel bedding.

$151-197$ cm (Unit F): This horizon contains coarse sand and gravel, derived locally from the Dox Formation, of which abundant lithic grains are present. Unit F contains a channel structure $\sim 1.5 \mathrm{~m}$ wide, which has been filled with gravel from the Dox Formation. At the location of section 4 the channel base occurs at $186 \mathrm{~cm}$; from $186 \mathrm{~cm}$ to $197 \mathrm{~cm}$, the base of unit F, sediment consists of coarse sand and gravel dominated by lithic fragments from the Dox Formation.
$197-213$ cm (Unit G): This horizon consists of parallelbedded coarse sand and gravel, dominantly derived from the Dox Formation.

213 - 238 cm (Unit H): Unit H contains buff-colored sand and silt, with little apparent sedimentary structure.

$238-\mathbf{2 5 5}+\mathbf{c m}$ (Unit I, to base of section): This lowermost unit contains dominantly silt and sand, but with interspersed lithic fragments from the Dox Formation as much as $1 \mathrm{~cm}$ across.

Section 4 summary.-Section 4 is interpreted to contain a combination of aeolian deposits (silt and sand) with locally derived sheet-wash deposits (gravel and coarse sand grains from the Dox Formation). The absence of diagnostic sedimentary structures in much of the silt/sand stratigraphy indicates that an aeolian origin cannot be confirmed; an alternate explanation for the parallel-bedded silt and sand units may be sheet wash (upper plane bed) redeposition of this finer sediment as a result of local precipitation and runoff events. The channel-fill sediment in unit $\mathrm{F}$ contains gravel (from the Dox Formation) as well as buff-colored silt and sand material.

\section{Lower Comanche, Section 5}

The stratigraphic diagram for section 5 is shown in Figure 45. Measurements are in $\mathrm{cm}$ below the ground surface.

Surface: This section is located at low elevation, closer to the river than any other section studied at Lower Comanche. Surface sedimentary characteristics are obscured by very heavy vegetation cover dominated by mesquite trees.

$0-48 \mathbf{~ c m}$ (Unit A): The uppermost sediment in Section 5 is silty sand with well defined parallel bedding. This unit is interpreted to be most likely of aeolian origin; sedimentary structures are probably aeolian climbing ripple forms.

$48-58$ cm (Unit B): Unit B consists of medium to coarse sand, with a large proportion of lithic clasts derived from the Dox Formation. The upper and lower contacts of this unit dip landward (east).

$58-98 \mathrm{~cm}$ (Unit C): This unit contains pinkish fine sand, with beds of buff-colored very fine silty sand or sandy silt. Bedding is horizontal, with stratification disrupted or bioturbated. This unit could be either of fluvial or aeolian origin; disturbance of sedimentary structures makes the interpretation ambiguous.

$98-101$ cm (Unit D): Well-defined fluvial climbing ripples are present in this silty very fine sand horizon, interpreted as a Colorado River flood deposit. Troughs of the ripples are filled with very fine sediment (mud/silt/clay).

$101-122+\mathrm{cm}$ (Unit $\mathrm{E}$, to base of exposure, which ends $\sim 25$ $\mathrm{cm}$ below the arroyo floor): This lowermost unit of section 5 consists of very poorly sorted sand that contains sandstone clasts from the Dox Formation. The general grain size is fine sand, but the clasts from the Dox Formation are as large as coarse sand. Subhorizontal stratification is visible. Deposition 
was likely dominated by slope-wash sedimentation, possibly with aeolian sediment incorporated also.

Section 5 summary.-Section 5 is the closest to the river of the measured profiles. One Colorado River flood deposit is clearly apparent (unit D); bioturbation and other surface modification of bedding render $\sim 30$ percent of the thickness in this section ambiguous (unit $\mathrm{C}$ ). The rest of the section represents sedimentary processes operating at the land surface: aeolian deposition and local runoff are apparent in units B and D.

\section{Lower Comanche, Section 6}

The stratigraphic diagram for section 6 is shown in figure 46 . Measurements are in $\mathrm{cm}$ below the ground surface.

Surface: The land surface above section 6 is cryptogamic, deflated, and locally heavily vegetated (the section is located under mesquite cover). All units in this profile are

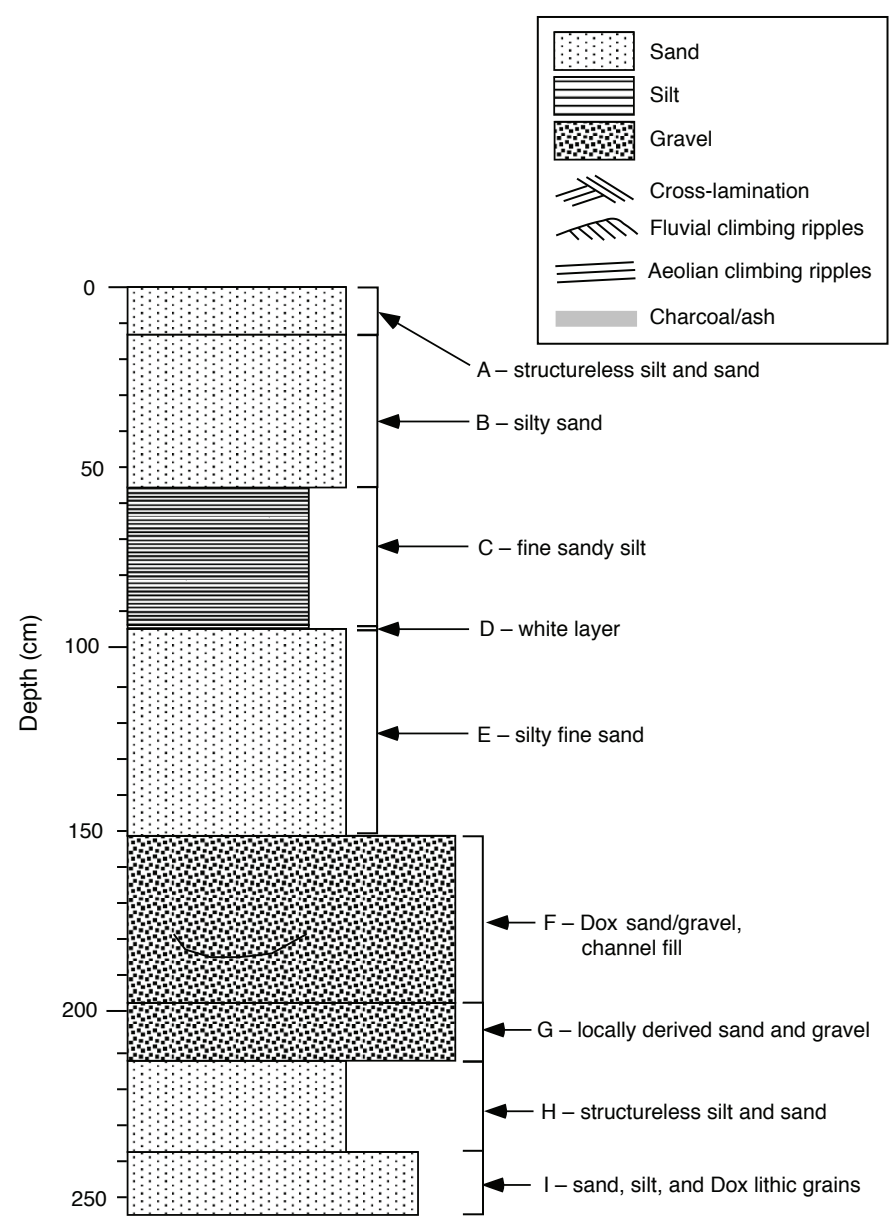

Figure 44. Stratigraphic diagram for section 4 at Lower Comanche. heavily bioturbated, with small rootlet pores and large roots disturbing stratification in every horizon.

0-42 cm (Unit A): Unit A is a bioturbated very fine sand with organic laminae. Lamination is approximately conformable with the land surface. This is a probable aeolian deposit. A concentration of granule-size charcoal fragments is visible that defines the lower contact of this horizon.

$42-56 \mathbf{~ c m}$ (Unit B): This is a bioturbated very fine sandy silt to silty very fine sand. Stratification is present, with some beds as much as $\sim 2 \mathrm{~cm}$ thick. Some beds have a pinkish color, while others are more gray. Some beds dip riverward (west), while others are subhorizontal. Finer scale lamination is locally apparent that appears parallel to larger scale beds that dip riverward; these are possible Colorado River fluvial ripples, though the stratification and potential climbing ripple structures are faint and only locally visible. The lower contact of unit B is corrugated on a mm scale, with unit $\mathrm{B}$ displaying a slightly pinker color at the contact while unit $\mathrm{C}$ is slightly grayer. Some of the beds within unit $\mathrm{B}$ are also corrugated on a mm scale (most likely reflecting bioturbation). One sediment sample was collected from this horizon: Com Strat 6, Unit B.

$56-80 \mathbf{~ c m}$ (Unit C): Unit $C$ is a silty fine sand that contains fine-scale laminations that dip generally landward (east).

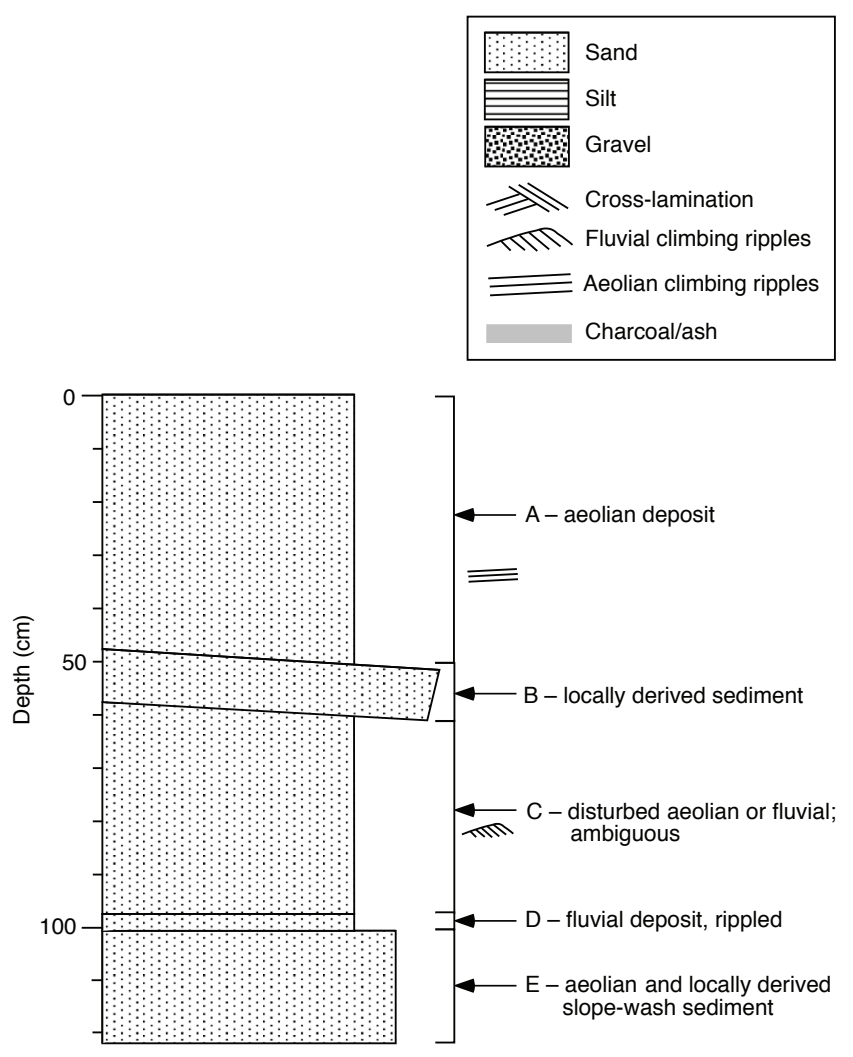

Figure 45. Stratigraphic diagram for section 5 at Lower Comanche. 
Some of the stratification is parallel to the set boundary, while some dips landward (as if in an upstream migration direction). The lower part of unit $\mathrm{C}$ contains less clear stratification, though approximately parallel bedding is visible. The lower boundary of unit $\mathrm{C}$ is a thick organic concentration. The upper part of unit $\mathrm{C}$ is interpreted as Colorado River fluvial deposit. The lower half of this unit may be either fluvial or aeolian; stratification is too disturbed to distinguish diagnostic sedimentary structures.

$80-81$ (90) cm (Unit D): This horizon is a heavily organicrich layer of variable thickness (ranging from $<1$ to $10 \mathrm{~cm}$ ) that represents a buried land surface. The large mesquite tree immediately above section 6 has formed roots in this layer where it outcrops $\sim 3 \mathrm{~m}$ riverward of the measured profile.

$90-103 \mathbf{~ c m}$ (Unit E): This is a very fine sandy silt. The lower half of unit $\mathrm{E}$ contains well-defined parallel lamination; in the upper half, lamination is much less distinct and is disrupted. The lower, well-laminated half pinches out landward of the exposure and may represent a former river channel pinching out laterally against the riverbank. In the offshore direction, this unit can be traced laterally for $>6 \mathrm{~m}$ from the profiled area, where well-defined fluvial climbing ripples become apparent. Unit $\mathrm{E}$ is a fluvial deposit, though the upper half may reflect reworking of flood sediment at the land surface (degrading fluvial sedimentary structures). The lower contact of unit E, defined by a thin organic concentration, climbs upward to the landward side of the outcrop, consistent with the pinching out of a river channel against its bank. Unit $\mathrm{E}$ has thinned to almost no thickness within $1 \mathrm{~m}$ landward of the measured section, and thickens riverward. One sediment sample was collected from unit E: Com Strat 6 Unit E.

$103-121 \mathrm{~cm}$ (Unit F): This unit, which is separated from unit $\mathrm{E}$ above by a thin organic-rich boundary, is better consolidated than unit E. Sediment is a sandy silt with small root holes in it. Bedding is subparallel and discontinuous; some stratification is wavy, approximately horizontal, and disrupted. The contact (organic layer) between units $\mathrm{E}$ and $\mathrm{F}$ is wavy, with 3-4 $\mathrm{cm}$ of topography (a disrupted surface that probably represents reworking of unit $\mathrm{F}$ sediment at the land surface). Depressions in this contact between units $\mathrm{E}$ and $\mathrm{F}$ are filled with sediment of unit $\mathrm{F}$ type. Stratification in unit $\mathrm{F}$ includes lamination that dips landward but not necessarily at the scale of subaqueous ripple structures. This could be aeolian material, though the upper $14 \mathrm{~cm}$ of unit $\mathrm{F}$ appear to locally contain faint fluvial ripple structures. Some lamination is approximately horizontal, while some dips landward very subtly. Faint ripple forms in the upper part of this unit appear to migrate riverward and slightly out of the outcrop plane (upstream) in one small area. The lower contact of unit $\mathrm{F}$ is defined by a slight increase in consolidation. One sediment sample was collected from this unit: Com Strat 6 Unit F.

$121-143 \mathbf{~ c m}$ (Unit G): The upper boundary of unit $\mathrm{G}$ is marked by a subtle downward increase in consolidation; its lower contact is defined by the appearance of distinct subparallel laminae. The upper $5 \mathrm{~cm}$ of this horizon contain disrupted beds. Subparallel lamination is present that dips landward; three sets of such bedding are visible. The depositional environment of unit $\mathrm{G}$ is not clear.

$143-145$ cm (Unit H): A 2-cm-thick silt bed defines unit $\mathrm{H}$, which contains wavy, subparallel lamination that dips landward at a low angle. This may represent the distal edge of a Colorado River flood deposit, on the basis of its similarity to other flood-related silt beds observed at Arroyo Grande. The lower boundary of this layer is the white layer (unit I).

$145-146 \mathrm{~cm}$ (Unit I): Unit I is the white-layer bed observed in other profiles at Lower Comanche. In this section it is 0.5 to $1.0 \mathrm{~cm}$ thick, with a mottled, burrowed base that is indistinct. The top is also gradational, but less so than the base.

$146-153 \mathrm{~cm}$ (Unit J): This is a massive, poorly stratified silty sand that has been modified by burrowing activity and apparent disturbance at the land surface. Its original depositional environment is assumed to be either aeolian or fluvial but cannot be confidently determined, given the extensive disturbance of sedimentary structures. The top of unit $\mathrm{J}$ is gradational, leading into the overlying white-layer horizon.

$153-161 \mathrm{~cm}$ (Unit K): Unit $\mathrm{K}$ is a fine to medium sand with sand-size lithic fragments of sandstone from the Dox

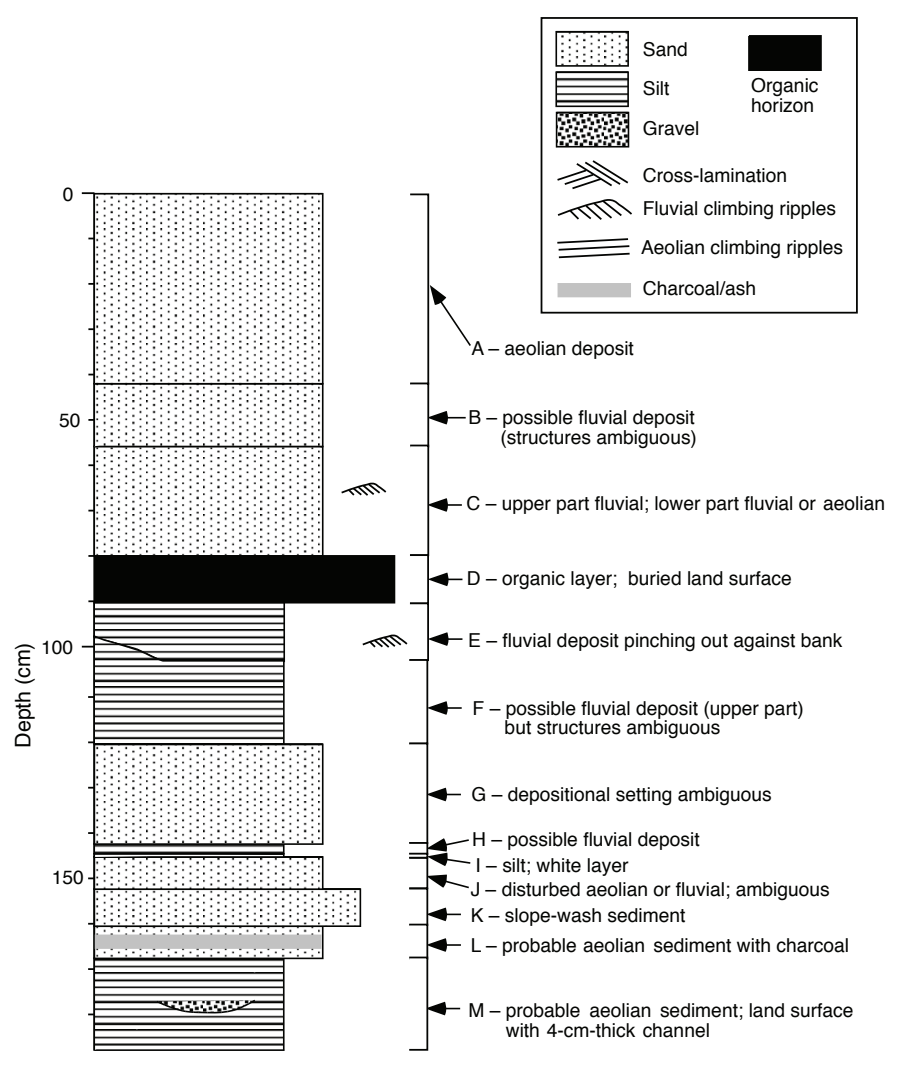

Figure 46. Stratigraphic diagram for section 6 at Lower Comanche. 
Formation. Parallel lamination is present; a slope-wash or arroyo-type (local runoff) depositional environment is inferred.

$161-168$ cm (Unit L): This locally charcoal-rich horizon contains horizontal paper-thin laminae, some of which are wavy. Some bedding appears to be aeolian stratification that dips landward. Unit L is interpreted as likely aeolian sediment that has undergone modification and incorporation of charcoal material at the land surface. Dominant grain size is silty very fine sand.

\section{$168-188+\mathrm{cm}$ (Unit $M$, to base of outcrop at arroyo}

floor): This horizon contains dominantly silt, with some very fine sand. Very thin stratification is locally apparent and is suggestive of an aeolian deposit. The upper part of this unit contains some subhorizontal paper-thin wavy laminae. Some beds are pinkish, while others are more gray. A 4-cm-thick pebbly sand lens (medium to fine sand) occurs within unit $\mathrm{M}$, which is filled by sandstone fragments from the Dox Formation that may be as large as $>5 \mathrm{~mm}$ across. This sand lens likely represents a small rivulet channel incised into a largely aeolian deposit at the land surface. Many calcified white rootlets are present.

Section 6 summary.-This section, the second-closest to the river (after section 5) contains clear evidence (in the form of sedimentary structures) for at least one Colorado River flood deposit (unit E), and possibly as many as seven flood units if units with ambiguous sedimentary structures are in fact fluvial in origin (units B, C, E, the upper part of $\mathrm{F}$, and possibly $\mathrm{G}, \mathrm{H}$, and $\mathrm{J}$ ). Aeolian deposition is inferred for at least three of the horizons in this section (units A, L, and $\mathrm{M}$, with possible aeolian sediment also occurring in units $\mathrm{F}, \mathrm{G}$, and $\mathrm{J}$ ). Many of the units in this profile show

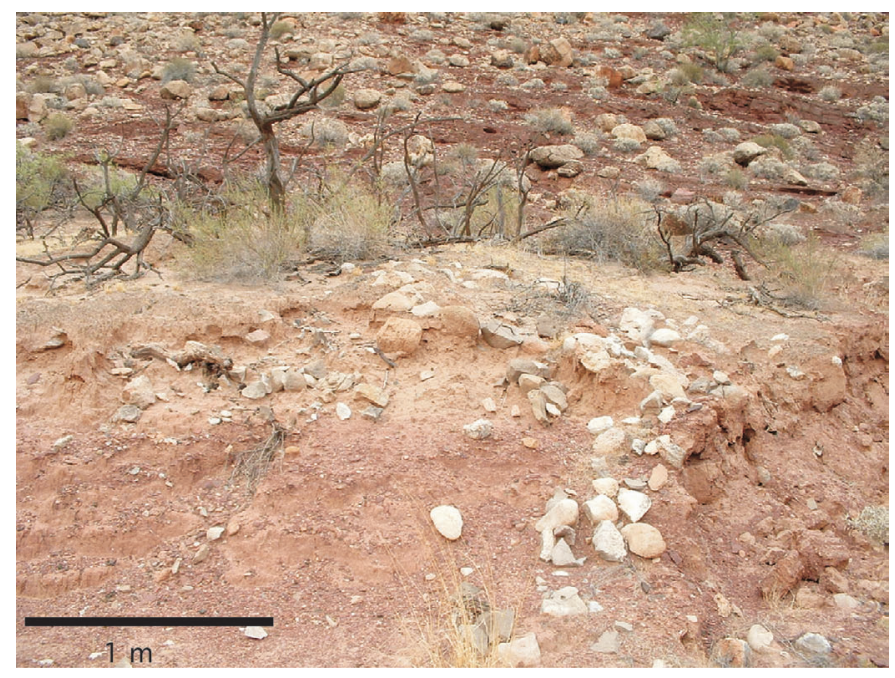

Figure 47. One of the roasting features, feature 3 (containing firecracked rock), at archaeological site C:13:273, Lower Comanche. The feature is affected by gully incision, as one branch of the main arroyo network has undercut much of this feature, causing artifacts to move downslope into the gully. evidence of having been exposed at the land surface, causing reworking, incorporation of locally derived sediment of the Dox Formation into fluvial or aeolian sediment, and disturbance of original stratification in these horizons.

\section{Stratigraphy and Geomorphology at Archaeo- logical Site Locations}

C:13:273 - This site contains several roasting features, one of which is one of the largest in eastern Grand Canyon. Arroyo incision to the north and east of the site will eventually threaten to undercut the larger roasting feature, while another has already been largely eroded by arroyo growth (fig. 47). Sedimentary exposure in the arroyo wall directly beneath the site indicates that the feature is built on alternating fine sand/silt and locally derived coarse sandstone slope-wash deposits from the Dox Formation. The site is at the modern land surface elevation, with a thin to absent aeolian sediment cover. Vegetation and cryptogamic crust development affect the modern surface. Excavation was completed in 1995 at the downstream side of C:13:273 and in 1997 at feature 5 of this site, which was located 70-130 cm below the surface and spanned a width of 40-85 cm (Leap, 1995; Matthews, 1997; Smith, 1997; Yeatts, 1998). Two radiocarbon analyses, collected

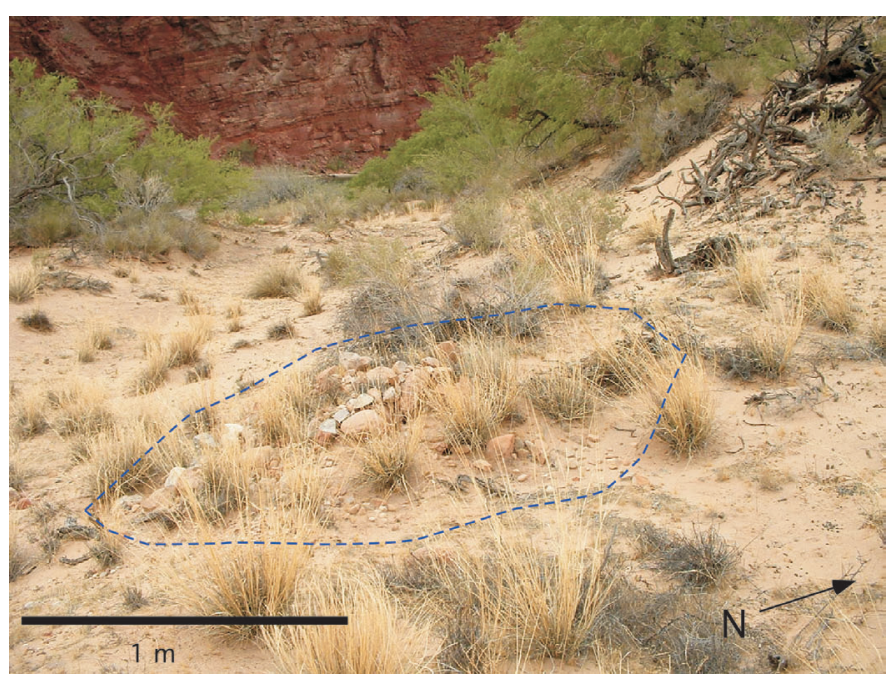

Figure 48. Roasting feature at archaeological site C:13:333 (within dashed line). This site, built on aeolian sand at high elevation in the large dune field at Lower Comanche, is affected by dune migration, as the dune on which it is built shows geomorphic evidence of northward migration (upcanyon, to the right of the photograph). Artifacts at this site have undergone some downslope movement (toward the left of the photograph) as sediment has been eroded by wind. It appears that the rocks of the roasting feature have armored the site to some degree; the rock mound shown faces south, downstream (into the direction of strongest winds at this site), apparently offering some protection to the sediment around it. 
from the hearth of Feature 5, yielded dates of A.D. 620 775 and $575-770$ (Yeatts, 1998). This site is affected by visitor use of the Beamer hiking trail, though this is not perceived to have caused major impact (Leap, 1995).

C:13:274-This site is built on a thin accumulation of aeolian coppice-dune sediment that is now cryptogamic and deflated, near a large dead mesquite complex. The site is affected by minor gullying and deflation. The coppice dune is at most $1 \mathrm{~m}$ thick at its thickest part, and overlies distal debris fan sediment and reworked relict river cobbles derived from the older (believed to be Pleistocene) deposits at higher elevation to the east. The site is exposed at the modern land surface, apparently as a result of some aeolian deflation.

C:13:333 - Artifacts at this site are exposed by northward dune migration; the site is built on aeolian sediment and is now located within an elevated interdune area (not a true playa surface). Very minor cryptogamic crust development is apparent on the land surface, with minor deflation evident around local vegetation. The site appears to be located on or near its original surface elevation, but it is moving gradually downslope in response to dune migration. It appears that the fire-cracked rock associated with the roasting feature at this site may actually be armoring the site from more rapid deflation (fig. 48); some scour is evident around the base of the rock mound, and a small amount of sand forms a sand shadow in the lee (north) of this roasting feature.

C:13:335-Cultural material at this location is exposed by deflation in the center of a large high dune (a small

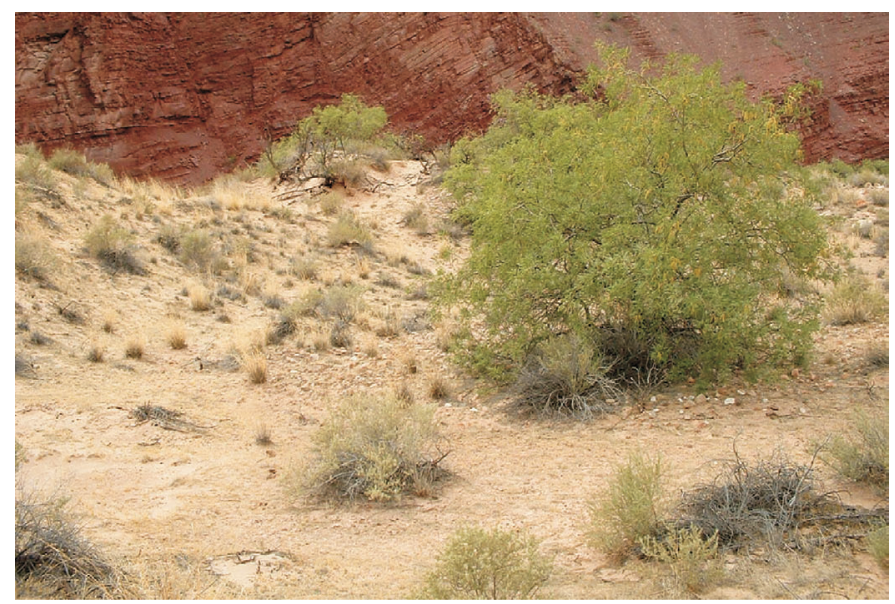

Figure 49. Archaeological site C:13:337, consisting of fire-cracked rock concentrated under the tree. This site is built on an interdune/ playa area within the large dune field at Lower Comanche. This area is affected by aeolian sediment transport and dune migration processes; the site is presently considered relatively stable (National Park Service, 2004). low area located at high elevation in the dune). This dune appears very active in general, although minor cryptogamic crust development has occurred in this deflated low area. Immediately to the south (downstream) of this site is a large active dune, across a small saddle from this site location. The slip face of that large active dune indicates migration to the north, toward the site. This site, considered relatively stable at present by NPS (National Park Service, 2004), is built on and buried by aeolian sediment, but it is being exposed by gradual deflation.

C:13:337-This site, containing exposure of fire-cracked rock, is the northernmost site in the main Comanche dune field (fig. 49). The site was constructed in a small playa/ interdune area affected by dune migration and associated aeolian sediment transport. Recent ponding of water in this interdune area is evident; mudcracked sediment was visible in the vicinity of the site in May 2004. This site is presently considered by NPS to be relatively stable (National Park Service, 2004). The site is not currently buried by sediment, but is located in an area where aeolian sediment deposition associated with dune migration would be expected to eventually cover and re-expose these artifacts over time.

$\mathrm{C}: 13: 373$ - This site is located at high elevation in the dune field and is eroding down the riverward side of a steep dune. It was originally built on aeolian sediment and is buried by a minor cover of aeolian material, though the site and its sediment cover have moved downslope as a result of deflation associated with dune migration.

\section{Appendix 3: Descriptions of Stratigraphic Sections and Geomorphology at Archaeological Site Locations, Arroyo Grande Area}

\section{Stratigraphic Sections}

\section{Arroyo Grande, Section 1}

Section 1 was recorded in two parts, $1 \mathrm{a}$ and $1 \mathrm{~b}$, which are separated laterally by $\sim 4 \mathrm{~m}$ (stratigraphic diagrams are shown in fig. 50). At both substations, the survey datum was placed at the base of aeolian sands. At both 1a and 1b, the upper $2.0-2.1 \mathrm{~m}$ of the section (including the uppermost $\sim 1.5 \mathrm{~m}$, in which stratigraphic depths were not logged in detail) is aeolian sand. The sand is fine grained, not silty, and is characterized except in the upper part by subcritically climbing translatent strata (see Hunter, 1977a,b) that are 1- 
$3 \mathrm{~mm}$ thick and dip at angles of less than 100 . The upper 0.5 $\mathrm{m}$ of the section has obscure or no visible stratification, and the upper structureless part grades down into the stratified part. The section below the aeolian sand differs in sections 1a and 1b. Depths are recorded as depth below the base of aeolian sand. This aeolian sand is considered to be unit A in both sections $1 \mathrm{a}$ and $1 \mathrm{~b}$.

\section{Section 1a}

0 - 14 cm (Unit B): Unit B, which is separated from aeolian sand of unit A above by a sharp contact, contains silt or very fine silty sand. Sediment is laminated, with fluvial climbing ripples migrating toward 330o. The lower contact of unit B is gradational. This is interpreted as a Colorado River flood deposit.

14-17 cm (Unit C): This is a clayey silt, whitish and consolidated, interpreted to be the basal unit of the overlying flood deposit. The base of this horizon is sharp.

17-20+ cm (Unit D, to base of exposure): This unit contains silt or silty sand, with no apparent sedimentary structures.

\section{Section $1 b$}

0-8 cm (Unit B): This unit contains fine to very fine sand with planar lamination, truncated at an angle of less than 5o by contact with overlying aeolian sand. The base of unit B is gradational. The depositional environment is ambiguous.

$8-45$ cm (Unit C): Unit C consists of very fine sand, grading down into silt toward its base, with fluvial (Colorado River) climbing ripples that migrated toward the northwest (upstream). The base of this unit is gradational.

$45-49 \mathrm{~cm}$ (Unit D): This unit is a clayey silt, whitish and consolidated, which probably forms the base of the flood deposit in unit $\mathrm{C}$ above. The base of this horizon is sharp.

$49-52+\mathbf{c m}$ (Unit E, to base of exposure): The lowermost unit exposed in section $1 \mathrm{~b}$ is a coarse silt or very fine sand. It is micaceous, suggesting incorporation of locally derived sediment.

Six samples were collected from section 1: AG Strat 1 \#1 (example of aeolian sand with good 'pinstriped' climbingripple structure, sampled near Section 1a); AG Strat $1 \mathrm{~b} \# 2$ (sampled silt from base of flood unit 0-1 $\mathrm{cm}$ above base of outcrop, slightly below arroyo floor); AG Strat 1b \#3 (sampled flood sediment 10-11 cm above base of outcrop); AG Strat 1b \#4 (sampled flood sediment 20-23 cm above base of outcrop, in area that contains fluvial climbing ripples); AG Strat 1b \#5 (sampled flood sediment 30-31 cm above base of outcrop); AG Strat 1b \#6 (sampled 40-41 cm
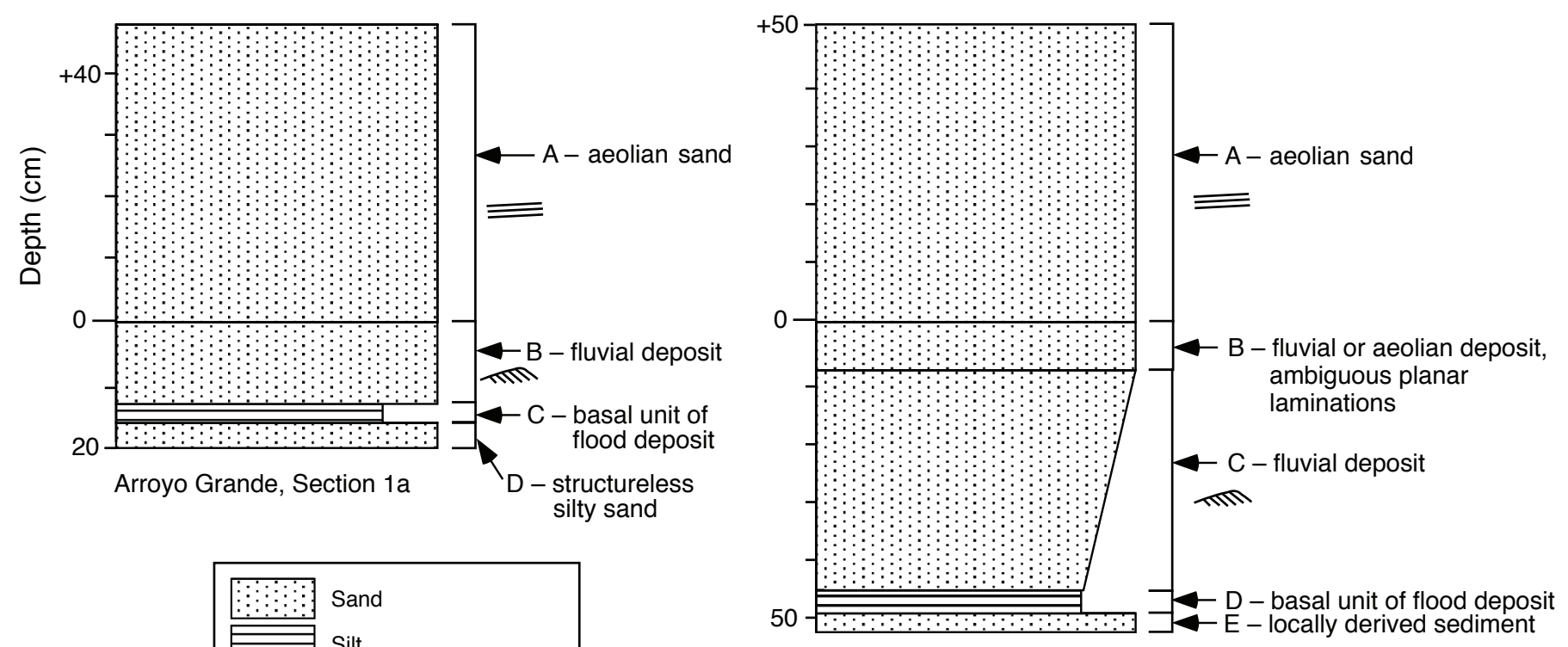

Arroyo Grande, Section 1b

Figure 50. Stratigraphic diagrams for sections 1a and 1b, Arroyo Grande. 
above base of outcrop; may be top of flood unit, or possibly in aeolian sand above the flood).

Section 1 summary.-This section (both parts $1 \mathrm{a}$ and $1 \mathrm{~b}$ ) is interpreted to include at least one, and possibly two, Colorado River flood deposits. Sediment with aeolian depositional structures makes up $\sim 1 \mathrm{~m}$ of the section above the flood unit(s), indicating reworking of fluvial sediment into aeolian dunes. Above the well-defined aeolian sedimentary structures, another $30-60 \mathrm{~cm}$ of sediment thickness is poorly exposed or contains few diagnostic sedimentary structures. Considering the gradational upward transition from aeolian to structureless sediment, this uppermost structureless material may be bioturbated aeolian sediment.

\section{Arroyo Grande, Section 2}

Section 2 was logged in two parts, $2 \mathrm{a}$ and $2 \mathrm{~b}$, which are separated laterally by $\sim 5 \mathrm{~m}$ (fig. 51 ). Section $2 \mathrm{a}$ is the upper portion of this profile, while $2 \mathrm{~b}$ is the lower part (exposure was not accessible below $2 \mathrm{a}$ or above $2 \mathrm{~b}$ ); there is some overlap in stratigraphic depth between $2 a$ and $2 b$. Depths are listed in reference to a survey datum within the section used for this exposure. An additional $\sim 1 \mathrm{~m}$ of poorly exposed and unexposed sediment is present above the highest levels described in section 2a.

Surface: Deflated, cryptogamic soil cover with grasses and mesquite tree above profiled area. Slumped sand, silt, and gravel obscure the exposure of stratigraphy immediately below the surface at both sections $2 \mathrm{a}$ and $2 \mathrm{~b}$. Measurements are in $\mathrm{cm}$ above $(+)$ and below an arbitrary datum in the section.

\section{Section $2 \mathrm{a}$}

$+\mathbf{5 0}-+\mathbf{3 8} \mathbf{~ c m}$ (Unit A): The uppermost exposed sediment in unit A of section 2a is a fine to very fine sand. This material contains scalloped cross-bedding that youngs in a direction downstream with respect to the Colorado River. This unit is interpreted as aeolian dune sand.

$+\mathbf{3 8}-+\mathbf{1} \mathbf{~ c m}$ (Unit B): The upper part of unit B contains fine to very fine sand (the whole unit appears to coarsen upsection). Clear fluvial climbing ripples are present, with some horizontal stratification. The upper part of the unit is mostly well-stratified; some unstratified areas appear bioturbated. Ripple migration direction is upstream toward $270^{\circ}$ in one ripple set and toward $290^{\circ}$ on another ripple

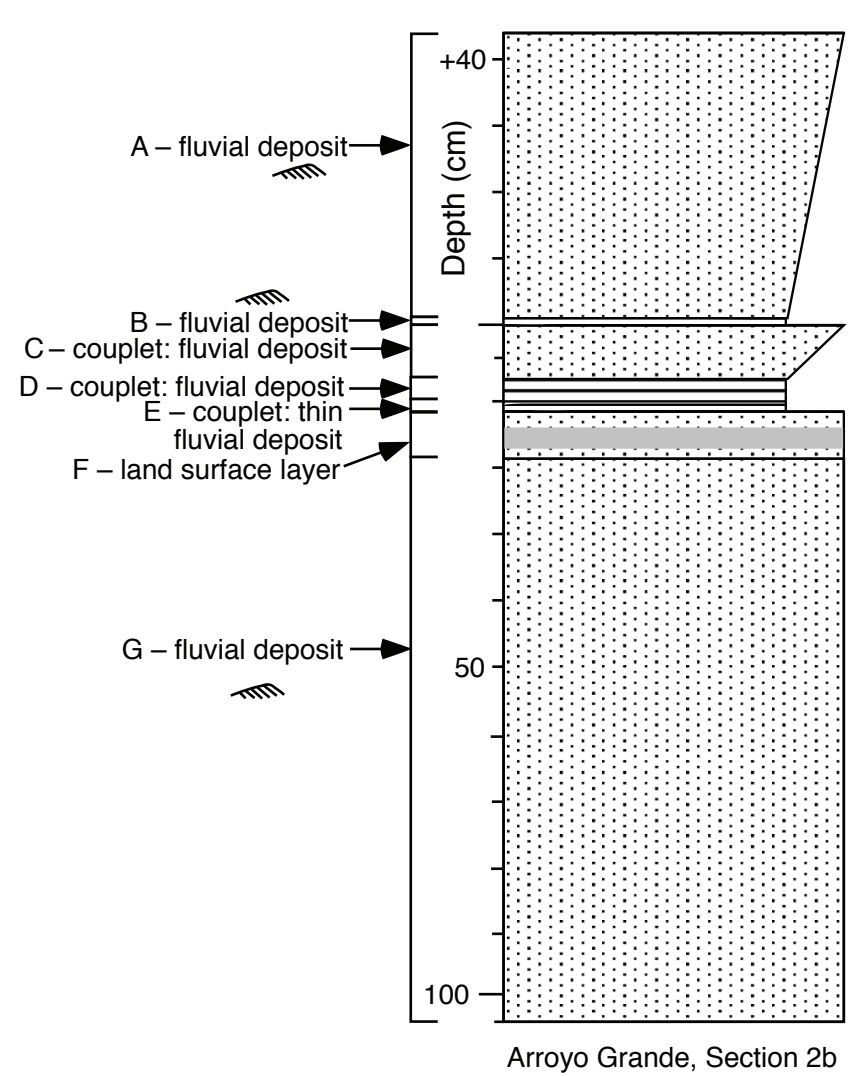

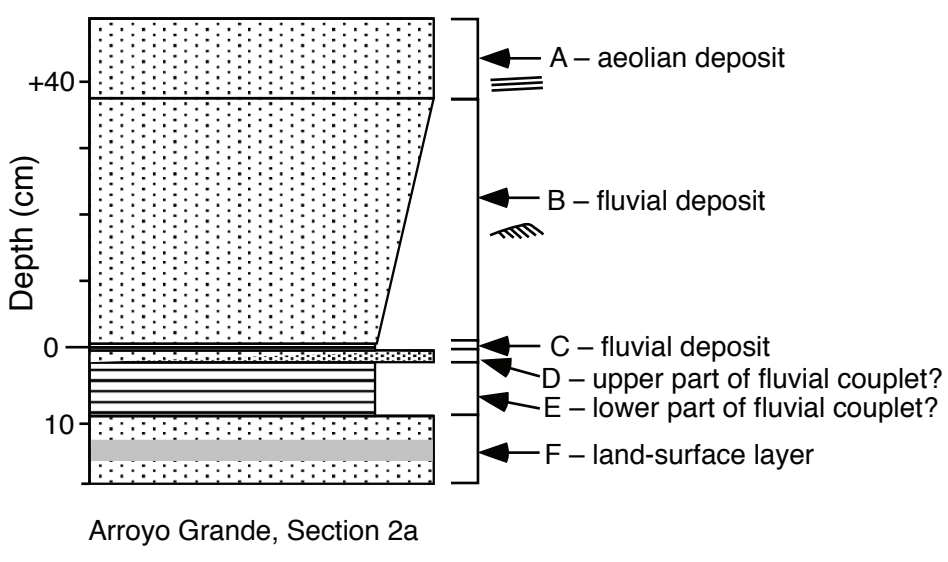

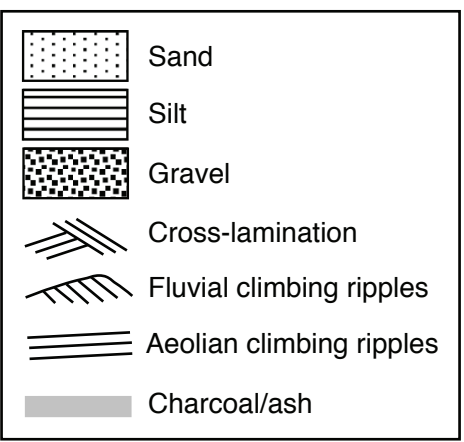

Figure 51. Stratigraphic diagrams for sections 2a and 2b, Arroyo Grande. 
set. The lower portion of this inferred flood couplet is a light-colored fine silt bed (1-2 cm thick) at the base of unit B. Unit B is interpreted to be a couplet representing a Colorado River flood deposit.

$+\mathbf{1}-\mathbf{0} \mathbf{~ c m}$ (Unit C): The base of unit $\mathrm{C}$ is the survey datum used to define stratigraphic depth in section 2 (a toothpick was used to mark this in the field). The upper part of the couplet is a brownish silt that is slightly coarser than the lower part. The base of unit $\mathrm{C}$ is a powdery, clean, whitish clayey silt; the unit has a bioturbated upper contact. Unit $\mathrm{C}$ represents an inferred fluvial deposit.

0 - $\mathbf{2} \mathbf{~ c m}$ (Unit D): This unit is coarser than unit $\mathrm{E}$ below and consists of a brownish very fine sandy silt. The sediment is very well sorted and has been bioturbated. Unit D may represent the upper part of a flood couplet (the lower portion being unit $\mathrm{E})$.

$2-10 \mathrm{~cm}$ (Unit E): This is a light-colored bed, finer than unit $\mathrm{F}$ below. Paper-thin laminae are present in powdery, clean silt, although bioturbation obscures some of the stratification. Its upper contact is gradational, with a $1-\mathrm{cm}-$ thick pinkish band through the silt. Unit $\mathrm{E}$ is interpreted as a Colorado River flood layer and may be the lower part of a fluvial deposit that forms a couplet with overlying unit D.

$10-20 \mathrm{~cm}$ (Unit F): Unit F is a brownish silty fine sand, with occasional disseminated charcoal fragments (of coarse sand size). There is crude, discontinuous horizontal stratification present, but this bedding is too poorly displayed to see real original bedding structures (possibly bioturbated). The upper contact is sharp. Unit $\mathrm{F}$ is interpreted as sediment that has undergone reworking and incorporation of charcoal while exposed at the land surface.

\section{Section $2 b$}

$+44-+1 \mathrm{~cm}$ (Unit A, to top of exposure where slumped, crusted sediment is present): Unit A contains well-defined fluvial climbing ripples. Ripple migration direction is upstream; this flood deposit is the same as unit B of section 2a. There is a clear trend toward coarsening upward in this layer. This is interpreted as a Colorado River flood deposit.

$+\mathbf{1}-\mathbf{0} \mathbf{~ c m}$ (Unit B): This thin flood couplet with a white silt base corresponds to unit $\mathrm{C}$ of section 2a. One sediment sample was collected from this layer: AG Strat $2 b$ \#1 (sample in two parts): sample of silt (inferred Colorado River deposit) from unit B.

$\mathbf{0}-\mathbf{8} \mathbf{~ c m}$ (Unit C): The upper portion of this layer is gray to buff silty fine sand with a small amount of charcoal in it. The lower portion is a light-colored silt with paper-thin laminae. The upper contact of unit $\mathrm{C}$ is abrupt. This flood couplet may be the lateral continuation of a flood couplet defined by units $\mathrm{D}$ and $\mathrm{E}$ in section 2a. Unit $\mathrm{C}$ is interpreted as a fluvial couplet.

$8-12 \mathrm{~cm}$ (Unit D): The lower part of unit D is a silt with paper-thin laminae, which grades upward into poorly stratified grayish silt with coarser charcoal pieces that suggest some reworking at the land surface. The upper part is only locally present, with a faint boundary between the upper and lower parts of the deposit. This is interpreted as a fluvial couplet.

$12-13 \mathrm{~cm}$ (Unit E): The resistant lower silt portion of unit $\mathrm{E}$ (white, clean silt) is $<1 \mathrm{~cm}$ thick. The silt is bioturbated, with several $\mathrm{mm}$ above it of coarser, disturbed sediment, similar to unit $\mathrm{F}$ below. Unit $\mathrm{E}$ is likely the very thin distal edge of a flood deposit couplet.

$13-20$ cm (Unit F): Unit F consists of a brown/gray silty fine to very fine sand with crude horizontal stratification and a small charcoal/ash concentration $\sim 1 \mathrm{~cm}$ thick centered at a depth of $20 \mathrm{~cm}$. The charcoal lens is bioturbated and spans just over $35 \mathrm{~cm}$ laterally. The upper contact of unit $\mathrm{F}$ is abrupt. The lower contact is inclined downstream and irregular; this unit thickens downstream, with the depth of the lower contact ranging from 20 to $35 \mathrm{~cm}$. Unit $\mathrm{F}$ in section $2 \mathrm{~b}$ is likely the same land surface that is described as unit $\mathrm{F}$ in section $2 \mathrm{a}$, though section $2 \mathrm{~b}$ contains evidence for more smaller floods between the reworking of sediment at the land surface in the two units $F$ and the deposition of the next clear correlative layer between these two profiles (the large flood deposit referred to as unit B in section 2a and unit $A$ in section $2 b$ ). Unit $F$ is interpreted as sediment that has undergone reworking and modification at the land surface between Colorado River flood events.

$20-105 \mathbf{~ c m}$ (Unit G, to base of section at the arroyo floor): The base of this layer is below the floor of the arroyo, so the complete thickness is not known. Well-defined fluvial climbing ripple structures are present in this fine to very fine sand, consistently migrating upstream. Ripples migrated toward 330o, indicating flow in an eddy during the flood event. Unit $\mathrm{G}$ is bioturbated and contains white, calcified rootlets; sediment is pinker than unit $\mathrm{F}$ above it. On the upstream side of the exposure, dune or bar foresets (crossbedding) are apparent that dip 28o toward 320o. Ripples were migrating toward $330 \mathrm{o}$; this therefore suggests that the ripples were migrating over the crest of a bar form. The upper contact is defined by a color change from pink to brown/gray; pinker sediment likely reflects incorporation of locally derived sediment from slope-wash deposition. The upper contact is irregular, as described above, and is bioturbated. Unit $\mathrm{G}$ is a Colorado River flood deposit.

Section 2 ( $a$ and b) summary.-These two sections reflect multiple Colorado River flood events, with reworking of sediment at the land surface implied by the unit $F$ in both sections. After deposition of unit $\mathrm{F}$, several small fluvial deposits were emplaced, followed by a thick flood deposit. The exposure at section $2 \mathrm{a}$ demonstrates deposition of aeolian sand above that thick flood unit (likely aeolian reworking of sediment derived from flood deposits). 


\section{Arroyo Grande, Section 3}

A detailed stratigraphic log was not made for section 3. A stratigraphic diagram made based on a field sketch for section 3 is shown in figure 52 .

Section 3 summary.-This profile appears to consist entirely of multiple sets of superposed flood couplets, despite the facts that (1) at least part of the profile was in a low channel at the time of deposition and (2) nearby profiles show multiple layers of slope-wash/channel gravels.

\section{Arroyo Grande, Section 4}

A photograph of the section 4 location is shown in figure 53; figure 54 shows the stratigraphic diagram for this section. Measurements are in $\mathrm{cm}$ below the land surface. On either side (upstream and downstream) of this measured section, facies are very variable laterally; the location of this profile in a zone of repeated channel incision and filling has resulted in little direct lateral continuity of stratigraphic horizons.

Surface: Deflated, grass-covered sediment with cryptogamic crust development. This section was logged immediately

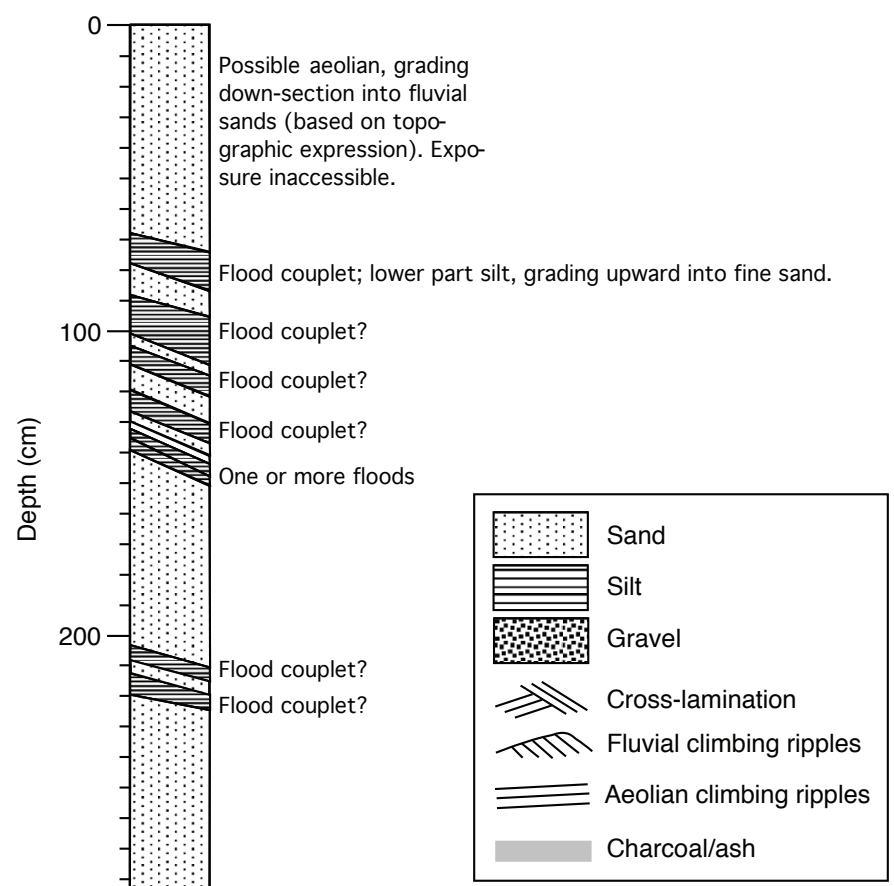

Figure 52. Field sketch of stratigraphic section at section 3, Arroyo Grande. below a large mesquite tree with roots extending down over the arroyo wall. Metal pegs in this arroyo wall mark locations where samples were collected for radiocarbon dating (sample RC5) by Hereford and others (2000).

0 - 18 cm (Unit A): Surface material, with no apparent sedimentary structures. Sediment is heavily bioturbated. Grain size is silty fine sand. Unit A has no distinct lower contact. Material is possibly reworked aeolian sediment, but sedimentary structures have been almost entirely obscured by root development.

$18-25$ cm (Unit B): This unit contains a burned zone (burned in place, as is evident from a reddish oxidation layer at the base of the ashy soil area). The ashy soil is contained in silty very fine sand that is massive, heavily burrowed, and bioturbated by roots. The lower contact of unit B is indistinct.

$25-40 \mathrm{~cm}$ (Unit C): The lowermost $3 \mathrm{~cm}$ of unit $\mathrm{C}$ are pale beige/gray silt, heavily bioturbated such that sedimentary structures are absent. The boundary between this silt and

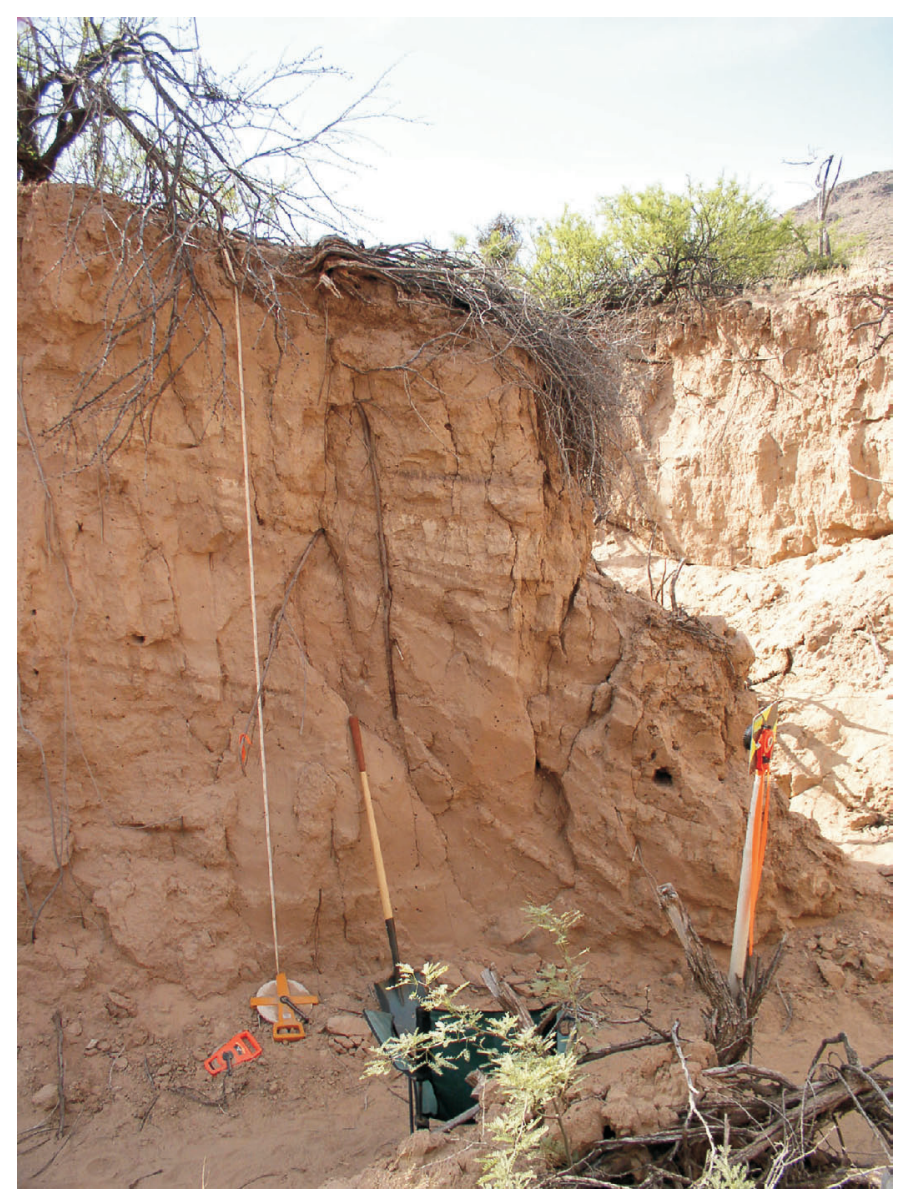

Figure 53. Location of section 4 at Arroyo Grande. The profile height (at location of measuring tape) is approximately $3 \mathrm{~m}$. This stratigraphic section is in a zone of repeated channel incision and filling (note beds that dip steeply to the right of the photo [north, shoreward]); there is therefore little lateral continuity of stratigraphic units at this site. 
the overlying coarser upper part of the flood couplet is smooth. The lower boundary (between units $\mathrm{C}$ and $\mathrm{D}$ ) is bioturbated. This is interpreted as a flood deposit that forms a sedimentary couplet.

$40-78 \mathrm{~cm}$ (Unit D): The upper part of unit D is a structureless silty fine sand. Numerous carbonate-filled rootlet nodules are present, as are many open rootlet pores. Sediment is heavily bioturbated. The lower contact is sharp and smooth, with an apparent increase in calcium carbonate content directly on the lower contact. Unit D is interpreted as a likely fluvial deposit on the basis of stratigraphic association and couplet structure; the lowermost $6 \mathrm{~cm}$ of this unit is a whitish very clean silt, more resistant than the upper portion.

$78-115 \mathrm{~cm}$ (Unit E): Unit E can be considered in four parts: $78-87$ cm (Subunit E1): Structureless fine sand, possibly an aeolian deposit that may represent reworking by wind of the upper part of a fluvial deposit. Alternatively, this could represent local alluvial material, as it grades laterally into a gravel lens that fills a channel $0.5 \mathrm{~m}$ wide that lies immediately upstream of section 4 .

$87-90 \mathrm{~cm}$ (Subunit E2): This horizon consists of a burned zone with ashy soil (burned in place) with very

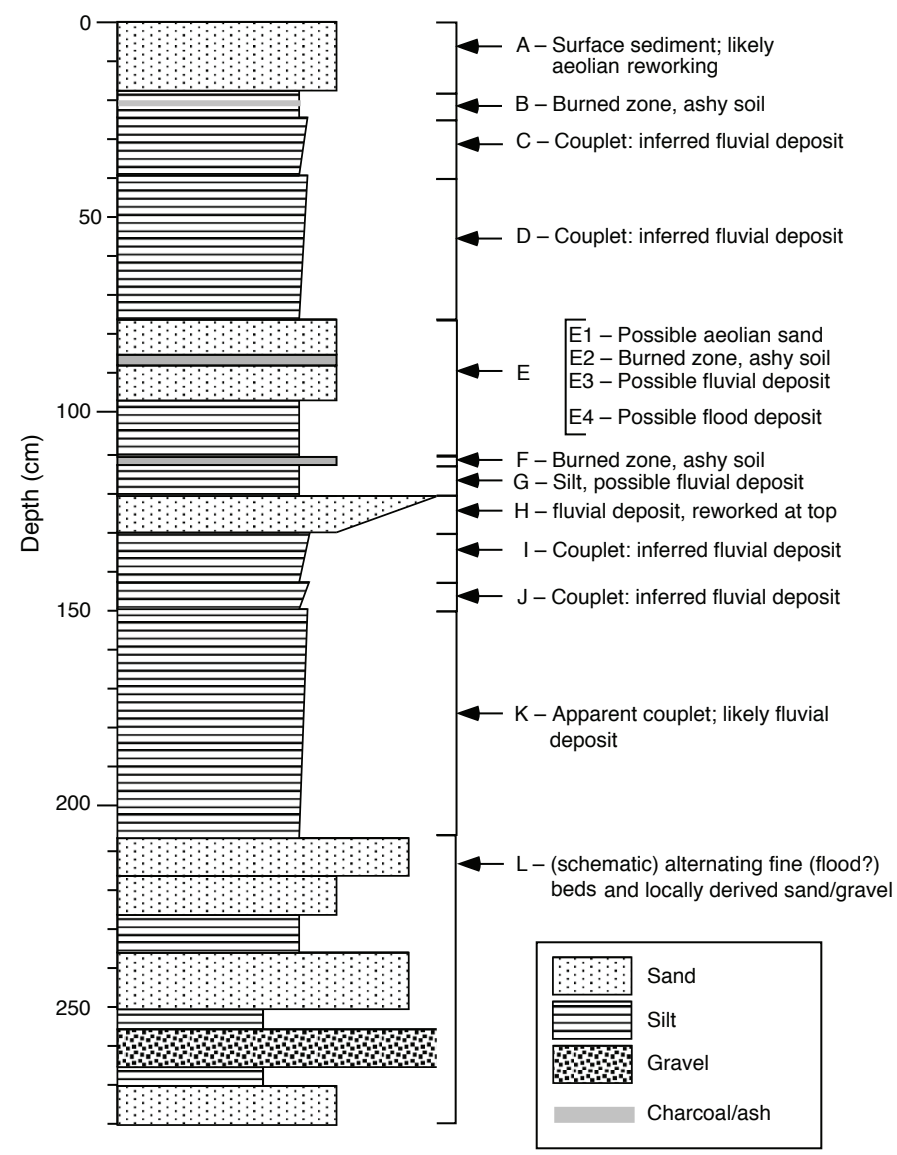

Figure 54. Stratigraphic diagram for section 4, Arroyo Grande. little charcoal. The upper and lower contacts are strongly bioturbated, and are clear but wavy.

$91-100 \mathbf{c m}$ (Subunit E3): This layer is a silty fine sand that may represent a flood deposit, but lacks sedimentary structures. Subunits E2 and E3 together may represent a flood couplet.

$100-115 \mathrm{~cm}$ (Subunit E4): Structureless clean silt with abundant calcium carbonate. The lower boundary is very abrupt and smooth.

$115-117$ cm (Unit F): Unit F is another burned zone (burned in place) with ashy soil. The lower contact is very bioturbated but clear.

$117-\mathbf{1 2 5} \mathbf{~ c m}$ (Unit G): This unit is a whitish silt layer. The lower boundary is sharp and smooth.

$125-135 \mathrm{~cm}$ (Unit H): The bottom of unit $\mathrm{H}$ contains fine sand, which grades into coarse sand and granules at the top. Laterally, this unit grades into a poorly sorted gravel bed that contains clasts as big as pebble sizes. The lower boundary of the upper part of unit $\mathrm{H}$ is difficult to see but is defined by an increase in silt content. The unit contains no clear sedimentary structures, but there is an increase in carbonate-filled root pores in the lowest $5 \mathrm{~cm}$ of unit $\mathrm{H}$. The lower contact is indistinct and smooth. The lower silty $5 \mathrm{~cm}$ pinch out riverward. This couplet is interpreted as a fluvial deposit that has experienced subaerial reworking at its top.

$135-148$ cm (Unit I): Unit I represents another sediment couplet (fluvial base, subaerially reworked top). The coarser upper part of the couplet extends from 135 to $139 \mathrm{~cm}$ below the modern land surface, and is dominated by silty fine sand with very faint, thin bedding. The transition from coarser upper sediment to lower, finer sediment within this couplet is fairly abrupt. The lower part of the couplet (from 139 to $148 \mathrm{~cm}$ ) is a very clean silt. This lower sediment is locally laminated, and contains isolated small pieces of charcoal but no evidence of an actual burned zone (the charcoal was not burned in place). Many rootlet pores and burrows are present. This unit is inclined more steeply than other bedded areas (the lower, silt portion of the couplet dips at 150 toward 262o). This is the same unit that yielded a radiocarbon date range of 40 B.C. to A.D. 330 (sample RC5 of Hereford and others, 2000). The lower boundary is bioturbated but abrupt.

$148-155 \mathrm{~cm}$ (Unit J): The upper part of this 'couplet' unit (148 to $151 \mathrm{~cm}$ ) is a silty fine sand. This contains charcoal pieces and is burrowed with silt-filled rootlet channels. Parallel laminae (horizontal) are present. The boundary between upper and lower portions of this couplet is indistinct. The lower part of the couplet (from 151 to $155 \mathrm{~cm}$ ) is a silt that gradually disappears in the downstream direction within this outcrop, grading into the unit from which the radiocarbon sample RC5 was obtained by Hereford and others (2000). Unit J thickens upstream in this outcrop. Its lower boundary is strongly bioturbated and indistinct. This is interpreted as another couplet most likely representing a fluvial deposit with a subaerially reworked top.

$155-205$ cm (Unit K): Locally, as much as $25 \mathrm{~cm}$ of 
topography occurs on the lower boundary of unit K. Downstream of this unit are two coarse gravel lenses (locally present only). This unit appears to be in part a local channel fill. There are many silty interbeds, but sediment generally grades from very fine sand at the base to fine sand at the top (coarsening upward). If unit $\mathrm{K}$ is a flood deposit, it may represent more than one flood event. The silty lower part of this apparent couplet is very variable and discontinuous. Where present, the lower sediment is a clean silt; this is discontinuous and locally lies directly above much coarser material of unit $\mathrm{L}$. This is a possible couplet, but with the division between upper and lower portions of the couplet indistinct.

$205-\mathbf{2 8 0}+\mathbf{c m}$ (Unit $\mathbf{L}$, to base of outcrop): The lowermost unit in section 4 contains alternating sequences of locally derived slope-wash material (lithic fragments) with silty sands as much as 10-12 cm thick. Beds of hard, cohesive clay are present in this sequence. Individual sandy beds vary between fine sands and pebbly gravels. Unit L may truncate an older Colorado River flood sequence at its base (inconclusive exposure).

Section 4 summary.-This exposure appears to be on the edge of some kind of channel, with channel forms filled with gravel beds in lenses on either side (upstream and downstream) of the vertical cut where section 4 was described. This section is in the main trunk (center) of the primary arroyo network at Arroyo Grande; the trunk of this large arroyo system has likely been at this approximate location (with some lateral migration) for an extended period of time. The area represented by section 4 may not have been a true "arroyo" but instead a local broad channel carrying locally derived sediment as well as being the return channel area for Colorado River floods.

\section{Arroyo Grande, Section 5}

Photographs from one horizon within section 5 (unit C) are shown in figures 55 and 56 . The stratigraphic diagram for section 5 is shown in figure 57 . Measurements are in $\mathrm{cm}$ below the land surface.

Surface: Deflated, grassy cryptogamic soil cover with pebbles of granite and amphibolite gneiss from talus slope behind and above. A pedestaled soil crust $\sim 1 \mathrm{~mm}$ thick is present. Section 5 is cut into arroyo of lower terrace, just riverward of boundary between upper and lower terraces. Approximately $2 \mathrm{~m}$ landward of section 5 is a nickpoint where arroyo incision into lower terrace is about to join with upper terrace incision (the nickpoint is now $\sim 3 \mathrm{~m}$ riverward of where it will meet the upper terrace drainage).

0-19 cm (Unit A): This unit is surface sediment with no microstructure; it is very bioturbated with root development. Clasts up to pebble size of granite and gneiss are present, derived from the talus above. Within that $19 \mathrm{~cm}$ is (from
15-17 $\mathrm{cm}$ below the surface) a heavy organic concentration. The lower contact of unit $\mathrm{A}$ is indistinct and gradational into better defined stratification until the microstructure in unit $\mathrm{B}$ becomes apparent.

19-38 cm (Unit B): Unit B consists of parallel stratification with beds defined by thin (less than $3 \mathrm{~mm}$ ) coarse sand lenses with some organic concentration horizons as much as $1-2 \mathrm{~cm}$ thick. Several areas with subaqueous ripples are defined in coarse sand; rivulet development is inferred down a distal alluvial fan surface with slope-wash sediment being reworked. Finer-grained areas have a pinkish color. Unit B reflects apparent surface sedimentation and reworking on the distal edge of an alluvial fan.

38-65 cm (Unit C): This unit is bioturbated with white calcified rootlets, but contains very well defined fluvial climbing-ripple structure throughout. Cuts at different angles show that ripple migration direction was upstream

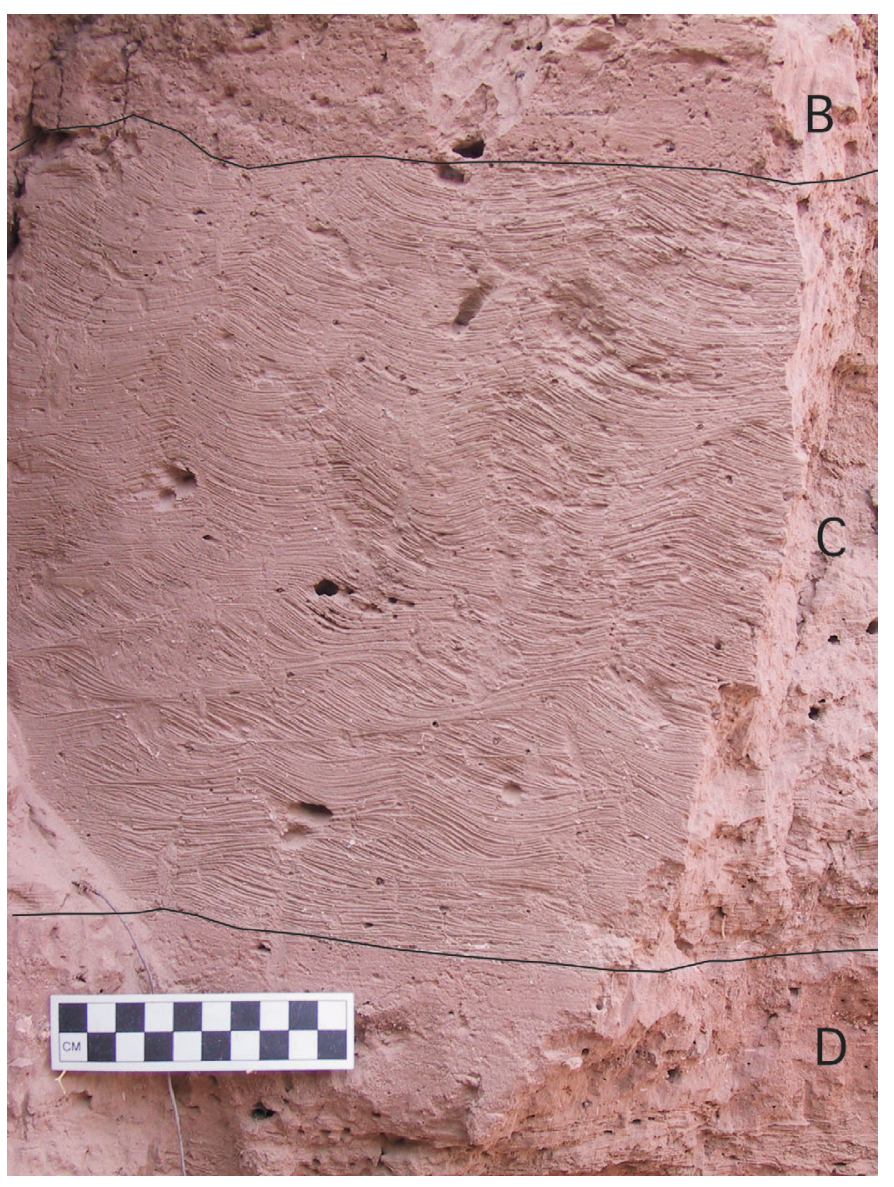

Figure 55. Excellent exposure of fluvial climbing ripples in unit $\mathrm{C}$ of section 5, Arroyo Grande. The current direction during deposition was from left to right (upstream), indicating flow in an eddy. The steep angle of climb indicates rapid deposition; increasing climb angle upsection indicates increasing deposition rate in the later stages of the flood. Grain-size analyses show that this unit fines upward slightly. Unit $C$ is slightly thicker in this exposure than the $15 \mathrm{~cm}$ measured at section 5 (this unit thickens riverward). 
(climb toward $290^{\circ}$ ), apparently representing flow in an eddy, during the flood. Photographs (figs. 55, 56) show that ripples at the base of this unit base climb subcritically (lateral migration of $\sim 6 \mathrm{~cm}$ in $1 \mathrm{~cm}$ of vertical aggradation). Ripple climb changes upward to almost vertical aggradation. Wavelength of the ripple set increases from 7 to $10 \mathrm{~cm}$ at top of unit. Appears to fine upward; base grain

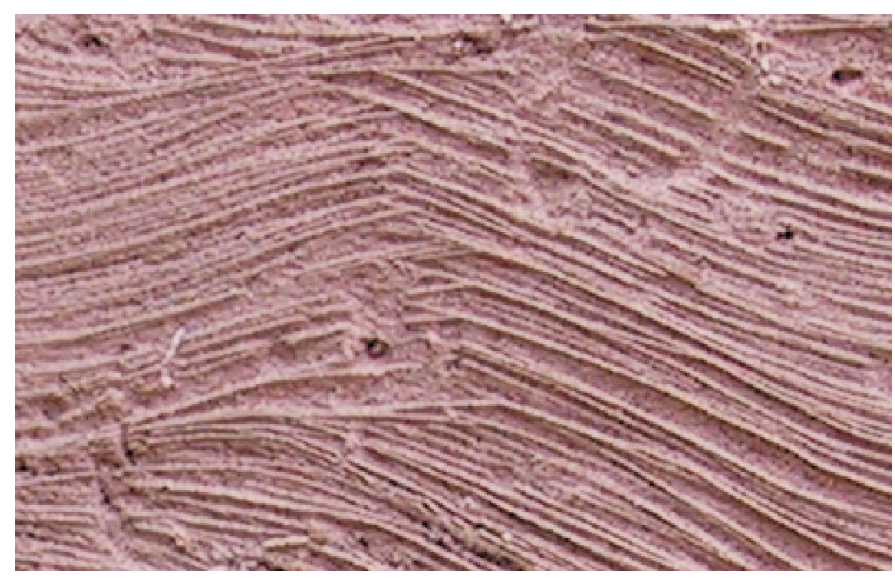

Figure 56. Close-up view of one ripple crest from the unit $\mathrm{C}$ flood deposit of section 5, Arroyo Grande. The nearly vertical angle of climb implies rapid deposition. The 'zig-zag' upsection oscillation of the ripple crest in individual laminae is interpreted to be a result of eddy pulsation (Rubin and MacDonald, 1995) during deposition.

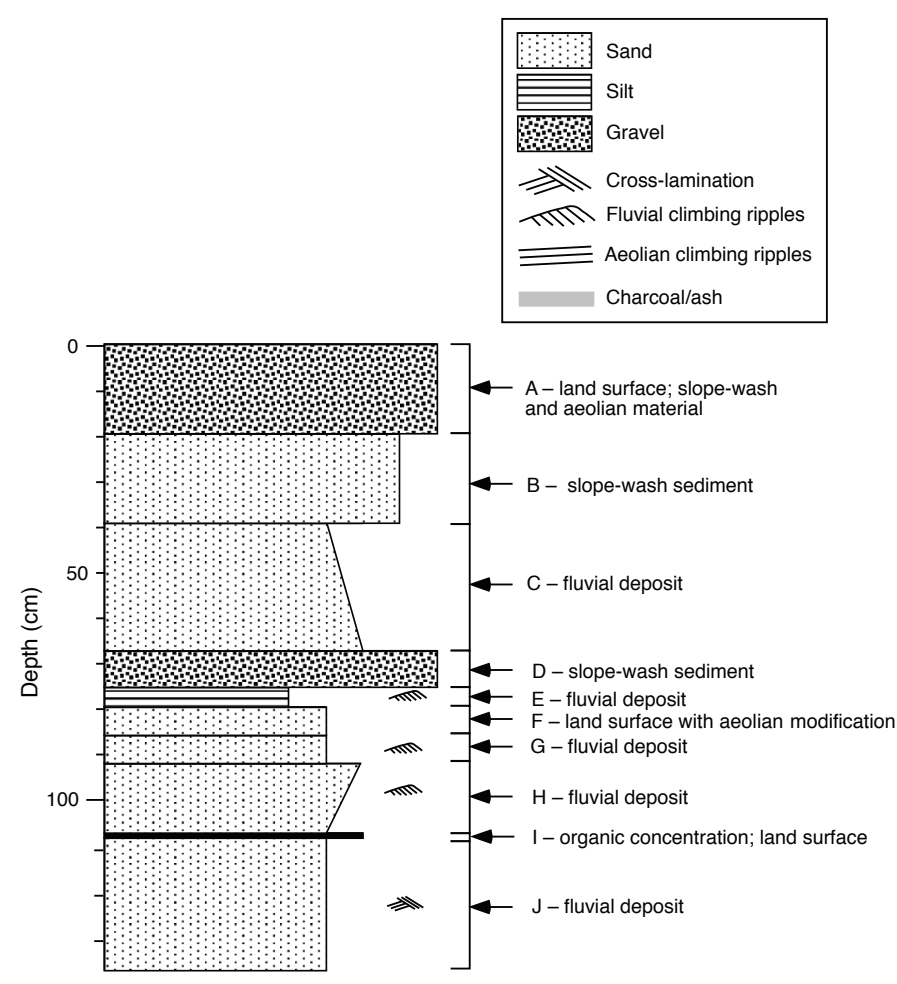

Figure 57. Stratigraphic diagram for section 5, Arroyo Grande. size is fine sand while the top of the unit is very fine silty sand. This unit thins very slightly toward the shoreward end of outcrop ( 25 vs. $27 \mathrm{~cm}$ thick). Interpreted as a Colorado River flood deposit, unit $\mathrm{C}$ has a sharp lower contact with a color change from fine gray Colorado River sediment to brown-pink coarser material below. Four grain-size samples were collected from this unit: AG Strat 5 \#1( Unit C base, 0-1 cm above base of unit); AG Strat 5 \#2 (Unit C 8-10 cm above base of unit); AG Strat 5 \#3 (Unit C 16-18 cm above base of unit); AG Strat 5 \#4 (Unit C 24-26 cm above base of unit).

67-75 cm (Unit D): Unit D consists of slope-wash sediment representing a land surface, with modifications by aeolian processes; this apparently represents a distal alluvial-fan environment. Sediment has a pink/brownish color, coarser than unit $\mathrm{C}$ above. Parallel bedding is defined by clasts as large as granule sizes that consist of K-spar-rich granite and amphibolite gneiss fragments. Bioturbated sediment, with white rootlets. Grain size ranges from granule down to fine and medium sand in parallel beds. Unit D is bounded by sharp upper and lower contacts.

75-79 cm (Unit E): This 2-4-cm-thick unit is a gray, finegrained subaqueous flood deposit, likely a Colorado River flood. Unit E contains well-defined subaqueous climbing ripples (small scale). Grain size is fine to very fine sand, with no evidence of lithic clasts as would be expected if it were a subaqueous deposit from an arroyo floor. Ripple migration direction is toward 254o, upstream (indicating an eddy). The unit thickens from 2 to $4 \mathrm{~cm}$ riverward in outcrop, over a distance of $\sim 1.5 \mathrm{~m}$. The lower contact is on an organic concentration a few mm thick (unit F), making the contact slightly irregular.

79-85 cm (Unit F): This unit is 2-6 cm thick (thickens toward the shoreward end of the outcrop, where overlying unit $\mathrm{E}$ is thinner). It includes an organic horizon $\sim 0.5 \mathrm{~cm}$ thick and is bioturbated with rootlets throughout. Unit $\mathrm{F}$ has a more pink/tan color than flood units ( $\mathrm{E}$ and $\mathrm{G}$ ) above and below. Find sand dominates, with no strong concentrations of lithic clasts but with some parallel bedding (not very distinct). The lower contact is sharp. This is an apparent land surface with aeolian modification, similar to units B and D above.

85-91 cm (Unit G): Unit G contains gray, fine to very fine sand with very well preserved subaqueous climbingripple structures. Ripples migrate toward 260o (upstream, indicating an eddy). The unit does not appear to coarsen upward. The lower contact is angular, separating two flood deposits $(\mathrm{G}$ and $\mathrm{H}$ ) in vertical sequence. This unit is interpreted as another Colorado River flood deposit.

91-106 cm (Unit H): This unit is $12-15 \mathrm{~cm}$ thick. The base consists of fine sand, with a pinkish gray color. The top is fine to medium sand, pinker and coarser than unit $G$ above. The base is organic rich, but contains better defined subaqueous climbing ripple development upward. This is interpreted to represent a separate flood deposit from unit $\mathrm{G}$, with no other apparent land surface or unconformity between this and the overlying flood unit $(G)$. Units $G$ and 
$\mathrm{H}$ may have been two peaks of same flood event, or two separate floods that occurred in rapid succession without reworking by aeolian, slope-wash, or other processes on the land surface between flood events. Because unit $\mathrm{H}$ is truncated by overlying unit $\mathrm{G}$, which contains sediment of different grain size and color, it likely represents a separate event. Unit $\mathrm{H}$ appeared in the field to coarsen upward. Four samples were collected for grain size analysis: AG Strat 5 \#5 (Unit H 1-2 cm above base of unit); AG Strat 5 \#6 (Unit H 5-6 cm above base of unit); AG Strat 5 \#7 (Unit H 9-10 $\mathrm{cm}$ above base of unit); AG Strat 5 \#8 (Unit H 13-14 cm above base of unit).

106-107 cm (Unit I): This unit consists of a concentration of organic matter as much as $1 \mathrm{~cm}$ thick, interpreted as a reworked land surface containing vegetation development that formed between Colorado River flood events.

107-135+ cm (Unit J, to base of outcrop): Contains pinkish sediment with well-developed bedding, but not climbing ripples. Grain size is fine to very fine sand, and the deposit does not appear to coarsen upward. Unit $\mathrm{J}$ is mostly parallelbedded with swales, suggesting possible subaqueous dunes. One small area of this unit, approximately 3 m laterally from the main logged section 5, contained subaqueous ripple forms. Unit $\mathbf{J}$ is interpreted as a Colorado River flood unit, possibly with its pinker sediment contributed by unusually high discharge from a tributary during the flood that deposited it.

Section 5 summary. - This section is located in a secondary arroyo system incised into the lower terrace area at Arroyo Grande, riverward and downstream of the stratigraphic sections described in the main arroyo network. Depositional environments in this section alternate between Colorado River flood deposition and modification of this flood sediment by reworking at the land surface, including the addition of sediment derived from local slope-wash. A minor component of aeolian sediment is inferred in unit A.

\section{Arroyo Grande, Section 6}

Photographs in figures 58 and 59 show detail of several stratigraphic horizons in section 6. A stratigraphic diagram for section 6 is shown in figure 60. Stratigraphic depths are reported in $\mathrm{cm}$ below the land surface. The survey datum for this section is $2.0 \mathrm{~m}$ below the terrace surface.

0-80 cm (Unit A): Inaccessible area. At the base of this unit is a thin whitish layer interpreted to be the base of a flood deposit.

80 - $150 \mathrm{~cm}$ (Unit B): Unit B is a slightly sandy silt, with very little original stratification apparent. The unit is bioturbated, and charcoal is present at two horizons (depths not recorded).

$150-168 \mathbf{~ c m}$ (Unit C): This is a silt that ranges in size from fine to coarse and slightly sandy, with paper-thin lamination.
Fluvial climbing ripples are present; this is interpreted as a Colorado River flood deposit. This unit coarsens upward, and more bioturbation is apparent in its upper portion.

$168-198 \mathrm{~cm}$ (Unit D): Fluvial climbing ripples are present throughout this horizon. No distinct trend in grain size is apparent. Unit D is interpreted as another Colorado River flood layer.

$198-228 \mathrm{~cm}$ (Unit E): This is a coarse silt, with fluvial climbing ripples indicating another flood deposit.

Bioturbation increases upsection within this horizon. The lower contact is sharp, with a basal white, very fine grained clayey silt less than $1 \mathrm{~cm}$ thick.

$228-231 \mathrm{~cm}$ (Unit F): This is a silt that contains fluvial climbing ripples and little bioturbation. At its base is 2-3 $\mathrm{mm}$ of white, very fine-grained clayey silt that has a sharp base and a gradational top.

$231-258$ cm (Unit G): Unit G can be broken into three subunits, each of which is interpreted as a fluvial deposit
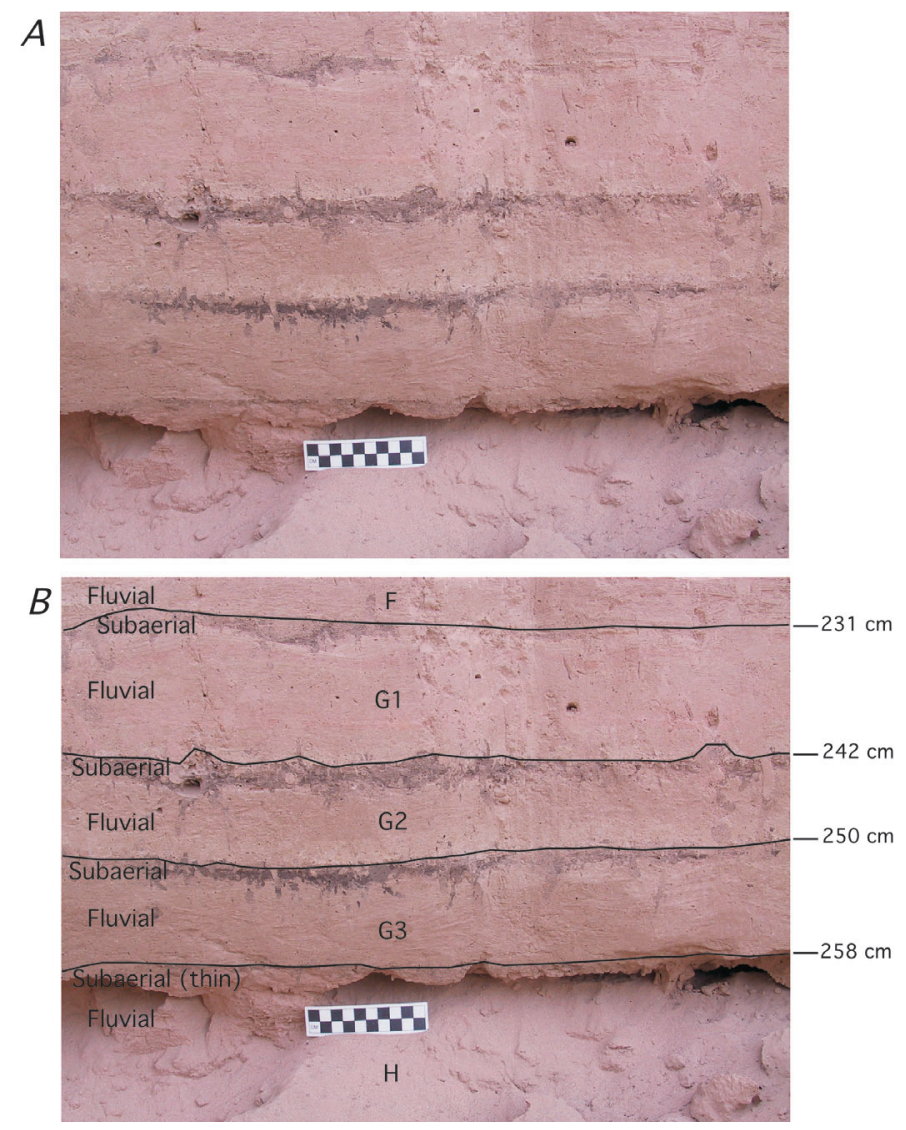

Figure 58. Uninterpreted $(A)$ and interpreted $(B)$ views of sedimentary couplets in unit $\mathrm{G}$, section 6 at Arroyo Grande. Each stratigraphic package shown is interpreted as a flood deposit that has subsequently been reworked at the land surface. Fluvial climbing ripples are present in the fluvial parts of each couplet. The subaerial portion of each couplet shown contains locally derived slope-wash sediment as well as charcoal and ash staining. The common presence of charcoal and ash in subaerial parts of couplets may reflect grass fires started by the prehistoric occupants of this area. Bioturbation has mixed subaerial sediment downward into the lower fluvial deposits. 
that shows evidence of reworking at the land surface (figure 58):

231 - 242 cm (Subunit G1): The upper part of this subunit is $\sim 1 \mathrm{~cm}$ thick, containing charcoal-rich silt or fine sand with sharp contacts. The middle portion of subunit G1 contains silt with fluvial climbing ripples, and has a gradational base. The lower part of this subunit contains $\sim 1$ $\mathrm{cm}$ of white, very fine-grained clayey silt.

$242-250 \mathrm{~cm}$ (Subunit G2): Upper part is $\sim 1 \mathrm{~cm}$ thick, containing charcoal-rich silt or fine sand with sharp upper and lower contacts. The middle portion of this subunit contains silt with fluvial climbing ripples; its base is gradational. The lower part of subunit G2 contains $\sim 1 \mathrm{~cm}$ of white, very fine-grained clayey silt.

$\mathbf{2 5 0}$ - $258 \mathrm{~cm}$ (Subunit G3): The upper part of subunit G3

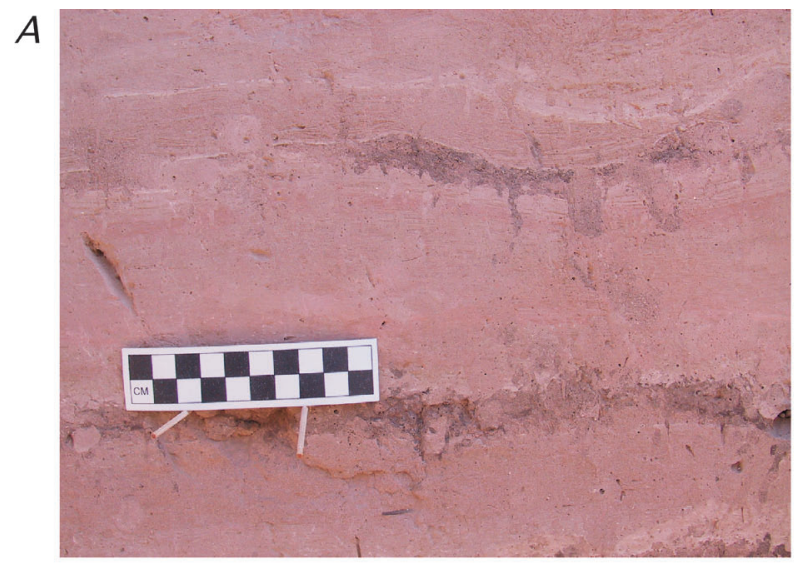

$B$

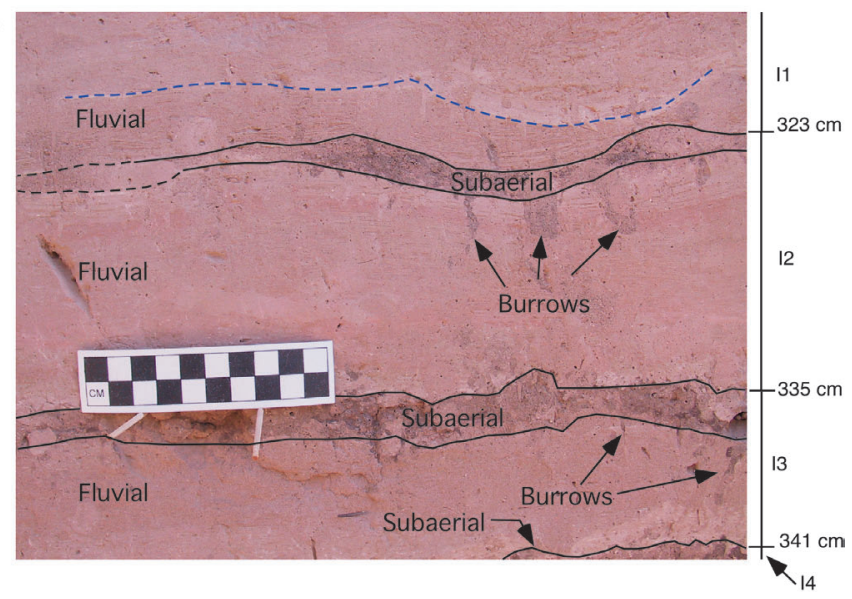

Figure 59. Uninterpreted $(A)$ and interpreted $(B)$ views of sedimentary couplets in the upper part of unit I, section 6 at Arroyo Grande. Each subunit is interpreted as a flood deposit that has subsequently been reworked at the land surface. Fluvial climbing ripples are present in the fluvial parts of each couplet. The blue dashed line in subunit I1 is believed to represent a small scour-and-fill sequence within that flood deposit. The subaerial portion of each couplet shown contains locally derived coarse sand and gravel as well as charcoal and ash. Bioturbation has mixed subaerial sediment downward into the lower fluvial deposits; several larger burrows are indicated, but bioturbation is evident on a smaller scale as well. is $\sim 1 \mathrm{~cm}$ thick, containing charcoal-rich silt or fine sand with sharp contacts. The middle portion of this subunit contains silt with fluvial climbing ripples, and has a gradational base. The lower part of this subunit contains $\sim 1 \mathrm{~cm}$ of white, very fine-grained clayey silt. Seven samples were collected from subunit G3 and the inferred land-surface sediment that immediately underlies (unit $\mathrm{H}$ ) and overlies (subunit G2) that flood deposit (the sampled bed extends from 251 to 261 $\mathrm{cm}$ below the land surface): AG Strat $6 \# 1(260-261 \mathrm{~cm}$ below surface; interpreted as land-surface material (contains charcoal) immediately below the base of the next overlying flood deposit; bioturbation has mixed this material with the silty basal sediment of the overlying flood unit); AG Strat 6 \#2 (258.5 - $259.5 \mathrm{~cm}$ depth; white silty basal flood sediment); AG Strat 6 \#3 (256 - $258 \mathrm{~cm}$ depth; within same flood couplet as \#2; paper-thin wavy laminae in silty sand); AG Strat 6 \#4 (255-256 cm depth; wavy laminated sediment farther up in same flood couplet); AG Strat 6 \#5 (252-253 cm depth; farther up in same flood unit); AG Strat $6 \# 6(251-252 \mathrm{~cm}$ depth; uppermost laminated part of this flood deposit; affected by burrowing); AG Strat $6 \# 7$ (250 - $251 \mathrm{~cm}$ depth; interpreted as land surface; charcoal-rich fine sand, burrowed from both above and below).

$258-302$ cm (Unit H): The upper part (1-2 cm) of unit $\mathrm{H}$ contains fine sand with charcoal and ash incorporated; bioturbation has mixed the silty base of subunit G3 into the coarser sediment of unit H. Fine sand grades down into silt

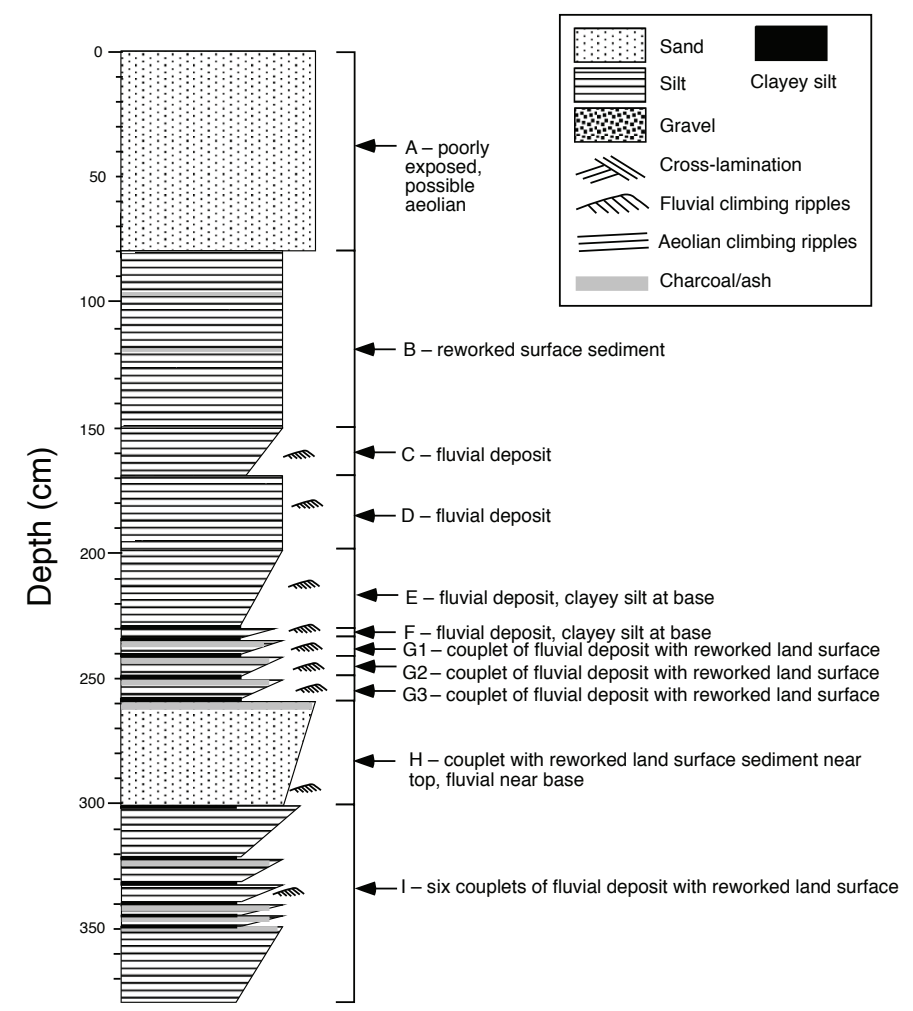

Figure 60. Stratigraphic diagram for section 6, Arroyo Grande. 
or very fine sand with silt laminae several mm thick. Some bioturbation is apparent, especially in the upper half of this unit. Fluvial climbing ripples are present, especially in the lower half. The lower contact of unit $\mathrm{H}$ is gradational. The lower $1 \mathrm{~cm}$ contains white, very fine-grained clayey silt.

$302-379+\mathbf{c m}$ (Unit I, to base of exposure): Unit I contains six subunits. Each subunit is interpreted as a Colorado River flood deposit that has been subsequently reworked at the land surface (fig. 59). Several of the subunits contain postflood charcoal-rich concentrations at the top. Four of the flood layers are overlain by a few $\mathrm{mm}$ to as much as $1.5 \mathrm{~cm}$ of unstratified sand, coarser than any sand within the flood layer. Each of the flood layers has a thin (several $\mathrm{mm}$ to $1 \mathrm{~cm}$ ) white, very fine grained clayey silt at its base, which may have a sharp base and gradational top. The bulk of each flood layer is silt or very fine sandy silt, in part with paper-thin lamination and fluvial climbing ripples. Some bioturbation occurs throughout. Depth ranges of individual subunits are: $302-323 \mathbf{c m}$ (Subunit I1); $323-335 \mathrm{~cm}$ (Subunit I2); 335 - 341 cm (Subunit I3); $341-345 \mathrm{~cm}$ (Subunit I4); 345 - 349 cm (Subunit I5); $349-379$ cm (Subunit I6).

Section 6 summary.-This section records the deposition of as many as 15 individual deposits from Colorado River flood events, separated by reworking at the land surface between floods. The typical flood sequence in this exposure contains a lowermost very fine clayey silt deposit, up to $1 \mathrm{~cm}$ thick. The bases of these fine silt layers are typically sharp, though subsequent bioturbation has modified their lower contacts in many cases. The fine basal clayey silt is overlain (often gradationally) by a coarser silt to fine sand deposit that, in this outcrop, commonly contains well preserved fluvial climbing ripple structures. The uppermost part of each sequence is typically bioturbated and, in the case of at least six of the flood events apparent in section 6 , contains a concentration of charcoal and ash that indicates exposure of this material at the land surface.

\section{Arroyo Grande, Section 7}

The stratigraphic diagram for section 7 is shown in figure 61 . Measurements are in $\mathrm{cm}$ below the ground surface. The land surface above section 7 is not accessible because its location is on a thin ridge separating two arms of the arroyo.

$0-18 \mathbf{~ c m}$ (Unit A): This uppermost sediment consists of alternating fine sand, silt, and small-pebble gravels. It is interpreted as dominantly slope-wash material. Several silt/ fine sand beds are present, approximately $5 \mathrm{~mm}$ thick, and appear to be crusts formed on former surfaces.

$18-54 \mathbf{~ c m}$ (Unit B): This horizon is laminated and appears to be waterlain, alternating fine sand and silt beds with laminae. There is distinct cross-bedding present, which is inferred to be of local origin rather than due to a Colorado River flood.
$54-58 \mathbf{~ c m}$ (Unit C): Unit C is a very fine sandy silt, strongly bioturbated and lensatic, that disappears to the north (shoreward). It may represent a Colorado River flood, but this interpretation is not certain. No depositional structures are visible.

$58-67 \mathrm{~cm}$ (Unit D): This layer is a massive very fine sand, which may represent a Colorado River flood deposit.

$67-67.5 \mathrm{~cm}$ (Unit E): This is a thin, discontinuous fine sandy silt lens, which may be the lower part of a flood deposit represented by unit $\mathrm{D}$.

$67.5-89 \mathrm{~cm}$ (Unit F): Unit F is a clean deposit of coarse sand and pebble-gravel, cross-bedded and lensatic; this comprises locally derived channel-fill deposits.

$89-94$ cm (Unit G): Unit $G$ is a clean silt, laminated in its upper 2 to $3 \mathrm{~cm}$, which is thought to represent a Colorado River flood deposit.

$94-99 \mathrm{~cm}$ (Unit H): This is a clean, structureless fine sand overlying a thin, discontinuous, obscure silt bed. These, together with the overlying silt of unit G, represent a flood sequence ('triplet') that dips to the south (riverward) into a small, channel-like depression. Units $\mathrm{G}$ and $\mathrm{H}$ appear to represent Colorado River fluvial deposition.

$99-127 \mathrm{~cm}$ (Unit I): Unit I consists of highly variable sands (fine to coarse sand); textural variations are localized and
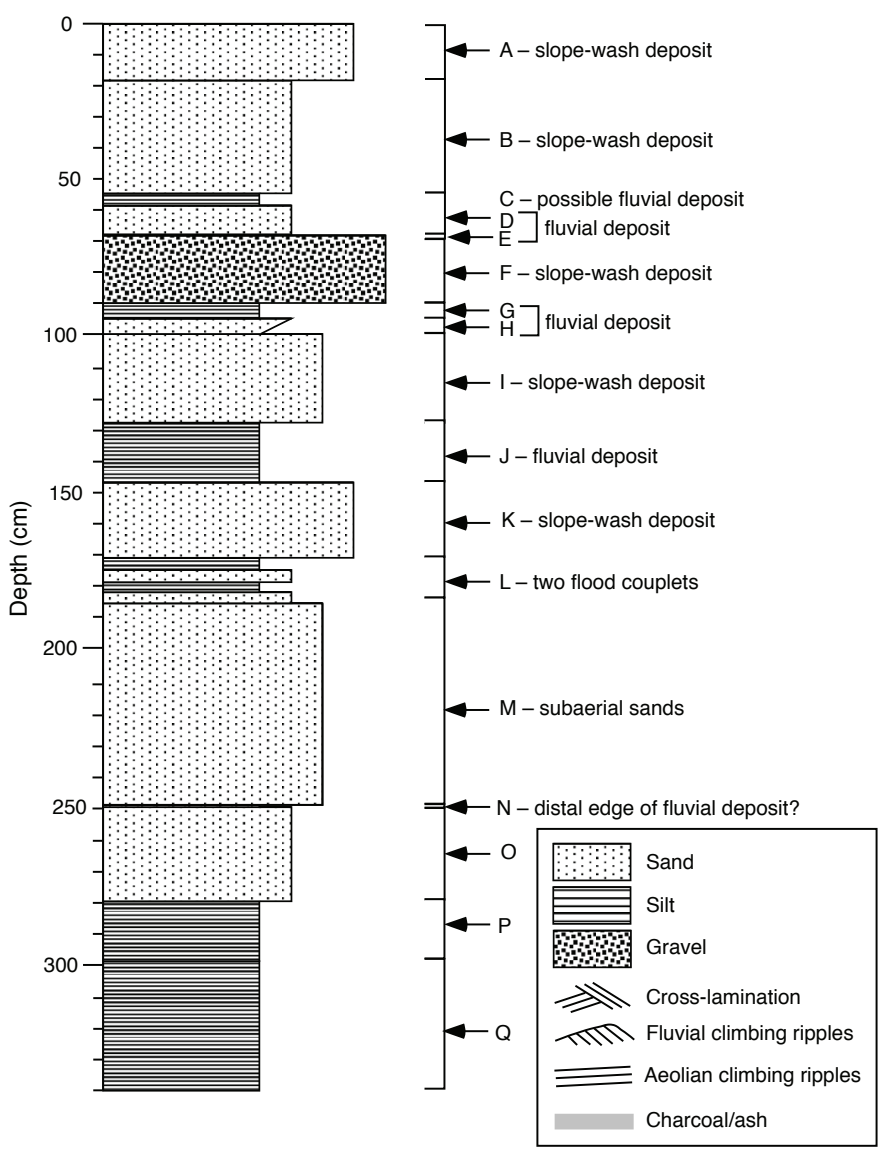

Figure 61. Stratigraphic diagram for section 7, Arroyo Grande. 
lensatic. Sediment in this horizon varies from clean to very poorly sorted and was apparently deposited by locally derived running water. The lower contact appears to be erosional.

127 - 146 cm (Unit J): This is a fine sandy silt, possibly with finer interbeds in the upper part. Numerous carbonate-filled rootlet pores are present. Sediment appears to be very thinly bedded or laminated, but the structure is obscure. The lower $4 \mathrm{~cm}$ of this horizon is bioturbated, clean, laminated silt. This silt-and-sand couplet appears to represent a single Colorado River flood event.

$146-170 \mathbf{~ c m}$ (Unit K): Unit $\mathrm{K}$ is a poorly sorted fine sandy gravel in its upper section, with cleaner fine sand in the middle and clean, coarse sandy pebble gravel in its lower part. Contacts within this stratum are gradational. Unit K was deposited by running water of local derivation.

$170-185$ cm (Unit L): This is a set of four beds: sand-siltsand-silt (in order downsection). The two sand layers are silty fine sands, separated by clean silt beds. The silt beds are laminated, especially in the upper and lower parts, whereas the sands appear structureless. This set of beds most likely represents two Colorado River flood deposits.

185 - 249 cm (Unit M): This horizon contains bedded sands (silty fine sand including poorly defined lenses of mediumcoarse sand with occasional small pebbles). Sediment is very micaceous. Internal contacts are gradual, which might suggest that these beds were deposited in one event, but a small patchy area of charcoal at approximately $240 \mathrm{~cm}$ suggests otherwise.

$249-250 \mathbf{~ c m}$ (Unit N): This is a very thin bed of very pure, whitish silt. This horizon is broken by occasional insect burrows, but remains surprisingly intact for so thin a bed. It cannot be traced for more than a few meters in any direction. Upper and lower contacts are abrupt and smooth. This may represent the distal edge of a Colorado River flood deposit.

$\mathbf{2 5 0}-\mathbf{2 8 0} \mathbf{~ c m}$ (Unit O): This horizon consists of very clean fine sand. Bedding is very obscure, but slightly siltier layers appear to dip riverward. A few burrows filled with ashy charcoal are present in the upper $10 \mathrm{~cm}$ of this unit. The lower contact is abrupt and wavy. This may represent the upper part of a Colorado River flood couplet.

280 - 299 cm (Unit P): Unit P is a very clean silt, laminated in its upper and lower parts, that dips steeply westward (upstream with respect to the river). This may represent the lower part of a Colorado River flood couplet (the upper part being unit $\mathrm{O}$ above).

299-340+ cm (Unit Q): This lowermost stratum is a very clean, laminated fine sandy silt, with well-defined climbing ripples in its upper 8-10 cm (locally). This grades into the silt above (unit P) and is interpreted as a Colorado River fluvial deposit.

Section 7 summary. - Section 7 appears to be somewhat transitional between the zone dominated by slope-wash sediment (similar to section 11) and the flood-dominated profiles (for example, sections 3, 4, and 6). The profile contains some sediments at the base that are clearly deposited by Colorado River floods, along with a number of gravelly beds that are clearly of slope-wash origin. In between are sand/silt couplets that appear similar in composition and sequence to beds that have been identified as flood sediments (inferred from the presence of fluvial sedimentary structures) in other stratigraphic profiles at Arroyo Grande, but this profile contains few distinctive bedding structures. Section 7 contains evidence for as many as eight Colorado River floods (possibly unit $\mathrm{C}$, units $\mathrm{D} / \mathrm{E}$, units $\mathrm{G} / \mathrm{H}$, unit $\mathrm{J}$, two in unit $\mathrm{L}$, unit $\mathrm{N}$, and units $\mathrm{O} / \mathrm{P} / \mathrm{Q})$. If these units are flood sediments, they were likely deposited on a surface that had a broad channel reaching from the terrace surface to the river.

\section{Arroyo Grande, Section 8}

The stratigraphic diagram for Section 8 is shown in figure 62 . Measurements are in $\mathrm{cm}$ below the land surface.

Surface: Deflated, grassy sediment with cryptogamic soil cover.

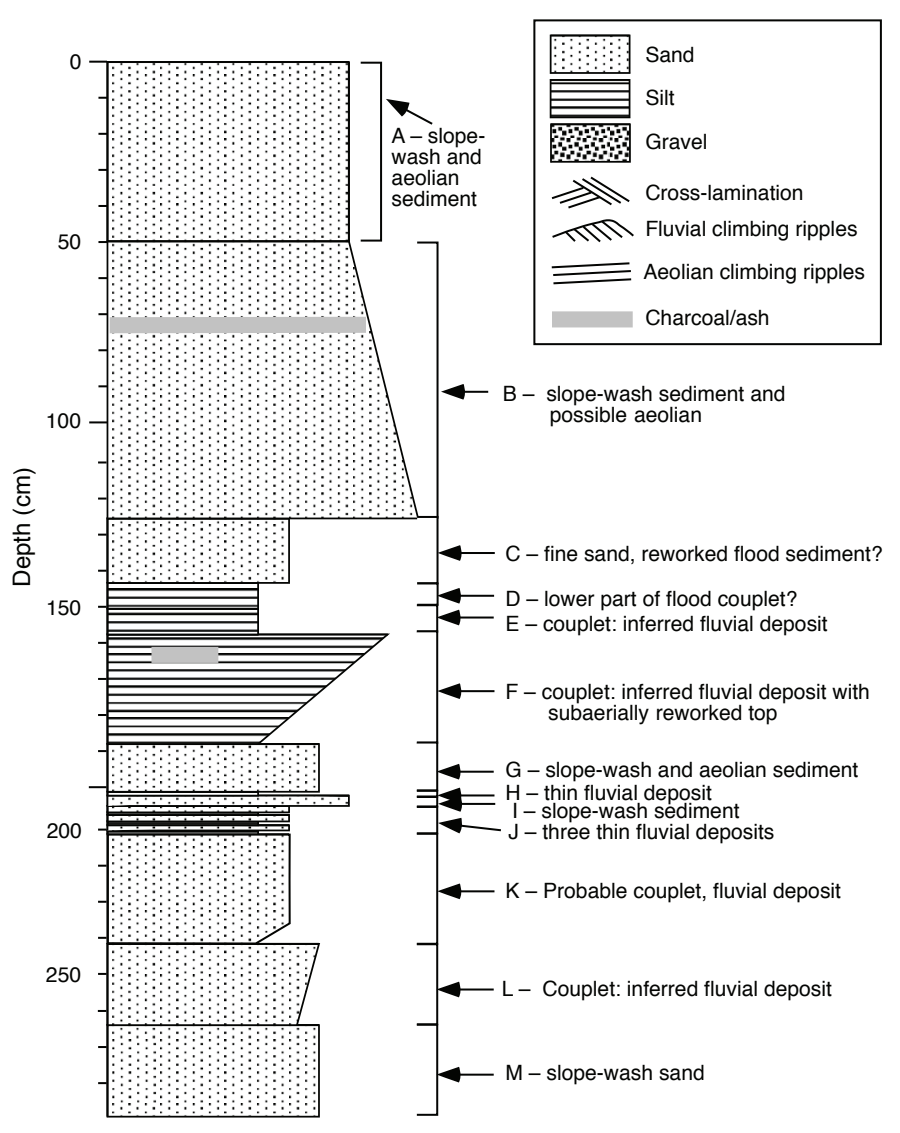

Figure 62. Stratigraphic diagram for section 8, Arroyo Grande. 
0 - 49 cm (Unit A): Unit A is variously bedded and/or laminated. This sediment contains locally derived pebbles and granules (granite and amphibolite gneiss grains) in places, but is dominantly silt or fine sand. Isolated charcoal pieces are present, not burned in place. The origin of unit A appears to be slope-wash and aeolian sediment, with multiple episodes of soil-crust development between deposition events.

$49-125$ cm (Unit B): Many localized lenses of locally derived coarse sand and granules are present, with some clasts up to pebble size. A burning episode is apparent, spanning $3 \mathrm{~cm}$ (from 64 to $67 \mathrm{~cm}$ below the land surface); this area was burned in place and is dark gray. Abundant disseminated charcoal is visible in this burned horizon. The charcoal layer is in the shape of a thin basin; its lateral extent is indeterminate. Below this burned area, unit B becomes coarser downward; from 95 to $125 \mathrm{~cm}$ below the land surface, the sediment is essentially gravel. Multiple episodes of slope-wash deposition are evident in this unit, but the greatest proportion of sediment in the upper part of unit $B$ is still fine sand.

$125-143 \mathrm{~cm}$ (Unit C): Unit C consists of fine sand that is thinly bedded. No clear sedimentary structure is apparent. This fine sand is relatively poorly sorted and includes a few coarse sand grains. This texture may indicate local sediment derivation, but it may also represent reworking of the upper part of a fluvial deposit (with underlying unit $\mathrm{D}$ forming the lower part of a fluvial couplet). The upper part of unit $C$ contains very thin $(<0.25 \mathrm{~cm})$ silt laminae; this layer could represent a Colorado River flood event or local ponding. The lack of visible mudcracks suggests that a fluvial origin is more likely than local ponding. Units $\mathrm{C}$ and $\mathrm{D}$ most likely represent a fluvial couplet.

$143-150 \mathrm{~cm}$ (Unit D): Unit D, the lower portion of the possible fluvial couplet formed by units $\mathrm{C}$ and $\mathrm{D}$, is a white resistant silty layer. Its uppermost $2 \mathrm{~cm}$ consist of bedded, alternating silt and fine sand. Both the upper and lower contacts of this 2-cm-thick upper region are abrupt and distinct. The lower silt layer is very clean and laminated, implying likely Colorado River flood derivation. Sediment is bioturbated and contains carbonate-filled rootlet pores. Unit D is very distinctly laminated with paper-thin laminae throughout its thickness.

150 - 157 cm (Unit E): The upper part consists of brownish silty fine sand. Sediment is structureless, with numerous bioturbation features. The contact between the upper sandy material and a lower silt portion is abrupt but bioturbated. The lower, silty unit contains silt that is less pure than that of lower unit D (best described as a fine to very fine sandy silt). This lower portion of unit $\mathrm{E}$ is very bioturbated and contains very faint paper-thin laminae. This unit is inferred to be another fluvial couplet deposit.

$157-187$ cm (Unit F): The upper portion of unit F contains a significant coarse-sand phase, with many granules and pieces of what appear to be mechanically deposited clasts of calcium carbonate. This carbonate material does not resemble rootlet filling, and may have been eroded from somewhere upslope and subsequently incorporated into this deposit. A burned zone 1 to $1.5 \mathrm{~cm}$ thick occurs within this upper sand portion (whether it was burned in place is not clear). Small pebbles are present at the same stratigraphic level as the charcoal. This upper sediment of unit $F$ is interpreted to be the upper part of a flood couplet that has undergone significant reworking (and incorporation of locally derived material) at the land surface after initial deposition. The silty, lower phase of the couplet is laminated, clean, very pure silt. Its lower boundary is abrupt and bioturbated, with some cementation evident at its base. Unit F is interpreted as a fluvial couplet. Three sediment samples were collected: AG Strat 8 \#1 (Unit F, in silt at base of unit; attempted to remove sand-filled burrows from sample); AG Strat $8 \# 2$ (Unit F, $1 \mathrm{~cm}$ above basal silt in relatively clean sand); AG Strat 8 \#3 (Unit F upper part, locally derived sediment with occasional charcoal; the sample contains clasts of consolidated silt).

$187-200 \mathrm{~cm}$ (Unit G): This horizon consists of medium sand that includes clasts as large as granule size (poorly sorted). Mica flakes and local lithic fragments are abundant. The lower part of unit $\mathrm{G}$ contains horizontal bedding with fine sand beds (very thinly laminated). Shoreward of the described section is an ashy charcoal soil at the same level with pieces of fire-cracked rock that suggest a cultural hearth feature. Unit $\mathrm{G}$ is interpreted as locally derived sediment that has likely undergone aeolian modification. Small pieces of consolidated silt are apparent, which may be related to disturbance of a hardened silt layer (unit $\mathrm{H}$ ) during original construction of the hearth feature.

$200-201$ cm (Unit H): This is a thin white silt layer that contains very delicate lamination. Sediment is very bioturbated and may have been disturbed during construction of the hearth shoreward of section 8 (the hearth is cut into units $\mathrm{G}$ and $\mathrm{H}$ ). This unit is most likely a Colorado River flood deposit, on the basis of its similarity to other interpreted flood silts in this and other sections.

$201-204 \mathbf{~ c m}$ (Unit I): Unit I contains medium to coarse sand, very poorly sorted. Sediment is locally laminated near the top but is generally structureless. This is interpreted as locally derived slope-wash material.

$204-212$ cm (Unit J): This horizon consists of three silt bands separated by sand. Each silt layer averages $\sim 1 \mathrm{~cm}$ thick and is fairly disrupted and discontinuous but very pure where present. Sediment is very bioturbated, as are the boundaries of each silt band. The sandier units between silt beds are silty fine sand, with local horizontal parallel bedding. The uppermost sand bed in unit $J$ contains flecks of charcoal and is slightly grayer (contains ashy soil). Unit J is interpreted as three thin flood deposits.

$212-242 \mathbf{~ c m}$ (Unit K): Unit $\mathrm{K}$ is dominantly a silty fine sand horizon, heavily bioturbated. Many insect burrows are present (it is a possible termite nest). Sediment appears very structureless. At a depth of $242 \mathrm{~cm}$ is a very thin $(<0.5$ $\mathrm{cm})$, discontinuous, very bioturbated silt layer. This silt bed, 
which is fairly pure but very disturbed and discontinuous, may be related to local wetting, but may alternatively represent the thin landward edge of a Colorado River flood.

$242-264$ cm (Unit L): The upper part of unit L consists of a poorly sorted coarse to medium sand with a large biotite component, implying local derivation. This material grades downward into a much cleaner (better sorted) medium sand, which at its base becomes a fine sand. The lower boundary of the fine sand is abrupt and wavy. This unit is interpreted as a possible fluvial deposit that has undergone reworking at the land surface after deposition.

$264-289+\mathbf{c m}$ (Unit M, to base of outcrop): The basal unit of section 8 contains a medium-grained sand with abundant biotite, implying local sediment derivation. This layer is structureless and has very uniform composition throughout its thickness.

Section 8 summary.-This section is interpreted to reflect alternating deposition of Colorado River flood sediment and locally derived slope-wash material. In the nearly $3 \mathrm{~m}$ thickness of this section, a maximum of 10 flood events may be identified. The smaller number of identifiable flood events in this section, compared with the 15 flood deposits in section 6 (which has a comparable thickness but is located $34 \mathrm{~m}$ riverward of section 8), is consistent with expectations that fewer flood events will have a discharge great enough to reach the more landward locations studied. Between floods, deposition of slope-wash and minor amounts of aeolian sediment are evident in section 8 .

\section{Arroyo Grande, Section 9}

The stratigraphic diagram for section 9 is shown in figure 63 . Measurements are in $\mathrm{cm}$ below the land surface.

Surface: At section 9, the land surface contains discontinuous cryptogamic crust. Vegetation locally includes grass, occasional mesquite, and creosote bushes. The surface is slightly deflated at this location, with $1-2 \mathrm{~cm}$ erosional pedestals.

$0-13 \mathbf{~ c m}$ (Unit A): Unit A contains poorly sorted silty fine sand. This horizon is bioturbated with rootlets, as are the other horizons in this profile.

$13-14.5 \mathbf{~ c m}$ (Unit B): This horizon is a thin, discontinuous, pale gray silt layer.

14.5 - $36 \mathrm{~cm}$ (Unit C): Unit C contains poorly sorted, primarily silty sands, with little obvious microstructure; it is interpreted as likely slope-wash sediment.

$36-38.5 \mathrm{~cm}$ (Unit D): This is a gravel lens containing lithic grains and clasts of K-spar-rich granite and amphibolite gneiss (material derived from local bedrock). This unit consists of slope-wash sediment.

$38.5-43 \mathbf{~ c m}$ (Unit E): Unit E contains massive, poorly sorted silty sands.

$43-45.5 \mathrm{~cm}$ (Unit F): This horizon contains poorly sorted silty sands, similar to unit E, but with ashy charcoal present.
45.5 - 57 cm (Unit G): Unit G contains massive, poorly sorted silty fine sand.

$57-61 \mathrm{~cm}$ (Unit $\mathbf{H})$ : This layer is a gravel lens containing slope-wash sediment. It is identical in character, composition, and inferred origin to unit $\mathrm{D}$.

$61-139.5 \mathrm{~cm}$ (Unit I): In contrast to the sedimentary character of units A through $\mathrm{G}$ above, unit I is a relatively clean silty fine sand. Two subunits are present within unit I: its upper part is probably Colorado River flood sediments, parallel bedded, with possible aeolian reworking. The lower part of this stratum is clearly a Colorado River flood deposit, with parallel bedding and more distinct, fine-scale climbing ripples near the base of the stratum. The boundary between the upper and lower parts of unit I is indistinct, marked by increasing frequency of Colorado River climbing ripples downsection.

$139.5-141 \mathrm{~cm}$ (Unit J): This stratum is interpreted as another Colorado River flood deposit, with a silty lower section that grades upward into a silty fine sand. No distinct bedding structures were observed.

$141-142.5 \mathbf{~ c m}$ (Unit K): Unit $\mathrm{K}$ is a laterally continuous ashy charcoal lens, interpreted to represent a former subaerial land surface.

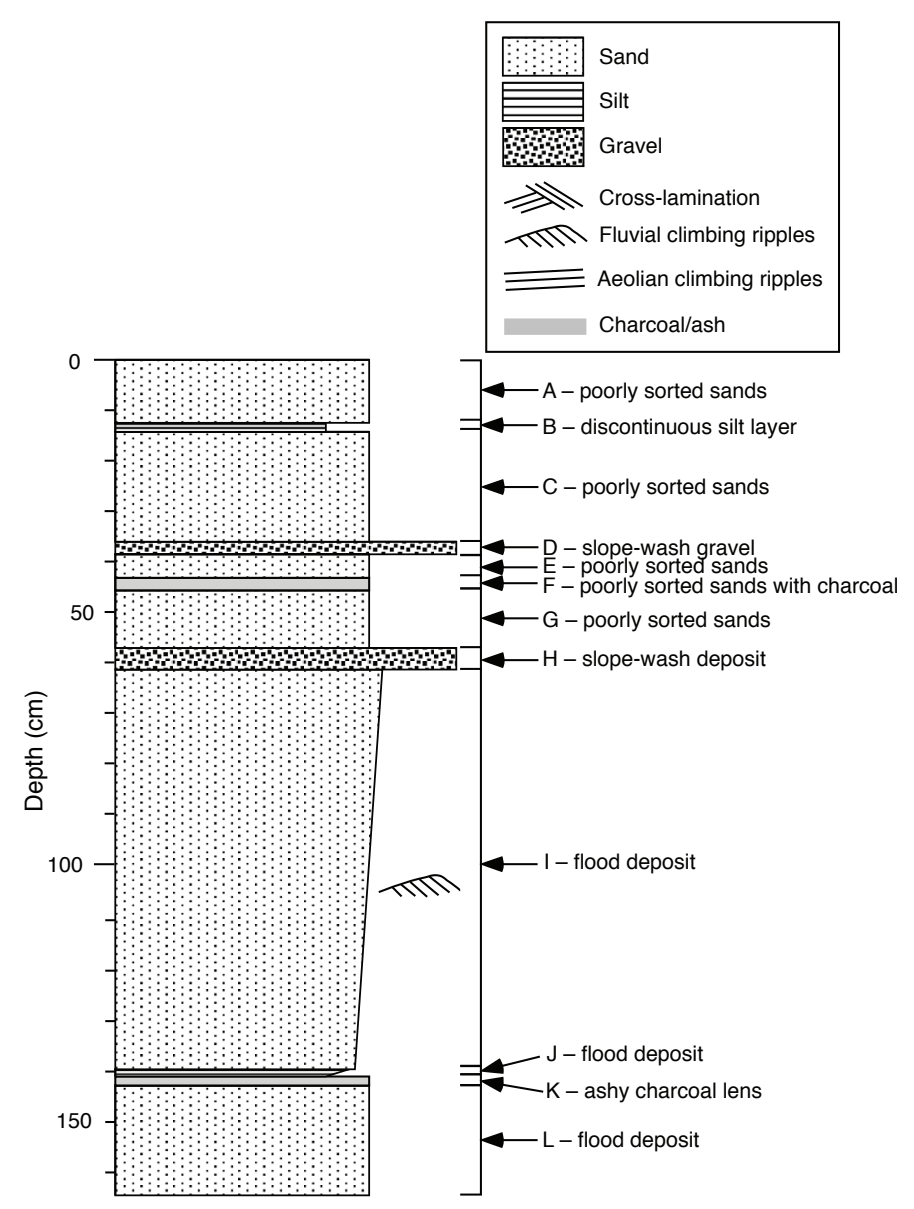

Figure 63. Stratigraphic diagram for section 9, Arroyo Grande. 
142.5 - 164+ cm (Unit L, to base of section): This lowermost unit contains distinct fluvial climbing ripples, indicating a Colorado River flood deposit.

Section 9 summary. - This profile can be divided into two distinct sections dominated by two different depositional environments. The upper portion (units A through $\mathrm{H}$ ) is predominantly locally derived slope-wash sediment, with interspersed poorly sorted silty sands that likely represent reworking and redeposition of fluvial or aeolian deposits by local runoff. The lower part of this profile (units I and below) contains multiple Colorado River flood deposits. There is evidence for at least two floods (units I and L), with unit $\mathrm{J}$ representing either the distal part of a third flood deposit or the lowermost silt layer at the base of the flood deposit in unit I. Between these two major flood deposits there is evidence for subaerial exposure and a fire (possibly, but not necessarily, indicating human occupation of the land surface), from the presence of the ashy charcoal in sediment that forms unit $\mathrm{K}$.

\section{Arroyo Grande, Section 10}

The stratigraphic diagram and a field sketch for section 10 are shown in figure 64. Stratigraphic thicknesses in this profile were measured in terms of heights above the survey datum, which is located at the base of the uppermost Colorado River flood deposit. In this section, contacts between unit are inclined; a range of upper and lower depths is given for most units.

170 to $70-80$ cm (Unit A): Unit A is land-surface sediment, with a poorly exposed upper part but becoming more stratified toward its base. The base of this material is gradational.

$70-80$ to $50-70 \mathrm{~cm}$ (Unit B): This is a fine-grained sand, with planar lamination. Unit B is interpreted as an aeolian deposit that contains subcritically climbing wind ripples.

50 - 70 to $30 \mathrm{~cm}$ (Unit C): This fine-grained sand contains planar lamination or ripple cross-lamination and includes a 15-cm-high bar or dune. This is most likely a Colorado River flood deposit, but may be aeolian in part.

30 to $0-4$ cm (Unit D): Unit D consists of very fine sand that is silty in part, with fluvial climbing ripples. This grades down into $1-2 \mathrm{~cm}$ of white clayey silt. The unit is interpreted as a Colorado River flood deposit. The base of this unit at one location within the outcrop is the survey datum.

0 - 4 to $-\mathbf{1 0}-\mathbf{- 1 2} \mathbf{~ c m ~ ( U n i t ~ E ) : ~ U n i t ~ E ~ c o n t a i n s ~ s i l t ~ o r ~ s i l t y ~}$ very fine sand, with charcoal concentrations and at least one cobble at its base.

Section 10 summary.-This section resembles section 1 in that it includes both fluvial and aeolian sediment. The upper aeolian sediment is most likely reworked material from fluvial deposition. Unit $\mathrm{C}$ of this section contains sedimentary structures that are inconclusive; a fluvial origin for this unit is most probable but aeolian material cannot be ruled out. The basal unit, E, includes charcoal and coarser sediment that implies a land surface with incorporated locally derived material.

Five samples were collected from Section 10: AG Strat 10 \#1 (0-2 cm above base of outcrop; powdery white silt, consolidated, interpreted as base of a flood deposit); AG Strat 10 \#2 (20-22 cm above base of outcrop; silty sediment within unit that contains fluvial climbing ripples); AG Strat 10 \#3 (44-46 cm above base; same flood unit as sample \#2, but on lee side of large bar/bedform); AG Strat 10 \#4 (57-59 cm above base; origin uncertain-possible aeolian deposit or possible subaqueous dune sediment); AG Strat 10 \#5 (50-52 cm above base, but shoreward of measured section; sand forms swales with charcoal interspersed. Possibly on contact between fluvial and aeolian sediment, or possibly within aeolian unit. This sample is stratigraphically above sample \#4).

\section{Arroyo Grande, Section 11}

The stratigraphic diagram for section 11 is shown in figure 65. Measurements are in $\mathrm{cm}$ below the land surface.

Surface: Surface sediment cover consists of pebbly sand with grasses and cryptogamic crust. The surface has no indication of pedogenic modification.

0 - 10 cm (Unit A): Cryptogam-capped pedestals in this uppermost unit indicate that 1 to $1.5 \mathrm{~cm}$ has been removed from this surface very recently. Unit A contains a wide variety of sediment sizes; from 0 to $5 \mathrm{~cm}$ there are alternating thin beds of fine sand and very thin beds of laminated silty fine sand. From 5 to $10 \mathrm{~cm}$ there are very poorly sorted coarse sands containing locally derived lithic clasts, up to and including granule size. All materials in unit A were apparently deposited by slope-wash processes, involving flowing water of varying velocities. The upper part $(0-5 \mathrm{~cm})$ is indicative of slower moving water that deposited the laminated silt; some of the silt beds represent silt crust formation at times in the past. From 5 to $10 \mathrm{~cm}$ more rapidly flowing water is implied, and this lower part of unit A represents a form similar to a precursor of the modern arroyo. The lower contact of unit A is abrupt, marked by a prominent change in texture.

$10-23$ cm (Unit B): Unit B can be divided into several subhorizons:

$10-13 \mathbf{c m}$ (Subunit B1): This is a clean fine to medium sand, a possible aeolian deposit. Sediment is structureless, and the lower boundary is abrupt and bioturbated.

$13-18$ cm (Subunit B2): This subunit consists of alternating fine sand and silt. It is primarily fine sand, but contains silt beds of thickness 2 to $5 \mathrm{~mm}$. This subunit is 
inferred to have formed under similar conditions to the upper part of unit A. It grades down into coarser sediment of subunit B3.

$18-23 \mathrm{~cm}$ (Subunit B3): This horizon is a sand and gravel lens that is virtually identical in character to the lower part of Unit A. Its lower boundary is abrupt. Within 1 $\mathrm{m}$ laterally, this same gravel lens contains grain sizes up to small pebbles.

23 - 61 cm (Unit C): Superficially, this unit resembles flood couplets in other profiles, by consisting of an upper fine sandy bed underlain by a silty fine sand. In this case, the upper fine sand is thinly bedded and locally laminated, with laminae inclined toward the northwest (upstream). Although mostly fine sand, it is poorly sorted and includes some locally derived coarse sand and rare coarse sand and granule lenses (single grain thickness). This is clearly a water-deposited unit, but it was not deposited all at one time. It is most plausibly interpreted as slope-wash material, but alternatively may represent a fluvial deposit that has been heavily reworked with locally derived sediment having been incorporated into it. The silty lower part ( $5 \mathrm{~cm}$ thick, from 56 to $61 \mathrm{~cm}$ depth) is a silty fine sand to fine sandy silt. It is heavily bioturbated and appears to have been alternating thin silt beds and fine sand; it is too disturbed to say much else with confidence. The lower boundary of unit $\mathrm{C}$ is diffuse and bioturbated.

$61-84 \mathbf{~ c m}$ (Unit D): Unit D consists of sand deposited by flowing water (inferred to be slope wash). It is primarily a poorly sorted fine to medium sand, which is very micaceous with some locally derived coarse and and granule sized particles. Within $1 \mathrm{~m}$ on either side of the profiled area are gravelly channel-fill deposits at this depth.
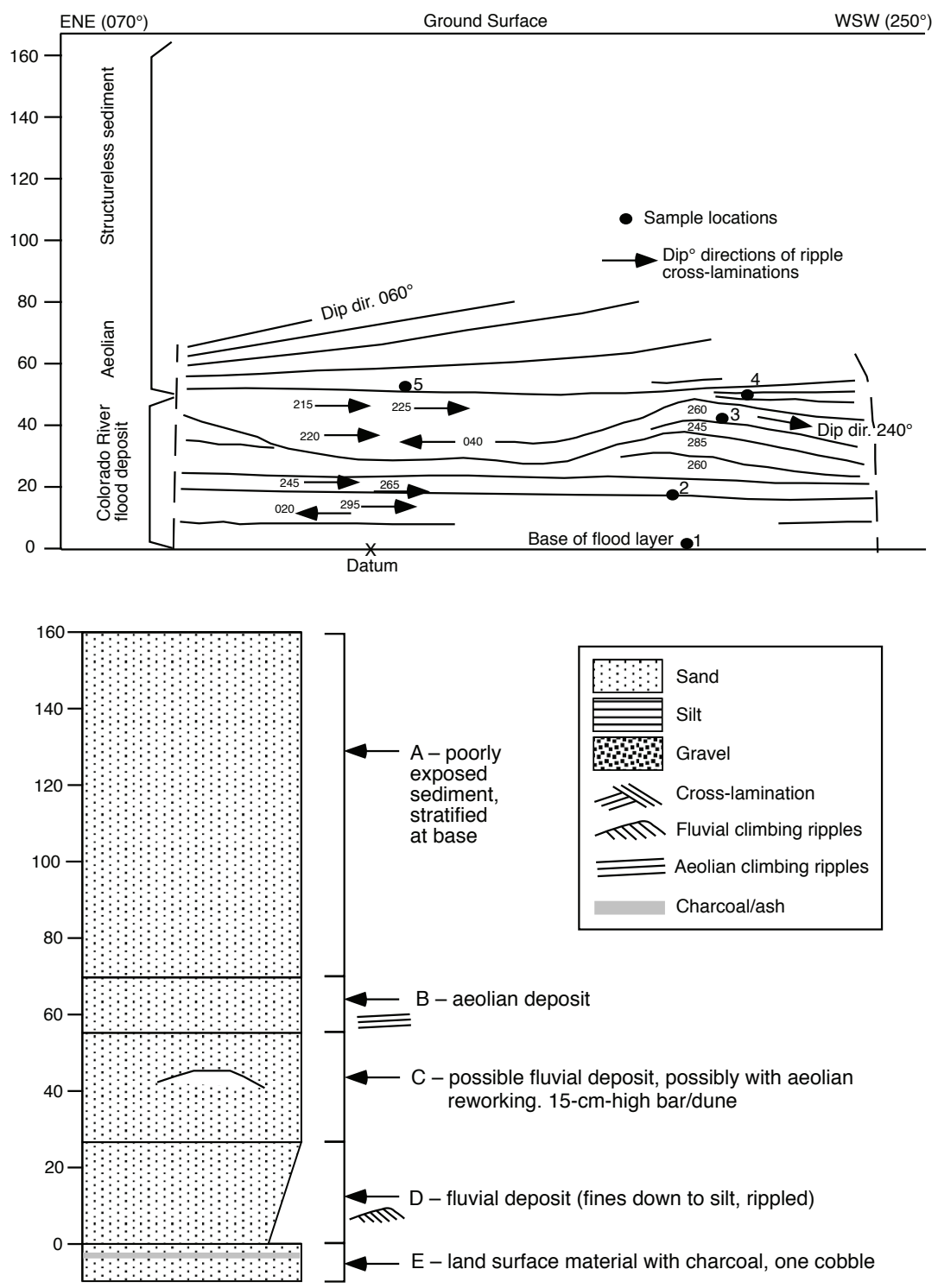

Figure 64. Stratigraphic diagram and field sketch of section 10, Arroyo Grande. 
The gravels contain particles up to (locally) medium-sized cobbles. Bioturbation is limited, likely due to the large grain sizes present. Other than the gravel lens, unit $\mathrm{D}$ is structureless.

$84-88 \mathrm{~cm}$ (Unit E): This is a silt which in some respects resembles flood silts seen in other profiles. It differs from other fluvial silt layers in being much less pure silt, with fine and medium sand grains present. The unit is heavily burrowed and can be traced laterally for only $3.5 \mathrm{~m}$, implying that it may have filled a small channel. Some lamination is present in its upper part. Unit $\mathrm{E}$ grades into very coarse channel-fill gravels in the downstream direction (with respect to the Colorado River), and disappears to the west (upstream). This silt is underlain and overlain by higher energy deposits (gravels and coarser sand). The lower boundary is bioturbated but distinct.

$88-192+\mathbf{c m}$ (Unit F, to base of section): This lowermost unit contains alternating lenses of high-energy waterlain deposits, which vary in texture from very poorly sorted sands to granules and medium-cobble gravels. These sediments are clearly locally derived and are a product of

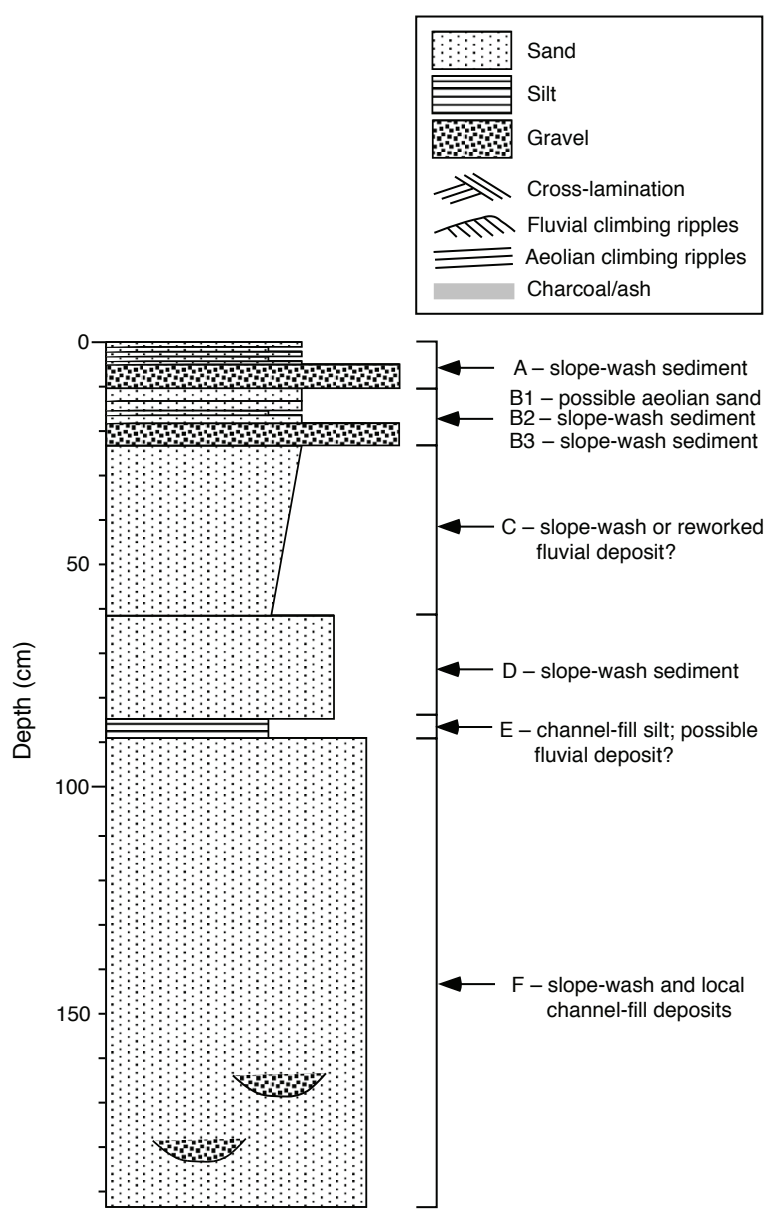

Figure 65. Stratigraphic diagram for section 11, Arroyo Grande. slope-wash and localized channel deposition. They appear to represent channel-fill gravels, forming lenses that vary from 10 to $40 \mathrm{~cm}$ in thickness. Unit $\mathrm{F}$ is interpreted to have been deposited in either surface tongues of coarse slopewash or in small channels.

Section 11 summary.-Stratigraphic profile 11 is a slopewash-dominated depositional sequence. Everything in the profile, except possibly the $84-88$-cm silt (unit E), is slope-wash sediment. The relative coarseness of most sediment reflects proximity to runoff source. This profile is the most distant stratigraphic section from the river, and the closest to valley-wall slopes. and consists almost entirely of slope-wash material. The present surface is within the zone of pebbly surface sediment. There are indications of minor pedogenic alteration below the surface. A variety of sediment types is represented, ranging from pure silt to fistsize cobbles. In general, the sediments here are the coarsest that we have observed in any location in this study. The small hearth observed in place at approximately 40-50$\mathrm{cm}$ depth and east of the profile was burned in place, and a very thin granule/small-pebble line and small angular pieces of silt that underlie the hearth suggests that a small pit may have been dug in preparation for the hearth.

\section{Stratigraphy and Geomorphology at Archaeo- logical Site Locations}

Of the four archaeological sites recorded in the Arroyo Grande area, observations of feature-specific localities were made only in reference to site G:03:064. Within this site, features are exposed on the modern land surface. Several of the additional features that are exposed within arroyo walls, below the surface, are described above as they relate to the measured stratigraphic sections.

The land surface around the archaeological features shows abundant evidence of recent deflation, cryptogamic crust formation, and pedestal development. Dune forms (now deflated) are visible near the upstream ends of the arroyo branches, above the locations of sections 1 and 2 described above (both of which contained sediment with aeolian sedimentary structures). Dunes in this area are shown in figure 66. The 'roots' of these dunes, where cultural features are located, may be fairly deep (for example, in Section 1, aeolian sediment extended from the surface to a depth of $\sim 2 \mathrm{~m}$ ); however, the primary terrace-constructing material has been fluvial sand, judging from the relative proportions of fluvial and aeolian sand present in the stratigraphic sections studied.

Features 1, 2, and 3 are located in the area where coppice dunes are present on the surface; feature 1 has been bisected by an arm of the arroyo (fig. 67). At the location of feature 3 , topographic relief on the dunes reaches $>2 \mathrm{~m}$ relative to the surrounding upper terrace surface. Features 4 and 5 are located in an interdune area that presently has an elevation above that of the surrounding upper terrace surface. The land 
immediately surrounding features 4 (which has been cut by the arroyo) and 5 has clearly been modified by wind but is now deflated and covered by cryptogamic crust, grasses, mesquite, and creosote bushes. Feature 6 is located on an area of the deflated upper terrace surface that is near, but not in, small coppice dunes and is beginning to be undercut by arroyo incision. Feature 7, on the upper terrace surface not immediately near coppice dunes, is not in imminent danger of being undercut by arroyo incision. Features 8 through 11 are all built near each other on the surface of the upper fluvial terrace, in an area where coppice-dune accumulation is not common.

Features 12,13, and 14 appear to have been built on small coppice-dune accumulations formed on the upper fluvial terrace. The main arroyo network has incised entirely around the perimeter of feature 12; the large mound of firecracked rock has effectively armored itself against gully incision while the sediment around it has been eroded away (fig. 68). At least $10 \mathrm{~cm}$ of deposition appears to have occurred after construction of the feature, judging from a small exposure of probable aeolian sediment at the shoreward edge of the feature with an elevation above that of the roaster surface. Deflation has removed the rest of the sediment that had been deposited. Sediment around features 12 and 13 is largely structureless silty sand. Feature 13 has been affected by incision of one arm of the secondary arroyo network. Feature 14, a roasting feature consisting of fire-cracked rock and ashstained soil, is exposed in a small drainage in close proximity to features 12 and 13.

Feature 15 is the only recorded feature north of the arroyo network. This roasting feature consists of a mounded concentration of fire-cracked rock with a perimeter of dispersed fire-cracked rock. The depositional context of this area includes a significant contribution by locally derived slopewash sediment overlying the distal part of the main fluvial terrace. Arroyo incision has not yet affected this area of the fluvial terrace, though a nickpoint is close to the feature.

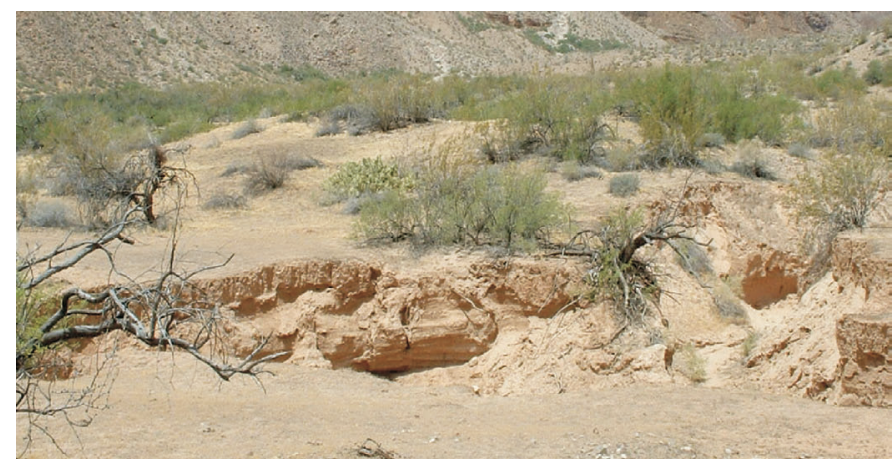

Figure 66. Dune forms built on the terrace at Arroyo Grande. These dunes are interpreted to have formed by aeolian reworking of fluvial sediment on this terrace. Dunes are now largely inactive, with vegetation and cryptogamic soil on the land surface. One branch of the main arroyo network is in the foreground (photograph faces northwest); the vertical arroyo wall in the foreground is approximately $1.5 \mathrm{~m}$ high.

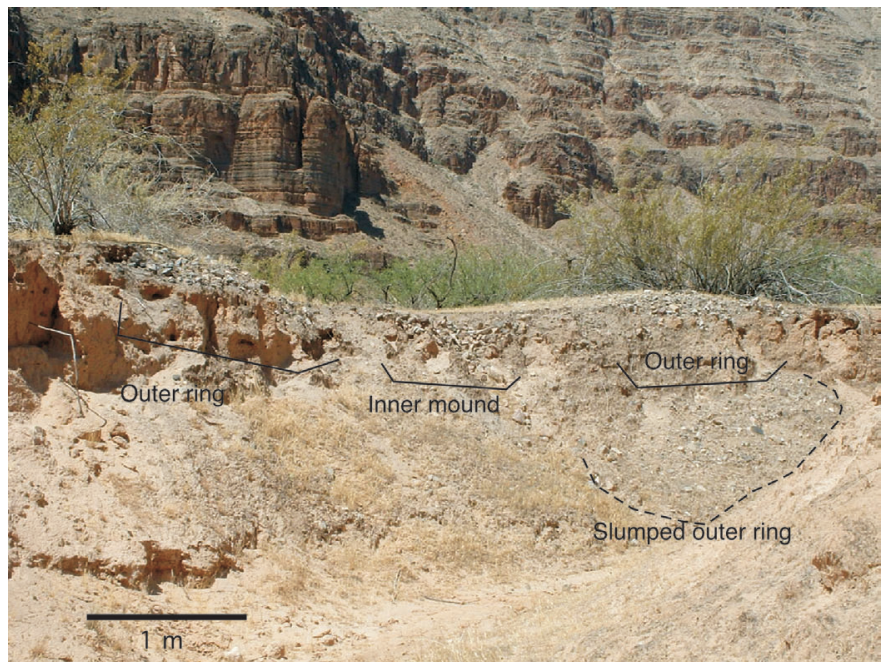

Figure 67. Feature 1 of archaeological site G:03:064 at Arroyo Grande. This large prehistoric-historic era roasting feature has been eroded severely by gully incision in the main arroyo network, so that a crosssection of the roaster is now exposed in the arroyo wall. The inner concentration of fire-cracked rock (where food was covered and left to cook) is visible in the center, with two exposures of the ring-shaped pile of discarded fire-cracked rock on either side.

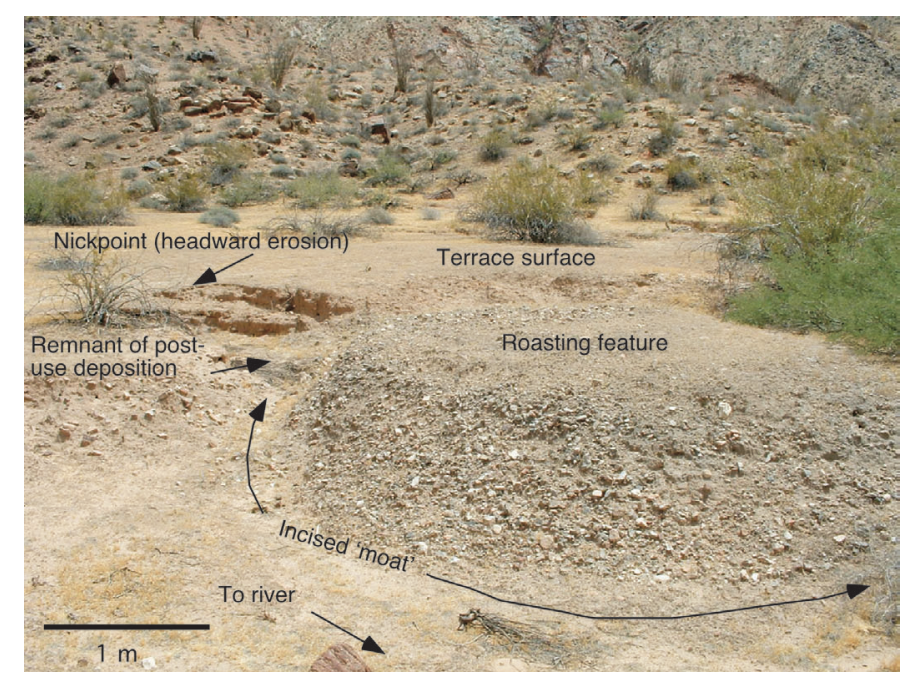

Figure 68. Feature 12 of archaeological site G:03:064 at Arroyo Grande. The large size of this protohistoric-historic era roasting feature, along with imported artifacts found at this site, indicates the social significance of this area. Like several other features at G:03:064, this feature has been affected by gully incision as the main arroyo network has grown. The rock concentration of this roasting feature has resisted erosion, armoring the structure while the terrace around it has eroded; a moat-like gully now surrounds the feature, the floor of which is $\sim 0.5 \mathrm{~m}$ lower than the elevation of the adjacent terrace surface. At the back left side of the roaster, a small remnant of sediment is visible that indicates at least $10 \mathrm{~cm}$ of deposition that covered part of the structure after the site was built. The arroyo branch that affects this site has continued to undergo headward erosion behind the armored roasting feature. 